\title{
EFFECTS OF SILVICULTURAL MANAGEMENT ON COAST REDWOOD FOREST COMPOSITION, DENSITY AND STRUCTURE IN SANTA CRUZ AND SAN MATEO COUNTIES
}

\author{
Master's Thesis \\ Presented to the Faculty of \\ California State Polytechnic University \\ San Luis Obispo \\ In Partial Fulfillment \\ Of the Requirements for the Degree \\ Master of Science in Forestry Sciences
}

by

Michael J. Papa

May 2011 
(C) 2011

Michael Joseph Papa

ALL RIGHTS RESERVED 
COMMITTEE MEMBERSHIP

TITLE:

EFFECTS OF SILVICULTURAL MANAGEMENT ON COAST REDWOOD FOREST COMPOSITION, DENSITY AND STRUCTURE IN SANTA CRUZ AND SAN MATEO COUNTIES

AUTHOR:

MICHAEL J. PAPA

DATE SUBMITTED: $\quad$ MAY 2011

COMMITTEE CHAIR: $\quad$ Dr. Walter Mark, Professor

COMMITTEE MEMBER: Dr. Douglas Piirto, Professor

COMMITTEE MEMBER: Dr. Ulric Lund, Professor 


\title{
ABSTRACT
}

\section{EFFECTS OF SILVICULTURAL MANAGEMENT ON COAST REDWOOD FOREST \\ COMPOSITION, DENSITY AND STRUCTURE IN SANTA CRUZ AND}

SAN MATEO COUNTIES

\author{
Michael J. Papa
}

The multiple-objective exploratory study investigates effects of various silvicultural management regimes commonly applied to coast redwood (Sequoia sempervirens [D. Don] Endl.) forests in Santa Cruz and San Mateo Counties, California, USA. A temporary forest inventory was installed in 24 harvest origin stands and 4 natural origin stands throughout the study area (sample area $=1189$ acres). Data from the systematic sample of 233 one-quarter acre nested cluster plots (sample intensity $=4.9 \%$ ) rendered overall forest descriptions in terms of species composition, density, and structure. The common forestry measures of trees per acre (TPA), basal area per acre (BA), and quadratic mean diameter (QMD) were calculated from the "snapshot" data and stratified by species groups and diameter ranges/canopy layers.

Forest components were derived from the dataset by selecting specific groups within the forest as defined by the California Forest Practice Rules, literature, and common forestry groups (refer to the table below). An example of a forest component would be TPA of conifers from 2.1-14.0 inches DBH. In all, 162 forest components were analyzed through three research objectives: (1) general forest components, (2) small stem density and distribution, and (3) large stem density. The driving question behind the analysis is whether forest management is creating significantly different forest structure. If so, in which components of forest composition, density, and structure do those difference reside?

A mixed-effects linear model tested overall significance and Fisher’s Least Significant Difference (LSD) method tested pairwise comparisons among the six management regimes. Each model was tested with a significance level of $\alpha=0.05$ (pairwise and experimentwise). 
A fourth objective compared two methods of late successional forest (LSF) classification based on QMD measures of canopy layers and diameter ranges. The methods were compared via a paired-sample t-test. The two methods are significantly different, but the investigation of LSF classification led to an examination of the validity of current LSF policy. It is suggested that the minimum overstory QMD for LSF classification be increased from 24.0 to at least 30.0 inches DBH. Furthermore, it is recommended that landowner incentives should be implemented by the State of California to encourage promotion of LSF and its functional elements.

An underlying theme of all research objectives in this study is an examination of forest restoration management. Restoration management is intentional treatments that begin or accelerate recovery of a degraded ecosystem in regards to its integrity and sustainability relative to a reference condition, often defined culturally, historically, or ecologically (Society for Ecological Restoration 2004, Hobbs 2004, Hobbs and Norton 1996, Stanturf 2005). Results and conclusions were synthesized to discuss current restoration efforts in the redwoods. Recommendations for target stand densities and silvicultural methods are presented.

Forest Inventory Summary by Management Regime

\begin{tabular}{|c|c|c|c|c|c|c|c|c|c|c|c|}
\hline \multirow[b]{2}{*}{ Forest Origin } & \multirow[b]{2}{*}{ Management Regime } & \multirow[b]{2}{*}{$\begin{array}{l}\text { Aumber of Plots } \\
\text { (n) }\end{array}$} & \multicolumn{2}{|c|}{ Trees Per Acre } & \multicolumn{2}{|c|}{$\begin{array}{c}\text { Basal Area per Acre } \\
\text { (square ft. acre) }\end{array}$} & \multicolumn{2}{|c|}{$\begin{array}{c}\text { Quadratic Mean } \\
\text { Diameter (in.) }\end{array}$} & \multicolumn{2}{|c|}{ Mean Height ${ }^{a}$ (ft.) } & \multirow[b]{2}{*}{$\begin{array}{c}\text { Redwood Clumps } \\
\text { per acre }\end{array}$} \\
\hline & & & $\begin{array}{c}\text { All } \\
\text { Specics }\end{array}$ & Conifer & $\begin{array}{c}\text { All } \\
\text { Specics }\end{array}$ & Coniler & $\begin{array}{c}\text { All } \\
\text { Spccics }\end{array}$ & Conifer & Oxerstory & Linderstory & \\
\hline \multirow{2}{*}{\multicolumn{12}{|c|}{$\begin{array}{l}\text { Pre-European } \\
\text { Vatural: }\end{array}$}} \\
\hline & & & & & & & & & & & \\
\hline & Natural & 32 & 199.1 & 89.0 & 730.24 & 683.54 & 278 & 41.0 & 193 & 86 & 8.4 \\
\hline & Statdard Error: & & $1169 i$ & $10.5 i$ & (39..2) & 101.21 & $1 \pi$ & i2.2! & 3.1 & 13.4 & 1.21 \\
\hline \multicolumn{12}{|l|}{ I Iarvest: } \\
\hline & Park So Cut & 69 & 3756 & 148.8 & 51665 & +19.41 & 19.1 & 23.3 & $16 i$ & 85 & $26 ! ! 1$ \\
\hline & $|S F|$ & & illit & 1100, & i 159 & $i 243 i$ & 0.5 & in. $6 !$ & 20 & (1.9) & $(1.3)$ \\
\hline & Iruncated & 36 & 208.7 & 17019 & 30302 & 233.29 & 142 & 16.6 & 137 & 74 & 18.6 \\
\hline & $|S E|$ & & $i 20.6$ & $i 50$ & $116.3 !$ & $i 25.51$ & 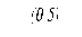 & 10.31 & $126 i$ & 2.2 & 11.4 \\
\hline & Large Trec Management & 18 & 1601.4 & 119.8 & 4113.33 & 368.83 & 22.8 & 253 & 174 & $8 ! !$ & 20.7 \\
\hline & ISE! & & $20.3 i$ & $185 i$ & $163 i$ & $i 35 ?$ & 1.2 & i1..! & 13.3: & $(4.6)$ & 201 \\
\hline & Percent Removal & 66 & 2.32 .3 & 1257 & 327.21 & $250.9]$ & 16.9 & $2 \pi .8$ & 1.51 & 76 & 20.2 \\
\hline & $i \$ E !$ & & $i 13]$ & {$[10.3 ;$} & $113.9 !$ & $16.0 !$ & 0.5 & $i 0.51$ & 1.5 & 23 & 10 \\
\hline & Unknoitn & 12 & 351.7 & 1860 & 426.18 & 379.10 & 151 & 19.5 & $15+$ & $9 i$ & 28.7 \\
\hline & $|S E\rangle$ & & $26.4 i$ & $13+i$ & $i 34 ?$ & $\mid 34.21$ & $i \theta ?$ & i1.0! & 120 & 4.11 & 25 \\
\hline & Harvest Origin Average & 301 & 263.7 & 1.01 .2 & 395.46 & 330.31 & 17.6 & 21.1 & 1.55 & 811 & 22.8 \\
\hline & $i S E !$ & & $\{3.2\}$ & $i 12 ?$ & $137.9 !$ & $13 \overline{1} .11$ & 16 & $i 1.51$ & 11 & (1) & 1.9 \\
\hline & Total Average & 233 & 251.4 & 137.1 & +46.04 & 373.21 & 19.0 & 24.0 & 160 & 81 & 20.5 \\
\hline & iSE! & & $7.3 i$ & 655 & $\mid 14.5 !$ & $115.5 !$ & $0+$ & $(0.31$ & 12 & 1.11 & 0.5 \\
\hline
\end{tabular}

${ }^{2}$ Height measurcment sample $(\mathrm{n})=1471[0 \mathrm{vcrstory}(\mathrm{n})=631 ;$ Lnderstory $(\mathrm{n})=840]$ 


\section{ACKNOWLEDGMENTS}

There are many people and organizations that I need to extend my most sincere gratitude towards, because a single graduate student cannot complete a project of this magnitude without assistance. Primarily, I would like to thank my graduate committee, Drs. Walter Mark, Douglas Piirto, and Ulric Lund, for their support and guidance during the development stages, and their confidence in me to manage this project. In addition, a few Cal Poly employees were priceless contacts for me when it came to weaving through the maze of graduate school and grants. Thank you to Elizabeth Ball, Jeff Reimer, and Jill DeMers.

The organizations that funded my project made my graduate education possible. I would like to thank Save the Redwoods League, especially Dan Porter and Ruskin Hartley for their support. I would also like to acknowledge The McIntire-Stennis Cooperative Forestry Program for the multiple years of funding support. Another organization that made this project possible through in-kind support was Swanton Pacific Ranch. Thank you to the entire staff at the ranch, including Dr. Brian Dietterick and Susan Burgess for helping me facilitate my research in the study area. My deepest and sincerest gratitude to Steve Auten, RPF for being my “safety officer” during data collection, for networking me into Santa Cruz forestry with your extensive contact list, and allowing me to run ideas by you at any time of the day.

This project would not be what it is today without the cooperation and collaboration of all the wonderful people opening gates to their forestland for me. In no particular order, my gratitude and appreciation are extended to: Portia Halbert, Tim Hyland, and all the rangers working for California State Parks-Santa Cruz Unit; Thomas Sutfin, Edmund Orre and the entire CAL FIRE staff at Soquel Demonstration State Forest; the people at the Land Trust of Santa Cruz County, including Julie Anne Hopkins, Jeff Helmer, and the Land Trust's consulting RPF, Steven Staub; the people at CEMEX- Davenport, including Kirk Toups and their consulting RPF, Gary Paul; Jennifer Clink at YMCA Camp Jones Gulch and the camp’s consulting RPF, Nick Kent; the Redwood Empire RPF’s David Van Lennup and Brian Bishop; Big Creek Lumber, 
especially Nadia Hamey and Janet Webb; and Dr. Bruce Krumland and Mitchell Haydon for their correspondence during the development phase.

Lastly, I would like to say thank you to the "Grad Hole" crew at Cal Poly. Graduate school was FUN because of all of you. Once again, in no particular order: Russell White, Mike Gaedeke, Kyle Jacobson, Valerie Lowe, Maurica Zimmerman, Eric Just, Carlos Torres, Nathan Smith, and Drew Perkins. Finally, words cannot express my appreciation for my peer reviewer and friend, Lauren Jeter. Thank you for the countless hours of editing my verbose writing and reminding me that not everyone is a forester. 


\section{TABLE OF CONTENTS}

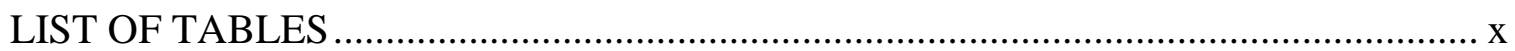

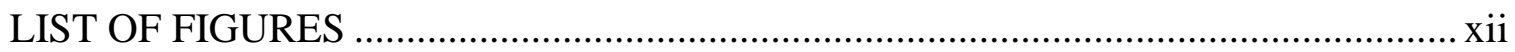

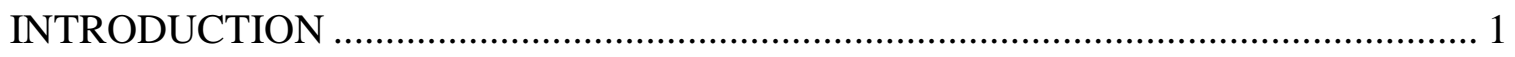

Problem Statement .......................................................................................... 4

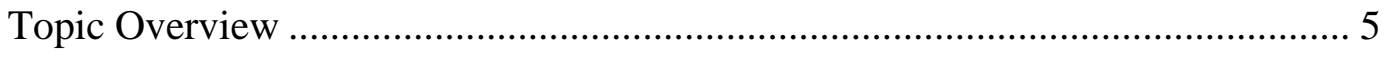

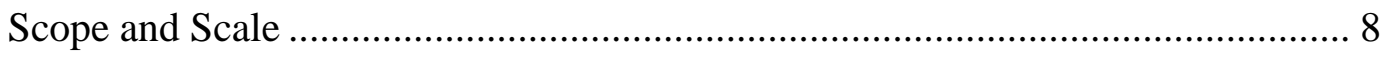

Governing Policies, Regulations and Management.............................................. 11

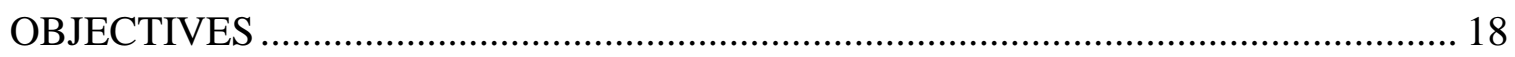

Objective One- General Forest Components ....................................................... 19

Objective Two- Small Stem Density and Distribution ......................................... 20

Objective Three- Large Stem Density ……………….......................................... 21

Objective Four- Late Successional Forest Classification Comparison................... 22

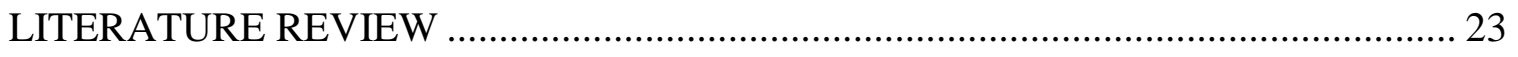

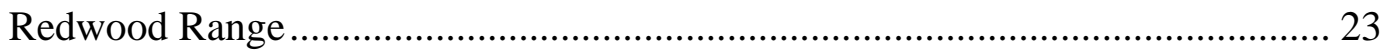

Associated Plant Species ................................................................................. 25

Redwood Ecology ……………………………………................................... 27

Forest Policy in California................................................................................ 40

Modern Timber Management ............................................................................. 70

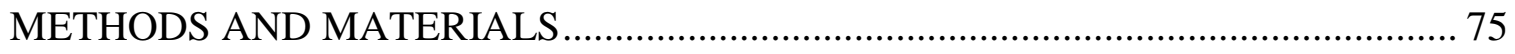

Management Regimes...................................................................................... 75

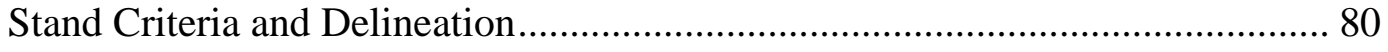

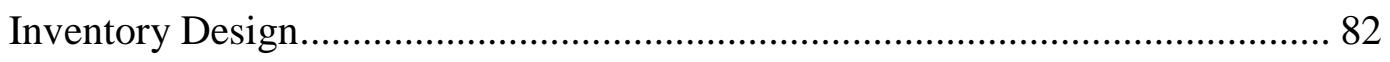




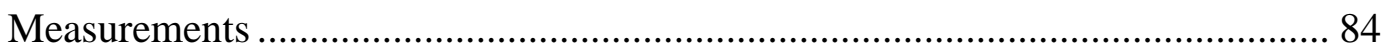

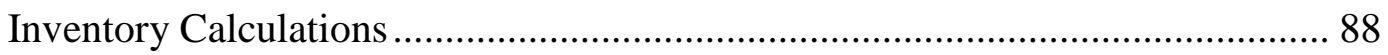

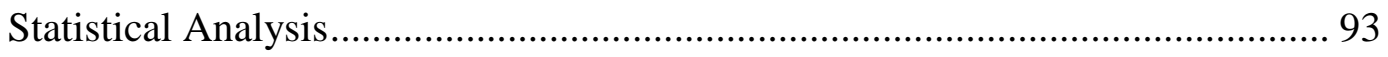

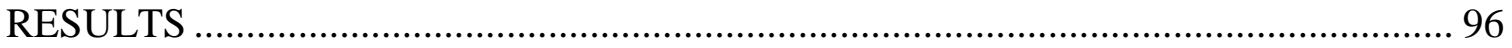

Objective One- General Forest Components ............................................. 101

Objective Two- Small Stem Density and Distribution .................................... 105

Objective Three- Large Stem Density ............................................................ 119

Brief Summary of Results for Objectives One, Two, and Three...................... 132

Objective Four- Late Successional Forest Classification Comparison............... 133

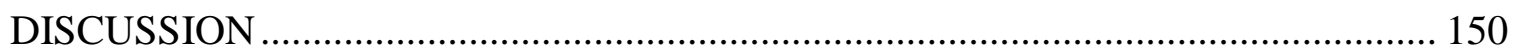

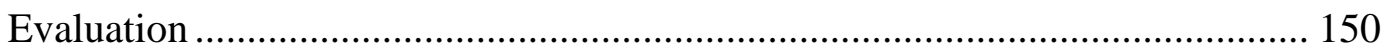

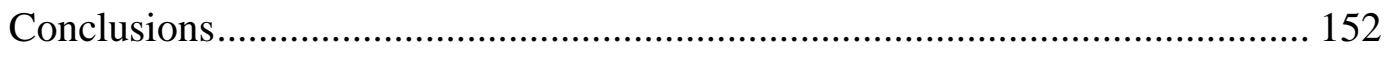

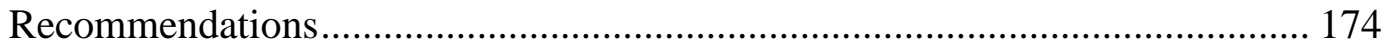

Project Summary.............................................................................. 184

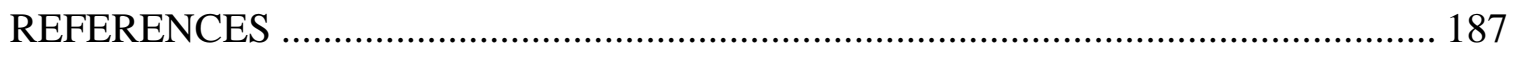

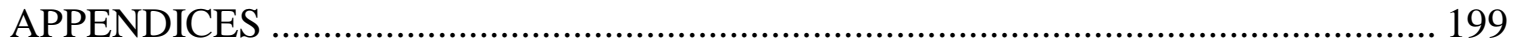




\section{LIST OF TABLES}

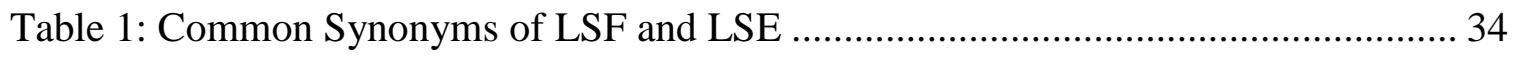

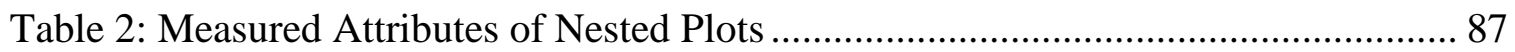

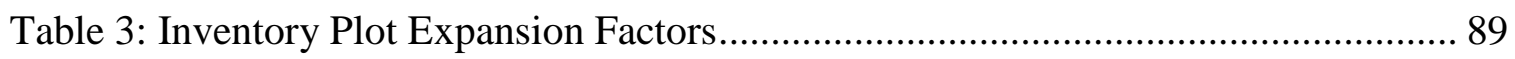

Table 4: General Component Data Summary by Management Regime.......................... 98

Table 5: Stand Table Data Comparison of Six Representative Stands ......................... 100

Table 6: General Forest Component Comparison Among Forest Origins ..................... 102

Table 7: General Forest Component Comparison Among Harvest Origin Plots............ 104

Table 8: Small Stem Density Distribution by 6-inch Classes (24.0” maximum) ........... 108

Table 9: “60/50 Rule” Small Stem Density Distribution (18.0” maximum) .................. 111

Table 10: Type A Owl Habitat Small Stem Density (18.0” maximum) ........................ 115

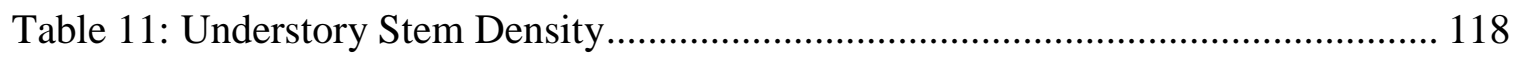

Table 12: Large Stem Sawtimber Density (10.5” minimum) ...................................... 121

Table 13: “60/50 Rule” Large Stem Density (18.1” minimum) ................................... 123

Table 14: Mature Large Stem Density (24.1” minimum)............................................ 125

Table 15: Type A Owl Habitat Medium \& Large Stem Density (18.1” minimum)....... 128

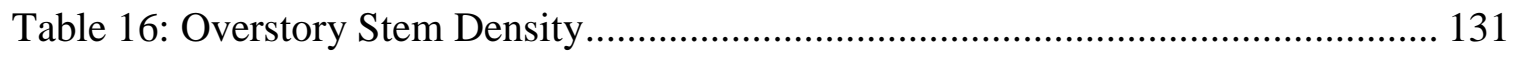

Table 17: Late Successional Forest Classification Comparison Descriptive Statistics .. 134

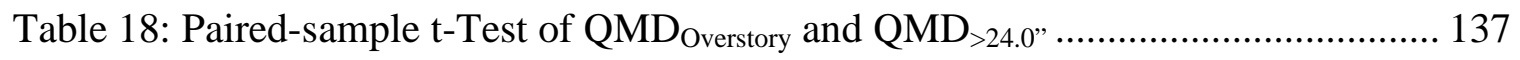

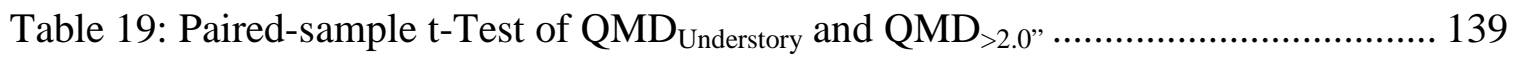

Table 20: Descriptive Statistics for General Forest Components ................................ 141

Table 21: Descriptive Statistics for 6-inch Diameter Class Components ....................... 142

Table 22: Descriptive Statistics for Small Stem “60/50 Rule” (14 CCR § 926.25) ....... 144 
Table 23: Descriptive Statistics for Small Stem Type A Owl Habitat and Understory.. 145

Table 24: Descriptive Statistics for Large Stem Sawtimber and Special Harvesting

Methods............................................................................................... 146

Table 25: Descriptive Statistics for "Mature” Trees (per Fox 1989)............................. 147

Table 26: Descriptive Statistics for Medium and Large Tree Type A Owl Habitat ....... 148

Table 27: Descriptive Statistics for Overstory...................................................... 149

Table 28: Overstory and Understory QMD by Harvest Origin Inventory Stand............ 171

Table 29: Summary of Target Stand and Potential Restoration Stand Descriptions ...... 181 


\section{LIST OF FIGURES}

Figure 1: Order of Scale for Inventory Terms ....................................................... 7

Figure 2: General Location of Santa Cruz and San Mateo Counties ................................. 8

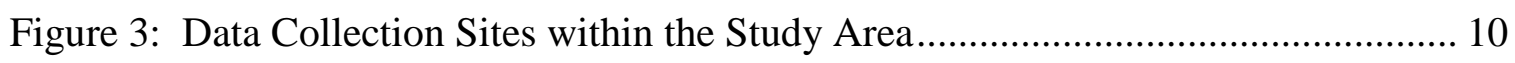

Figure 4: General Organization of Management Types, Treatments and Regimes.......... 14

Figure 5: Sequoia sempervirens Species Range, West Coast, USA ............................... 24

Figure 6: Generalized Relationships of Species Diversity, Biomass Volume and

Biomass Production Rate versus Stand Age .................................................... 29

Figure 7: Generalized Truncated Regime Stand Curve and Harvest Tree

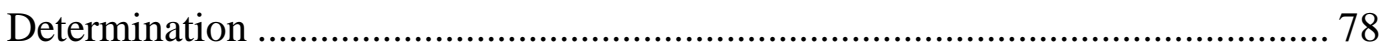

Figure 8: “L-shaped” Cluster of Three Nested Plots .................................................. 83

Figure 9: Sample SPSS Syntax for Mixed-effects Linear Model and Normality Plots.... 94

Figure 10: Sample SPSS Syntax for Paired-sample t-Test, Histogram, and Scatterplot .. 95

Figure 11: Comparison of Six Representative Stand Charts ...................................... 99

Figure 12: Stand Graph of 6-inch Diameter Classes by Management Regime .............. 110

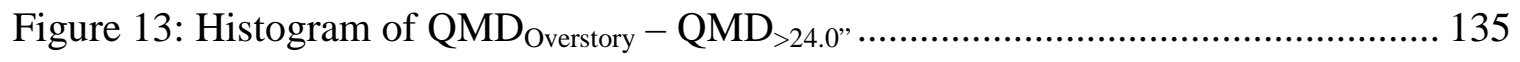

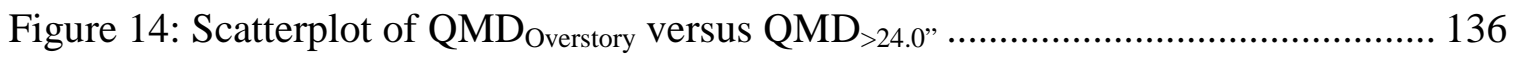

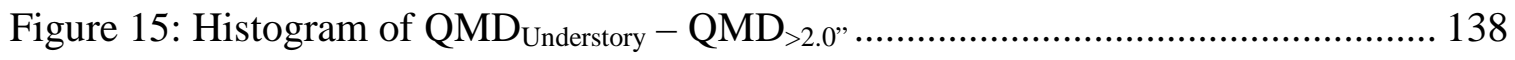

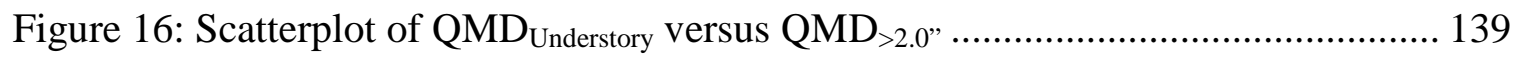

Figure 17: Overstory and Understory QMD by Management Regime.......................... 173

Figure 18: Typical Natural Regime Plot Photograph .............................................. 180

Figure 19: Typical Large Tree Management Regime Plot Photograph ......................... 183 


\section{EFFECTS OF SILVICULTURAL MANAGEMENT ON COAST REDWOOD FOREST COMPOSITION, DENSITY AND STRUCTURE IN SANTA CRUZ AND SAN MATEO COUNTIES}

\section{INTRODUCTION}

People are drawn to the beauty and aesthetics of the coast redwood (Sequoia sempervirens [D. Don] Endl.) forest for reasons that are as unique as the redwoods. Redwood forests have been heavily debated for more than 150 years. Debates focus on management, forest policy, endangered species, watershed impacts and aesthetics among other things. Coast redwoods are geographically and botanically unique, which means the management of this forest type is different from other forest types in California (Noss 2000, O’Hara 2002). Economics are a major factor in policy formation and management. The relatively small geographic range of redwoods, compared to other commercial conifers in the Pacific Northwest, holds the majority of timber value in the state (Burns and Honkala 1990, Laaksonen-Craig et al.. 2003). History shows that major changes in California forest policy have originated from the redwood region (refer to Forest Policy in California beginning on page 40). Some of the endangered and threatened species in Northern California are obligated to the redwood forest for food, shelter, or breeding. Finally, the precedent-setting court decision (NRDC v. Arcata National 1976), which made timber harvesting in California conform to California Environmental Quality Act of 1970 (CEQA), was based on cumulative watershed impacts in Redwood Creek. The uniqueness of this forest spans from minute genes to the tallest living organism on Earth, from environmentalism to the timber industry, and from the public to the private sector. 
Individual redwood trees are reported to be the tallest trees in the world and redwood trees have many other unique characteristics. Mature stems commonly reach heights greater than 300 feet and diameters greater than 120 inches (Olson et al.. 1990). The tallest individual living organism in the world is a redwood tree named Hyperion, found in Redwood National Park, Del Norte County, California. Hyperion stands 379.1 feet tall and there are currently 137 trees documented taller than 350 feet (Wilson 2007). The largest individual redwoods are concentrated north of the San Francisco Bay. Many large stems are present at Big Basin Redwoods State Park in Santa Cruz and San Mateo Counties; however, the majority of the southern section is second growth forest. Mature second growth redwoods in the southern section commonly grow between 180-250 feet tall and up to 60 inches in diameter. Redwood is the most valuable commercial timber species in California, having a stumpage value more than double any other species (Laaksonen-Craig et al.. 2003). In 2000, redwood ranked fourth in the state for harvested volume by species, but represented 43 percent of the total timber harvest value for California (Laaksonen-Craig et al.. 2003).

Until the environmental movement of the 1960's, redwood forest management focused on two objectives, timber volume production and fuel reduction (Arvola 1976, Clar 1959 and 1969). Maximized volume production drove industry and research. In 1973, California's forest policy was re-written and major changes began, and continue to develop through present day (CAL FIRE 2010). Although the California Board of Forestry and Fire Protection has authority over forest policy, counties received the right to amend forest rules and regulations in 1970 . County specific regulations must adhere to the statewide standards and are not valid until approved by the Board of Forestry and Fire 
Protection. Subsequently, Santa Cruz and San Mateo Counties developed restrictions on even-aged management regimes. In the years that followed 1970, these two counties also passed several specific rules for uneven-aged management and silviculture. The evenaged management ban led to the application of numerous uneven-aged, or "selection," management regimes. Uneven-aged management regimes plan activities to sustain and regenerate a stand with at least three distinct age classes (Helms 1998). This management type selects only certain trees for harvest, identified by species, size, or relative location and canopy position. After selection harvests, a residual forest continues to occupy the site.

The forests' structure and governing regulations are always changing, but at different rates. The regulatory shift from even-aged to uneven-aged management occurred overnight in ecological time. The forest structure is unable to change as rapidly; and almost four decades later, some of the redwood forests of the Santa Cruz Mountains actively pursuing uneven-aged structure have yet to achieve that desired future condition (Swanton Pacific Ranch 2007). Foresters had to modify uneven-aged management regimes to meet the even-aged forest structure developed from clearcutting approximately a century ago. This transition usually requires multiple harvests over three or more decades. Foresters and forest industry had to balance ecological and political changes during a time of regulatory uncertainty.

Forest industry has been a major stakeholder and contributor to management regime and policy development in California. Foresters are not immune to the idiom "If it is not broken, do not fix it.” For any single ownership, little effort was devoted to testing other management regimes for the site, since the current regimes were fulfilling 
the duties of regulatory compliance and timber volume output. Small changes to the level of volume harvested or physical spacing between residual trees were tested, and modifications made. However, these changes do not necessarily constitute a different management regime. Comparisons between regimes usually consider the bottom line, volume per acre at harvest. Limited research has investigated management affects on the various forest components that collectively describe the density and structure of the forest ecosystem in the southern subsection of the coast redwood range.

\section{Problem Statement}

Prior to this study, second growth redwood stand data has not been compared between or among management regimes. Historically, redwood research has focused on large, industrial forestlands from Sonoma County north. Research has been published out of Santa Cruz and San Mateo Counties, but the quantity of publications definitely tips the scale towards the northern part of the species range.

Calculating a stands' stocking is a common forestry practice. However, the effects those management regimes have on forest structure and density distributions cannot be analyzed by volume output alone. In order to identify differences in forest composition, density and structure, the stand data must be dissected into more descriptive, homogeneous groups. These groups are based on species, density measure, and diameter range or canopy layer. This study refers to these groups as “forest components.”

In addition, practicing foresters and researchers have intuitions of the most appropriate management regime for restoration, yet data to investigate these questions does not exist, or is not published. At this time, the majority of restoration forestry 
projects are harvested with a thin-from-below method that removes smaller understory trees and encourages growth of a few, large overstory trees (Guisti 2004). This method of restoration is encompassed by the Large Tree Management regime for this study. Other regimes represented in this study include the most commonly applied regimes in the study area and are described in "Management Regimes" beginning on page 75. All management regimes conform to the Rules at the time of harvest.

A cross section of stand descriptions and data is difficult to locate for many reasons. Foresters or landowners collect proprietary stand data. Stand data are quantitative measures of a contiguous group of trees uniform in species mixture, density, and structure (Helms 1998, Avery and Burkhart 2002). Proprietary information is seldom disclosed for research. Therefore, stand data available to the public is uncommon for the Santa Cruz Mountains. Plot inventory is time consuming and expensive, another reason manager's are reluctant to release it to the public. Remote sensing and aerial photogrammetry are alternatives to inventory plots, but neither alternative obtains equivalent accuracy or precision, especially when analyzing the understory vegetation due to the dense canopy cover. Compiling pre-existing data from numerous sources creates issues with statistical analysis and dispersion reporting. The most accurate approach for this study is to create a dataset from a temporary plot inventory utilizing a common sampling design.

\section{Topic Overview}

This multiple objective study examines the effects of silvicultural management on redwood stands in Santa Cruz and San Mateo Counties. Management regimes influence the composition, density and structure of forest stands differently according to the 
specific silvicultural prescriptions (Helms 1998). Differences between regimes are anticipated to be evident in quantitative measures of composition, density, and structure of forest components.

This exploratory and descriptive study on redwood forest management uses forest inventory data to compare and contrast management regimes in common use. Experimental units are one-quarter acre fixed-radius plots with a nested one-twentieth acre fixed-radius regeneration plot. Quantitative measures are calculated for a per acre basis. These measures represent "snapshot" data, or data from a single point in time, and describe the state of the forestland as of winter 2007-2008. Plots are located within stands, homogenous forest units similar in species mix, stocking, and structure (Helms 1998). Stands have not achieved their management goals due to the relatively short period of management activities, in most cases from five to 30 years. However, the documented management regimes have altered the stand structure at least once prior to data collection.

There are two types of stand origins in the dataset. (1) Natural origin stands were established prior to European influence and have never been harvested. These stands are a reference for the desired future condition pertaining to restoration forestry and represent approximately $14 \%$ of the plots in the dataset. (2) Establishment of harvest origin stands followed clearcutting between 1880 and 1930. All harvest origin plots represent the remaining $86 \%$ of the dataset.

Interactions of the forest ecosystem, timber harvesting and fire influence the forest in various ways. Fire has a major role in the redwood forest (Fritz 1931, Veirs 1980 and 1982, Sawyer et al.. 2000b, Thornburgh et al.. 2000, Keeley 2002, Stephens and 
Fry 2005). Redwoods' resistance to fire, especially stand-replacing fire, allows for the assumption that fires' influence on redwood density and structure is significantly less than the influence of forest management through timber harvesting. However, fire does have a significant influence on the species composition of the forest. The associated tree species of the redwood forest type usually experience significant damage or mortality after fire (Olson et al.. 1990, Roy 1980). The effect of fire on stand composition is, therefore, included in the analysis. Presence or absence of fire scorch on living trees was recorded for plots in all stands. Due to scarce historical records, it was difficult to determine the frequency and last occurrence of wildfire for all stands.

The order of scale is important to consider for this study. Trees are measured on inventory plots. Inventory plots are installed within stands. Stands are homogeneous management units delineated from within forests, and forests are sometimes synonymous with ownerships. Refer to the illustration in Figure 1 below.

Figure 1: Order of Scale for Inventory Terms

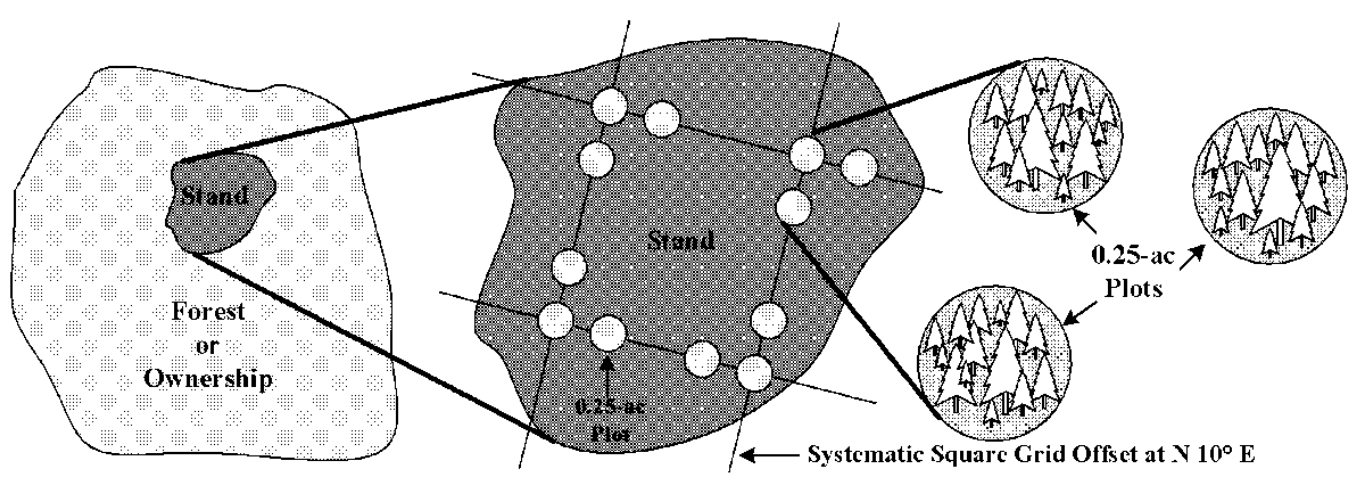




\section{Scope and Scale}

Geographic, production potential and regulatory boundaries define the study site.

Redwood forestland in Santa Cruz and San Mateo Counties consisting of Site Class II and III ground were potential collection sites. Refer to the general location of study area map presented in Figure 2 below. Sites also had to meet criteria for minimum acreage and redwood density. In this study area, the Southern subdistrict office of the CAL FIRE Coast forest district oversees regulatory compliance.

Figure 2: General Location of Santa Cruz and San Mateo Counties

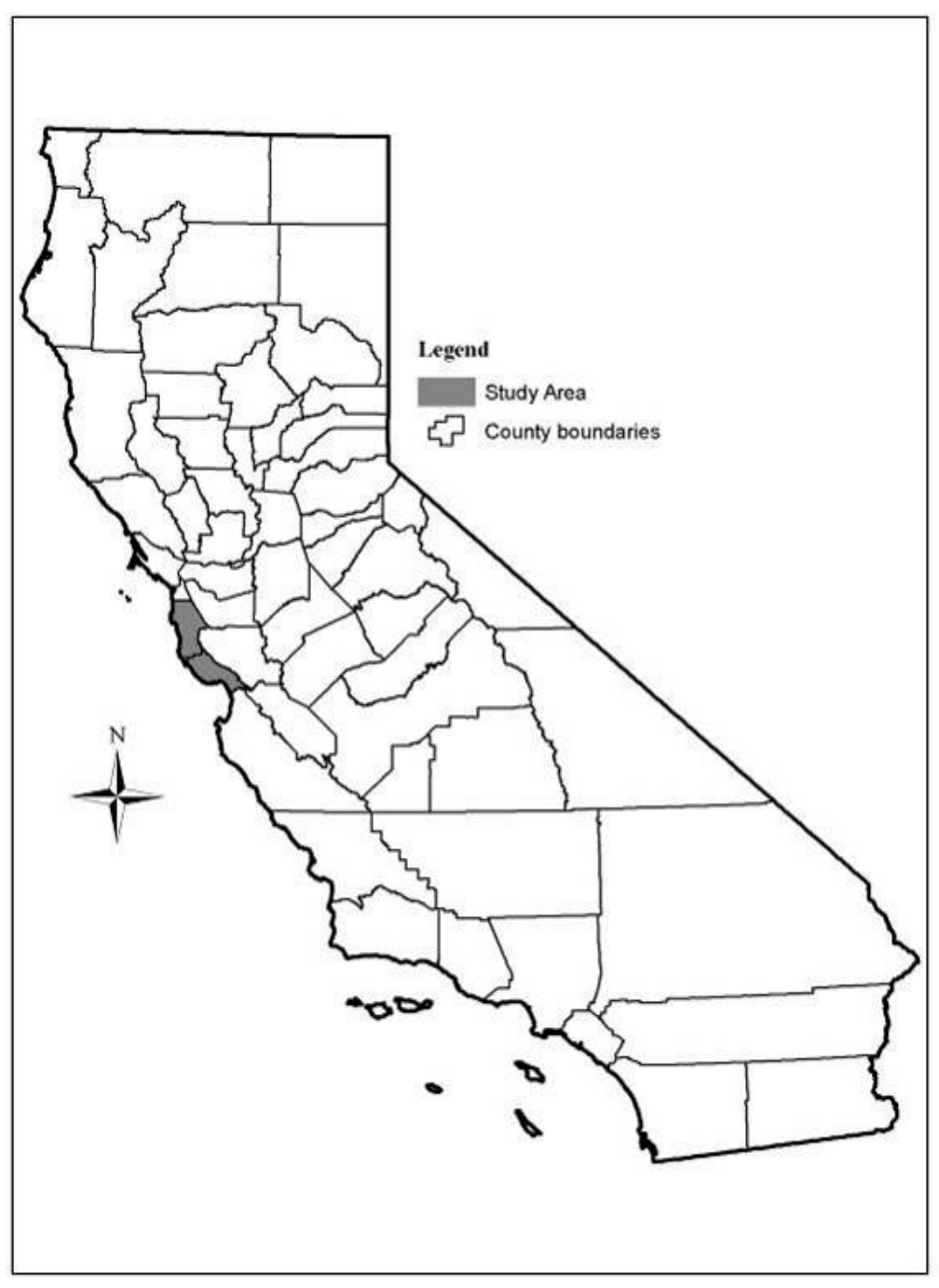


The final factor that determined potential sites was the willingness of landowners to grant permission for research on their land. Access to the sites was also a limiting factor, however many access issues were resolved by landowners allowing vehicle traffic on roads during dry weather and by the researchers’ willingness to hike long distances. Figure 3 on page 10 shows the distribution of data collection sites throughout the study area. 
Figure 3: Data Collection Sites within the Study Area

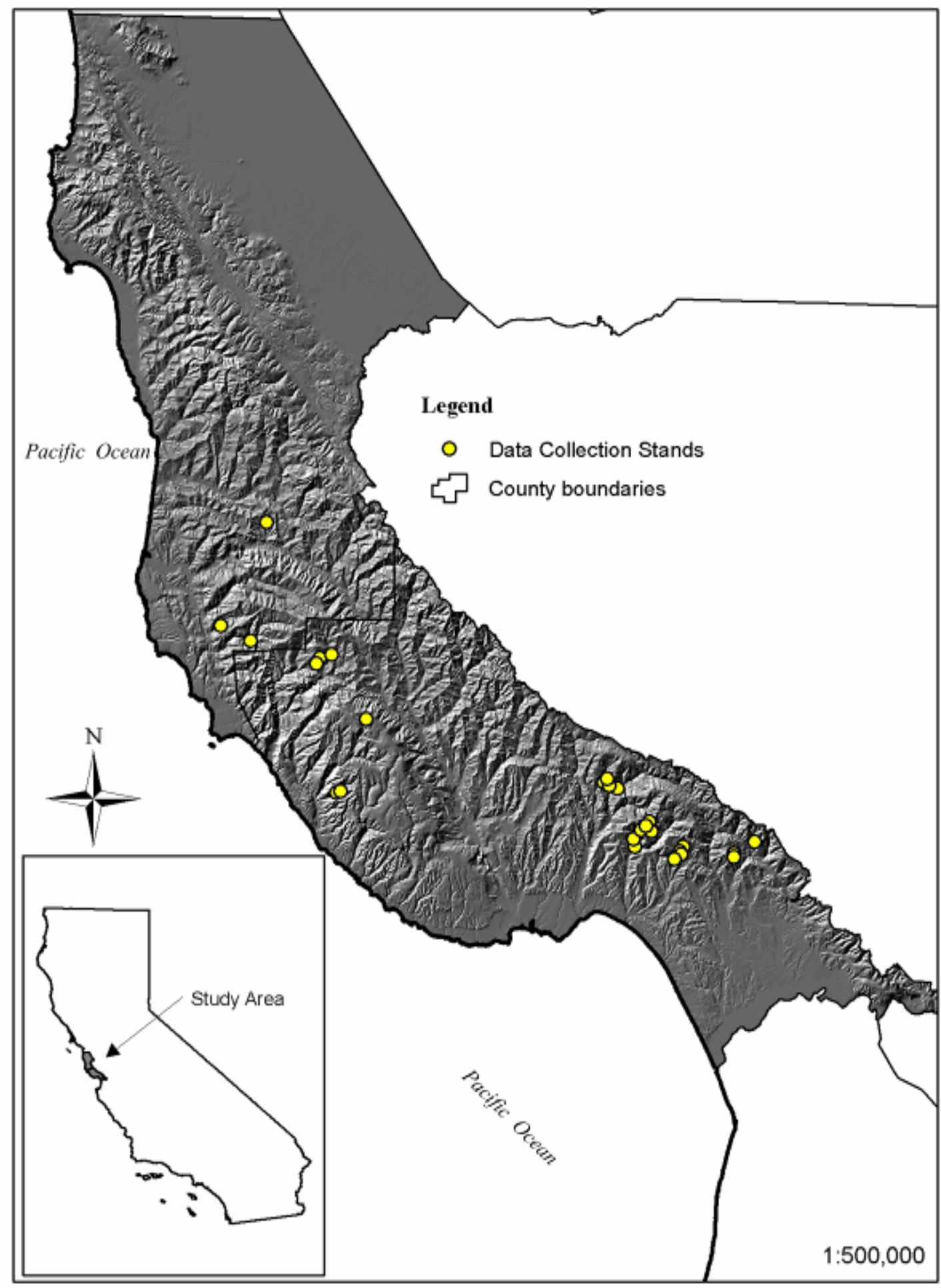

Note: Santa Cruz and San Mateo Counties identified by shaded portion of map. 
Governing Policies, Regulations and Management

Redwood forestlands are divided into a multitude of holdings, which are either "public" or "private” lands. The public lands include National and State Parks, Demonstration State Forests, community forests and university forests. The private lands include timber production zone (TPZ) forestland, conservation forests or easements, and forests owned by private entities. It is simple to divide the types of holdings into two categories; it is much more complicated to categorize the holdings by the governing policy and regulation.

The federal and state government holds public lands in trust for all American citizens, which includes national and state parks. The management of national parks falls under the regulation of the National Environmental Policy Act of 1970 (NEPA). California State Parks are managed under the equivalent state policy, CEQA. For all other private and state lands in California, any activity or project that has potential adverse environmental impacts is regulated by CEQA. Timber harvesting meets the CEQA definition of a "project". However, a separate law was codified specifically to regulate timber harvesting activities, and it is known as the Z'berg-Nejedly California Forest Practice Act of 1973 ("the Act" hereafter). The Act is implemented by the California Forest Practice Rules (“the Rules" hereafter). The Act and Rules adhere to CEQA procedural and multidisciplinary review guidelines. Any projects that take place on forestlands or timberlands in California that produce or are capable of producing high quality timber products are governed by the Act and the Rules. Projects in State Parks do not apply to the Act or Rules because harvesting of timber products is not allowed within park boundaries. 
The Forest Practice Rules have many functions. First, they provide means for implementing the Z’berg-Nejedly Forest Practice Act of 1973 and maintaining consistency with other procedural, resource, and environmental laws (Title 14, California Code of Regulations section 896 or 14 CCR § 896). These other laws include, but are not limited to CEQA of 1970, the Porter-Cologne Water Quality Act of 1969, Federal Clean Water Act of 1972, the California Endangered Species Act of 1969, and Timberland Productivity Act of 1982. The Rules also state the requirements for harvesting plans. Multidisciplinary plan review teams use the Rules for evaluation guidelines and criteria to determine if a plan conforms to the current regulations.

Harvest of commercial timber species in California is dependent upon the approval of environmental documentation. The three most common documents outlined by the Rules are the Timber Harvesting Plan (THP), the Non-industrial Timber Management Plan (NTMP), and the Sustained Yield Plan (SYP); collectively referred to as "plans" hereafter. These plans have been certified as "functionally equivalent" to the Environmental Impact Report (EIR) requirement of CEQA, pursuant to California Public Resource Code Section 21080.5. The process of harvesting timber cannot commence until a plan has been filed, publicly reviewed, and approved by the Director of CAL FIRE, also known as California Department of Forestry and Fire Protection (formerly $\mathrm{CDF})$.

The Act and Rules require countless topics to be included in a harvesting plan. The overall purpose of a plan is to document, disclose, or mitigate Maximum Sustained Production (MSP), adverse environmental impacts, and cumulative impacts. MSP of high quality timber products states that a forester must balance growth and harvest 
volume over time (14 CCR § 913.11). In other words, you may only cut what you grow for a given period, usually one decade but sometimes as long as a century. The majority of regulations are involved with the mitigation of significant adverse environmental impacts. These regulations are limited to "practical and feasible" stipulations within the bounds of the project. The Rules encompass mitigation criteria and thresholds designed to lessen significant adverse impacts to resources such as habitat continuity, water resources, and biological diversity. A Cumulative Impacts Assessment is also required, which evaluates the on- and off-site activity impacts for projects in the past and reasonably foreseeable future for the resource area, or planning watershed (Title 14 California Code of Regulations sections 898 and 1034 or 14 CCR §§ 898, 1034).

It is easy to get lost in regulatory language, code numbers, and acronyms. The essence of any plan is to sustain the growth of the forest for the long-term and lessen adverse impacts to natural resources.

\section{Managing Forest Resources}

There are many different ways of managing a forest. The landowner/manager defines the goals and objectives for the resource, and the vehicle used to achieve the goals is a management regime. A regime is a specifically designed order of treatments and activities that complies with current regulations. The regime defines the harvest schedule, tree selection method(s), desired harvest volume, and other prescribed treatments such as competing vegetation control. Implementing and coordinating a forest management regime is challenging for a forester. The objectives may be achieved through a multitude of management regimes. Selecting the correct regime is rhetorical. The foresters' selection relies on environmental, economic, and social values and the 
stated goals of the landowner. The organization of management types and harvest methods approved by the Rules is presented in Figure 4 below.

Coordinating the landowners' goals and objectives with ecological processes, scientific analysis, and environmental regulation is challenging, but reduces regime choices. Excluding specific management for alternative resources (recreation, wildlife, watershed, utilities, and fire and fuels management), timber management regimes vary by forest type and structure, region, and topography. Timber management regimes aim to achieve MSP of high quality forest products, while considering alternative resources. Many regimes meet this output in the redwoods. However, little is known about whether these management regimes have created or caused significantly different forest structure.

Figure 4: General Organization of Management Types, Treatments and Regimes

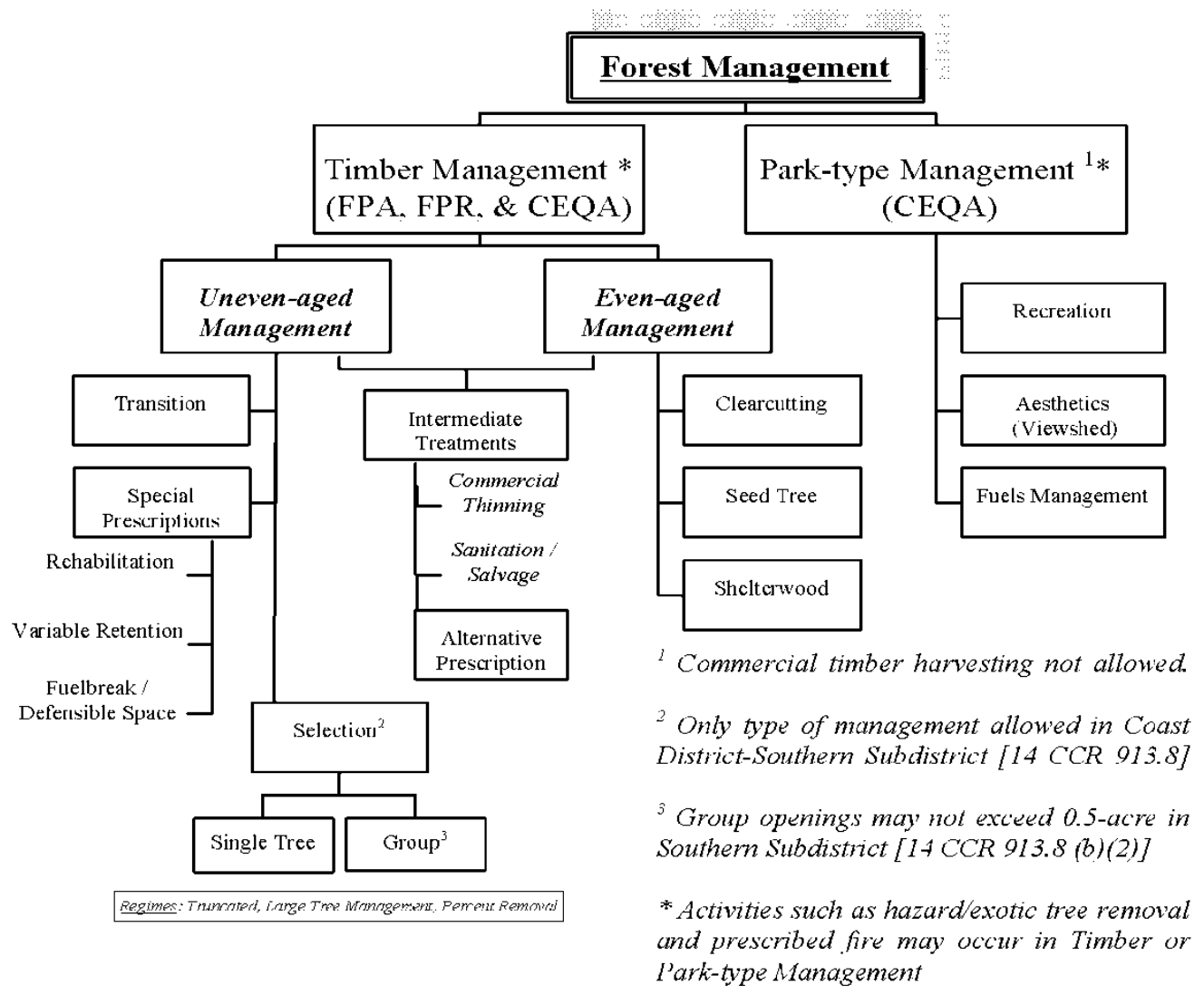


The intent of the Act requires that values other than timber be considered when developing a plan (PRC § 4513 (b)) (CAL FIRE 2010). Recreation, wildlife and forage, watershed and fisheries, and fire and fuels management are among the alternative forest resources associated with timber management. Recreation management focuses resource management to outdoor leisure activities that result in satisfaction by humans (Helms 1998). A few of the more popular recreational activities in the redwood forests include hiking, running, cycling, camping, photography, and wildlife or bird watching. Wildlife management activities maintain or manipulate species population for scientific or recreational purposes (Helms 1998). The wildlife populations of particular interest are mainly mammals, birds, and fish. Watershed management is a large-scale approach to managing the land-use activities in a region drained by a single stream, river, or drainage network to a common point to maintain or manipulate the hydrologic cycle (Helms 1998; Brooks et al.. 2003). Many watershed management objectives preserve or maintain municipal water supplies and fisheries. Fuels management are specific vegetation management activities designed to control flammability and lessen resistance to control of wildland fuels through mechanical, chemical, biological, or manual means, or by the use of prescribed fire (Helms 1998). Fire management is the active process of extinguishing a blaze. It is important to note that forest resource management, including timber, does not preclude any of the alternative resource objectives.

\section{Forest Restoration Management}

Few regimes have been developed for forest restoration management. Restoration management is intentional treatments that begin or accelerate recovery of a degraded ecosystem in regards to its integrity and sustainability relative to a reference condition 
(Society for Ecological Restoration 2004, Hobbs 2004). The relative reference condition, or desired future condition, is often defined culturally, historically, or ecologically, and sometimes excludes human related disturbance (Hobbs and Norton 1996, Stanturf 2005). In this study, the restoration regime is categorized under timber management since activities, including harvesting by a thin-from-below prescription, are often part of the process. Restoration management differs from preservation in this respect.

Restoration forestry for redwoods seeks to accelerate the forest into a simulated mature state by applying vegetation management techniques to mimic natural processes that normally occur over long periods. In essence, the restoration goal for redwood forest is to create stands with large, old trees with few understory trees if any at all (Guisti 2004). This open, "park-like" setting is most desirable to restorationists and is evident in a popular movie “Stars Wars Episode VI: Return of the Jedi.” The Ewoks' home, the forest moon of Endor, is an example of a park-like redwood forest. The scenes were filmed at Jedediah Smith Redwoods State Park in Del Norte County, California. Through the well-known "speeder" chase scene, the scenery is a park-like stand of natural origin redwood trees that are large in diameter and widely spaced. These trees have few limbs close to the ground and few understory trees beneath them. Ferns and large woody debris cover the forest floor. All of these attributes develop naturally through hundreds, maybe thousands of years as the forest matures.

According to current forest practice regulations, qualitative descriptions of desired future conditions, such as "park-like," or excerpts from motion pictures do not qualify as silvicultural prescriptions. Clear, quantitative descriptions of the desired future condition are needed to derive the appropriate management strategies (Wagner et al.. 2000). 
Difficulty arises when attempting to determine historic natural conditions and desired future conditions because social, cultural, and/or political values are intertwined (Hobbs 2004). Therefore, the determination of a suitable desired future condition may be assisted by scientific research, but scientific research cannot be the sole method (Keddy and Drummond 1996, Stanturf 2005). Once a quantitative desired future condition is established, the most appropriate forest management regime may be determined to achieve the condition. 


\section{OBJECTIVES}

There is growing evidence that political and social changes will lead to more stringent forest practice rules, thereby limiting the options forest managers have for harvesting trees. Evidence already exists to limited options in specific rules for the Southern subdistrict of the CAL FIRE Coast district, Santa Cruz County, and San Mateo County (14 CCR §§ 913.8, 926 and 928, respectively) (CAL FIRE 2010). These special rule sets apply to management practices in the specified subdistrict or county that append or modify the Rules for the Coast district. Even with these restrictions, forest managers have numerous options for management regimes that conform to the Forest Practice Act and Rules.

This study represents the most common management regimes in practice for Santa Cruz and San Mateo Counties. However, little information exists for how these regimes affect the form of the forest in comparison to another regime. Management regimes and silvicultural methods vary, but whether these create forests of different forms is unknown. Despite professional intuitions from forest managers, data has not been presented for comparing similar redwood forest types undergoing different management regimes.

Specifically, the research objectives use plot data from the forest in the current state, known as "snapshot” data. Comparisons are accomplished through four objectives focused on various forest components. A forest component is a selected group of stems defined by a species or species group, a density measure, and a range of diameters or canopy layer. The use of multiple objectives and forest components is necessary because one clear, concise metric to describe a forest does not exist. The measures used to 
describe the forest in this study are trees per acre (TPA), basal area per acre in square feet (BA), and quadratic mean diameter in inches (QMD). The organization of objectives and forest components have been defined according to pertinent scientific literature, the Forest Practice Rules, or commonly used components utilized by the timber industry. Descriptions of these research objectives, forest component groupings, and related literature are presented on pages 19-22. Each group is independent from all other groups between and among research objectives.

\section{Objective One- General Forest Components}

\section{Hypotheses:}

Null Hypothesis $\left(\mathrm{H}_{\mathrm{O}}\right)$ : The forests managed by all regimes have equal composition, density, and structure.

Alternative Hypothesis $\left(\mathrm{H}_{\mathrm{A}}\right)$ : At least one forest management regime is different.

General forest components describe a broad portion of the stand, rather than dissecting the stand into more precise components. The purpose of this objective is to statistically test for differences in quantitative measures of overall composition, density, and structure based on management regimes. The analysis will be conducted twice, once including the natural origin plots and again without the natural origin plots. Questions that led to this objective include: Are natural and harvest origin forests part of the same population? Is management creating different redwood forest structure? Which harvest origin management regime best simulates natural origin structure? 
Objective Two- Small Stem Density and Distribution

Hypotheses:

$\mathrm{H}_{\mathrm{O}}$ : Density distributions for small trees and understory trees are equal under all management regimes.

$\mathrm{H}_{\mathrm{A}}$ : At least one management regime has a different small tree density distribution.

Determine if there is a statistically significant difference in small tree and understory tree density distributions based on management regime. Questions that led to this objective are: Is management significantly influencing the understory trees? Has timber harvesting created a hardwood-dominated understory?

Small tree and understory definitions:

1) 6-inch diameter classes up to 24 inches DBH.

2) Special Harvesting Methods of Santa Cruz County leave tree standards. Small trees in two classes, less than 14.0 inches DBH and from 14.1 inches to 18.0 inches DBH per 14 CCR § 926.25 (a). Also referred to as the “60/50 Rule.” (CAL FIRE 2010)

3) Type A Owl Habitat live-tree structure and size class defined as "small tree" (<18.1 inches DBH) per the Forest Practice Rules (14 CCR § 895.1)

(CAL FIRE 2010).

4) Understory canopy layer described as trees with crown classes Intermediate or Suppressed (per Parisi, Motroni and Robards 2007). 


\section{Objective Three- Large Stem Density}

Hypotheses:

$\mathrm{H}_{\mathrm{O}}$ : Density measures for large trees are equal under all management regimes. $\mathrm{H}_{\mathrm{A}}$ : At least one management regime is different.

$\mathrm{H}_{\mathrm{O}}$ : Density measures for overstory trees are equal under all management regimes. $\mathrm{H}_{\mathrm{A}}$ : At least one management regime is different.

The purpose of this objective is to test for statistically significant differences in large tree and overstory tree density based on management regime. Large tree analysis in Objective Three does not consider the distribution of stems in diameter classes; rather a single measure of density based on the respective forest component. Furthermore, for the purpose of this study, large stems will refer to forest components defined by a diameter range and overstory stems will refer to forest components defined by canopy layer.

Large tree and overstory definitions:

1) Tree diameters greater than 10.5 inches $\mathrm{DBH}$, defined as 'sawtimber' by the empirical yield tables for young growth redwoods (Lindquist and Palley 1963).

2) Special Harvesting Methods of Santa Cruz County leave tree standards. Large trees greater than 18.0 inches DBH per 14 CCR § 926.25 (“60/50 Rule”) (CAL FIRE 2010).

3) “Mature” tree diameters greater than 24 inches DBH (per Fox 1989). Also referred to as “old growth” in original publication.

4) Type A Owl Habitat live-tree structure and size classes defined as "medium tree” (18.1-35.0 inches DBH) and "large tree” (>35.0 inches DBH) per the Forest Practice Rules (14 CCR § 895.1) (CAL FIRE 2010). 
5) Overstory canopy layer described as trees with crown classes Dominant or Codominant, (per Parisi, Motroni and Robards 2007 and Helms 1998).

Objective Four- Late Successional Forest Classification Comparison Hypotheses:

$\mathrm{H}_{\mathrm{O}}$ : The difference between QMD calculation methods equals zero. $\mathrm{H}_{\mathrm{A}}$ : The difference between methods differs significantly from zero.

This objective is designed to evaluate two methods for determining the classification and measurement of late successional forests (LSF) in terms of quadratic mean diameter (QMD). The first method is recommended by CAL FIRE and the California Department of Fish and Game (DFG) (Parisi et al.. 2007). The second method was developed and applied by the authors of the Swanton Pacific Ranch NTMP (Swanton Pacific Ranch 2007), in lieu of the recommended classification suggested by the agencies. The Coast District of CAL FIRE subsequently accepted the Swanton Pacific Ranch NTMP. Refer to “Inventory Calculations” on page 88 for descriptions of calculation methods. These two methods are compared for equivalency and discussed as it pertains to late-successional forest classification and policy. 


\section{LITERATURE REVIEW}

\section{Redwood Range}

The distribution of Sequoia sempervirens, or coast redwood, is an irregular strip along the Coast Ranges stretching from the Chetco River in southwest Oregon [lat. $42^{\circ} 09^{\prime}$ N.] to Salmon Creek in southern Monterey County, California [lat. 35 41’ N.] (Roy 1980, Fox 1989 and 1996, Olson et al.. 1990, Holland and Keil 1995, Sawyer et al.. 2000a, Stuart and Sawyer 2001). The general width of the range varies between 5 and 35 miles (Olson et al.. 1990). Redwood ranges in elevation from sea level to 3,000 feet, but found between 100 and 2,500 feet most often (Roy 1980). A major split in the range by the Douglas-fir forest cover type occurs in southern Humboldt County (Olson et al.. 1990, Fox 1996). The redwood range occupies approximately 6.8 percent of the conifer forestland in California, nearly 1.3 million acres (FRAP 2003). Within this acreage, the forest varies dependent upon latitude, distance from the ocean, and elevation. Refer to Figure 5 on page 24.

Three sections are defined as the northern, central and southern redwood forests (Sawyer et al.. 2000a). The northern section includes the forests from southwest Oregon to the mountains east of Humboldt Bay near Eureka, California. This region is home to Redwood National and State Parks, which encompass most of the oldest known redwood stands. The conglomerate of three California state parks and one national park is intermixed with some of the most productive commercial redwood forests in the entire range. The central section stretches from Humboldt Bay to San Francisco Bay. The southern section stretches from San Francisco Bay to the southern extent of the range in Monterey County. This section houses many redwood state parks including the first, Big 
Basin Redwoods State Park established in 1901 (Clar 1959). A viable timber industry exists in southern section, operating primarily on private lands.

Figure 5: Sequoia sempervirens Species Range, West Coast, USA

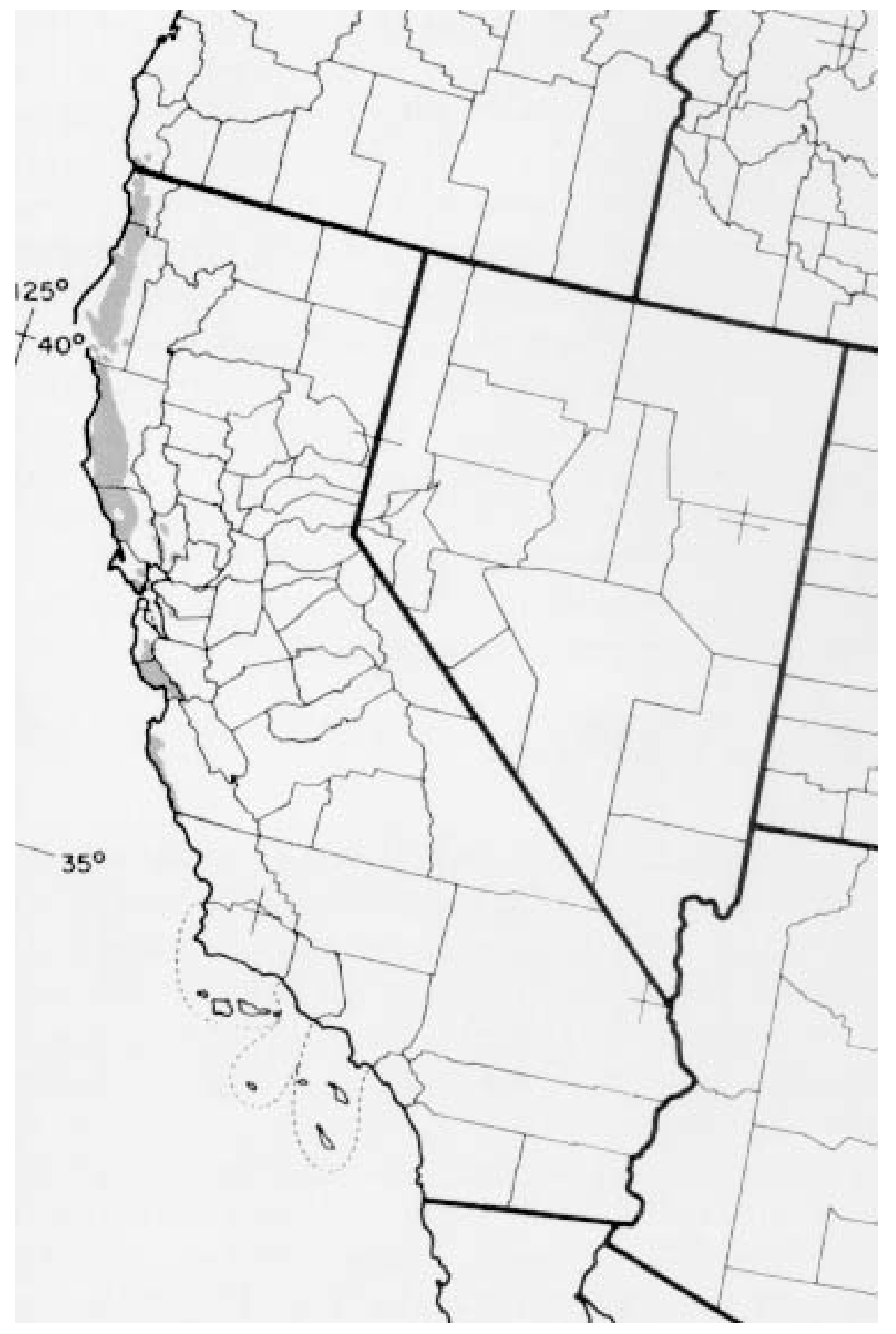

Figure 5: Redwood dominated forest shown in shaded area. (Olson et al.. 1990) 


\section{Associated Plant Species}

The following plants constitute genera and/or species commonly observed during data collection. Botanical nomenclature follows Jepson Manual structure (Hickman 1993). Some plants were not inventoried on the sample plots, but were observed in areas adjacent to research stands. For a more comprehensive list of vegetation found in the redwood and redwood/Douglas-fir forest cover types, the interested reader should refer to Noss (2000) or Holland and Keil (1995). For species lists of associated lichens, fungi, and fauna along with listing status, refer to Noss (2000) and Sholars and Golec (2007).

There are many associated tree species within the southern section of the redwood range. A common coniferous associate of redwood is Douglas-fir (Pseudotsuga menziesii [Mirbel] Franco). Another conifer found in this region is Pacific yew (Taxus brevifolia Nutt.) but is uncommon. On dry, upland sites, redwoods intermix with the oak-pine forest type, where other conifer species exist, such as Monterey pine (Pinus radiata D. Don), knobcone pine ( $P$. attenuata Lemmon), Bishop pine ( $P$. muricata D. Don) and Monterey cypress (Hesperocyparis macrocarpa [Hartw.] Bartel). However, within the redwood forest cover, many tree species are angiosperms, or hardwoods. Tanoak (Lithocarpus densiflorus [Hook \&Arn.] Rehd.) is the most abundant and wellestablished in the understory. Tanoak may be located in the overstory in tree-form or in the understory in shrub-form dependent upon seral stage. Other species include Pacific madrone (Arbutus menziesii Pursh), California bay-laurel (Umbellularia californica [Hook \& Arn.] Nutt.), numerous oak species (Quercus sp.), and big-leaf maple (Acer macrophyllum Pursh). Another common hardwood found in riparian corridors is white 
alder (Alnus rhombifolia Nutt.) (Holland and Keil 1995, Stuart and Sawyer 2001, Sawyer et al.. 2000a, Hickman 1993). These species occupy most of the middle to lower canopy layers, but there is still ample growing space for lower forms of vegetation.

Hundreds of understory shrubs, herbaceous plants, and ferns grow underneath the redwood canopy. A few of the notable shrubs are California huckleberry (Vaccinium ovatum Pursh), blackberry (Rubus ursinus Cham \& Schldl.), thimbleberry ( $R$. parviflorus Nutt.), and poison-oak (Toxicodendron diversilobum [Torrey \& A. Gray] E. Greene). Herbaceous plant species are abundant, most notably clover (Trifolium sp.), redwood sorrel (Oxalis oregana Nutt.), Douglas's iris (Iris douglasiana Herbert), and plantains (Plantago sp.). Ferns occupy both xeric, dry sites, and mesic, moist sites in the understory. Bracken fern (Pteridium aquilinum [L.] Kuhn var. pubescens [L.] Underw.) is usually found on more xeric sites, while woodfern (Dryopteris arguta [Kaulf.] Maxon), sword fern (Polystichum imbricans [D. Eaton] D.H. Wagner), and chain fern (Woodwardia fimbriata Smith) are found on more mesic sites (Hickman 1993, Holland and Keil 1995, Sawyer et al.. 2000a, Stuart and Sawyer 2001).

Mature redwood forests have many associated understory plants that exhibit a diverse layer arrangement (Olson et al.. 1990). What makes this forest unique is that even in 20 feet above the forest floor, there may be numerous layers of vegetation in addition to those layers higher in the canopy. The introduction of gaps into the old forests also increases the amount of horizontal and vertical plant diversity (Sawyer et al.. 2000b, Van Pelt and Franklin 2000). 


\section{Redwood Ecology}

Sequoia sempervirens is capable of living for more than 2000 years (Peattie 1953, Olson et al.. 1990, Veirs 1996). A long-lived species such as redwood denotes a forest ecosystem that continually changes and looks very different dependent upon the stage. One theory that models these changes is succession, where each stage is a sere (Clements 1936). The non-cyclic or linear progression through seral stages begins with lower vegetation dominating the landscape in early successional stages, and terminates in climax stage, usually referred to as late successional. Redwood forests are a climax vegetation type (Clements 1936). Natural and anthropogenic disturbances can cause succession to be set back one or more stages. However, this linear model will remain in the climax stage in perpetuity until a major disturbance alters the structure.

The forest characteristics progress from early to late successional after redwoods establish on a site. Early successional stages have high biomass production rates as the stand continues to establish. Small stems growing rapidly account for most of the production rate, especially when compared to old forest biomass production rates. As young forests transition into the intermediate successional stages, vigor and production rates decline but the forest begins to increase biomass volume, structural complexity and species diversity (Biswell et al.. 1966). The dominant stems initiate the self-thinning process, where large neighbors shade smaller trees out. This process is also called shadeinduced mortality (Davis et al.. 2001, Thornburgh et al.. 2000, Poage and Tappeiner 2002). The weaker, suppressed trees begin to lose the fight for light, water, and nutrients and stand development slows in terms of number of trees per acre and biomass production (Olson et al.. 1990). Typically, young forests have low species diversity, 
medium to high biomass production, and low to medium biomass volume. The low species diversity is debatable, since much of the understory is dominated by a few species of shade-tolerant trees and woody shrubs. However, diversity present within the herbaceous and non-vascular plant communities is extremely high (West 2009).

Forest structure becomes more complex during the intermediate seral stage. Multiple canopy layers develop as shade tolerance and competition influence individuals. An understory of hardwoods, brush and bryophytes establish as canopy closure decreases light, temperature and moisture loss on the forest floor. Most second growth forests are managed in the intermediate seral stage. The forest is not mature enough for certain late successional characteristics to have developed yet. Species diversity is average, but biomass production and volume are high (Figure 6, page 29).

Little information is known about the length of time needed for intermediate stage redwood forests to progress to late successional. Research refers to a wide range of late successional age, such as 80-1000 years (Norse 1990, Franklin and Spies 1991a and 1991b, Giusti 2004, Youngblood 2001). However, late seral characteristics commonly begin to develop between 80-200 years (Franklin and Spies 1991a, Youngblood 2001). Ecology of the old forest can be described as climax, or self-sustaining (Clements 1936). Old forests in late successional stages have high biomass production rates, extremely high biomass volumes, and high species diversity. Up to 40 percent of annual growth for an individual late seral tree is applied to appendages, such as large diameter branches and reiterated tops (Sillett 2009). The complex, layered structure of a late successional redwood forest provides many unique, endangered, or threatened species with ecological niches (Mazurek and Zielinski 2004, Giusti 2004, Norse 1990). For more information 
regarding specific characteristics, refer to the Late Successional Forest section beginning on page 31.

Figure 6: Generalized Relationships of Species Diversity, Biomass Volume and Biomass Production Rate versus Stand Age
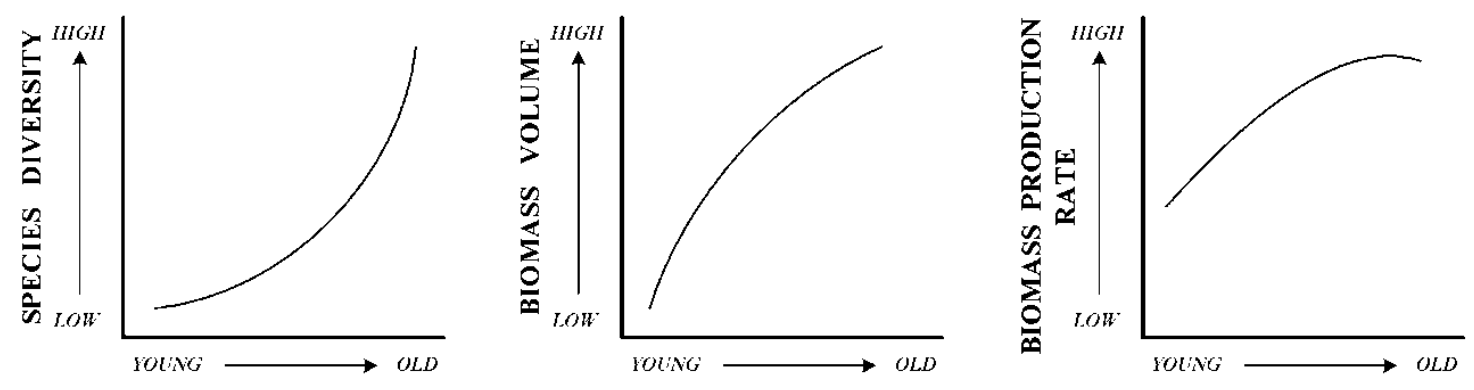

STAND AGE

Generalized relationships synthesized from Lindquist and Palley 1963, Biswell et al.. 1966, Olson et al.. 1990, and Davis et al.. 2001.

Some researchers discount climax succession theory and favor the gap-phase regeneration theory (Youngblood 2001, Van Pelt and Franklin 2000, O’Hara et al.. 1996). The gap-phase theory models the ecosystem based on the mosaic characteristic of vegetation across the landscape. Disturbances create gaps in existing vegetative communities allowing another community opportunity to establish. The gap size varies, along with disturbance type (Van Pelt and Franklin 2000). It may be modeled as disease or insect epidemics creating gaps hundreds of acres in size, a small lightning fire burning only a few acres, or a single windthrown tree creating a gap in the forest canopy 60 feet in diameter. These natural disturbances initiate changes in the vegetation composition, density, and structure. Both theoretical models, succession and gap-phase, are heavily debated. Some ecologists agree with one and not the other, but the majority agree that both are useful in describing the metamorphosis of forest structure. 


\section{$\underline{\text { Spatial Structure }}$}

Redwood has an uncommon and unique genetic characteristic known as hexaploidy, in which the organism contains six complete sets of chromosomes (Douhovnikoff et al.. 2004, Rogers 2000, Becking 1996). Hexaploidy in redwoods is unique among all species in Coniferales (Sclarbaum and Tsuchiya 1984). This genetic composition enables asexually reproduction of ramets that are genetically different from the parent (Douhovnikoff et al.. 2004). The genetic makeup means that within a fairy ring arrangement there could be various numbers of different genotypes, rather than one clonal genotype of the parent tree (Ahuja and Neale 2002, Douhovnikoff et al.. 2004). Polyploidy is not as common in conifers as haploid (1n) or diploid (2n) (Olson et al.. 1990). Redwoods reproduce by seed and coppice sprouting. Reproduction by seed is possible, but uncommon due to high occurrence of defective seeds and deep duff layers (Becking 1996). Coppice regeneration produces new stems from burls on the root or stump (Helms 1998, Olson et al.. 1990; Roy 1980, Sawyer et al.. 2000a, Florence 1965). The combination of coppice and seed regeneration is rare among western conifers (Roy 1980, Olson et al.. 1990). Redwood forests are considered "clumpy” due to these genetic traits and regeneration methods.

Clonal rings, of fairy rings, are not the only form of spatial arrangement in the redwoods. Other common forms include linear, figure eights, chains, partial circles, concentric circles and disjoint patterns (Douhovnikoff et al.. 2004). Some clones have been found more than 130 feet ( 40 meters) away from the parent tree. This is likely due to sprouting from the root system along a runner (Rogers 2000, Douhovnikoff et al.. 2004). Other linear patterns may occur when a large tree is toppled by high winds or 
flood. In this case, branches initiate apical dominance and begin primary, upward growth. Over decades and centuries, the toppled parent tree slowly decays as trees in a linear pattern grow from what was once a branch. Furthermore, it is speculated that a true natural origin forest would have established from seed generation. This would take place during primary succession; therefore, the spatial arrangement would not be linked to clonal and asexual regeneration of the species. In this instance, the forest would most likely have a random distribution of single stems rather than clumps. However, no significant differences have been identified between harvest and natural origin forest clonal spread and genetic footprints to date (Douhovnikoff et al.. 2004). Further investigation is needed on this topic.

\section{$\underline{\text { Late Successional Forests }}$}

Researchers have been attempting to define this topic for over four decades. One of the main problems is relatively few sites remain. Estimates range from three to nine percent of the original redwood forest area are currently late successional (Bolsinger and Waddell 1993, Fox 1989 and 1996, Noss 2000, Sawyer et al.. 2000a, Thornburgh et al.. 2000, Giusti 2004, Yee 2003, FRAP 2003). This six-percent difference in the estimated acreage of late successional forests exemplifies the variability of the subject matter, as it represents tens of thousands of acres in variation between estimates. Some definitions rely on age, others on tree size. Methods have been developed using indices that account for multiple forest and environmental factors, or species diversity and richness. And yet, other models are so complex it resembles a launch algorithm for the space shuttle. The problem is simple, we know what it looks like and we know what it feels like to walk 
through an old redwood forest, but we cannot agree upon what to measure to define and classify the structure.

Before a definition may be discussed, a title is needed. Late successional forests have many synonyms like: old growth/forest, virgin growth/forest, decadent forest, natural origin, Pre-European, ancient forest, late-seral, mature, high conservation value, park-like, cathedral-like, and the list goes on (Old Growth Definition Task Group 1986, Franklin and Spies 1991a and 1991b, Spies and Franklin 1991, Norse 1990, Poage and Tappeiner 2002, Spies et al.. 2002, Bonnicksen 2000, Youngblood 2001). Many of these titles refer to age, lack of manipulation, period of establishment, and certain euphemisms for structure. The title selected for use in this study, and presently used by CAL FIRE and the forest industry is late successional forests (LSF). This term implies the function and ecology of the forest, rather than age or establishment period. This term also implies that if the functional elements exist, it is LSF, whether is it second growth timber or a stand established prior to European influence.

Definitions of LSF emphasize the subject at hand and the authors (Norse 1990, Franklin and Spies 1991a). Dendrochronologists develop definitions based on age. Wildlife biologists develop definitions based on habitat and species diversity. Forest ecologists develop definitions based on structure. Most LSF research emerges from the Pacific Northwest, and is associated with Douglas-fir/spruce/hemlock and redwood/Douglas-fir forest types. The majority of definitions include broad descriptions of composition, crown closure and/or gaps, multiple canopy layers, presence of snags and coarse woody debris, and large trees (Franklin and Spies 1991a, Youngblood 2001, Thornburgh et al. 2001, Norse 1990, Old Growth Definition Task Group 1986, Bolsinger 
and Waddell 1993). Criticisms abound related to these definitions calling them too inclusive, too exclusive, too focused on timber, not ecologically driven, too inflexible, not flexible enough, too simple, and too complex (Norse 1990, Youngblood 2001, Franklin and Spies 1991a, Spies et al. 2002). The development of an acceptable LSF definition seems impossible considering criticisms and critics. On the other hand, a multitude of definitions has focused on a core set of reoccurring attributes.

Developing a system of defining and classifying old forests has been a goal of researchers, managers, and naturalists for almost four decades. Attempts began in the late 1970's, the first publication with working definitions came from a joint USDA-USDI task group in the mid-1980’s (Old-Growth Definition Task Group 1986, Norse 1990, Franklin and Spies 1991a). The interim definitions developed by the group were adaptive to forest type, geography, and topography. This adaptive approach continues today in order to capture the variability of forests along latitude, elevation, moisture gradients (Franklin and Spies 1991b, Spies et al. 2002, Giusti 2004). The core set of attributes used in defining LSF also carries a long list of synonyms. However, this study will refer to them as late successional elements (LSE). The adaptive approach to quantifying LSE means definitions have ranges or thresholds rather than specific values.

Late successional elements are the functional characteristics extant in the ecosystem. LSE serve specific purposes in LSF ecology for certain organisms or communities. The most common LSE are snags, downed woody debris, basal hollows, multiple canopy layers, and trees with complex structure (Old Growth Definition Task Group 1986, Franklin and Spies 1991a and 1991b, Spies and Franklin 1991, Norse 1990, Poage and Tappeiner 2002, Spies et al. 2002, Bonnicksen 2000, Youngblood 2001, Van 
Pelt and Franklin 2000, Bolsinger and Waddell 1993, Giusti 2004). Refer to Table 1 for a brief list of LSF and LSE synonyms.

Table 1: Common Synonyms of LSF and LSE

\begin{tabular}{|c|c|}
\hline Term & Common Synonyms \\
\hline Late successional forests (LSF): & $\begin{array}{l}\text { Old growth, natural origin, pre-Furopean, virgin } \\
\text { forest /growth, late seral, decadent, mature, ancient }\end{array}$ \\
\hline Late successional elements (LSE): & $\begin{array}{l}\text { Old growth characteristics/attributes, late seral } \\
\text { characteristics/attributes, functional clements }\end{array}$ \\
\hline Downed woody debris (DWD): & $\begin{array}{l}\text { Coarse woody debris (CWD), large organic debris (IOD), } \\
\text { large woody debris (IWD), downed organic material, fuel } \\
\text { loading, debris piles, nurse logs }\end{array}$ \\
\hline Basal hollow: & Trunk hollow, goose pen, fire scar, cat face, basal cavity \\
\hline Standing dead tree: & $\begin{array}{l}\text { Snag, schoolmarm, buck-skin, spike-top (sometimes still } \\
\text { living), candlestick, cavity tree, wildlife tree }\end{array}$ \\
\hline Individual complex structures: & $\begin{array}{l}\text { Reiterated crown'top, flat-top, spike-1op, large diameler } \\
\text { branches, forked, crook (in upper stem), candelabra }\end{array}$ \\
\hline
\end{tabular}

The area of LSF must be large enough for the system to be self-regulating and buffered from outside influences. Edge-effect occurs as one community transitions to another, and is called an ecotone. The ecotone usually contains different structure and less LSE than the interior of the LSF unit (Russell et al. 2000). The interior is the functional size of the LSF unit. The functional size is directly correlated to three times the height of edge trees. Units with high perimeter-to-area ratios occur often, such as polygons or ameba-like shapes. The high perimeter-to-area ratio further reduces the effective size of LSF units (Russell and Jones 2001).

Regulations and definitions state minimum acreages for LSF. The California Forest Practice Rules mandate a 20-acre minimum for LSF classification (14 CCR § 895.1). California Department of Fish and Game recommend analyzing at least a 40-acre unit when determining successional stage, but stratification of habitat is acceptable (Parisi, Motroni and Robards 2007). A 10-acre minimum size for LSF stands is widely 
applied in Douglas-fir forests of Oregon and Washington (Norse 1990). However, others have stated a viable late-successional system must be at least 80 acres (Morrison 1988). Forest ecologists generally agree with the 80 -acre minimum for a functioning forest ecosystem (Noss and Cooperrider 1994). Discrepancies and contradictions of LSF unit area are common and widely variable.

Standing dead trees are important elements in late successional structure. Factors that influence snags and niche type are the diameter, height, species, level of decay, and density across the area. Many mammal and bird species require large diameter trunks (>25 inches) in order for snags to be viable habitat (Norse 1990, Spies and Franklin 1991). Other definitions place minimum snag diameters at twice that size (Franklin and Spies 1991a). Snag height is important since many species can occupy different levels of the snag dependent upon layer and diameter (Norse 1990, Spies and Franklin 1991, Noss 2000, Youngblood 2001, Mazurek and Zielinski 2004). The species of tree affects the viable period based on decay rates. Redwood snags typically last longer than Douglas-fir snags due to decay resistance of heartwood. Douglas-fir snags in the Pacific Northwest remain viable habitat for more than 80 years, and sometimes as long as 125 years (Norse 1990). Further research is needed for snag density or occurrence. However, forest management plans in Oregon and Washington have adopted densities ranging from 1.5 to 5.5 snags per acre of at least 20 inches DBH and 15 feet tall (Norse 1990, Spies and Franklin 1991, Franklin and Spies 1991a). Most LSF definitions describe snags as a functional element, but do not state threshold quantities.

Similar to snags, coarse woody debris is an important feature to many species associated with LSF. However, few studies exist that quantify the amount of woody 
debris in the late-seral stands (Sawyer et al. 2000a, Welsh et al. 2000). Reports identify widely varying volumes from a low of 12 metric tons per hectare to greater than 200 metric tons per hectare (Franklin and Spies 1991a, Sawyer et al. 2000a, Welsh et al. 2000, Norse 1990, Youngblood 2001). The variation occurs mainly in management and fire history of the sites. However, some studies report volumes for all standing and downed woody debris, while others report volumes for only large logs and snags. Once again, LSF definitions focus on a presence of this element due to its ecological role with animals, amphibians, insects, and fungi.

Multiple canopy layers are essential for late-seral structure. The number of layers, height of layer, and distance between layers are important factors. Species diversity increases as a multi-layered forest canopy develops (Mazurek and Zielinski 2004). The layered structure provides many microclimates and habitat niches for a variety of wildlife, vegetation, fungi, and insects (Olson et al. 1990, Sawyer et al. 2000a, Sawyer et al. 2000b, Van Pelt and Franklin 2000). Some research has even focused on associations of fungi and microarthropod indicator species and LSF classification (Camann et al. 2004, Willett 2001, Sawyer et al. 2000b). Multiple canopy layers increase potential aerial soil formation. This unique characteristic of late-seral forests also provides niches for epiphytes and associated organisms high above the ground as detritus collects on large diameter branches (Sillett 1999, Sawyer et al. 2000b). Other features of the upper canopy include reiterated tops and crooks resulting from wind or lightening damage (Veirs 1996, Giusti 2004, Van Pelt and Franklin 2000).

Late successional forests in California are classified according to the Rules and protocols developed for the California Wildlife Habitat Relationship (CWHR) program. 
The CWHR program uses forest data to calculate potential suitable habitat based on breeding, cover, and feeding, as determined by species experts (Parisi et al. 2007). LSF units must meet uneven structure (CWHR size class 6) or even structure with large average diameter (>24.0 inches $\mathrm{DBH})$ criteria and medium to dense stocking (CWHR size class 5). Uneven structure has distinct height separation between layers and at least 10 percent canopy cover by layer, or at least three size classes present. Minimum requirements for size class 6 are overstory QMD greater than 24.0 inches $\mathrm{DBH}$ and an understory QMD between 6.0 and 23.9 inches $\mathrm{DBH}$ (size class 3 or 4). The qualitative characteristics associated with LSF are in sections 895.1 and 919.16 of the Rules. For clarification on size class determination refer to Parisi, Motroni and Robards 2007.

\section{$\underline{\text { Disturbance Regimes }}$}

Redwood forests are resilient to many types of disturbance, but not immune. The species characteristics have developed along with naturally occurring disturbances. Some disturbances affect entire stands, while others focus on individual trees. The most common disturbances include fires (natural and prescribed), floods, and biological (insects/beetles, disease, and mammals).

Fire is a natural part of the forest ecosystem. Average fire return intervals (FRI) for redwood forests vary dependent upon distance from the ocean and associated shrub and understory species (Veirs 1980). Typical return intervals range from seven years in the pre-European era to 130 years presently (Brean and Svensgaard-Brean 1998, Brown and Sweetnam 1994). Other FRI's have been published stating average periods up to 500 years. However, a fire history project in the Santa Cruz Mountains identified a regional FRI of 12 years, and a grand mean FRI for single trees in the sample equal to 16.3 years 
(Stephens and Fry 2005). Most historic ignitions are attributed to Native Americans and early immigrants (Fritz 1931, Keeley 2002, Stephens and Fry 2005).

Fire is beneficial to redwood forests. Burning removes accumulated fuels and competing understory vegetation. The thick fibrous bark insulates the cambium from severe damage during light intensity burns (Olson et al. 1990, Veirs 1996). Redwood can also coppice sprout following fire damage. Basal hollows are formed from repeated burning and healing (Finney 1996, Norse 1990). Most severe fire damage occurs above alluvial flats, as disturbance type is related to relative slope position.

Annual flooding occurs in the alluvial flats in some areas. Massive silt deposits are left once water resides, which is detrimental to most species. However, redwood is able to produce a new lateral root system in response to heavy silting (Veirs 1996). The new lateral roots arise from burls on the buried stem and root collar, and the old root system typically senesces (Becking 1967, Stone and Vasey 1968). During the winter, when flooding occurs, strong winds and storms combine for another common disturbance. Windthrow occurs when trees are toppled, usually when soils are saturated (Sugihara 1996). This disturbance can be detrimental when young commercial stands are thinned too widely and most trees are windthrown. However, wind has beneficial LSE impacts such as breaking treetops or toppling individuals. This type of occurrence provides opportunity for reiterated tops, complex canopy structure and increased coarse woody debris (Veirs 1996, Sugihara 1996, Sawyer et al. 2000b).

Redwood has many silvical traits, which increase the species resistance to insects and disease. The species thick bark is the first line of defense. Underneath the bark, the wood composition is high in tannins and other extracts that help to repel decay fungi and 
boring insects (Olson et al. 1990). Few diseases are known to target redwoods, however some rots affect the species. The pathogens found in the redwood forest include Annosus root rot (Heterobasidion annosum[Fr.] Bref.), Armillaria root rot (Armillaria mellea [Vahl] P. Kumm.), brown cubical heart rot (Poria sequoiae Bonar) (Olson et al. 1990, Bega 1978). These rots are known to cause extensive cull (Bega 1978). Seedlings are susceptible to Botrytis fungi (Botrytis sp. P. Micheli ex Haller) and damping off during the first year after planting (Hepting 1971). In recent years it has been identified as a foliar host species for Sudden Oak Death (Phytophthora ramorum Werres and de Cock) (Maloney et al. 2002, California Oak Mortality Task Force 2002). This pathogen mainly affects younger individuals with cankers on small branches ( $<0.20$ inch) and discoloration of foliage (Maloney et al. 2002). These symptoms are not fatal. At present, the disease does not seem to have an impact on commercial redwood forests. Further research is continuing.

Other biological agents that damage redwoods are insects and mammals. Redwoods host insects and beetles, but few cause significant stand-wide damage (Olson et al. 1990). Some of these organisms are termites (e.g.: Isoptera), flatheaded twig borer and girdler (Anthaxia aeneogaster Gory \& Laporte), two redwood bark beetles (Phloeosinus sequoiae Hopkins and P. cristatus Wood \& Bright), and a Sequoia pitch moth (Vespamima sequoiae Edwards) (Furniss and Carolin 1977, Olson et al. 1990). Bark stripping and girdling are damages typical of mammals. Common species that create this damage are black bears (Ursus americanus Pallus) and wood rats (Neotoma sp. Say \& Ord) (Olson et al. 1990). In addition, this type of damage opens a pathway for diseases, fungi, and insects previously discussed. 
Many natural disturbances occur among redwoods, but very few are standreplacing in nature (Olson et al. 1990, Bega 1978). The species is not dependent upon any of the disturbance, like some species require fire to regenerate, but redwoods have adapted to cope. Fire, wind, flood, and biological agents all occur on independent cycles. Some cycles are related, but not obligatory. The greatest disturbance to redwood stands in recent history has been by humans.

\section{Forest Policy in California}

Management and regulation of forest products are common in modern society. Since the late 1960's and 1970's, the environmental movement has progressed from a few hundred people assembling on Capitol Hill, to now hundreds of thousands working for government agencies, resource management firms, non-profit organizations, and consultants (FRAP 2003, Yee 2003, Thompson and Dicus 2005). All work towards the goals of environmental protection, stewardship, sustainability, and mutually acceptable policies. However, this movement started long ago in California and most notably in the redwoods of the Santa Cruz Mountains. How has California’s forest policy developed and evolved? And how has forest policy and regulation influenced the structure of the forest? The first question may be answered with historical research, but the second answer must be synthesized. An attempt to answer both questions in this manner is presented here to aid in understanding the redwood forests we see today.

\section{Native Americans and Spanish-Mexican Occupation}

Early uses of forest resources in California date back centuries. Native Americans are considered the first forest managers, using fire to manipulate the forest 
habitat (Keeley 2002). Fire was used in systematic ways to improve hunting and foraging along the ecotones of the forest (Keeley 2002, Clar 1959). The earliest recorded use of California's timber by Europeans was ship repairs to the Golden Hind in 1579 by Sir Francis Drake (Clar 1959). From 1580 to the late 1700’s, ship and boat building took place in California, what was then known as Alta California. The Portola expedition headed north from Mexico in 1769 with the goal of establishing commerce via a chain of missions in Alta California and to Christianize the "pagans," or Native Americans (Clar 1959, Carranco and Labbe 1975). The prized commodity to the Spanish-Mexican expedition was not precious metal, silk, agriculture, or timber, it was fur. During this expedition, the Franciscan Padre Serra first encountered the enormous trees in the Santa Cruz Mountains and wrote in his journal calling the trees "palo colorado", meaning "red wood” (Stanger 1967, Carranco and Labbe 1975). The name has been used ever since.

Given the long history of the use of redwood, the quantity utilized was a fraction of the resources extent. Native Americans had no need for large timber. Tribes were generally nomadic and revisited camps often (Keeley 2002). The use of fire to improve forage, hunting, and travel was concentrated in grassy areas near densely vegetated redwood forests (Thompson 1916, Veirs 1982). Furthermore, fire return intervals range from six to 600 years dependent upon the area (Sawyer et al. 2000a, Thornburgh et al. 2000). In fact, it is difficult to determine the natural fire return interval in the redwoods because the Native Americans inhabited the region for so long (Keeley 2002). The policies that regulated use of the big timber were those of physics and engineering, meaning that during this time humans did not possess the technical knowledge to harvest the tallest trees in the world. Therefore, non-native inhabitants sought alternative timber 
resources, for example the Bishop (Pinus muricata D. Don) and Monterey pines (P. radiata D. Don) located near the Alta California capitol city of Monterey (Clar 1959). Redwoods were harvested, but the combination of Native American, Spanish-Mexican, and early European utilization had negligible impacts to forest structure.

The first half of the $19^{\text {th }}$ century brought many changes to the region, including formal policies and new tools. In 1813, a Spanish decree was issued placing all woods and plantations in the charge of the "ayuntamiento," similar to a modern-day mayor (Clar 1959). The decree made this official responsible for conservation of the resource and reforestation activities (Arvola 1962, Clar 1959). This was the first forest policy and regulation in California, a mere seven years prior to the first cross-cut saw arriving in the region (Clar 1959). A second Spanish decree was issued in 1830, which established guidelines for trade of lumber. The decree regulated a fair price and tax for size, dimension, and volume of lumber, and that these measures were not to include bark. It called for no waste during the milling process, perhaps an early attempt at conservation. The decree also stated the buyer is responsible for payment that includes milling and transportation costs. Furthermore, the inhabitants of the area were granted local timber supply rights. In the decade following the decree, lumbering began throughout the Santa Cruz Mountains by locals and immigrants (Arvola 1976, Stanger 1967, Carranco and Labbe 1975, Clar 1959, 1969, Martin 1989, Sawyer et al. 2000c). Santa Barbara was the first city to act against the lumbering, prohibiting the cutting trees without a permit in 1839 (Clar 1959). Also in that year, Mexican Minister of Interior Romero suggested restricting the cutting of forests and replanting cutover areas in order to combat drought and poor crop harvests. 
As the 1840's came to close, regulations and permits had been proclaimed, yet adequate enforcement made them of little use. The 1830 decree granted rights to landowners and squatters alike, but since the majority of mills were man- or waterpowered and lumber transported by animal power, the impact to the forest was slight. Trees harvested during this time were likely close to creeks, rivers, towns, roads, or on the forest edge due to limited transportation technology and power. A single mill site might have harvested a few acres per year, given the lumber production rate at that time. However, there is no evidence that clearcutting was the silvicultural practice. Individual trees might have been cut or left for various reasons. Furthermore, the dispersion of the mill sites throughout the Santa Cruz Mountains and the area of harvest units suggest that lumbering had minimal influence on forest structure by 1850. The second half of the century promised to bring even more changes.

\section{$\underline{\text { California Statehood (1850) }}$}

California was granted statehood in 1850, and by joining the United States all previous policies, regulations, and property titles were nullified. Many attempts at forest policy were made beginning in 1850, but they seemed futile (Arvola 1962). First, there were no laws prohibiting lumbering on unclaimed lands and previous landlords were powerless against the masses of immigrants (Clar 1959). Most of the public considered government regulation of timber to be an infringement on property rights, even though numerous court decisions upheld the governments defense (Arvola 1962). Nevertheless, without an existing infrastructure for regulating forest practices, the public was free to keep lumbering. Another common public opinion at this time was that the timber 
resource was inexhaustible, despite warnings of possible timber famine and short-term thinking follies by government officials (Clar 1959).

The need for lumber increased proportionally with the increase in population. By 1852, California’s population was approximately 225,000 and the population would triple in less than 20 years (Clar 1959). The number of mills increased and the amount of timber produced continued to increase with population. In 1862, there were 329 mills producing approximately 166 million feet of lumber and 28 million shingles statewide annually. By 1872, there was one less mill, yet production increased to 265 million feet of lumber and 191 million shingles statewide annually. The industrial revolution had been introduced to the timber industry.

The increased volume output from the forests signifies the beginning of forest structure change. The harvest practice at this time was most likely clearcutting, although some operations could have been high-grading, where the biggest, best, or readily accessible trees are harvested and the rest are left. Most literature does not describe the specific harvesting methods, rather the process is only referred to as "lumbering" (Clar 1959, Arvola 1962). The harvest origin, or second growth forests followed, but some areas were lost to hardwood dominated forests or brush. If unharvested, these second growth sprouts will eventually grow into the even-aged forest structure present in the Park/No Cut regime inventoried for this study.

The Governor signed the first law prohibiting trespass, and essentially timber theft in 1862 and stated the penalty as a misdemeanor (Clar 1959). This would have been a good start, but the law contained language that exempted 21 counties, most of which were heavily timbered. Some speculate the government and the public did not considered 
timber theft a problem, let al.one a crime. In 1863, another law prohibiting the cutting, destroying, or carrying away of timber from state or school lands deemed to be swamp, marsh, tidal, or overflow lands was signed by Governor Stanford. This had little effect on the lumbering of redwoods. The first law regulating silviculture was passed between 1872 and 1874 . However, it prohibited the cutting of any tree over 16 feet in diameter, which was mainly aimed at protecting the giant sequoia (Sequoiadendron giganteum [Lindl.] Buchh.) of the Sierra Nevada. This law had the most unlikely adversary, the famous preservationist John Muir. Muir opposed the law citing it as "absurd and shortsighted." His reasons were "all the young trees might be cut and burned, and all the old ones might be burned but not cut” (Muir 1997). The preservation of such relics became a topic known nationally and even U.S. congressmen authored bills to protect and conserve the great timber basket of the West (Clar 1959). The Timber and Stone Act was passed in 1878, which granted citizens the right to purchase 160-acre homesteads for $\$ 2.50$ per acre. The only stipulation was that the purchaser must occupy and settle the homestead. Unfortunately, this stipulation caused many homesteaders to clear the land of timber for crops or grazing.

The few forest policies and regulations that were passed between 1850 and 1878 had little effect on regulating lumbering. The common practice was to clearcut the land of all standing trees; usually on the scale of an entire drainage, approximately 10-100 acres. After felling, the logs were not hauled to the mill for at least one year. During that year, the clearcut area was burned to remove brush and slash to ease hauling by animal teams, donkey engines, or locomotives. The forest structure was not just influenced, it was erased. Planting of trees was not a common practice either, but redwoods are 
capable of sprouting from stumps or exposed roots. Until 1878, regulations were passed to determine who could cut the timber, except the one diameter limit law; therefore, policy has had no effect on the forest structure. Incidentally, the Timber and Stone Act of 1878 had adverse effects on forestlands in general. Much of the public domain was sold to private homesteaders so there were no large tracts of forestland for companies, or even the state to purchase for continual production forest products (Clar 1959). The public domain was essentially “locked-up” by homesteads.

California developed the Board of Forestry in 1885, a legislative committee staffed by three governor-appointed members (Clar 1959, Arvola 1962, Dicus and Delfino 2003). This committee was the first of its kind in the United States (Clar 1959, Dicus and Delfino 2003). Despite good intentions, the Board of Forestry was unable to accomplish much policy creation before it was dissolved in 1893 (Clar 1959, Arvola 1962). The busy public did not seem to care enough about forest matters to keep the Board in existence, but some speculated political corruption (Clar 1959). The Board of Forestry was on hiatus until reestablishment in 1903 (Arvola 1962). Meanwhile, the clearcutting continued and new, second-growth forests were sprouting throughout the Santa Cruz Mountains.

\section{$\underline{20^{\text {th }} \text { Century }}$}

Forest policy was moving fast at the beginning of the $20^{\text {th }}$ century. During the same year the Board of Forestry reconvened, California Assembly Bill (AB) 75 was passed, which granted a $\$ 15,000$ budget with equal matching funds from the federal government to complete a forestry survey (Clar 1959). The Joint Survey of the Forest Situation was charged with mapping California's forestlands, identifying potential 
reservoir and canal sites, and gauging streamflow. This was a daunting task for the State Forester's office, which only had four employees including administrative staff. This office was charged with administering and enforcing California’s forest policy.

California legislature passed The Forest Protection Act of 1905, which addressed most factors of forest practices. However, the vast majority of the act focused on fire protection and prevention (Clar 1959). This began a forest policy trend that would not end until 1945 (Clar 1959, Arvola 1985). Furthermore, the creation of state parks was also handled by the Board of Forestry, which added to the shadow cast over forest practices by fire prevention. Forest policy was in place, yet once again little funding was available for the implementation of the Forest Protection Act. The Board of Forestry annual budget for 1905 was $\$ 18,800$, of which $\$ 10,000$ was allocated directly to the development, operation and maintenance of Big Basin Redwoods State Park established in 1901 (Clar 1959). The remainder of the annual budget was to cover all other Board activities and operating costs. The limited and insufficient budget led to the inability for the State Forester to enforce the regulations. Without adequate enforcement, regulations are nothing more than words on paper.

The major problem with the Forest Protection Act of 1905 was it did not specify who should bear the cost of fire suppression (Clar 1959). Some thought the State should pay all costs associated with fire suppression, while the prevailing mentality for over two decades thought the State's responsibility should end with education and persuading local interests, namely the timber companies, to protect their own lands. This meant that the owner of the parcel where the fire originated is largely responsible for the suppression costs (Clar 1969). This put the timber companies in a major predicament. Section 19 of 
the Forest Protection Act discussed slash disposal after logging. The common practice was still to burn the slash using the "light-burning" method, similar to broadcast or prescribed burning today. Furthermore, the State Forester from 1911-1919 held the opinion that the lumbermen had a legal and moral obligation to dispose of slash. This predicament is most likely why Section 19 is often referred to as "The Menace Law" by lumbermen of the era (Clar 1959).

California was not the only state worried about wildfire. During three days in August 1910, three million acres burned in Montana and Idaho. In total, 85 people died, including 78 fire fighters (Maclean 1992). This event became known as the "Big Blow Up of 1910.” In California 519,463 acres burned, more than twice the annual average (Clar 1959). Fire was public enemy number one, and government and industry mobilized to stop it at all costs.

The people were interested in protecting forests and their cities. In 1912, a public meeting in San Francisco took place where forestry problems were openly discussed (Clar 1959). Topics included the light-burning theory, creation of a state fire service, and reforestation of cutover lands. A few years later, scientists mobilized research efforts in fire behavior, forest insect and forest disease studies. Counties began to establish fire plans. Among the first were Santa Cruz and San Mateo Counties between 1916 and 1918, and both plans included provisions and funding.

Clearcut practices remained unchanged, but the efficiency and production continued to increase. The lumbermen had to realize that stands that were clearcut in 1850 were now approximately 70 years old. There is no evidence that second-growth stands were harvested again at this time. They continued cutting tracts of old growth. 
Perhaps their mentality was 'Why cut a 24-inch tree when we can cut a 120-inch tree?' A modern forester could speculate that the cutover lands had minimal redwood regeneration due to brush and hardwood competition.

An overhaul of forest policy took place in 1919. Changes to the Forest Protection Act of 1905 included the addition of members to the Board of Forestry with interests alternative to lumber production. The State Forester could form fire protection groups. The State would now bear some financial responsibility of the fire service as well (Clar 1959). The overhaul also included the four "planks" of California forest policy. These planks included appropriations for (1) funds to fight wildfire on forest, grain, and pasture lands outside of National Forests, (2) acquisitions of cutover lands for State forests to secure future timber supply, (3) surveys of watersheds for conservation of irrigation and domestic water supply, and (4) reforestation of cutover lands (Clar 1959).

In the year following these major changes, another public meeting took place in San Francisco. Dr. Pardee, then chair of the Board of Forestry and ex-Governor of California led the meeting for lumbermen (Clar 1959). The major topics discussed were fire protection and prevention, use of cutover forests for growth of new timber supply, and methods of slash disposal and treatment. However, in response to this meeting, approximately half of the redwood timber industry decided to hire a consultant. The consultant, David T. Mason, suggested to stop using fire and to plant seedlings to supplement the coppice regeneration. On his advice, two large timber companies, Pacific Lumber Company and Union Lumber Company, invested \$234,000 in nurseries. From 1922 to 1932, the two companies planted 12 million seedlings on 26,400 acres of cutover 
redwood forestland with a seedling survival rate of 36 percent (Mason 1922). The timber industry was beginning to realize the resource was not endless.

California’s forest policy and industry were maturing due to Forest Protection Act changes and evolving interests in alternative resources and forest regeneration. One of the advocates for many of the land stewardship ideals was Emmanuel Fritz. Fritz contributed to California forests in many ways. He was one of the first scientists to study redwoods and he personally reforested cutover lands (Arvola 1985). Fritz lobbied for the creation of state forests and encouraged the legislature to get involved in forest regulation for the general welfare of the state. One man made a positive difference, but another man was about to cause a negative difference.

A new Governor was elected in 1923 named Friend William Richardson. The Board of Forestry had submitted a biannual budget to the new Governor totaling $\$ 187,820$ (Clar 1959). Once the Governor had approved it, the Board’s budget was a mere $\$ 34,642$. In addition, the Board lost cooperative funds totaling $\$ 45,000$ from the federal government and $\$ 34,000$ from matching county appropriations. The Governor's decision meant no tree planting, no state park care or maintenance, and no cooperative state aid for private conservation or preservation activities. The budget cuts angered Dr. Pardee, a former California Governor, so much that he resigned his position as the chair of the Board of Forestry within days.

In 1927, the state passed two bills that created needed infrastructure for resource agencies. A 27-year old lawyer from San Francisco named B. J. Feigenbaum authored both bills (Clar 1959). The first, AB 1123, created the Department of Natural Resources, and passed without recommendations. Then, he introduced AB 1176, which divided the 
Department of Natural Resources into four resource specific groups, the Division of Mines, the Division of Parks, the Division of Fish and Game, and the Division of Forestry. AB 1176 also described the administrative body for each, for example, the Division of Forestry was lead by the State Forester and the seven Governor-appointed members of the Board of Forestry.

These bills were passed and divisions formed during the years of Prohibition. While legislatures were busy increasing governmental controls and regulations, the public was bitter towards many division personnel. Among the most hated were game regulations and Game Wardens. Forest Rangers were reluctant to follow direct orders to assist Game Wardens on field visits, for fear of being guilty by association (Clar 1969).

The printing presses were working overtime in 1933. The US Forest Service published The National Plan for America’s Forests, also referred to as The Copeland Report. In this document, the Forest Service warned the public that the "cut-out-and-getout” forestry practices followed on private timberlands has decreased productivity, made taxation nearly impossible, and caused a virtual collapse of private ownership (Stanford Environmental Law Society 1973). A similar survey of the forest situation was published in California in the same year, The Sanford Plan (Clar1969). While many of the Forest Service's warnings resonated in the Sanford Plan, the first paragraph outlined the responsibilities and ideals still present in California's forest policies:

The State should recognize fully its responsibility for adequately safeguarding water supply, timber resources, and recreational, scenic and wild life values. The ultimate plan should be for the State to assume the full cost of effective protection of the general public values pertaining to these resources, the funds to be derived by general state taxation and from such Federal sources as may continue available. The costs of protection of values of a private nature, or of excess value of a purely local nature should be borne by the individuals or agencies concerned. - The Sanford Plan of 1933 (in Clar 1969). 
The U.S. government consistently attempted regulation of private forest practices from 1920 through 1940’s (Clar 1959 and 1969, Arvola 1962, Stanford Environmental Law Society 1973, Cubbage 1995). Very few of these efforts were successful due to wartime appropriations, the Great Depression, and overall lean budgets. One act that succeeded was the National Recovery Act of 1933, also referred to as the National Industrial Recovery Act (Cubbage 1995, Vaux 1986). This act was declared unconstitutional two years later, however it is mentioned since Article $\mathrm{X}$, the Code of Fair Competition for Lumber Industry, was focused on the sustainable cutting of timber and preventing acts of poor forest practices (Vaux 1986). Over the next decade, the selfregulated timber industry in California willingly continued to follow the guidelines set forth by Article X.

The states continued to resist federal regulation of private timber, but in California, counties took initiative before the legislature could act. San Mateo County was the first to pass logging regulations in 1937 and Placer County followed in 1944 (Arvola 1970). The San Mateo regulations included the issuing of logging permits. These were the only two counties to take action prior to the Forest Practices Act of 1945.

During this time, reforestation and fuels treatments were obviously making a difference in fire behavior. Nevertheless, the clearcut harvesting practices continued. There is some evidence that selection harvests took place, but were most likely highgrading the forest. The mentality was largely cut-out-and-get-out.

The early 1940's would change forestry in California forever. Funding for the Division of Forestry and the fire service more than doubled as federal funds became available following the Great Depression through the Clark-McNary Act, enacted in 1924 
(Clar 1969). These funds were provided on a reimbursement basis. Public Works Administration projects increased the infrastructure throughout the state assisting the fire service and other state agencies. Forest policy and funding were now relatively consistent and the stage was set to focus on the regulation of forest practices.

The second law restricting the cutting of specific trees in California was codified in 1943. Recall the first law, from the early 1870’s, prohibited cutting of trees greater than 16 feet in diameter. The 1943 law added to Public Resource Code chapter 172, sections 4850-54, and prohibited the cutting of trees smaller than 18 inches in diameter (Arvola 1962, Stanford Environmental Law Society 1973). The statute included provisions to allow improvement and sanitation harvests, or for land-use conversion (Arvola 1962). However, the law was repealed only two years later with the passage of the Forest Practices Act of 1945.

\section{The Forest Practices Act of 1945}

The California Forestry Study Committee convened in 1943 to investigate the status of forestry in the state and reported to the state legislature in 1945. The committee concluded that the forestlands were not productive enough to ensure a sustained yield of forest products to meet California's demand (Arvola 1985). They also stated current practices impaired alternative resources such as watersheds, recreation, wildlife, and scenic values. The committee identified the four most eminent problems with forests and forestry. They requested the legislature to address the (1) cutting of old growth timber, (2) reforestation of cutover lands, (3) reduction of total timberland damages by fire, insect, and disease, and (4) lack of continuity for state forest policy (Arvola 1985). The 
legislature responded quickly by introducing Senate Bill (SB) 637, which became the Forest Practices Act of 1945 (Arvola 1985, Stanford Environmental Law Society 1973).

Between 1940 and 1945, major timber producing western states enacted forest practice policies. California, Oregon, Washington, and Idaho passed forest policies during similar social and political climates (Vaux 1986). The policies attempted to undermine the timber famine fear created during the first half of the $20^{\text {th }}$ century (Dicus and Delfino 2003). California’s policy goal was “...to encourage, promote and require such development, use, and management of forests and timberlands as will maintain the continuous production of forest products, to the end that adequate supplies of forest products are assured for the needs of the people and industries” (Stanford Environmental Law Society 1973). Mention of alternative resources was absent, but the goal satisfied the timber industry.

The Forest Practices Act of 1945 had many strong points. The regulations focused heavily on timber production, forest practices, and fire (Arvola 1962 and 1970, Dicus and Delfino 2003). Through a series of amendments from 1945 to 1963, the act required on-site inspections during logging operations, permitting and notice of operations, the creation of District Technical Advisory Committees (DTAC), set minimum/maximum standards, and provided means to enforce laws and assess penalties for non-compliance (Arvola 1962 and 1970, Stanford Environmental Society 1973). The act divided the state into four districts broadly based on forest types, and the DTAC's developed district-specific rules the Board of Forestry could adopt (Vaux 1986). However, the issue of county specific rules was still at hand. 
There were many criticisms and shortcomings of the Forest Practices Act of 1945. On-site inspections found operators and inspectors debating standards in the rules with relative rather than quantifiable terms (Arvola 1970). The Division of Forestry inspection crew was severely understaffed, with only eight inspectors statewide regulating 8.5 million acres of forestland (Stanford Environmental Law Society 1973). The permitting system was not established until 1957 and powers to apply sanctions and penalties were not granted to the Division of Forestry until 1963 (Stanford Environmental Law Society 1973). Furthermore, the penalties were no more than a misdemeanor or a minor fine (Arvola 1962). The posting of advanced notice required operators to notify the landowner, instead of the Division inspectors (Arvola 1970). This complicated efficiently executing on-site inspections (Arvola 1976). Appointments to the DTAC’s were restricted to forestland owners and industry representatives only, which compounded the amount of industry self-regulation (Vaux 1986). By 1956, San Mateo, Santa Cruz and Nevada counties had stricter logging regulations than the state (Arvola 1970). However, issues surrounding the Nevada County regulations raised questions of the validity of local laws. The California Attorney General offered Opinion 56-103, which stated general forest practice regulation, excluding fire, was preempted by the State. Counties finally received the right to regulate certain forest practices in 1970, when AB 507 amended Public Resource Code section 4582. Marin, Santa Clara, and San Mateo counties passed laws soon after, but Santa Cruz did not. Counties were not alone finding problems with the 1945 act. Add this list of criticisms to the changing political and environmental climate of the 1960's and 1970's and the future of the Act of 1945 appeared grim. 
During the 1940's and 1950's, the timber industry had converted to selective logging practices (Vaux 1986). It is unclear if these selective harvests resembled current uneven-aged management, as outlined by "Regeneration Methods Used in Uneven-aged Management” (14 CCR § 913.2) or if high-grading was the common practice. Policy and economic reasons caused the shift from even-aged to uneven-aged silviculture. The forests began to transition to uneven-aged or all-aged structure with the introduction of selective harvesting and the availability of commercially grown seedlings.

From 1945 to 1960, the Forest Practices Act did not allow clearcutting. Amendments to the act in 1960 allowed “alternative plans” for clearcutting upon approval of the Division of Forestry (Arvola 1962 and 1976, Vaux 1986). Clearcutting was allowed prior to amendments under exemption for land-use conversion. Due to that loophole in the law, the forest practice rules could be circumvented by posting notice of land use conversion. From 1946 to 1970, more than 900,000 acres, approximately 10 percent of the private forestland in California, had posted notice of conversion (Vaux 1986). Over 75 percent of conversions during this period were either abandoned or incomplete, illustrating the cut-out-and-get-out mentality of private forestry identified by the US Forest Service (Arvola 1962 and 1976, Stanford Environmental Law Society 1973, Vaux 1986).

Issues with the 1945 act continued to rise, and the Board and Division of Forestry attempted to address them. In 1967, the state legislature tried to appease those calling for better protection of non-forest values and resources (Arvola 1970). They sponsored 11 bills, but none passed. That same year, the Board of Forestry ordered a review of all rules not amended within the previous five years. In 1970, the State Forester and the 
Board requested a review of the rule packages for the redwood and Sierra districts. The reviews produced new and amended rules adopted under emergency status. However, no matter how many new rules or amendments passed, it seemed the Board could not please the public.

Part of the difficulty the Board of Forestry faced was the changing demographics in California's population. During the 1960's, there was a major shift in State Senate representation. Out of 40 senators in 1960, 12 had forested counties in their constituencies (Vaux 1986). By 1970, those 12 had been reduced to four. The urbanization of the Los Angeles basin contributed greatly to this reduction. One senator represented Los Angeles County in 1960. Just 10 years later, there were 10 senators representing Los Angeles County exclusively, and six more senators representing the greater Los Angeles area. Demographics and constituencies were not the only problems the Division of Forestry and the Board faced in the early 1970's.

San Mateo County had become a focal point of forest policy during the 1960's. Numerous lawsuits, injunctions, local court decisions, and Attorney General Opinions occurred during the decade concerning attempts to ban logging within the county (Arvola 1970). Since San Mateo was one of a few counties that exercised the right to pass county-specific regulations, any timber harvest within the county had to obtain a permit from the San Mateo County Planning Commission (Stanford Environmental Law Society 1973). The Bayside Timber Company planned to harvest a 70-acre parcel along La Honda Creek and obtained the state logging permit, road permit, and county planning commission permit. Local residents from the urbanized community pressured San Mateo County to stop the harvest. The County Board of Supervisors conceded and repealed the 
Planning Commissions' decision to issue the permit (Stanford Environmental Law Society 1973, Vaux 1986).

Bayside Timber Company filed suit against the San Mateo County Board of Supervisors citing three major issues. First, the Forest Practice Act of 1945 preempted the county regulations. Second, the refusal of logging constituted a taking of private property. Third, the Board of Supervisors had abused their discretion in revoking the permit due to political pressures. Superior Court found in favor of Bayside Timber Company, mainly citing preemption by state regulation (Stanford Environmental Law Society 1973). The San Mateo Board of Supervisors appealed to the California State Appellate Court, which reversed the lower courts decision. The Appellate court's decision stated the Forest Practice Act of 1945 rule-making procedures were unconstitutional due to inadequate guidelines and the composition committees having "pecuniary" interest in regulation matters (Stanford Environmental Law Society 1973, Vaux 1986, Dicus and Delfino 2003). The final decision posted on December 15, 1971, and the Forest Practice Act of 1945 was officially dead.

\section{Z’berg-Nejedly Forest Practice Act of 1973}

California was without formal forest policy for two years following the courts decision. The forest industry voluntarily agreed to continue operations pursuant the Forest Practice Act of 1945 until the state legislature and Board of Forestry could adopt new regulations (Vaux 1986). Three bills were submitted in early 1972, The Collier Bill (SB 1326), The Nejedly Bill (SB 361), and The Z’berg Bill (AB 2346). The California Forest Protective Association, the major forestry and lumber lobbyist in the state, authored the Collier Bill (Stanford Environmental Law Society 1973). It made minor 
changes to the 1945 act and contained weak, unenforceable language regarding standards. The original draft of the Nejedly Bill contained enforceable language and called for three on-site inspections per harvest, posting of performance bonds, and the filing of a logging plan. However, through the amendment process, many of the strong aspects were omitted and sections of the Collier Bill were inserted verbatim. Another major drawback to the Nejedly Bill was a request for $\$ 2$ million to develop a computer database to track forest management and timber operator performance. The amount requested was sixtimes the annual budget of the Division of Forestry in 1972. The strongest of the proposed was the Z’berg bill, but it was not perfect. This bill called for a seven-member Board of Forest Resources with the majority of members not having pecuniary interests in the timber industry. The bill focused on setting goals rather than limits. Other regulations proposed that made this bill strong were strict restocking standards, follow-up inspections, performance bonds, timber harvest plans, and granting citizens legal standing to sue to enforce the act. However, the Z'berg bill proposed weak erosion control standards, omitted sustained yield planning, and called for the creation of "Certified Forest Planners.” Out of the three proposed bills, there were enough strong aspects to keep moving forward instead of starting over.

The Nejedly and Z'berg bills were combined, amended and developed. Governor Ronald Reagan signed into law the Z’berg-Nejedly Forest Practice Act of 1973, or the Act (Vaux 1986, Martin 1989, Dicus and Delfino 2003). Initially, the Act required approval of timber harvest plans (THP) written by Registered Professional Foresters 
$\left(\mathrm{RPF}^{1}\right)$. The Act also called for sustained yield planning, on-site inspections, strict restocking standards, erosion control standards, creation of a nine-member Board of Forestry, and once again granted counties the right to create logging regulations (Vaux 1986, Dicus and Delfino 2003).

THP's describe, in detail, the logging operation, including the owners and operators contact information, maps of logging areas, roads and trails, demonstration of maximum sustained productivity (MSP), and descriptions of erosion control measures. The idea of the Certified Forest Planner evolved into the Registered Professional Forester, which is a professional license requiring seven years of experience and successful completion of a multidisciplinary exam. On-site inspections required by the Act occur throughout the life of the THP, which was three years to complete operations and an additional five years to meet restocking standards. The nine seats on the Board of Forestry consist of five general public members, three forest industry members, and one member representing rangeland interests (Dicus and Delfino 2003). With all of these regulations in place, the California Forest Practice Act of 1973 is considered the strictest statute of its kind in the United States (Siegel 1974, Vaux 1986, Martin 1989, Dicus and Delfino 2003)

The Act was more stringent than all other state forest policies, and it approached forest policy and regulation in a different manner. California’s policy emphasized water quality, erosion control, recreation, and aesthetic values (Vaux 1986). For the first time,

\footnotetext{
${ }^{1}$ The Professional Foresters Law (Public Resource Code Sections 750-783) outlines the requirements for Registered Professional Foresters.
} 
the size and shape of clearcuts were regulated in California (Siegel 1974). Accountability now resided with the landowner, the timber operator, and the RPF. Furthermore, the Act ensured independence between the Board of Forestry and the timber industry. Only time would tell how the public, state, industry, and forests would react.

\section{"Functional Equivalency"}

Three years would pass before the Forest Practice Act would become effective. During that time, the Forest Practice Rules were being developed. A delay to this process occurred in 1974 when the Natural Resources Defense Council, Inc. (NRDC) filed suit against Arcata National Corporation, Louisiana-Pacific Corporation, Simpson Timber Company, and the State Forester in Humboldt County Superior Court (Arvola 1976). The three timber companies had concurrent harvest operations in the Redwood Creek watershed adjacent to Redwood National Park (Arvola 1976, Martin 1989, Thompson and Dicus 2005). NRDC cited that timber operations required an Environmental Impact Report in compliance with the California Environmental Quality Act of 1970. The EIR process was significantly more convoluted and time consuming than timber harvest plan review at that point in time (Arvola 1976, Martin 1989). The suit was kept pending for two years with anticipation the timber operators would improve their forest practices.

Senator Collier introduced SB 707 while the lawsuit awaited hearing. The bill would become the most important law of 1975 . The bill amended Public Resource Code section 21080.5 of CEQA authorizing an alternative environmental review process to be certified by the Resources Secretary as "functionally equivalent" to the EIR required by CEQA (Martin 1989). 
The following year, Judge Broaddus issued his decision in NRDC v. Arcata National, stating that timber harvesting was subject to CEQA compliance. The companies appealed the "Broaddus decision," but the Appellate Court only reaffirmed the connections between timber harvesting, the Forest Practice Act of 1973, and CEQA (Martin 1989, Thompson and Dicus 2005). The next step was to seek functional equivalence certification.

The Division of Forestry ${ }^{2}$ and the Board of Forestry had to demonstrate THP review complied with CEQA. The CEQA criteria that must be met were public disclosure and notification, public review, feasibility analysis, cumulative effects analysis, and appeals procedures (Thompson and Dicus 2005). The public disclosure and notification requirements were met by emergency rule adoptions initially. Timber harvest plans were available for public review for 45 days, notice of intent must be posted near the plan site in plain view on public property, and a notice must be printed in a local publication of common use (Martin 1989, Vaux 1986). The feasibility and cumulative effects analyses were added to the requirements of the THP to be written by the RPF. The Board of Forestry adopted appeals procedure to meet the final requirement. After many meetings, emergency rule adoptions, letters, and official opinions, Resources Secretary Dr. Claire Dedrick certified the timber harvest plan review process “functionally equivalent” to CEQA review (Arvola 1976, Vaux 1986, Martin 1989,

\footnotetext{
${ }^{2}$ The Division of Forestry became the California Department of Forestry in 1976 following approval of Senate Bill 78.
} 
Thompson and Dicus 2005). The Forest Practices Rules were codified, and the Act of 1973 was finally effective in 1976.

\section{$\underline{\text { Public Law 92-500, Section } 208}$}

The official title of Public Law 92-500 was the Federal Water Pollution Control Act of 1972 and later changed to the Federal Clean Water Act (Martin 1989). The majority of the law dealt with point-source water pollution or pollution that can be traced back to a single source or site, like a drainpipe (Helms 1998, Brooks et al. 2003). However, sections 208 and 404 focused on non-point source, thereby including forestry operations under this law. Section 404 was delegated to the Army Corps of Engineers due to their responsibility of managing navigable waterways, and has had minimal impact on forest practices; therefore, this section will not be discussed further. Section 208 was the most complicated issue in the history of California forest policy. The timeline and events surrounding the mandates of Section 208 and the California Forest Practice Act are too convoluted and beyond the scope of this paper, therefore the interested reader is referred to "The Tale of Two Certificates: The California Forest Practice Program, 1976 through 1988” (Martin 1989). A brief summary of events and the implications to forest management and practices is presented here.

The Clean Water Act, under Section 208, mandates the minimization of non-point source water pollution through the implementation of best management practices, or BMP’s. Compliance with the Clean Water Act is determined by Environmental Protection Agency (EPA) approval of the BMP’s. The State of California assigned Federal Clean Water Act oversight responsibilities to the State Water Resources Control Board (Martin 1989). The State Water Resources Control Board was already responsible 
for California’s Porter-Cologne Water Quality Control Act of 1969. By 1976, the State Water Resources Control Board began discussions with the Board of Forestry regarding forest practice regulation, BMP's, and Section 208 compliance. For many reasons, these issues would take more than a decade to resolve.

Rule revision difficulties were multiplied by mandates of three separate statutes, namely CEQA, AB 1111, and Section 208. Revisions involving functional equivalency with CEQA have already been discussed. Assembly Bill 1111 was passed to reduce the amount of laws and regulations statewide. The law required any state regulations, past, present and future, to adhere to a set of six criteria. The six criteria were (1) proof of necessity, (2) clarity, (3) consistency with related state rules and regulations, (4) authority to adopt the proposed regulation, (5) references to pertinent information and/or precedence, and (6) uniqueness or non-duplication of regulations (Martin 1989). The Office of Administrative Law (OAL) was created to approve the regulations, but the burden of review rested with the regulatory authority, in this case, the Board of Forestry. Essentially, the Board of Forestry was charged with reviewing all existing forest practice regulations and developing two new comprehensive rule packages to comply with CEQA and Section 208, concurrently. Difficult tasks, considering the three mandates were often contradictory.

The relationship between the Board of Forestry and State Water Resources Control Board was far from friendly. Over the course of many years, Board of Forestry rules would finally gain the approval of the water board, only to be rejected by OAL. Many instances of this occurrence were because of lack of authority or feasibility of requirements. By law, the forestry board's authority is limited to forest practices, not 
waterways or water quality. Furthermore, the water board continually insisted that erosion control regulations meet "zero-discharge” requirements. This was obviously not reasonable given the conditions under which forest operations take place and implied that watercourses do not naturally transport sediments, which is false. The water board also requested regulations regarding pre-commercial activities, such as pre-commercial thinning. However, the Board of Forestry was only authorized to regulate commercial activities (Martin 1989). OAL decisions sided with the Board of Forestry repeatedly concerning these matters, but the proposed rules were rejected per AB 1111 criteria. After many joint board meetings, studies, rule proposals and rejections, and bitter discussions, it seemed that BMP certification reached an impasse.

Alternatives to BMP certification began developing in the early 1980's. These alternative measures continue today, as the Forest Practices Act has yet to be certified as Best Management Practices by the EPA. In lieu of BMP’s are erosion control plans and a three-year post-harvest monitoring and maintenance period (Martin 1989, Thompson and Dicus 2005). Many rule changes due to Section 208 became effective in October 1983. They included Watercourse and Lake Protection Zones, preliminary mapping of roads and landings, end-hauling of spoils, and full-bench road construction requirements. During the previous six years, the Rules were constantly amended, omitted, or adopted on emergency basis and RPF's pleaded for relief. It was extremely difficult to develop plans during this rule-making turmoil. Finally, there appeared to be some constancy.

The creation of Watercourse and Lake Protection Zones (WLPZ, commonly pronounced wil-pez) had a significant impact to plan preparation and forest structure. The WLPZ's are areas surrounding and encompassing streams, which buffer the 
watercourse from potential adverse impacts. A variable buffer distance is determined by the stream classification. Each WLPZ required identification with inter-visual flagging, which is time-consuming, sometimes dangerous, and always adventurous. Depending upon the watercourse class, harvest and equipment activities are either restricted or prohibited. Since watercourses are one of the most common features used for harvest unit boundaries, it is safe to say that almost all timber harvests in California include at least one WLPZ. Typically, silviculture is restricted within the buffer zone, limiting the amount of trees available for harvest based on distance from the bank-full edge or minimum residual canopy cover. These restrictions help maintain aquatic habitat and water temperature. Since the early 1980's, the short-term effects of WLPZ restrictions has been beneficial, however studies are currently underway to analyze possible longterm effects like native hardwood exclusion and nutrient depravation (Gasser 1996). Nonetheless, most foresters, hydrologists, and aquatic biologists agree that WLPZ's are favorable to the environment.

\section{$\underline{1990 ’ s \text { to Present Day }}$}

The amount of rule making and revisions until 1983 was exceptional for the Board of Forestry. The remaining years of the decade would bring more rule revisions, but the next hurdle to overcome would begin with the following decade. Public concern about the environment and endangered species grew over previous years and culminated in an unprecedented display by California voters’ in 1991-93 (Gasser 1996). Three voter initiatives received enough signatures to be placed on the ballot. Among them were the Sierra and Grand accords (Gasser 1996, Davis et al. 1991, Thompson and Dicus 2005). Although none of the initiatives passed, the Board of Forestry understood the message 
proclaimed by this form of "ballot-box forestry" (Davis et al. 1991). The board acted and produced sweeping changes the following year.

Once again, the rules were going through a major overhaul. Some rules were so short-lived, or altered so often that the effectiveness was impossible to determine (Ice et al. 2004). However, in 1991 the Board adopted rule amendments, emergency rules, and brand new rule packages (Gasser 1996, Thompson and Dicus 2005, Dicus and Delfino 2003, Yee 2003). Amendments were made to the Northern Spotted Owl habitat areas and the archeological site requirements. Emergency rules were adopted for the protection of Marbled Murrelet habitat. New WLPZ, Roads and Landings, and Cumulative Impacts rules package were adopted. More constraints on even-aged management, specifically clearcutting, were codified. Regulations requiring large industrial timberland owners to file long-term management plans were also passed. These long-term plans include the Sustained Yield Plan (SYP), the Option A, and the Non-Industrial Timber Management Plan (NTMP). Finally, items were added to the THP form requesting more information when late successional or "old-growth" stands are present. Most of these regulations remain intact; however, in 1994 and 1995, the "Points of Light" amendments passed to further clarify and define the new rules (Thompson and Dicus 2005).

From that time to present day, the Forest Practice Act has continued evolving, and the focus targets alternative resources as well as timber. Water quality and endangered species are major focal points in any THP. Although the Director of CAL FIRE and the Board of Forestry and Fire Protection have final compliance determination for THP's, the Regional Water Quality Control Boards hold a lot of influence with this decision (Thompson and Dicus 2005). In 2000, more intensive water quality interim regulations 
passed for Threatened and Impaired (T \& I) watersheds. These interim rules were adopted officially in 2002 for improved salmonid habitat protection. The T \& I watershed rules have been revised, and as of January 1, 2010 the rule package has been incorporated into "Protection and Restoration of the Beneficial Functions of the Riparian Zone in Watersheds with Listed Anadromous Salmonids” (14 CCR § 916.9).

Management of timber and silviculture regulations is the most steadfast part of the Rules. Forest structure and the influence of management on structure should be apparent, given consistent implementation and documentation. The majority of rules focus on all aspects surrounding the trees, from ridge top roads to the creeks flowing down in the canyons. Influence from rules occur, but are secondary or tertiary to directly affecting the measurable forest structure.

CAL FIRE and the Board of Forestry and Fire Protection represent the fulcrum between polarized groups of industry and environmentalists. Undoubtedly, critics of the forest practices program remain vocal. Either side can debate every aspect of the Rules, and often do. Industry's dissatisfaction lies with the Rules being too inflexible, bureaucratic and procedural (Gasser 1996, Ice et al. 2004, Thompson and Dicus 2005). The forest practice rules were never meant to substitute for forest management, nor were they designed to guide every feasible site-specific issue (Arvola 1962 and 1970). Furthermore, rule changes are often politically driven, which tends to serve lawyers rather than forests (Gasser 1996). The increasing cost of THP development and implementation has resulted in land-use conversions to other forms of agriculture, timberland disinvestment, and an overall decrease in timber output (Gasser 1996, Thompson and Dicus 2005). California's increasing forest products demand and 
decreasing local supply has been compensated by imports from regions with lesser environmental standards, echoing the NIMBY- "Not In My Backyard” mentality (Thompson and Dicus 2005). These, and other criticisms, are summarized by the view that the California forest practices program is designed to discourage poor practices rather than encourage quality environmental stewardship (Dicus and Delfino 2003, Thompson and Dicus 2005).

The negatives tend to overshadow the positive aspects of the program, however many positives aspects persist. Over three decades (1973-2003) 16 major rule packages were adopted and/or amended, making rule effectiveness difficult to assess (Yee 2003, Ice et al. 2004). A survey of forest managers cited erosion control measures, road planning regulations, WLPZ, Cumulative Impacts Analysis and erosion hazard ratings as a few of the benefits the program has provided (Gasser 1996). The required sustained yield analysis has caused reforestation to become a normal and necessary cost for THP's. Possibly one of the most important has been the structured multidisciplinary review process, including channels for in lieu practices, THP amendments, and appeals.

Statistical evaluation of rules may be difficult, but some descriptions are certain. CAL FIRE performs approximately 10 inspections per THP (Ice et al. 2004). The positive aspects of the Rules led to a 97 percent implementation rate for water quality and erosion control rules, determined from a sample of THP's from 1996 to 2001. Another sample of THP's from 1998 to 2000 identified 975 total violations from 4,749 THP's queried, approximately one violation for every five THP's completed. These numbers suggest discouragement of poor forest practices. 
It is easy to ascertain the unique nature of the California forest practices program by objectively viewing the positive and negative issues represented by all stakeholders. The challenge of the policy framers is much like trying to balance a marble on a bowling ball. However, each stakeholder has their own marble they want balanced.

\section{Modern Timber Management}

The axe and saw are the major disturbance factors that alter the redwood forest structure today. Typically, research in the redwood range has focused on maximized volume production. This research often occurs in the northern and central sections of the range. When redwoods began to be cut in the 1830's, the silviculture of choice was clearcutting. However, the silvicultural practices of that era were closer to deforestation since the lumbermen did not actively regenerate the forest. This regime continued for over a century, creating even-aged second growth stands. Over the years, many regimes have been developed for timber management. Some have focused on maximizing profits, while others attempt to manage for a specific forest structure.

When tractor technology was introduced to the woods around 1930, a new form of silviculture was also introduced (Clar 1959). This new form of selective harvesting is often confused with a similar term, selection harvesting (O'Hara 2002). The two differ by selective harvesting only removes the biggest and best trees, also referred to as highgrading. This management represented misunderstandings of stand dynamics and the commonly assumed correlation between tree age and diameter. Therefore, managers selectively harvested the largest trees in an attempt to maintain an all-aged forest structure (O’Hara 2002). Selection harvesting was adapted from European forestry, in which trees were harvested based on a desired diameter distribution for the stand (Davis 
et al. 2001, O’Hara 2002). Selection management was a viable option in forestry, but many industrial timber companies continued to apply even-aged management regimes such as clearcutting. Even today, the commonly used empirical yield tables for young growth redwood reflect this era of even-aged management (Lindquist and Palley 1963).

Research for selection harvesting is based on the release effect. The purpose of selection is to reduce competition and increase, or release, growth in the residual trees. Many studies implemented over the years tested various treatments of thinning levels and growth response (Fritz 1938 and 1945, Cole 1983, Oliver et al. 1994, Lindquist 2004). The two approaches to thinning are pre-commercial and commercial (Davis et al. 2001). Pre-commercial thinning removes trees before they are of merchantable size. The treatment is costly because there is no immediate financial return, but it is a value-added approach to increase returns when the mature stand is harvested (Davis et al. 2001). Commercial thinning harvests merchantable trees, therefore immediate returns are possible. However, in younger stands, the returns often break even with logging costs. In the redwood range, pre-commercial treatments are rarely, if ever, applied (Giusti 2004).

The goal of selection management is to create a regulated stand distribution and growth rate. Some models are based on even-aged approaches and financial maturity, where the mean uneven-aged tree diameter was used to calculate mean annual increment (MAI) and periodic annual increment (PAI) (Davis et al. 2001). Similar approaches determine time of harvest when relative growth rates are equal to the discount rate of the commodity (Nautiyal 1983). One approach, represented in this study (Truncated), aims to regulate the uneven-aged stand diameter distribution by a function of desired residual 
basal area (B), maximum diameter (D), and a slope factor (q) of an exponential decay model (Leak 1964, Guldin 1991, Piirto et al. 1996). The BDq function seeks to distribute harvest trees across a range of diameters. Currently, the most widely applied harvest regimes in the redwood forest are individual tree selection and group selection (Lindquist 2004, Helms and Hipkin 1996, Oliver et al. 1994). Single tree and group selection regimes prescribe proportions of harvest and retention of density (TPA or BA) and area, respectively. The proportions vary by region and management objective.

Growth rate increase and release have been studied since the late 1930's (Fritz 1938 and 1945). Early research showed general increases in annual diameter growth ranging from 0.28 to 0.48 inch for thinned plots compared to 0.32 to 0.40 inch for unthinned plots (Cole 1983). Another study stated an average increase of approximately 10 percent in basal area annual increment for all diameters as a result from selective harvesting (Person 1942).

Population along the California coast continued to increase as the forests grew. This brought a different type of impact to the timberlands, land-use conversion. A landowner must obtain a conversion permit to change the land-use of timberland pursuant to Public Resource Code $\S 4621$ (CAL FIRE 2010). For the three decades between 1969 and 1998, 112,866 timberland acres were converted from TPZ to other uses statewide (Shih 2002). Approximately 40 percent (45,345 acres) of the total conversion acreage took place in the Coast forest district on 175 permits. Amazingly, 80 percent (36,270 acres; 65 permits) of the conversions in the Coast forest district occurred during the four years prior (1969-72) to the passage of the Forest Practice Act of 1973. From 1979-1998, statewide more than half of the converted acreage was developed into subdivisions and 
housing. Grazing, subdivisions, and other agriculture are the most common conversion permit requests. Although this does not constitute forest management, it does represent a large proportion of timberlands that were harvested one last time before ceasing timber production.

Long-term variable thinning research began at Whiskey Springs on Jackson Demonstration State Forest in 1970 (Lindquist 2004). The study began with 40-year old redwood stand with BA stocking of 400 square feet per acre. The commercial thinning retained 25-, 50-, and 75-percent of the pre-harvest basal area, with 100 percent retention in control plots. After 29 years, the percent BA growth trend decreases with more retention, with 25, 50, 75, and 100 percent retention growth rates equal 2.9, 2.3, 1.7 and 1.2 percent respectively. Similar trends are shown for cubic volume growth percentage. The greatest board foot volume increase, 3002 board feet per acre per year, was recorded for the 75 percent retention treatment, and least increase, 1803 board feet per acre per year, was evident in the 25 percent retention treatment. Applicability of this study to the Southern subdistrict of the Coast District is bounded by “60/50 Rule,” however for treatments of 50- and 75-percent retention indicate growth rates greater than 2500 board feet per acre per year (Lindquist 2004).

Similar findings for this site, and two other in northern California, are reported by Oliver, Lindquist and Strothmann (1994). This study reports the first 15 years after thinning on three sites in Northern California. Board foot growth rates range from 4.2 to 7.0 percent for thinned plots, compared to 3.6 to 4.8 percent for unthinned plots (Oliver et al. 1994). Overall, volume production decreased with higher leave tree percentages. Another study conducted at Jackson Demonstration State Forest compared various 
retention levels with individual tree and group selection methods (Helms and Hipkin 1996). The BA growth were lowest in stands with the highest retention levels (65-84 percent) ranging from 2.1 to 2.6 percent. Contrasted with the lowest retention levels (3860 percent), BA growth rates range from 2.3-3.9 percent. Board foot volume increase was fairly constant, 2.0-3.0 percent, except for one treatment of combined single tree and group selection. This combination retained 65 percent BA and had a 5.0 percent growth rate (Helms and Hipkin 1996). In summary, thinning a stand by any proportion will induce a release effect.

The Modern Timber Management section presented different approaches to silviculture and levels of thinning. However, the state of California mandates maximum sustained productivity, or MSP, for timberlands within the state (14 CCR § 913.11). This mandate is achieved through the specified management regime and there are as many pathways to achieve MSP as there are regimes to manage the forest. The silvicultural approach of "cut only what is grown" summarizes most approaches to MSP at this time. 


\section{METHODS AND MATERIALS}

The following chapter outlines the process of data collection and statistical methods used. Data collection began with defining the various types of management to include. Once the management regimes were selected, forests undergoing that specific management were identified. Delineation of stands took place prior to inventory plot establishment. Common forestry measures for the plot-level inventory were calculated, summarized, and statistically analyzed.

\section{Management Regimes}

The inventory sites for this project are all managed for one or more resources, whether it is timber, recreation, watershed quality, wildlife, or aesthetics. Two broad categories of management are defined for the purpose of this study; management where no timber is harvested from the forest, and timber management where trees are harvested from the forest for commercial use. However, all stands included in this study are managed for a minimum of two resources.

Even though parks are thought to be preserved, many activities still occur within the boundaries that constitute management. Of the state parks in this study, Big Basin Redwoods would be the one most likely identified as unmanaged, since it encompasses the largest and oldest stands of redwoods south of Mendocino County. Yet, since 1978, the California Department of Parks and Recreation have been using prescribed fire in much of the park, but focused in the areas that have never been harvested (pers. comm. Halbert 2007). Another form of management includes roads, trails, and fire-breaks. These structures have been constructed and maintained annually in all the state parks. 
Wildfire suppression has been a major concern for state and federal resource agencies since their formation, but a professionally trained and equipped fire service was not effectively used until the twentieth century. The subsequent removal of fire represents the final form of management. Parkland may not be managed for timber production, but the land is still managed with many permitted uses, such as hazard/invasive/exotic removal, recreation, utility lines, and hydroelectricity.

Within the study sites managed primarily for timber, there are various methods, or regimes, of uneven-aged management. The regimes vary by how trees are selected and when the trees are harvested. Each regime has specific goals and objectives. Landowners and/or forest managers define the goals and objectives, and then implement silvicultural prescriptions to achieve them.

\section{$\underline{\text { Regime Definitions }}$}

A total of six management regimes were identified for natural and harvest origin forests. All plots in a stand were classified into only one regime. Classifications were based on management objectives and goals as discussed with the forest managers or owners. All plot data collection occurred after management regime classification. All harvest methods implemented were in compliance with the Forest Practice Rules at the time of harvest.

\section{$\underline{\text { Natural Regime }}$}

The Natural management regime is the only regime that includes natural origin forests. These stands have never been harvested. In addition, the establishment of the stand occurred prior to European settlement within the study area. Stand establishment is 
the initiation of tree cover, by either afforestation or natural regeneration (Helms 1998). The remaining management regimes include the harvest origin stands.

\section{$\underline{\text { Park/ No Cut Regime }}$}

The Park/No cut regime is characterized by stands under California State Parks management. The harvest of high quality timber products is prohibited from these lands. However, these stands developed from clearcut harvests prior to entering the parks system. Since they have not been harvested since clearcut, the Park/No cut regime will serve as a control for the harvest origin group. The remaining regimes of harvest origin, sometimes referred to as Timber management regimes, were all established by clearcut harvests, just as Park/No Cut, but at least one partial-cut harvest has occurred since.

\section{Truncated Regime}

The Truncated management regime gets this name because a maximum diameter is defined for the stand. Three variables, desired residual basal area (B), maximum diameter (D), and a slope factor (q) define the parameters of this management model (Leak 1964 and 1965, Guldin 1991, Piirto et al. 1996). The function describes the ideal stand density of trees per acre by diameter class. The BDq function is also referred to as the inverse J-shaped, negative exponential or exponential decay curve (Figure 7, page 78). The $\mathrm{BDq}$ function is applied to the stand table and excess trees in diameter classes are harvested. An important modification to this management regime has been made to the maximum diameter variable. Trees greater than the maximum diameter exist within the stands in all instances, and will remain in the stands as "heritage" or "legacy" trees. It is also important to note the Truncated management regime conforms to the silviculture 
standards pursuant to the Special Harvesting Methods for Santa Cruz County (14 CCR § 926.25).

Figure 7: Generalized Truncated Regime Stand Curve and Harvest Tree Determination

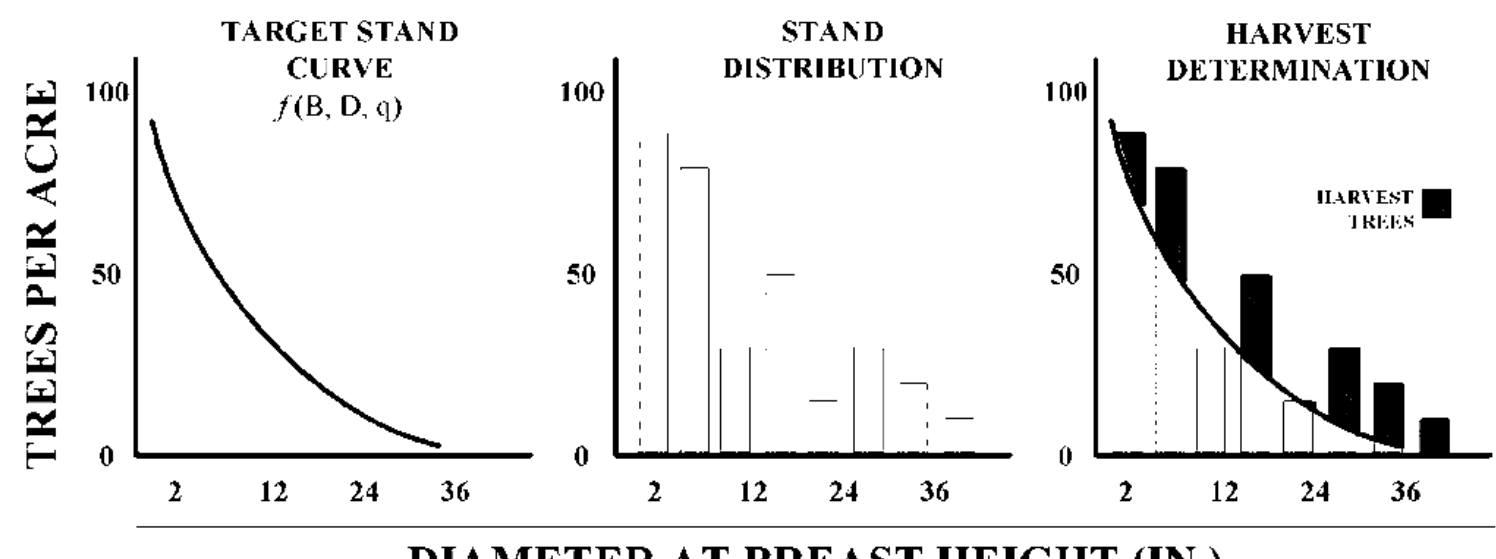

DIAMETER AT BREAST HEIGHT (IN.)

Note: Figure 7 developed for this volume, adapted from Leak 1964, Leak 1965, Guldin 1991, and Piirto et al. 1996.

\section{Large Tree Management Regime}

The Large Tree Management regime consists of stands undergoing restoration through applied forest management. The regime is characterized by timber harvests defined as thin-from-below (Nyland 2002). This harvesting method targets trees in the understory canopy layer of merchantable size. Trees are thinned from under the overstory trees to increase spacing and decrease competition. This management regime is uncommon in the study area and is proportionally represented in the dataset. However, it is included in all analyses since it is the only form of applied forest restoration in current practice.

\section{$\underline{\text { Percent Removal Regime }}$}

Percent Removal is the most commonly applied timber management regime in the area. The methods for implementing this regime are outlined in the Forest Practice Rules 
under Special Harvesting Methods for Santa Cruz County (14 CCR § 926.25). This section of the Rules is often referred to as the "60/50 rule". Even though the rule is county-specific, it is often applied in San Mateo County according to the standards of Santa Cruz County. The parameters of the regime, as outlined by the Rules, state that no more than 60 percent of the trees greater than 18.0 inches DBH may be cut during a single harvest. If less than 50 percent of the trees greater than 18.0 inches DBH are harvested, then the next harvest may occur in 10 years, rather than 14 years. However, only 40 percent of trees from 14.0-18.0 inches DBH can be harvested regardless of reentry period. These are the maximum cut limits as stated by the Rules, however all RPF's of stands classified into this regime apply a modified approach. The managers never harvest more than 50 percent of trees greater than 18.0 inches DBH to retain the 10-year re-entry period. The percent removal range of trees greater than 18.0 inches DBH is between 30-50 percent for this study. Furthermore, the managers only prescribe a "cleansing" cut for trees between 14.0-18.0 inches, never a percent removal of density from this diameter range. A "cleansing” prescription harvests trees with broken, deformed, or otherwise un-merchantable traits in the stem.

\section{Unknown Regime}

The Unknown management regime encompasses only one stand. The Gazos Falls stand is located within Butano State Park in southern San Mateo County. This stand has been under the Park/No cut management regime since the mid-1980's. Butano State Park was established in 1961, however portions of the Gazos Creek watershed, including this stand, were added to the park at later dates. There is evidence of partial-cut timber harvests throughout the stand. Historical records indicate that harvests took place within 
the watershed through the 1950's, and the eastern portion of the stand may have been harvested in 1985. It is certain that the stand was not clearcut a second time. Since the cutting methods were not determined by research or local knowledge, the applied management regime was classified as Unknown. There are confounding implications with the statistical analysis since this regime is represented by only one stand. Any significant differences are inconclusive because the difference may only be the characteristic of this one stand.

\section{Stand Criteria and Delineation}

Data collection within all stands had to meet minimum criteria. The minimum criteria for stands are defined by composition of redwood, stand acreage, subsequent harvesting, and potential site productivity.

Minimum Stand Criteria:

1) Stand composition is 50 percent basal area per acre of redwood, defined as a majority forest cover type (Roy 1980).

2) Acreage of stand must be a minimum of 10 acres.

3) All subsequent timber harvests in harvest origin stands must be a partial-cut method of uneven-aged management.

4) Potential Site Productivity:

- Harvest Origin- Stand must occupy Site Class II or III ground (Lindquist and Palley 1963, Fox 1989)

- Natural Origin- No published classification systems exist for determining potential productivity for natural origin stands (pers. comm. Krumland 2007). 
A stand, in silvicultural terms, is a distinguishable unit of trees growing on a site of uniform quality with homogeneous age-class distribution, species composition, and structure (Helms 1998). A stand is equivalent to a management unit to which treatments or prescriptions are applied. The types of stands used for this study include preexisting stands, a portion of a preexisting stand, and stands delineated by the researcher.

One of the three methods delineated all stands, regardless of origin or management regime. This method gave priority to preexisting stands. Preexisting stands are those delineated by the landowner or forest manager. The stand boundaries remained intact if there was a uniform silvicultural prescription, not including variations in the prescription for WLPZ's. When variations occurred within the prescription for the timber strata, or if the preexisting unit was greater than 100 acres, a portion of the stand was selected and bounded by logical features. For areas where stands did not exist for management, mainly within state parks, logical features delineated stands. Common stand boundary features are topographic (ridges and changes in slope or aspect), hydrologic (creeks and drainages), manmade features (roads and trails), and historical logging information. All potential stands were visited prior to data collection to ensure that the forest satisfied the definition of a stand.

Data collection took place across numerous ownerships, therefore a variety of agreements were arranged. In most private land cases, the landowners required a release of liability contract or a hold harmless agreement. On public lands, such as California State Parks, a Biological Investigation Permit was obtained through the Santa Cruz District Office in Felton, California. In all instances, data collection could not begin until permission and proper access procedures were discussed with the property management 
(Appendix E). In turn, the local knowledge of the property managers proved valuable to stand delineation. Inventory stand maps are presented in Appendix A.

\section{Inventory Design}

The forest inventory was specifically designed for this study and the unique characteristics of the redwoods in the Santa Cruz Mountains. The cluster plot design and method of plot location are further discussed. The tree and plot attributes were also developed in accordance with the research objectives. Once the design was developed, the plots were installed in the field and trees measured. The field data collection began in September 2007 and concluded in April 2008.

\section{$\underline{\text { Plot Design }}$}

A cluster of three plots, each with a nested seedling/sapling plot was used for inventory. Each intersection of the systematic square grid designated the center of a three-plot cluster. This design was developed to capture the locally variable conditions of a redwood forest, variability that is commonly characterized as "clumpy”. Clumps are usually spaced horizontally from 20 to 150 feet. Therefore, the centers of the three 0.25 acre line plots in the cluster are spaced 175 horizontal feet apart. Two of the three plots are located at 90 degrees from the middle plot along the systematic grid bearing to capture topographical and elevational variation. The direction of these two plots along the grid usually pointed toward the interior of the stand to avoid plot overlap of stand boundaries. Ultimately, the directionality of the "L-shaped" plot was determined to avoid plot boundaries overlapping the stand bounds. A diagram of the cluster plot design is shown in Figure 8 on page 83. 
Figure 8: "L-shaped” Cluster of Three Nested Plots

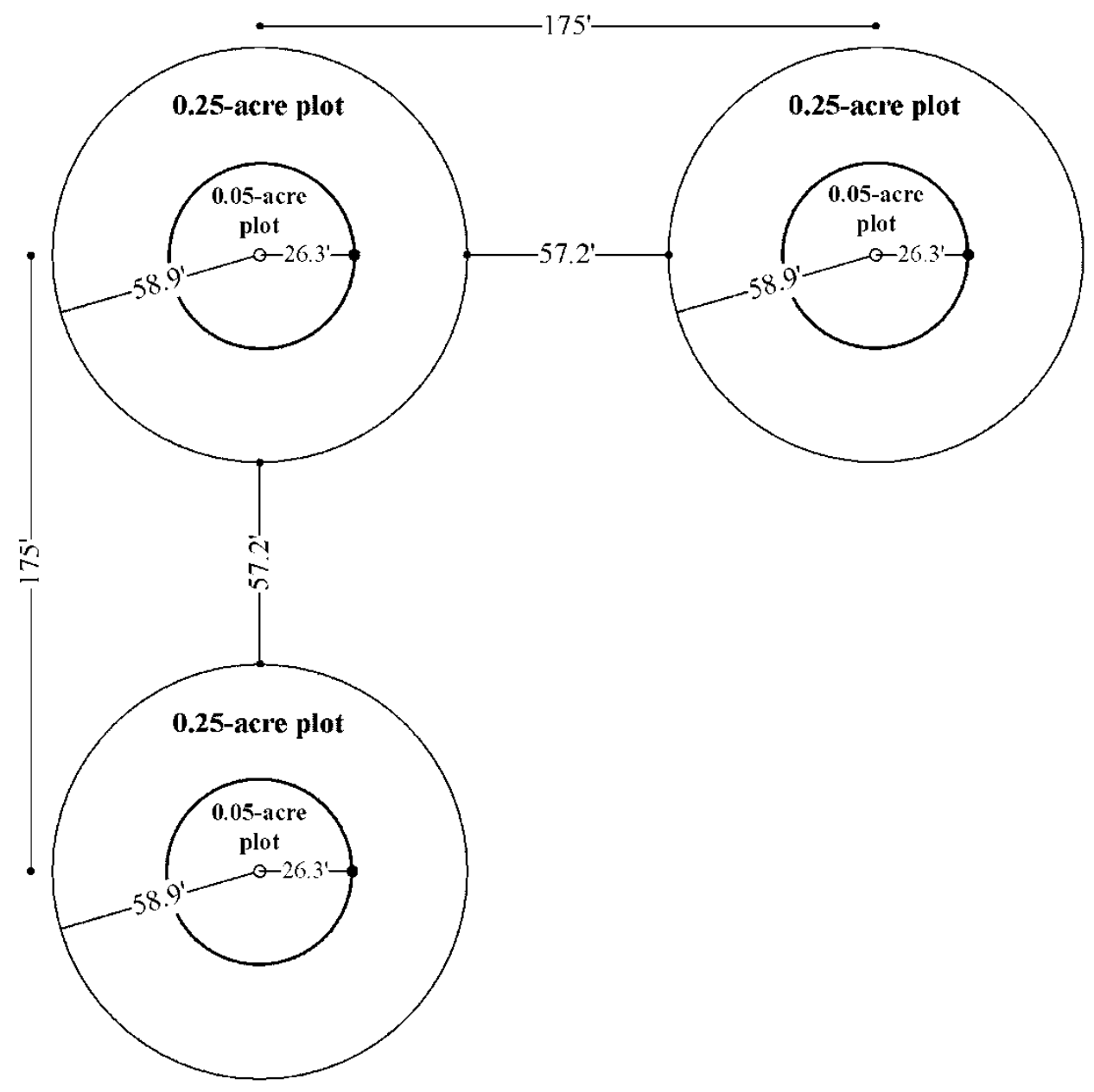

\section{Plot Location}

Plots were randomly located within stand boundaries. A systematic square grid was calculated for each stand depending on number of plots, stand acreage, and the exact sample intensity. Plots are located at the intersection of the grid lines. Once the grid was developed for the stand, a random number between zero and 89 was generated from "RandBetween"[function = randbetween(min\#, max\#)] function in Microsoft Excel 2003. This random number determined the bearing offset in degrees from North. The number 90 was omitted since, for a square grid, 90 degrees is equal to zero degrees. A coin flip 
determined the direction of the offset: if the coin showed 'heads,' the bearing was offset to the West, 'tails,' offset to the East. The offset systematic grid was randomly overlaid on a map of the stand boundary. The grid was nudged one way or another until the required number of plots was within the stand boundary. This process was completed using ArcGIS 9.2 software (ESRI, Inc. 2006). Each map was visually inspected to ensure plot centers avoided ponds, roads, streams, buildings, or inner gorge areas. Topographic maps with ratio scale greater than 1:12000 and contour intervals of 40 feet was used for plot locations in all stands. Basic orienteering methods with map and compass from known points were used to establish plots in the field. Distances between plots were measured with a MDL LaserAce rangefinder.

Plot frequencies and distributions by slope, aspect, and 10-year age class are presented in Appendix B.

\section{Measurements}

Descriptive characteristics were recorded for each individual plot. A unique plot number and code were recorded for each plot. The aspect of the plot was determined using a Silva Ranger hand compass. Aspect was recorded to nearest quarter-cardinal direction (North, Northwest, West, Southwest, South, Southeast, East, or Northeast). The average slope, in percent, of the plot was measured using a Suunto clinometer. The date and time collection occurred for the plot was recorded. Plot characteristics were measured after plot center had been established and before individual tree measurements occurred.

Tree-level data was collected using a nested plot design for trees and saplings. Both plots originate from the same plot center, marked by an eight-foot tall surveyors 
range pole and a one-foot square target. All diameter measurements were taken at breast height, defined as 4.5 feet above the ground on the uphill side of the stem. Stems were determined in or out of the plot by using a MDL LaserAce hypsometer as a laser rangefinder. Where visibility was good, the horizontal distance was measured from the approximate center of the stem to plot center. In instances where understory vegetation or slope obscured the plot center marker, a horizontal distance was calculated using a slope distance measured to the nearest 0.1 -foot with a 100 -foot steel tape and a slope measured to the nearest 1.0-degree using a Suunto clinometer. The horizontal distance (HD) is equal to the slope distance (SD) multiplied by the cosine of the absolute value of the slope degree:

$$
H D=S D \times \cos \mid \text { Slope Degree } \mid
$$

Where: HD = Horizontal Distance (ft.); SD = Slope Distance (ft.); Absolute value of Slope Degree since slopes are both positive and negative.

The 0.05 -acre circular line plots (26.3 ft. radius) were installed for all live sapling stems between 0.1 and 5.0 inches in diameter at breast height (DBH). Diameters of all live stems with a height greater than 4.5 feet were recorded to the nearest 0.1 -inch. In addition to diameter measurements, each stem was counted within the plot and the species was determined and recorded. The crown position of the sapling was recorded as well. Seedlings less than 4.5 feet tall were inventoried by a stem count by species only, no diameter information was recorded.

The 0.25 -acre circular line plots (58.9 ft. radius) were installed for all live tree stems greater than 5.1 inches at DBH. All characteristics recorded for saplings were collected for trees; in addition, Live Crown Ratio (LCR) and total heights were also 
measured. Diameters were measured to the nearest 0.1-inch using a steel Spencer diameter tape. Two other characteristics were measured additionally. Live crown ratio was estimated to the nearest 10 percent. This measure describes a proportion of the length of live foliage in the crown to the total height of the tree. For example, a tree with 50 percent LCR and a total height of 200 feet would have 100 feet of live foliage. Also, the relative crown position for each stem was determined according to a modified Kraft's crown class model (Helms 1998). Each stem was classified as dominant, codominant, intermediate, or suppressed. The modified classification system consisted of merging the predominant and dominant crown classes into the dominant class, and omitting the dead crown class since the inventory only considered live stems. Dominant crowns receive full light from above and partial light from the sides, and extend above the crown level of its immediate neighbors. Codominant crowns receive full light from above and relatively little light from the sides, whose crown occupies the main canopy layer. Intermediate crowns extend into the lower portions of the canopy, but shorter in height than codominant trees, and receives little direct light from above and none from the sides. Suppressed crowns receive no light from above or the sides and are completely overtopped by the neighboring trees.

Total tree heights of two trees per crown class per plot were measured using a MDL LaserAce hypsometer. Total tree heights were measured to the nearest 1.0-foot. Qualitative tree characteristics were noted if present. Such qualitative notes include forked stems, broken tops, dead or spiked tops, basal catfaces, signs or symptoms of disease, and damage from logging activities or windthrown trees. A summary of attributes collected in the nested plot is shown in Table 2 on page 87. 
Table 2: Measured Attributes of Nested Plots

$\begin{array}{ccc}\text { Measured Characteristic } & \begin{array}{c}\mathbf{0 . 2 5} \text {-acre } \\ \text { Tree Plot } \\ \text { Plot Identification }\end{array} & \begin{array}{c}\mathbf{0 . 0 5} \text {-acre } \\ \text { Sapling Plot } \\ \text { YES }\end{array} \\ \text { Tree Number on plot } & \text { YES } & \text { YES } \\ \text { Species } & \text { YES } & \text { YES } \\ \text { Crown Class } & \text { YES } & \text { YES } \\ \text { Diameter at breast height (DBH) } & \text { YES } & \text { YES } \\ \text { Live crown ratio (LCR) } & \text { YES } & \text { NO } \\ \text { Total height } & \text { YES } & \text { NO }\end{array}$

\section{$\underline{\text { Photographic Points }}$}

A photographic record was completed for each plot. A Pentex Optio WPi 6.0 megapixel waterproof digital camera was used to take all photographs. Four photographs per plot were taken, one in each cardinal direction. Each photograph was taken from an approximate distance of 30 feet from plot center target to lens, measured by the laser rangefinder function of a MDL LaserAce hypsometer. Plot center is marked in all photographs by a standard surveyors range pole with alternating orange and white sections one-foot in length. A target was hung on the range pole that measures one-footby-one-foot square. In some instances, photographs were omitted because of zerovisibility due to heavy understory vegetation. A complete archive of all photo-points is available upon request to the author.

\section{Field Notes}

Field notes were recorded at each plot for understory vegetation and cover, fire, and canopy structure. In addition, any unique features of the plot, such as topography, geology, hydrology, or archeology were noted. Understory vegetation was inventoried 
by ocular estimate of common associated species to the nearest five percent (5\%). Tree seedlings, shrubs, and ferns were identified to genus or species, and herbaceous plants and grasses were stratified categorically in groups bearing the same titles, respectively.

The presence or absence of fire scorch was recorded for overstory trees. Secondgrowth redwoods are good indicators of the occurrence of wildfire because of low firerelated mortality. Approximate average height of stem scorch was recorded for each plot, as well as the relative intensity of scorching per species, if noticeably different. Scorch heights were measured with a MDL LaserAce hypsometer. The presence or absence of cat-faces, or goose-pens, was noted. For prominent cat-faces, the approximate percentage of basal area missing from the stem was recorded for the tree.

Descriptive and qualitative notes were taken for forest structure. A brief description of the spatial arrangement of stems on the plot was noted. Spatial arrangements ranged from very tight-knit clumps of stems less than two-feet apart at the ground surface within a clump, to stems randomly and evenly spaced within the plot. For clumpy arrangements, the range of horizontal distance between clumps was estimated on the plot. Furthermore, the range of number of stems per clumps and their associated crown class was recorded. Finally, the number of vegetation layers, or vertical stratification of the canopy was recorded. All vegetation layers were included in the layer count, including herbaceous plants.

\section{Inventory Calculations}

This section describes the process of converting raw plot data to the quantitative forest components used in the statistical analysis. Calculations and stratification of data 
is presented for the measures of composition, density, central tendency, and vertical structure.

The composition of the forest describes which species are present. Measured trees were all identified to species. The analyses test four different compositional groups. The first group has been defined as all species present. A group of all conifers (redwoods and Douglas-fir) is tested for differences in forest components, as is all hardwoods. Hardwoods are dominated by tanoak, however other hardwoods such as madrone, California bay, and true oaks are represented. Finally, the last compositional group is comprised solely of redwoods.

Table 3: Inventory Plot Expansion Factors

\begin{tabular}{ccc} 
Plot Type & Plot Size (acre) & Expansion Factor \\
\hline Sapling & 0.05 & 20 \\
Tree & 0.25 & 4 \\
\hline
\end{tabular}

A one-dimensional measure of density calculated for each nested plot was trees per acre (TPA). The TPA is a simple count of stems within each plot boundary. The plot count is expanded to a per acre basis using the respective expansion factor (Table 3). In natural and harvest origin stands this measure provides limited information about density (Avery and Burkhart 2002). Two stands with similar TPA density can have drastically different structures. For example, compare one stand that was clearcut and replanted 10 years ago with 250 TPA on 15-by-15 foot spacing with a 100-year old second growth stand that has 250 TPA and a mean diameter of 18 inches DBH. Each stand has 250 TPA, but obviously different structure. 
Trees per acre is calculated:

$$
T P A=\sum \text { Plot Stem Count } \times \text { Expansion Factor }
$$

In order to calculate a total TPA for all diameter classes, the TPA for each nested plot, 0.25-acre and 0.05-acre, must be summed.

Basal area (BA) is the cross-sectional area occupied by the stem of a tree measured in square feet. This two-dimensional measure of density calculates the surface area occupied by a stem at breast height. The calculation is based on the diameter in inches and a conversion factor. Basal area per acre (BA/ac) is summed from the basal area of individual trees and then expanded to a per acre value using the respective expansion factor.

$$
\begin{aligned}
B A & =0.005454154 \times D B H^{2} \\
B A / a c & =\sum B A \times \text { Expansion Factor }
\end{aligned}
$$

Where: BA= Basal area per stem; 0.005454154= factor that converts square inches to square feet (Avery and Burkhart 2002); $\mathrm{DBH}=$ stem diameter at breast height in inches; and $\mathrm{BA} / \mathrm{ac}=\mathrm{Basal}$ area per acre.

In order to calculate a total basal area per acre for all diameter classes the BA/ac for each nested plot, 0.25-acre and 0.05-acre, must be summed. The measure further describes a forest stand. Using the example presented with TPA, the 10-year old stand can now be described as 250 TPA with $45 \mathrm{ft}^{2}$ basal area per acre, and the 100-year old second growth stand as 250 TPA with $290 \mathrm{ft}^{2}$ basal area per acre. The combined measures of TPA and BA begin to describe the stand more completely, much like a balance sheet for an accountant.

In forestry as in statistics, the mean or average stand diameter is considered a measure of central tendency. Specifically in forestry, a secondary mean diameter value is 
calculated. The tree with the mean basal area, or quadratic mean diameter (QMD) is not identified as a measure of density, however this measure is used in many quantitative and relative density indices and late successional forest classification (Avery and Burkhart 2002, Davis et al. 2001, Parisi et al. 2007). QMD calculation accounts for the number of stems present and the basal area occupied by the stems. QMD is skewed towards larger trees, and as such will always be greater than the arithmetic mean diameter. The calculation can be completed for any grouping, as long as the TPA and BA are from the specified group. The calculation for QMD is:

$$
Q M D=\sqrt{\frac{\sum B A / a c \div \sum T P A}{0.005454154}}
$$

Where: $\mathrm{QMD}=$ quadratic mean diameter (inches); $\mathrm{BA} / \mathrm{ac}=$ basal area per acre $\left(\mathrm{ft}^{2}\right)$; $\mathrm{TPA}=$ trees per acre; 0.005454154= factor that converts square feet into square inches (Avery and Burkhart 2002).

Canopy positions or layers measure vertical structure. However, diameter ranges may be used as a surrogate pursuant scientific literature, common practice or forest regulations. Overstory and understory canopy layers used in analysis are derived from the modified Kraft's crown class previously described in this chapter. The canopy layer describes the vertical structure of the forest. Refer to grouping definitions associated with research objectives two and three beginning on page 20 for literature and regulations defining surrogate measures of canopy layers.

\section{Conditional Calculations of Forest Components}

The quantitative components used to analyze differences in the forest are composed of three elements and selected based on conditions set by the research objectives. Each component consists of a compositional group, a single density measure 
(TPA, BA or QMD), and a structure layer or diameter grouping. When applied, the lump of general stand data is refined to describe a specific part of the forest. While stand level totals of trees per acre or basal area illustrate the density of a plot, the research objectives focus on the parts that make up the whole. Moreover, in this case the components will ultimately define the differences in forest structure rather than the sum of the parts.

\section{Objective Four- Late Successional Forest Classification Calculations}

The comparison of the methods includes the recommended method by the regulatory agencies (Parisi et al. 2007) and a surrogate method developed by the authors of the Swanton Pacific Ranch NTMP. The agency method includes QMD calculations for overstory and understory canopy layers. These canopy layers have been defined previously. The Swanton Pacific Ranch NTMP applied diameter ranges to capture the canopy layers, rather than the relative canopy position of each tree. The overstory canopy layer was captured by calculating QMD for all stems greater than 24.0 inches DBH. The understory canopy layer was captured by calculating QMD for all stems greater than 2.0 inches DBH. QMD components were calculated for each canopy layer and surrogate using the formula on the previous page. 


\section{Statistical Analysis}

The statistical model fit to analyze the plot data is exploratory in nature. In total, 162 dependent variables were tested for objectives one, two, and three. A mixed-effects linear model had the best fit for the square-root transformed data. The fixed-effect for the model is management regime. Random-effects are the stand number nested within the management regime. Overall model significance was tested with a significance level of 5 percent, or $\alpha=0.05$. All models were run including the presence or absence of fire scorch as a fixed-effect covariate. In some cases, the model was over-parameterized as indicated by a non-positive Hessian matrix; therefore, a simpler model was fit excluding the fire scorch covariate and the nested random-effect of stand number within management regime. Pairwise comparisons were analyzed using Fisher’s Least Significant Difference (LSD) method, with an experimentwise rate of Type I error occurrence equal to 5 percent, or $\alpha=0.05$. The statistical package used for the analysis was SPSS 15.0 (SPSS, Inc. 2007). An example of the SPSS mixed-effects linear model syntax is shown in Figure 9 on the next page.

\section{Conflicting Statistical Results}

Multiple statistical analyses require multiple statistical evaluations. The statistical model used a Type III test of fixed-effects followed by Fisher's Least Significant Different (LSD) multiple pairwise comparison. The LSD pairwise comparison is secondary to the Type III test of fixed-effects. Therefore, when interpreting the results, the F-statistic and corresponding p-value for the Type III test should be evaluated before considering the pairwise differences noted by the LSD analysis. If the analysis failed to 
reject the null hypothesis of the Type III test, the results of the LSD comparison should be used with caution, even if they are significantly different.

Figure 9: Sample SPSS Syntax for Mixed-effects Linear Model and Normality Plots

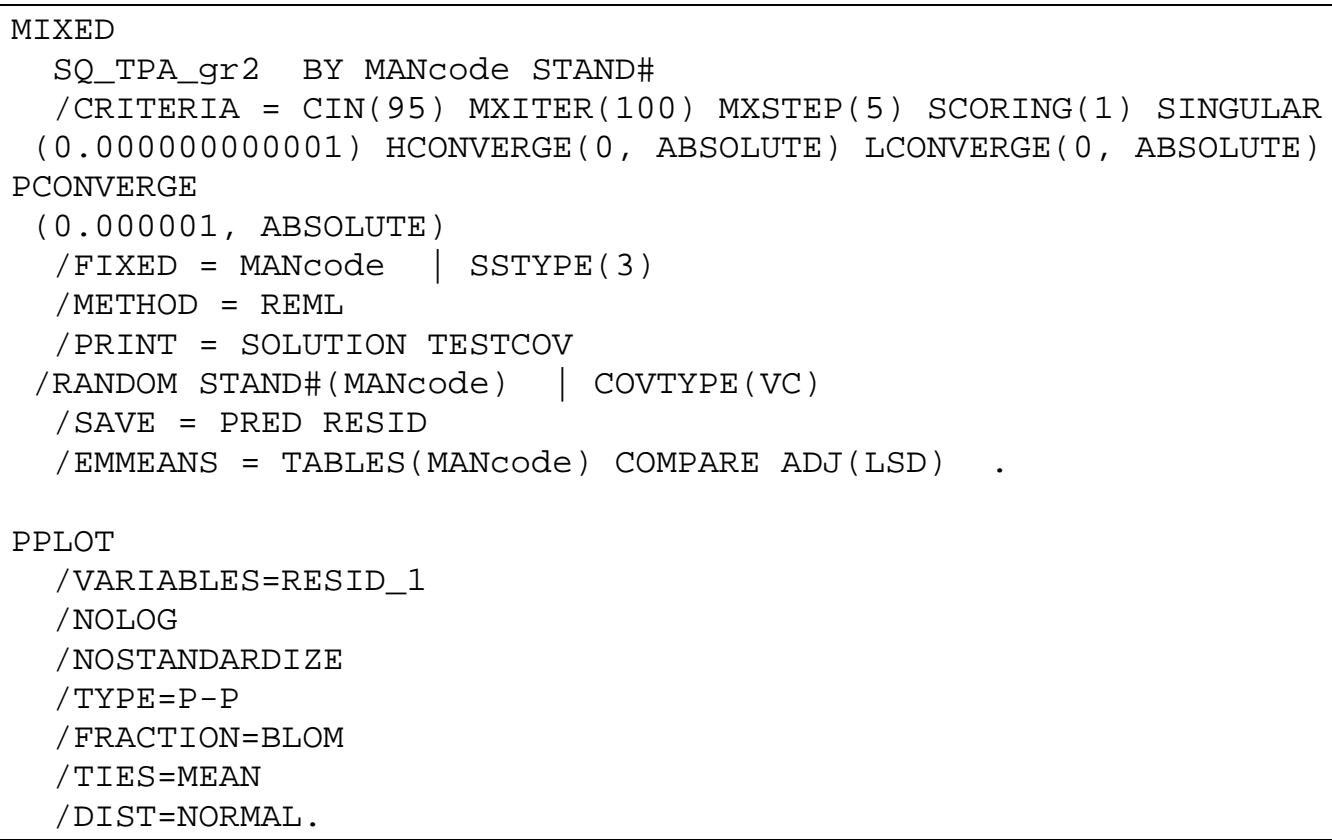

The late successional forest classification objective was a comparison of means. A paired-sample t-test analyzed the difference between two sample means of quadratic mean diameter. For instances where the assumption of normally distributed data was not satisfied, the results should be treated with caution. These models were completed using SPSS 15.0. Histograms and scatterplots were also created using SPSS 15.0 graph builder. An example of the SPSS syntax for t-test and residual analysis is presented in Figure 10 on the following page. 
Figure 10: Sample SPSS Syntax for Paired-sample t-Test, Histogram, and Scatterplot

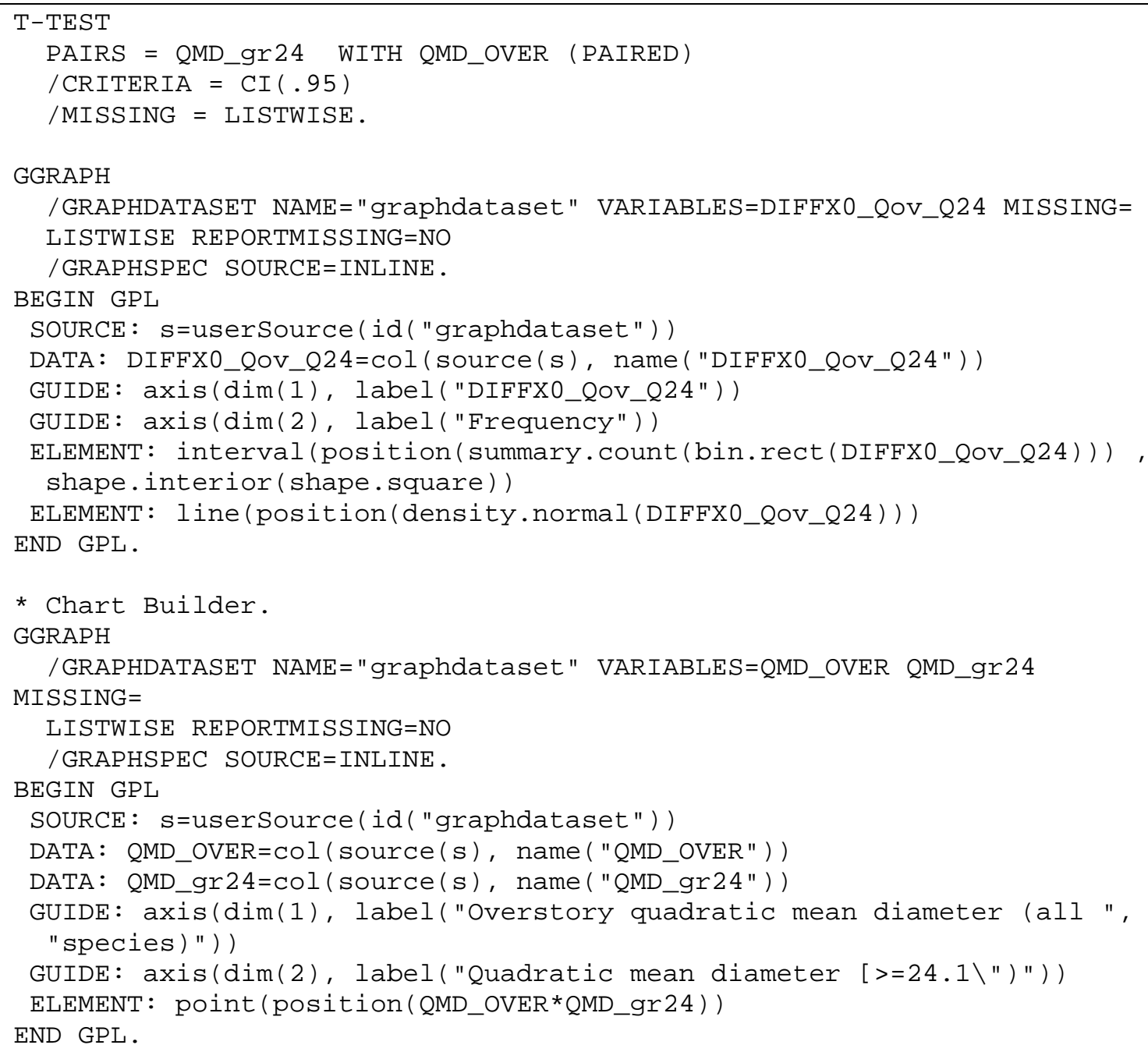




\section{RESULTS}

Density and structure measures were calculated for all stems greater than 2.0 inches in diameter, unless otherwise denoted. From this point forward, basal area (BA) refers to basal area per acre, rather than the basal area of a single stem. The fire scorch covariate was an insignificant factor in all cases during the first iteration of analyses. Therefore, the results presented in this section were completed in the second iteration excluding this covariate. Fisher’s Least Significant Difference (LSD) pairwise comparison analyzed differences between management regimes. Table 4 on page 98 shows an overview of forest component characteristics and values that begin to describe the forest and the various components that make up the whole. Due to the number of forest components tested, the descriptive statistics for Objectives 1-3 are presented at the end of this chapter in Tables 20-27 on pages 141-149. Stand tables and summaries for individual inventory stands are presented in Appendix D.

A reference regime is designated for each analysis in Objectives 1-3. This reference regime is similar to a control group for the statistical analysis, in that all other management regimes are compared to the reference. For example, the reference for Objective Three- Large Stem Density is Park/No Cut regime. Each of the four other harvest origin regimes (Truncated, Large Tree Management, Percent Removal, Unknown) are compared to the reference individually. Therefore, a notation of significant difference for Large Tree Management is interpreted as only being significantly different from Park/No Cut. Inferences made between two management regimes that do not include the reference are not valid. 
In the interest of brevity, this chapter will discuss the results in terms the Natural or Park/No Cut regimes as a reference. Results for Objectives 1-3 where other regimes are used as a reference are found in Appendix C. The same interpretation applies to the tables in Appendix C, where all other regimes are compared to the reference on an individual basis.

The research question that began this study was "is forest management making a difference in the forest?” To aid the reader in identifying some of these differences in forest composition and density, I have included a graphical and tabular comparison of six stands, each representing their associated management regime. Refer to Figure 11 (page 99) for a comparison of stand charts and Table 5 (page 100) for a stand table comparison of the representative stands.

These stand tables and charts begin to show the differences between the various management regimes and how the associated silviculture affects the forest components based on which species and diameter are actively managed. Notice the resemblance of the Truncated stand graph to an inverse J-shaped curve (e.g. exponential decay function) as produced by the BDq method. Also note the bimodal distribution of the Natural regime with the largest stocking of stems greater than 41.0 inches. The Park/No Cut and Large Tree Management regimes have fairly uniform distributions across the diameter range, however the species composition and stocking levels vary. Finally, note the similarities between the Truncated and Percent Removal regimes in density, as well as the contrast in species composition. The following three research objectives delve into whether all of these similarities and differences are statistically significant. 
Table 4: General Component Data Summary by Management Regime

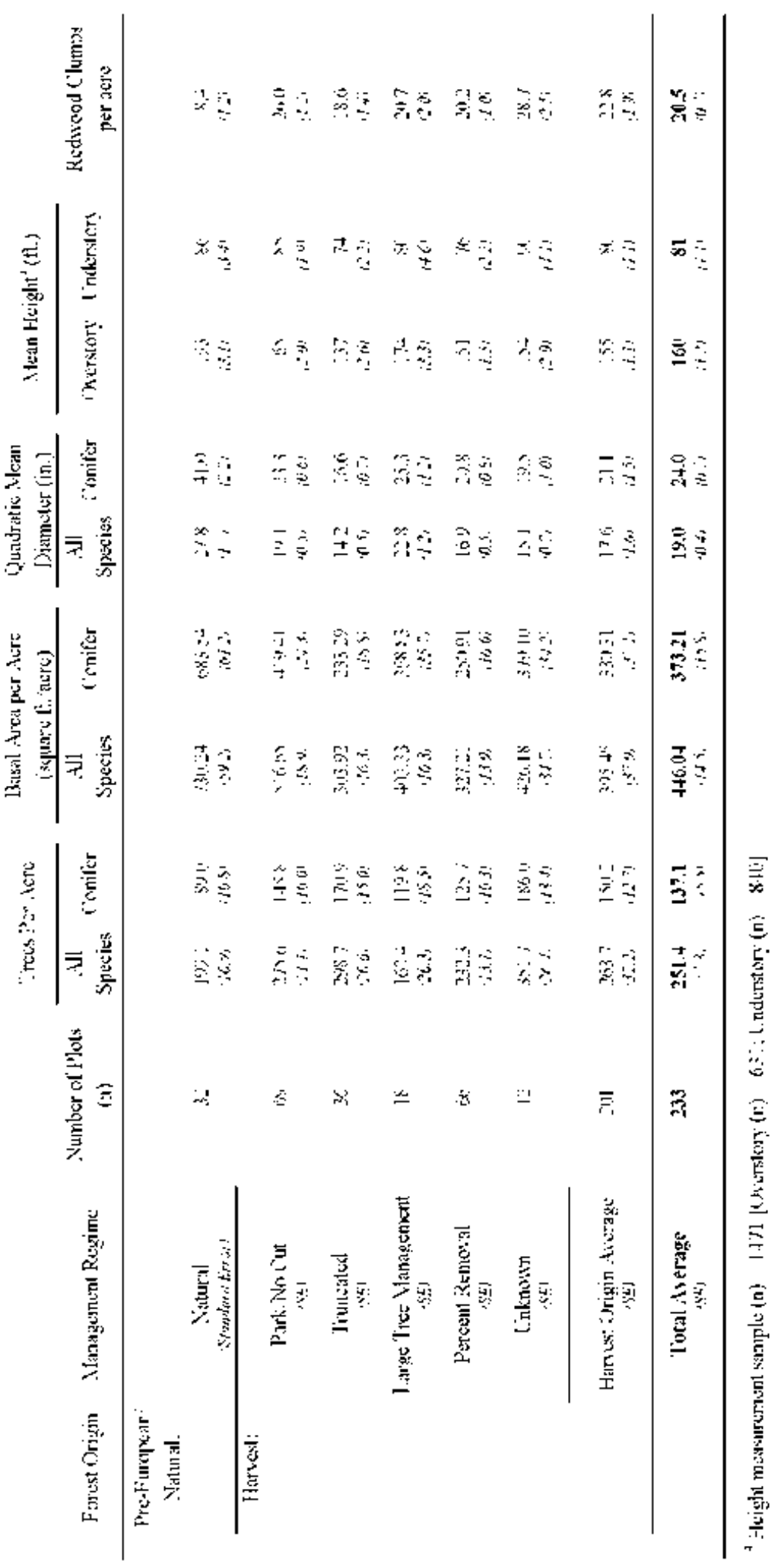


Figure 11: Comparison of Six Representative Stand Charts
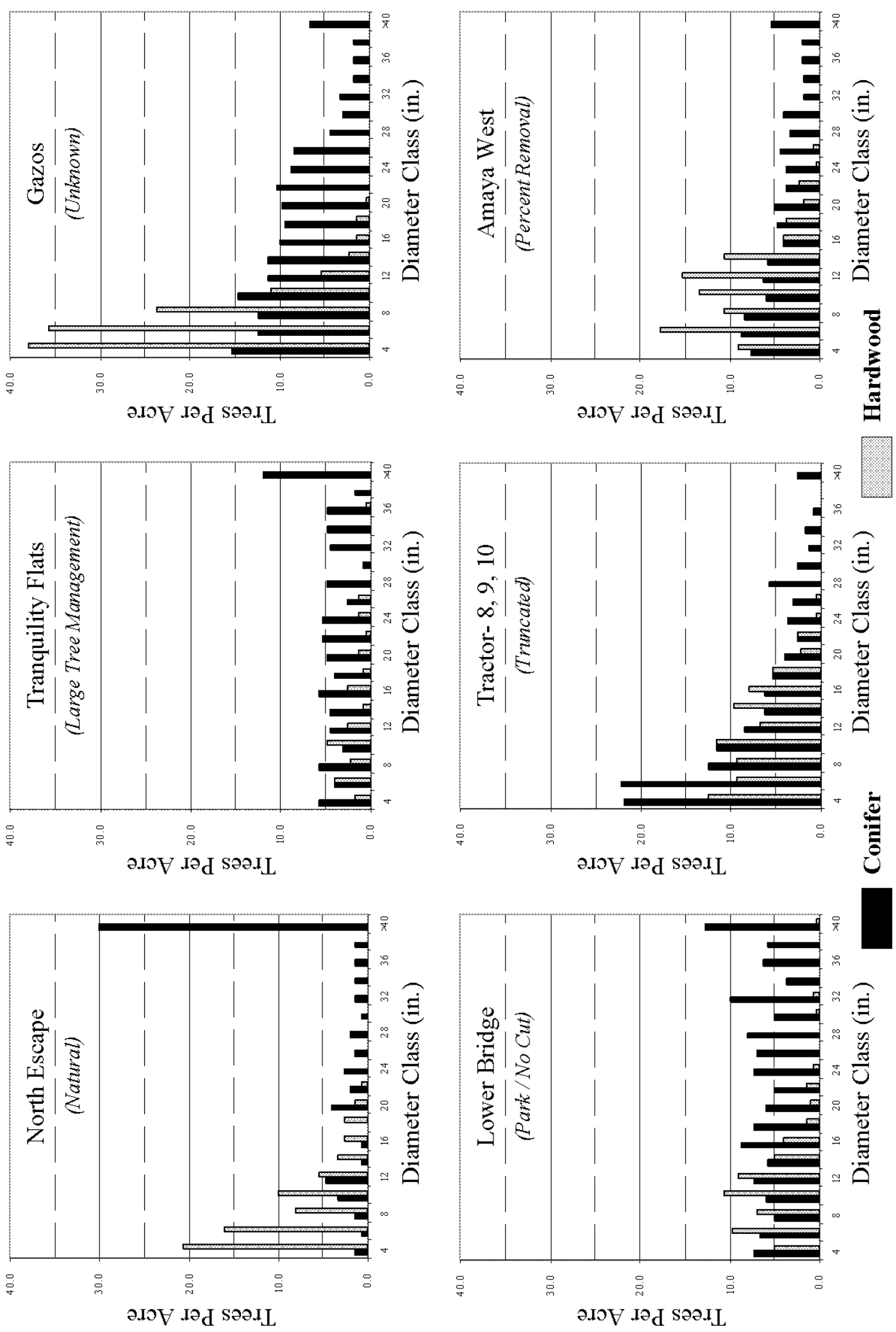
Table 5: Stand Table Data Comparison of Six Representative Stands

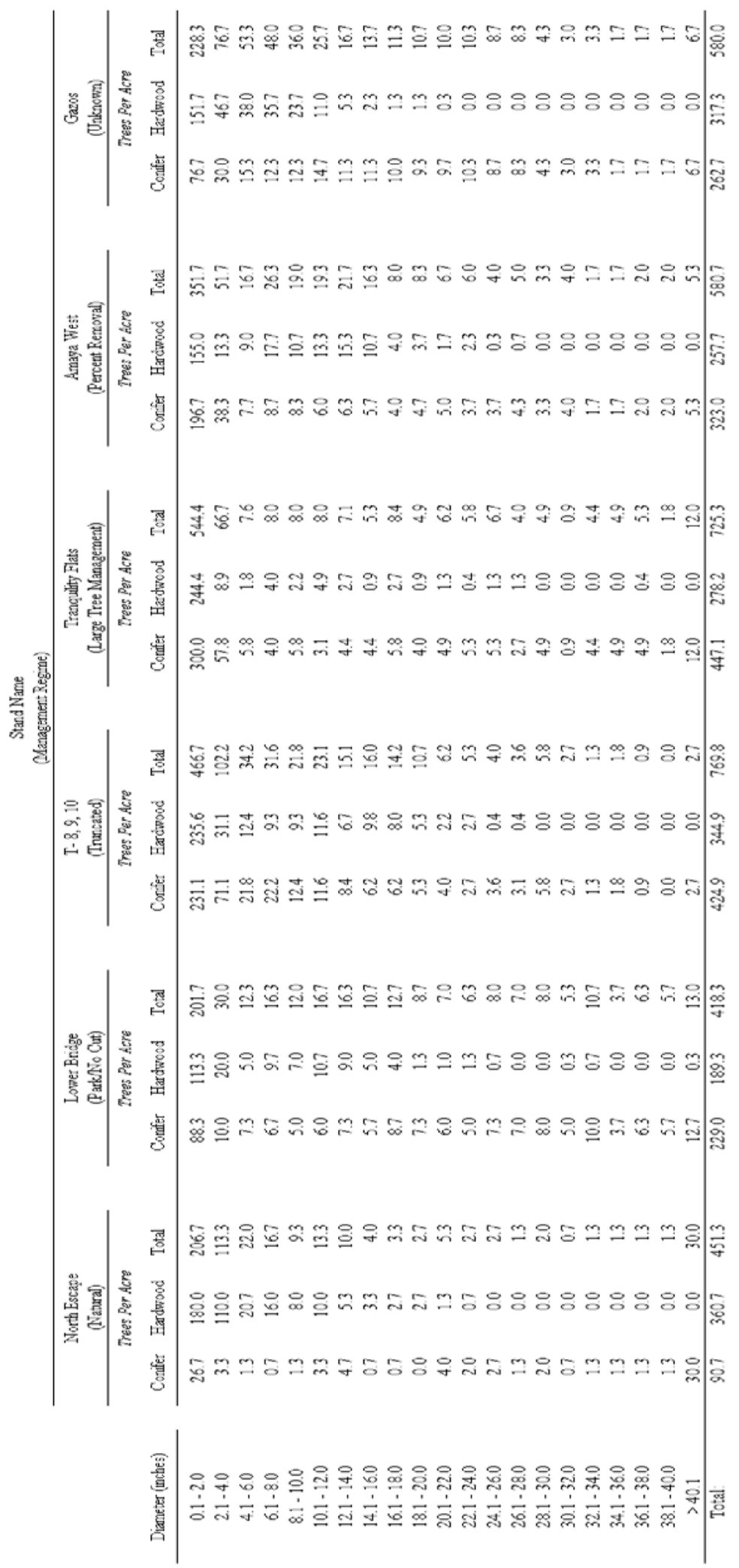




\section{Objective One- General Forest Components}

The plot analysis for natural and harvest origin stands was completed for general forest components. The Natural management regime was the reference.

All harvest origin regimes differed significantly from the Natural regime in terms of BA of all species (p-value $<0.001$ ), BA of all overstory trees (p-value $<0.001$ ), BA of conifer trees (p-value < 0.001), QMD of conifers (p-value $<0.001$ ), and QMD of overstory trees (p-value $<0.001)$. The BA of all understory trees was significant with a p-value of 0.018 , but there were no management regimes identified as significantly different from Natural per Fisher’s LSD. The Park/No Cut regime was significantly different in terms of TPA of overstory trees (p-value $=0.003)$. The Unknown management regime was significantly different in terms of TPA of understory trees $(\mathrm{p}$-value $=0.017)$. Two regimes, Truncated and Percent Removal, were significantly different in terms of the QMD of understory trees ( $\mathrm{p}$-value $=0.001$ ). The Park/No Cut, Truncated, and Unknown regimes were significantly different in terms of TPA of all trees $(\mathrm{p}$-value $=0.006)$ and TPA of all conifers $(\mathrm{p}$-value $=0.011)$. Finally, all harvest origin regimes, except Large Tree Management, were significantly different from the Natural regime in terms of QMD of all species ( $\mathrm{p}$-value $<0.001)$. The complete results for this analysis are shown in Table 6 on the following page. 
Table 6: General Forest Component Comparison Among Forest Origins

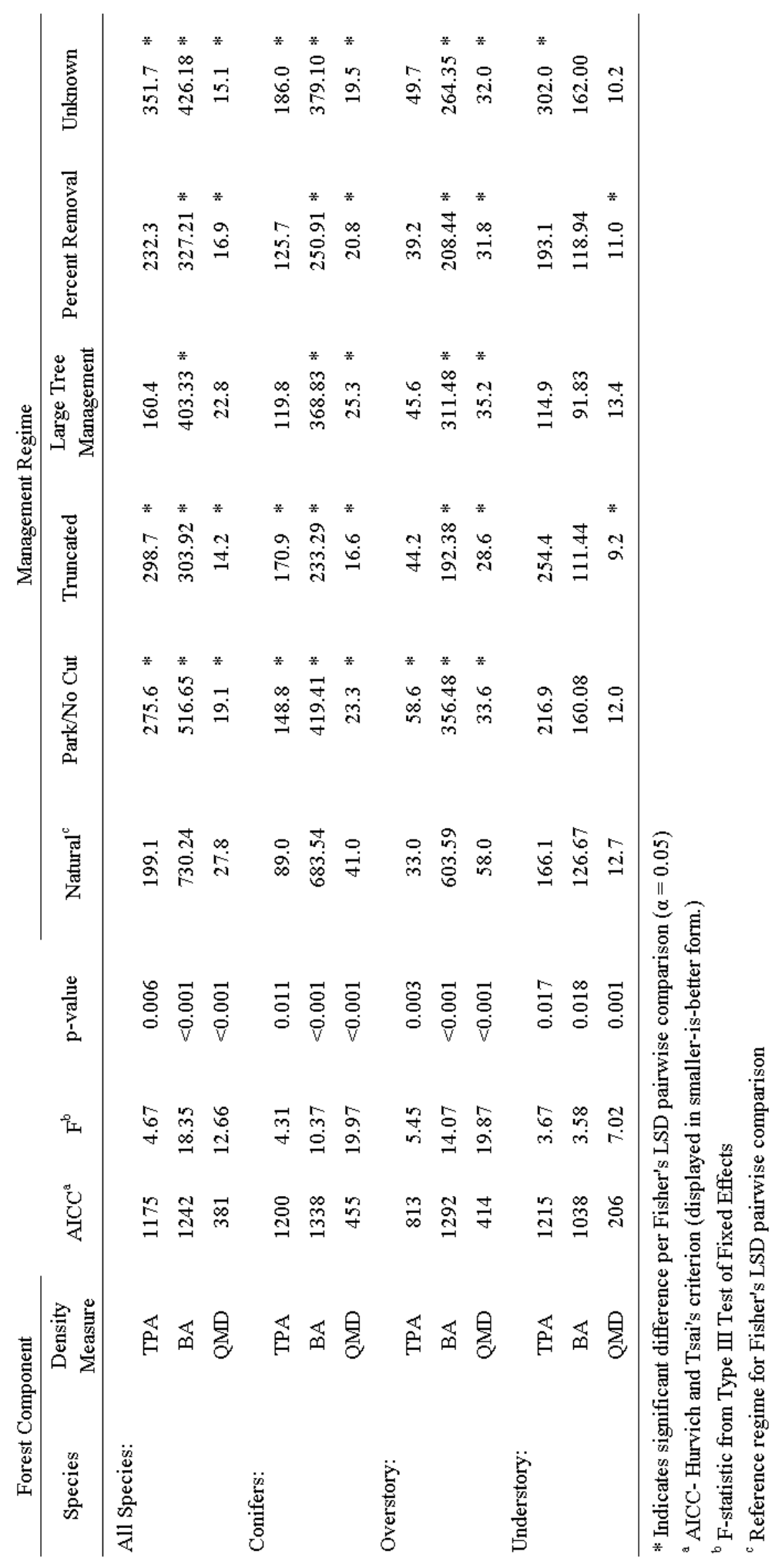


The same 12 general forest components were retested using the same model and Fisher's LSD. The Natural management regime data were filtered, or removed from the dataset, to conduct a comparison between the Harvest origin regimes only. The reference for this model was the Park/No Cut regime, since this regime represents unharvested second growth forest structure. No other alterations were made.

In two cases, QMD of overstory trees and TPA of conifer trees, the model failed to reject the null hypothesis with p-values equal to 0.344 and 0.119 , respectively. There is no significant difference in these components beyond the difference in management regime. All results for the second iteration are presented in Table 7 on the following page. 
Table 7: General Forest Component Comparison Among Harvest Origin Plots

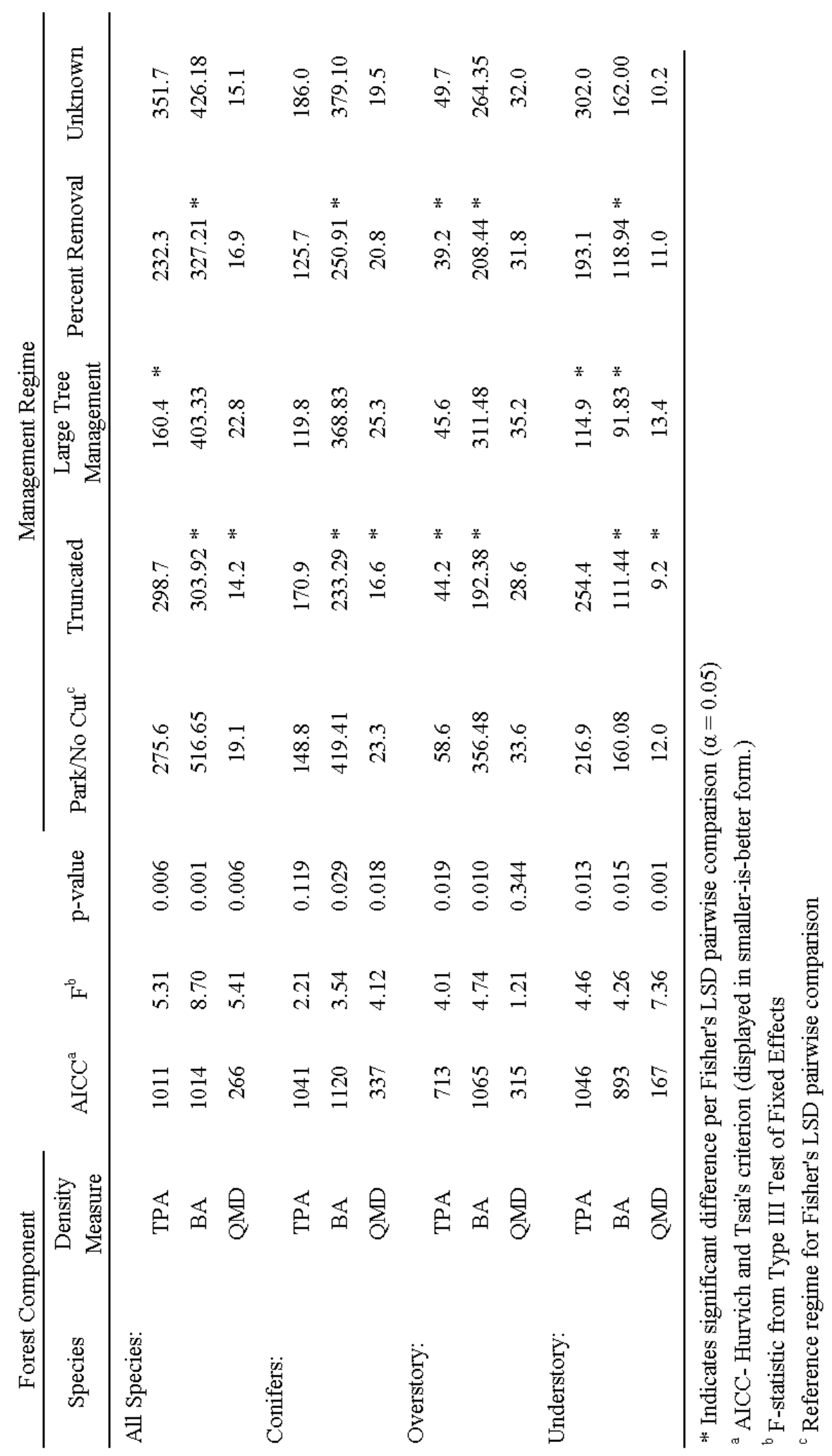


Truncated and Percent Removal regimes were significantly different from the Park/No Cut regime in terms of BA of all species (p-value $=0.001)$, BA of overstory trees $(\mathrm{p}$-value $=0.010)$, BA of conifer trees $(\mathrm{p}$-value $=0.029)$, and TPA of overstory trees $(\mathrm{p}$-value $=0.019)$. Those two regimes, in addition to Large Tree Management, were significantly different in terms of BA of understory trees (p-value $=0.015)$. The Truncated regime was significantly different in terms of QMD of all trees (p-value $=0.006), \mathrm{QMD}$ of understory trees (p-value $=0.001)$, and QMD of conifers (p-value $=0.018)$. The Large Tree Management regime differed significantly in terms of TPA of all species $(p$-value $=0.006)$ and TPA of understory trees $(p$-value $=0.013)$. Refer to Appendix C, Tables C-1 and C-2, for results of all pairwise comparisons for Objective One-General Forest Components.

\section{Objective Two- Small Stem Density and Distribution}

Various groupings of small stem were selected from literature, regulation and commonly used diameter classes. Refer to Objective 2- Small Stem Density and Distribution section on page 20 for citations associated with groupings. Per previous results from Objective One analysis which included the Natural regime, the Natural regime was omitted from the dataset for subsequent analyses. The Natural regime was determined to be part of a separate statistical population. The reference management regime for this objective is Park/No cut. 


\section{$\underline{\text { 6-inch Diameter Classes }}$}

The analysis of distribution of small stem density was completed for stem diameters less than 24.1 inches DBH. Components of TPA and BA for the diameter classes (e.g.: 0.1-6.0 in., 6.1-12.0 in.) were calculated for the four composition groups. QMD components were omitted given the narrow diameter ranges.

The Truncated regime was significantly different in terms of BA of all species less than or equal to 6-inches DBH (p-values $=0.032$ ). Large Tree Management was significantly different in terms of BA of all species 6.1-12.0 inches DBH $(\mathrm{p}$-value $=0.013)$. Large Tree Management and Unknown regimes were significantly different for all species 6.1-12.0 inches DBH in terms of TPA (p-value $=0.005$ ) and only Large Tree Management was significantly different in terms of BA (p-value $=0.013$ ). Redwood trees 12.1-18.0 inches had significantly different BA (p-value $=0.015)$ and TPA (p-value $=0.020$ ) in the Percent Removal regime. All conifers 18.1-24.0 inches had significantly different BA (p-value $=0.004)$ and TPA $(\mathrm{p}$-value $=0.005)$ under the Unknown management regime. The Unknown regime was also significantly different for BA $(p$-value $=0.027)$ and TPA $(p$-value $=0.032)$ of redwoods 18.1-24.0 inches.

Truncated and Large Tree Management regimes were significantly different in terms of BA $(p-v a l u e=0.041)$ and TPA $(p-v a l u e=0.046)$ for all species 18.1-24.0 inches DBH. The Truncated and Unknown regimes were significantly different in terms of TPA of all conifers 6.1-12.0 inches DBH (p-value = 0.008). Truncated, Large Tree Management, and Unknown regimes were significantly different in terms of BA of conifers 6.1-12.0 inches DBH $(\mathrm{p}$-value $=0.016)$. Large Tree Management, Percent Removal, and 
Unknown regimes differ significantly in terms of BA $(p-v a l u e=0.002)$ and TPA $(\mathrm{p}$-value $=0.003)$ of conifers 12.1-18.0 inches DBH.

Two components were significant from the F-test, yet showed no significant differences between management regimes from the LSD pairwise comparison. These two components were BA of hardwoods 0.1-6.0 inches DBH (p-value $=0.036)$ and TPA of redwoods 6.1-12.0 inches DBH (p-value = 0.040). Fisher's LSD identified eight forest components as significantly different, but the respective models failed to reject the null hypothesis of the F-test. The Truncated regime had four components with conflicting results: TPA of all species 0.1-6.0 inches DBH (p-value $=0.117$ ), TPA and BA of conifers 0.1-6.0 inches DBH (p-values $=0.054$ and 0.073, respectively), and TPA of redwoods 0.1-6.0 inches DBH ( $\mathrm{p}$-value $=0.104)$. Large Tree Management also had four components with conflicting results: TPA and BA of all species 12.1-18.0 inches DBH (p-values $=0.070$ and 0.058 , respectively), as well as TPA and BA of hardwoods 6.1-12.0 inches DBH (p-values $=0.060$ and 0.084, respectively). Because the F-test failed to reject the null hypothesis, results from the LSD comparison are inconclusive.

Refer to Table 8 (pages 108-9) for a summary of the small-stem density distribution results. The forest components that failed to reject the null hypothesis are included in Table 8 and show no significant difference beyond the classified management regime as interpreted by the F-test and p-value. The TPA distribution by management regime is depicted graphically in Figure 12 on page 110. All pairwise comparisons are presented in Table C-3 in Appendix C. 
Table 8: Small Stem Density Distribution by 6-inch Classes (24.0” maximum)

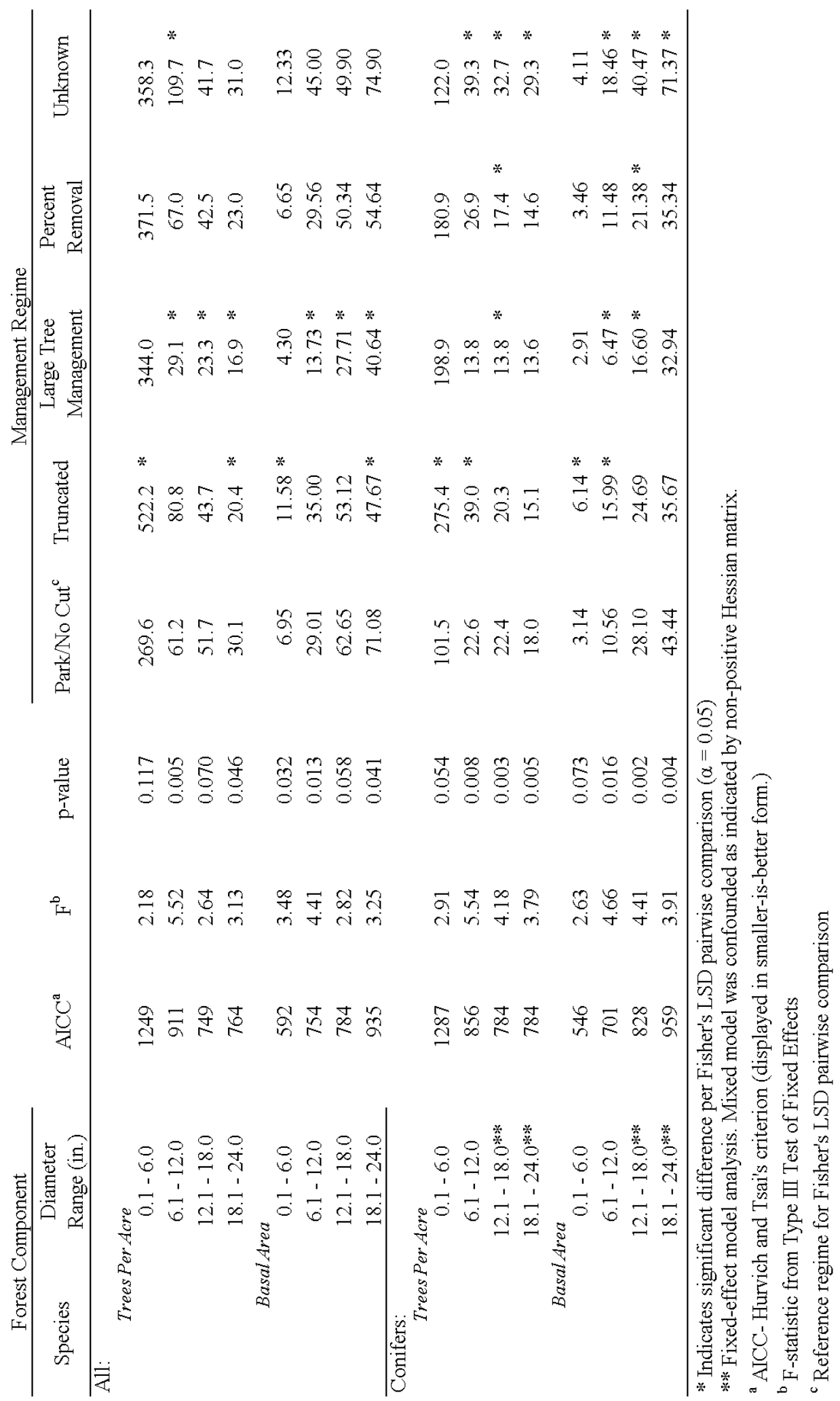


Table 8: Small Stem Density Distribution by 6-inch Classes (continued)

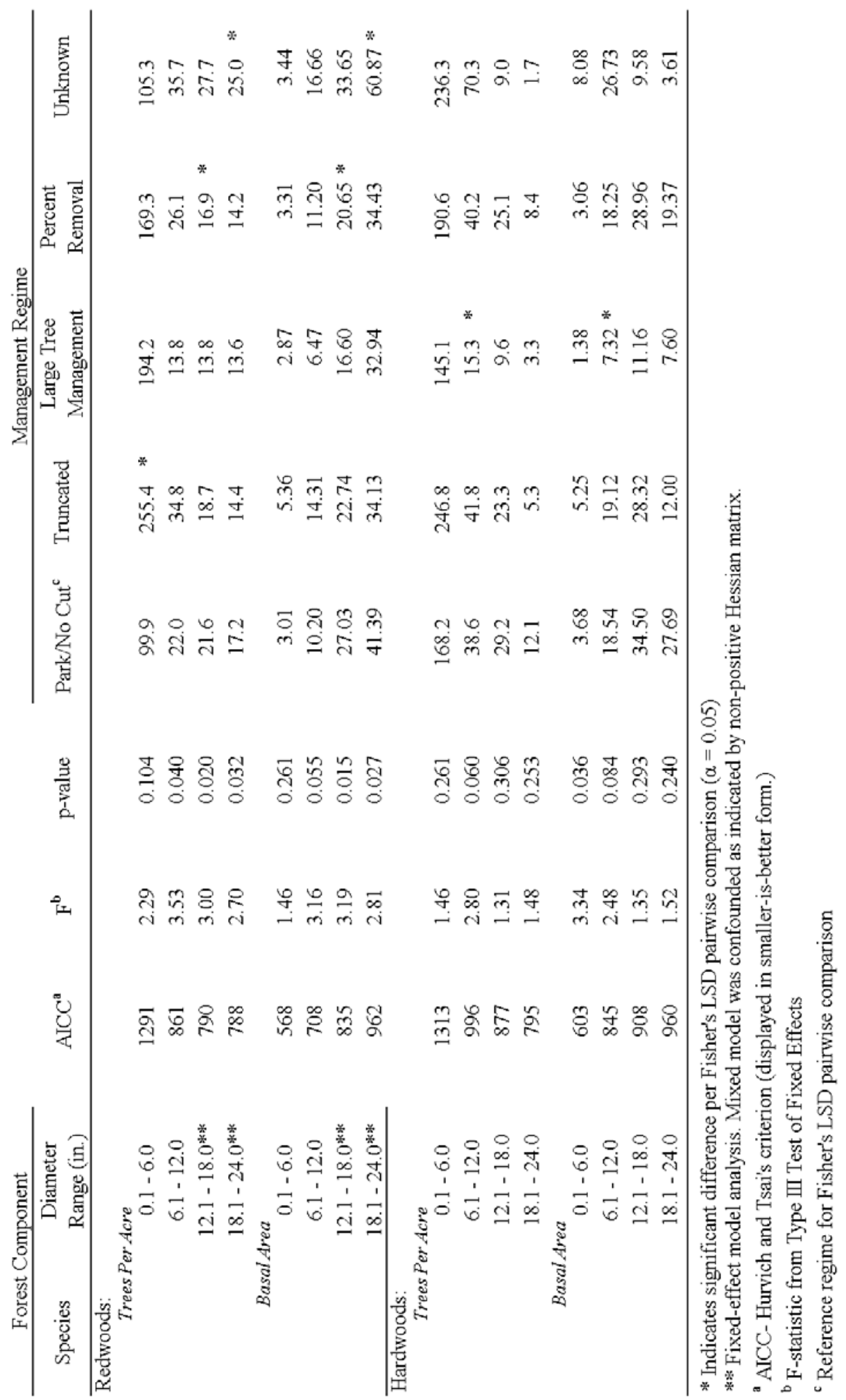


Figure 12: Stand Graph of 6-inch Diameter Classes by Management Regime

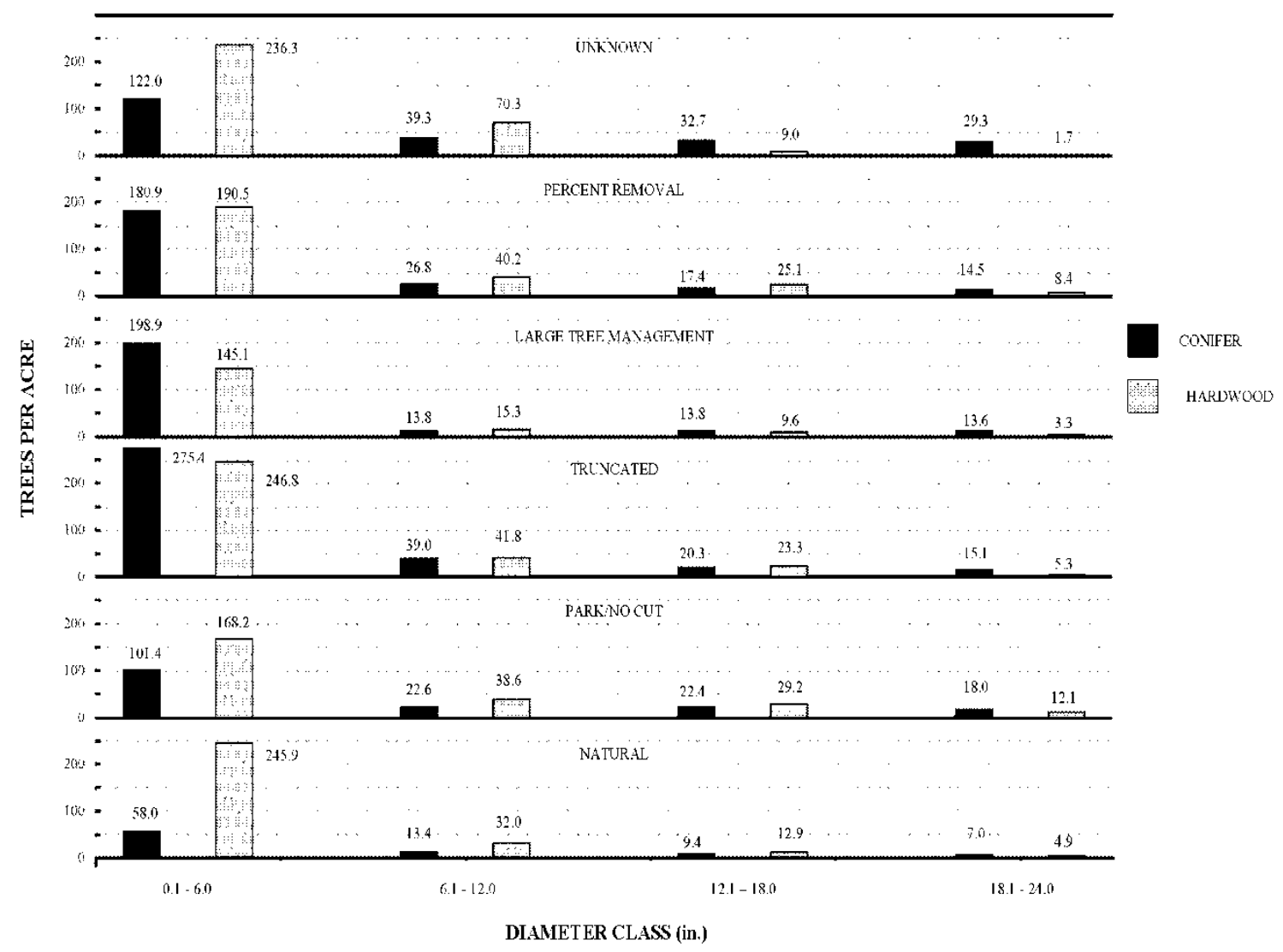

Special Harvesting Methods for Santa Cruz County (14 CCR § 926.25)

The Forest Practice Rules have designated three diameter classes in association with the “60/50 Rule.” The small stem objective selected the two smallest groups, 2.0-14.0 inches and 14.1-18.0 inches DBH. Forest components were developed around these commonly used diameter classes and compared by the mixed-effects model.

The analysis of density distributions associated with the "60/50 Rule” showed no significant difference beyond the management regime for 16 out of 24 components of TPA, BA, and QMD. The eight remaining forest components that rejected the null hypothesis are discussed. 
Table 9: “60/50 Rule” Small Stem Density Distribution (18.0” maximum)

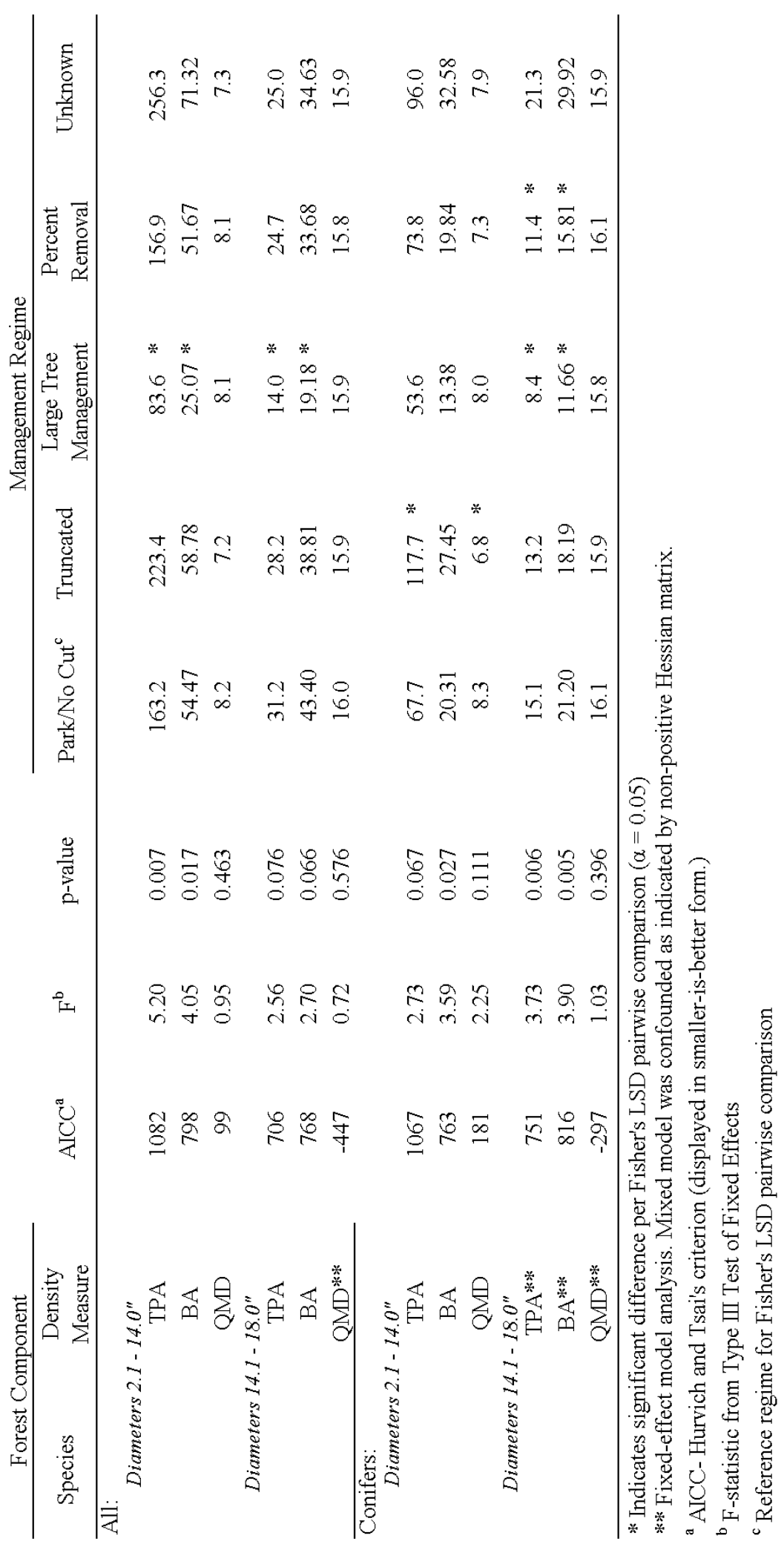


Table 9: “60/50 Rule” Small Stem Density Distribution (continued)

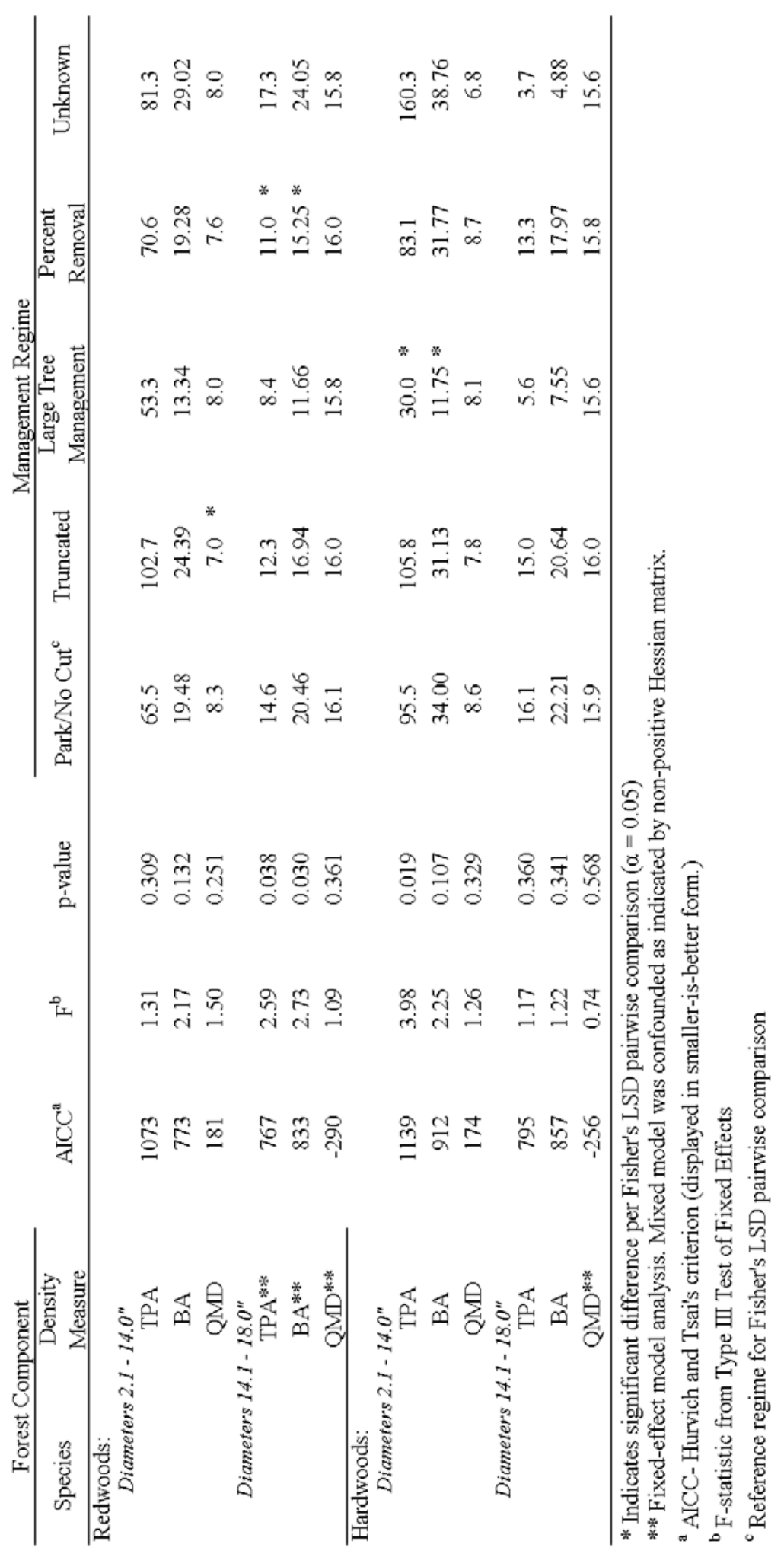


Large Tree Management was significantly different in terms of BA of all species 2.1-14.0 inches DBH (p-value = 0.017), TPA of all species 2.1-14.0 inches DBH $(\mathrm{p}$-value $=0.007)$, and TPA of hardwoods 2.1-14.0 inches DBH $(\mathrm{p}$-value $=0.019)$. TPA and BA of redwoods 14.1-18.0 inches DBH in the Percent Removal regime were significantly different with p-values of 0.038 and 0.030 , respectively. The Truncated and Percent Removal regimes were significantly different in terms of TPA ( $p$-value $=0.006$ ) and BA (p-value $=0.005)$ of conifers 14.1-18.0 inches DBH. Finally, there was no significant different between management regimes in terms of BA of conifers 2.1-14.0 inches DBH (p-value $=0.027)$ according to the LSD pairwise comparison.

Six forest components failed to reject the F-test null hypothesis, but management regimes were still identified as significantly different by the LSD comparison. The Truncated regime was significantly different per LSD for TPA and QMD of conifers 2.1-14.0 inches DBH (p-values = 0.067 and 0.111, respectively) and QMD of redwoods 2.1-14.0 inches DBH (p-value $=0.251)$. Large Tree Management was significantly different per LSD for TPA and BA of all species 2.1-14.0 inches DBH (p-values $=0.076$ and 0.066, respectively) and BA of hardwoods 2.1-14.0 inches DBH (p-value $=0.107)$. These results are inconclusive since the F-test failed to reject the null hypothesis.

Refer to Table 9 (pages 111-12) for pertinent statistics and information, including forest components that failed to reject the null hypothesis. The components that failed to reject the null hypothesis show no significant difference beyond the classified management regime. All pairwise comparisons are presented in Table C-4 in Appendix C. 


\section{Type A Owl Habitat (14 CCR§ 895.1)}

The Type A Owl Habitat defined in the Rules specifies three diameter classes. This grouping tests the smallest of the three classes since the other classes consist of commercially merchantable timber. Therefore, only the density of this diameter range is analyzed rather than the distribution of the density across classes.

The analysis of “small” tree (2.1-18.0” DBH) density associated with Type A owl habitat, as defined by the Forest Practice Rules, showed no significant difference beyond management regime for 13 out of 24 components of TPA, BA, and QMD.

The small tree densities were grouped and analyzed by species for the given diameter class. The Truncated regime was significantly different in terms of QMD of small conifers ( $\mathrm{p}$-value $=0.025)$. Large Tree Management differed significantly in terms of BA of all small trees ( $\mathrm{p}$-value $=0.027)$, BA of small conifers ( $\mathrm{p}$-value $=0.025)$, TPA of all small trees $(\mathrm{p}$-value $=0.007)$, and TPA of small hardwoods $(\mathrm{p}$-value $=0.031)$. All other components tested failed to reject the null hypothesis at a significance level of 5\%, which implies no difference beyond the classified management regime.

Three components failed to reject the F-test null hypothesis and were identified by Fisher's LSD to be significantly different. The Truncated regime was significantly different per LSD comparison in terms of TPA of conifers (p-value $=0.080$ ) and QMD of redwoods $(\mathrm{p}$-value $=0.086)$. Large Tree Management was significantly different per LSD comparison in terms of BA of hardwoods (p-value $=0.211)$. Refer to Table 10 on page 115 for pertinent statistics and information. All pairwise comparisons are presented in Table C-5 in Appendix C. 
Table 10: Type A Owl Habitat Small Stem Density (18.0” maximum)

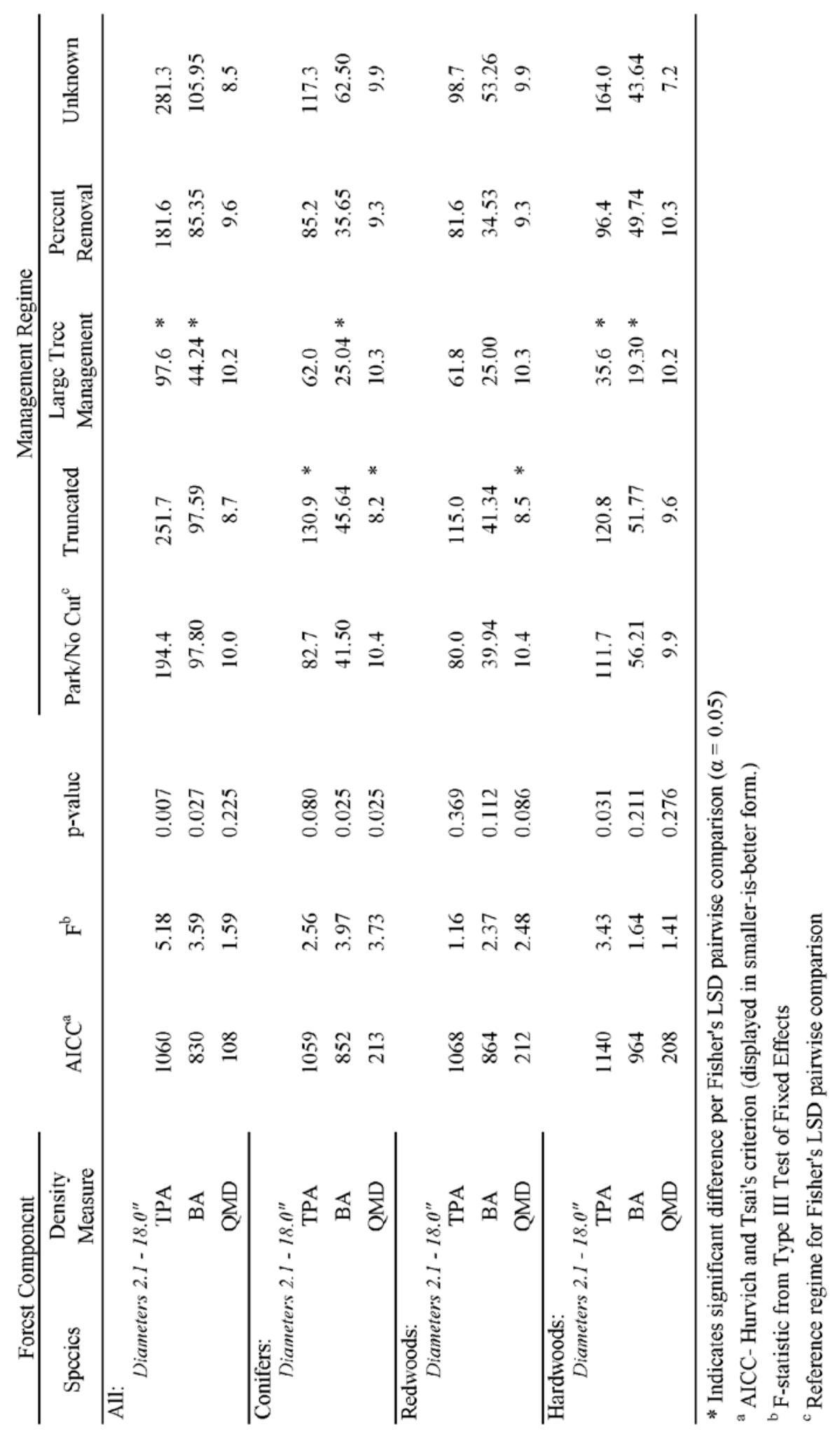




\section{Understory Canopy Layer (Parisi, Motroni and Robards 2007)}

The understory canopy layer presented in this analysis is associated with the protocol of late successional forest classification. The layer consists of suppressed and intermediate crown class trees. Whether these trees are truly suppressed remains to be seen, however this canopy layer receives little light from above because it is overtopped by the overstory canopy layer. The forest components analyzed represent the density of this layer, rather than the distribution of the understory density.

The analysis of the understory canopy layer showed no significant difference beyond the management regime for 7 out of 12 components of TPA, BA, and QMD. Understory forest components include stems greater than 2.0 inches DBH.

The Truncated regime differed significantly in terms of QMD of all understory trees $(\mathrm{p}$-value $=0.001)$. Large Tree Management was significantly different in terms of TPA of understory trees $(\mathrm{p}$-value $=0.013)$ and TPA of understory hardwoods $(\mathrm{p}$-value $=$ 0.042). Truncated and Percent Removal regimes were significantly different in terms of QMD of understory conifers (p-value $=0.009)$. Truncated and Unknown regimes differed significantly from in terms of QMD of understory hardwoods ( $\mathrm{p}$-value $=0.016$ ). Truncated, Large Tree Management and Percent Removal regimes differed significantly in terms of all understory BA (p-value $=0.015)$.

Three forest components were significantly different according to Fisher's LSD pairwise comparison, but failed to reject the F-test null hypothesis. The BA of understory conifers was significantly different for the Percent Removal regime (p-value $=0.071$ ). The Truncated regime was significantly different for QMD of redwoods (p-value = 0.069). Large Tree Management was significantly different for BA of hardwoods 
$(\mathrm{p}$-value $=0.147)$. Because the F-test failed to reject the null hypothesis, results from the LSD comparison are inconclusive. Refer to Table 11 on the next page for pertinent statistics and information, including forest components that failed to reject the hypothesis. Results from all pairwise comparisons are presented in Table C-6 in Appendix C. The components that failed to reject the null hypothesis specify no difference beyond management regime. 
Table 11: Understory Stem Density

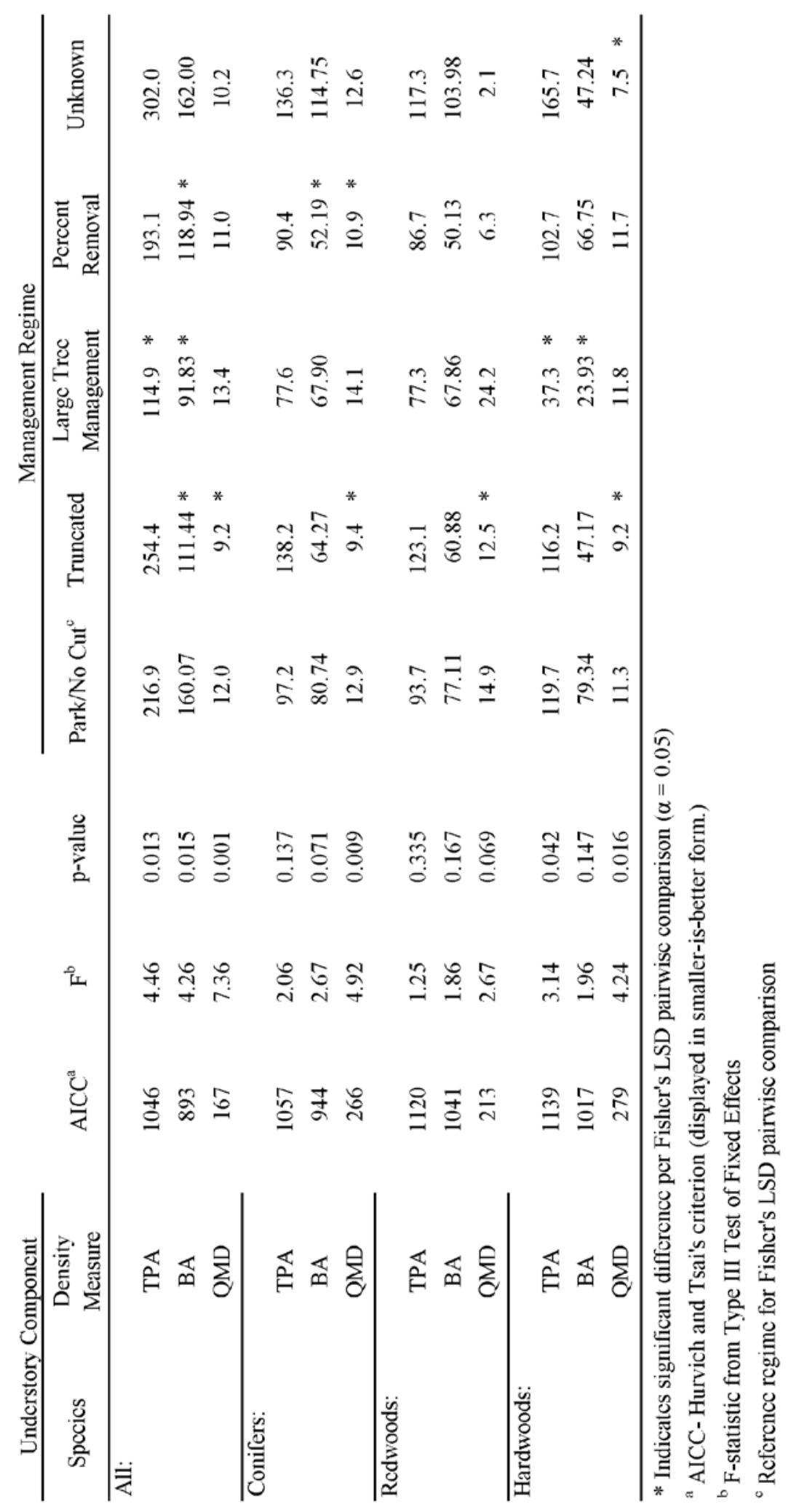




\section{Objective Three- Large Stem Density}

The groupings in this objective continue the format from the small stem objective. However, this objective mainly deals with commercially merchantable timber and large diameter hardwoods. These stems provide the bulk of timber volume and beneficial wildlife characteristics, respectively. The following analyses filtered the Natural management regime from the dataset per previous results. The reference regime is Park/No cut.

\section{$\underline{\text { Sawtimber Stand (Lindquist and Palley 1963) }}$}

The diameter classes used by Lindquist and Palley’s 1963 yield tables were applied to the data. This diameter range was titled "sawtimber” by Lindquist and Palley (1963). Only two composition groups were tested for this analysis since the yield tables are species specific. Therefore, the conifer group, including Douglas-fir, and hardwoods were omitted. All species grouping was included to add a frame of reference for the redwood stand data.

Six forest components of stand density and structure were tested for stems greater than 10.5 inches DBH. This diameter range is designated as sawtimber. Both QMD variables, all species and redwood sawtimber, failed to reject the null hypothesis, as determined by p-values 0.194 and 0.372 , respectively. The Truncated and Percent Removal regimes were significantly different in terms of BA of all sawtimber $(p$-value $=0.001)$ BA of redwood sawtimber $(p$-value $=0.011)$, and TPA of redwood sawtimber $(\mathrm{p}$-value $=0.009)$. Truncated, Large Tree Management, and Percent Removal regimes were significantly different in terms of TPA of all sawtimber ( $\mathrm{p}$-value $=0.002$ ). Refer to Table 12 on page 121 for a summary of pertinent statistics and information 
regarding all components analyzed and Table C-7 for all pairwise comparisons in Appendix C. The sawtimber forest components that failed to reject the null hypothesis indicate no difference beyond the classified management regime. 
Table 12: Large Stem Sawtimber Density (10.5” minimum)

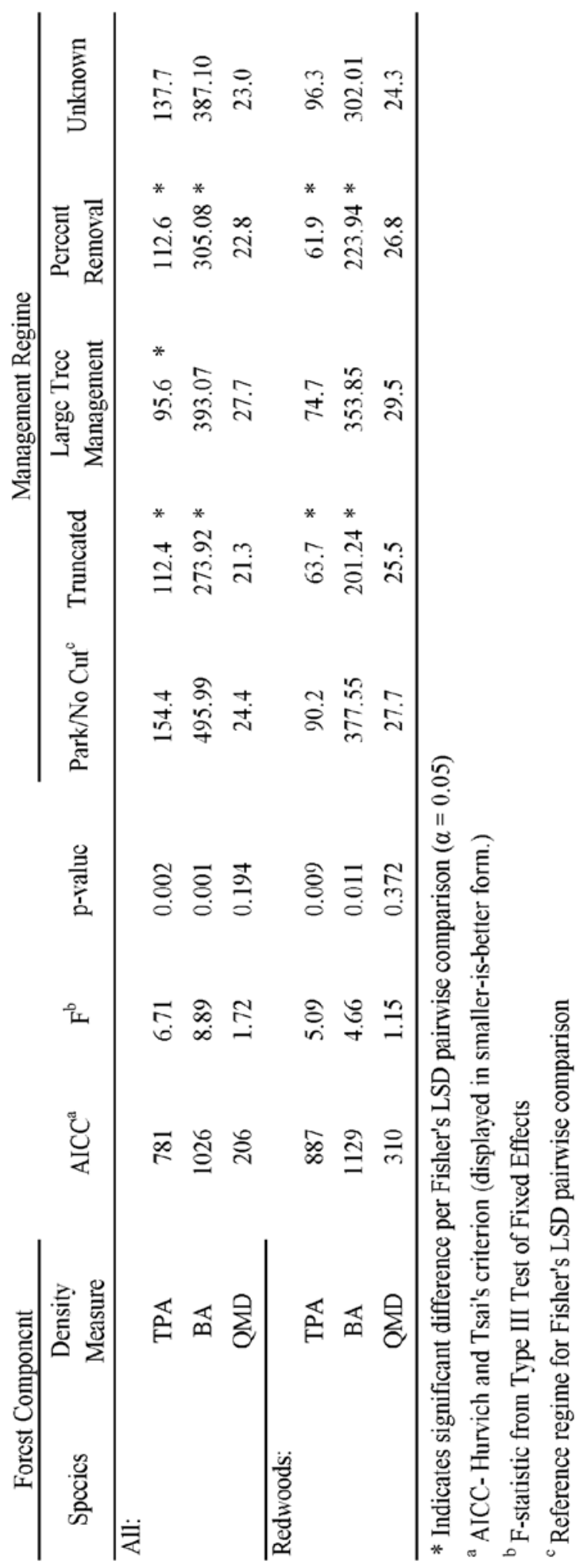




\section{Special Harvesting Methods for Santa Cruz County (14 CCR § 926.25)}

The densities of trees greater than 18.0 inches DBH were tested per the guidelines of the "60/50 Rule.” The Rules only regulate commercial timber species, but forest managers are concerned with all species in the stands. The composition groups for this analysis include conifers and hardwoods.

The analysis of large tree density associated with the "60/50 Rule” showed no significant differences above and beyond management regime for TPA and BA of hardwoods greater than 18.0 inches DBH (p-value $=0.252$ and 0.234 , respectively) and all QMD components for all species groups. Truncated and Percent Removal regimes were significantly different in terms of TPA of conifers greater than 18.0 inches DBH $(\mathrm{p}$-value $=0.007)$ and TPA of redwoods greater than 18.0 inches DBH $(\mathrm{p}$-value $=0.009)$. In terms of BA, these two regimes differed significantly for trees of all species greater than 18.0 inches DBH (p-value = 0.003), conifers greater than 18.0 inches DBH $(p$-value $=0.023)$, and redwoods greater than 18.0 inches DBH $(p$-value $=0.011)$. The Truncated, Percent Removal, and Large Tree Management regimes were significantly different for TPA of all trees greater than 18.0 inches DBH (p-value $<0.001$ ). The Unknown regime failed to reject the F-test null hypothesis, but was identified as significantly different per Fisher's LSD in terms of BA of hardwoods greater than 18.0 inches DBH (p-value $=0.234)$. This result is inconclusive since the analysis failed to reject the null hypothesis. Refer to Table 13 on the next page for pertinent statistics and information for all forest components tested under this grouping and Table C-8 for all pairwise comparisons in Appendix C. 
Table 13: “60/50 Rule” Large Stem Density (18.1” minimum)

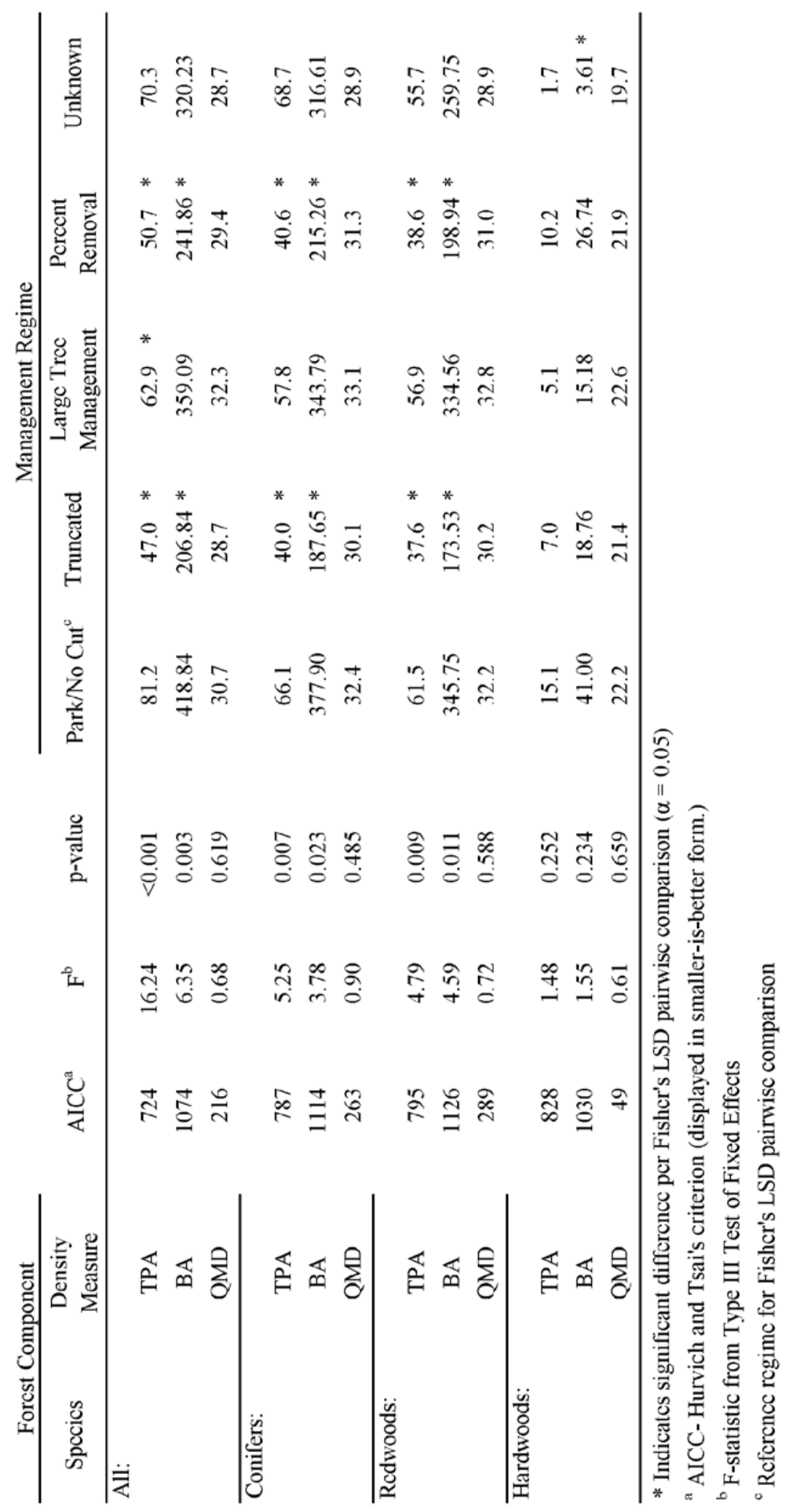




\section{Mature or Old Growth (Fox 1989)}

A diameter range of trees greater than 24.0 inches DBH was described as “mature” and/or "old growth (Fox 1989). The report also states that only 10 percent of the area classified needed to consist of "old growth" or natural origin structure. From the remote sensing techniques used in this study, it is uncertain if some areas classified as “old growth” were dominated by mature second growth. Therefore, this grouping should not be confused with LSF or the Natural management regime.

The analysis of “mature” trees failed to reject the null hypothesis for all QMD components. In addition, TPA and BA of mature hardwoods failed to reject the null hypothesis with p-values 0.383 and 0.366 respectively. Truncated and Percent Removal regimes were significantly different in terms of TPA of all mature trees ( $p$-value $=0.003$ ), TPA of mature conifers (p-value $=0.009)$, and TPA of mature redwoods $(\mathrm{p}$-value $=0.012)$. In terms of BA, these two regimes differed significantly for all mature trees $(p$-value $=0.017)$, all mature conifers $(p$-value $=0.028)$, and all mature redwoods $(\mathrm{p}$-value $=0.015)$. No other management regimes were identified as significantly different according to the LSD pairwise comparison. Refer to Table 14 on page 125 for pertinent statistics and information for a complete summary of this grouping analysis and Table C-9 for all pairwise comparison in Appendix C. 
Table 14: Mature Large Stem Density (24.1” minimum)

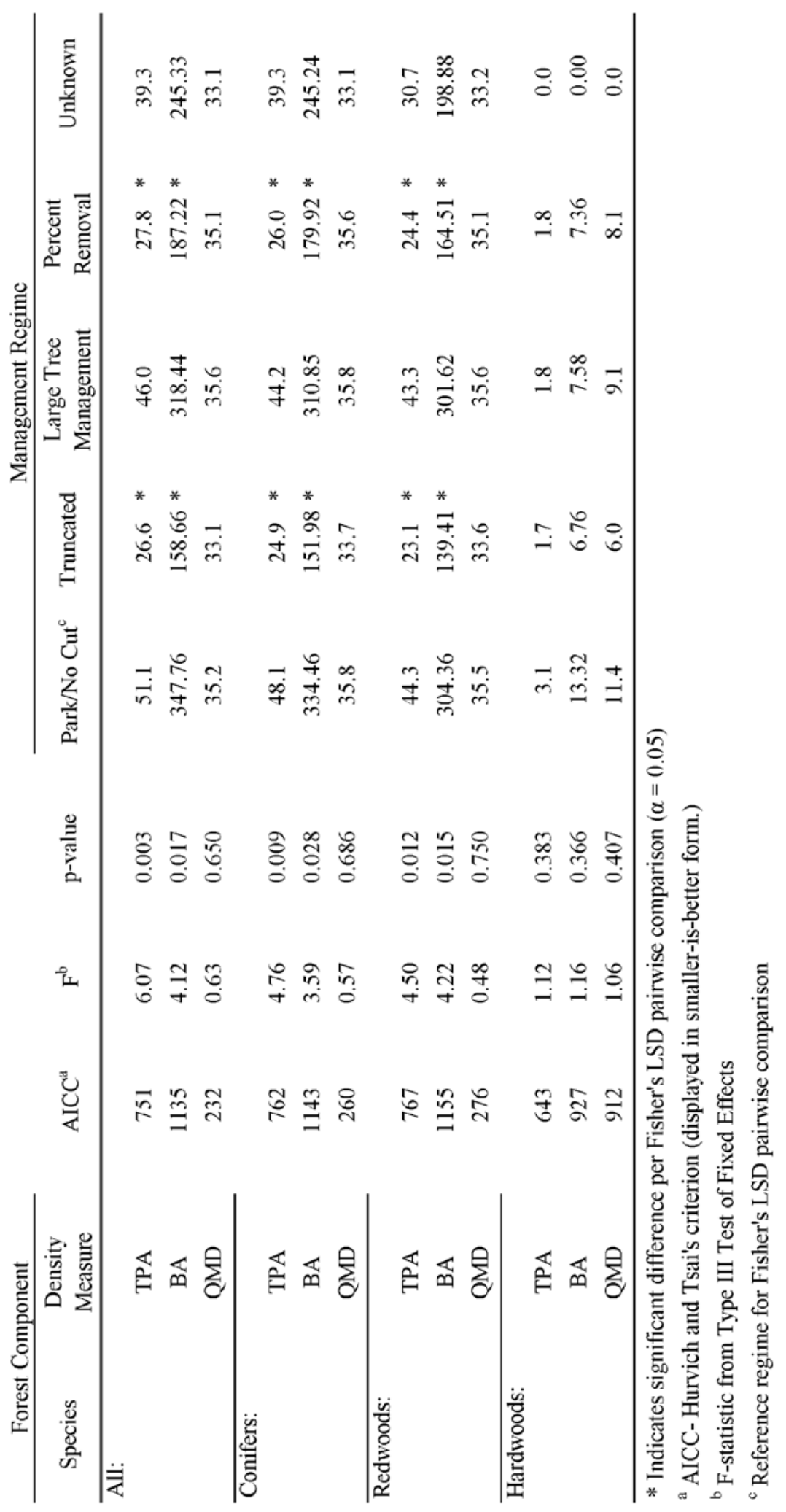




\section{Type A Owl Habitat (14 CCR§ 895.1)}

The groupings analyzed for the Type A Owl Habitat defined by the Rules are the only instance when more than one diameter class was analyzed for large stem density. These groups aid in classifying nesting, roosting, and foraging habitat for owls. Although the density distribution of trees greater than 18.0 inches $\mathrm{DBH}$ is presented, the analysis and conclusions will consider the two classes independently.

The “medium” tree (18.1-35.0 inches DBH) and "large” tree (>35.0 inches DBH) densities were tested for differences between management regimes using the LSD pairwise comparison method. For large tree hardwood components (>35.0” DBH), there were very few plots with occurrences of hardwoods of this size. The statistical model was over-paramatized; therefore, a fixed-effect model was fit instead of the mixed-effect model. Given the small sample size for these components, a simple model was fit to remedy the models' violations.

Twelve forest components of “medium” tree densities were analyzed for significant differences with half of the components failing to reject the null hypothesis indicating no significant difference beyond management regime. The Truncated and Percent Removal regimes were significantly different in terms of BA of medium stem diameters for all species ( $p$-value $=0.002)$, conifers ( $p$-value $=0.016)$, and redwoods $(p$-value $=0.040)$. The same regimes were significantly different in terms of TPA of medium conifers $(\mathrm{p}$-value $=0.014)$ and TPA of medium redwoods $(\mathrm{p}$-value $=0.045)$. Finally, the Truncated, Large Tree Management, and Percent Removal regimes were significantly different in terms of TPA of all species 18.1-35.0 inches DBH $(p$-value $=0.002)$. 
Twelve forest components of "large" tree densities were analyzed with the model of best fit with seven components failing to reject the null hypothesis showing no significant difference beyond management regime. The BA of all large trees (p-value $=0.052)$, all measures of hardwoods, and all QMD components failed to reject the null hypothesis. However, Fisher's LSD identified the Truncated and Percent Removal regimes significantly different in terms of BA of all species greater than 35.0 inches DBH despite the failure to reject the F-test null hypothesis; therefore, these results are inconclusive. Truncated and Percent Removal regimes were significantly different for this diameter range in terms of TPA of all large trees ( $\mathrm{p}$-value $=0.027)$, TPA of large conifers ( $\mathrm{p}$-value $=0.025)$, and TPA of large redwoods $(\mathrm{p}$-value $=0.019)$. In terms of BA, these two regimes also differed significantly in terms of large conifers $(\mathrm{p}$-value $=0.050)$ and large redwoods $(\mathrm{p}$-value $=0.032)$. No other regimes were significantly different when classified by this grouping per the LSD pairwise comparison method. Refer to Table 15 (pages 128-9) for pertinent statistics and information regarding all components tested for this grouping and Table C-10 for all pairwise comparisons in Appendix C. 
Table 15: Type A Owl Habitat Medium \& Large Stem Density (18.1” minimum)

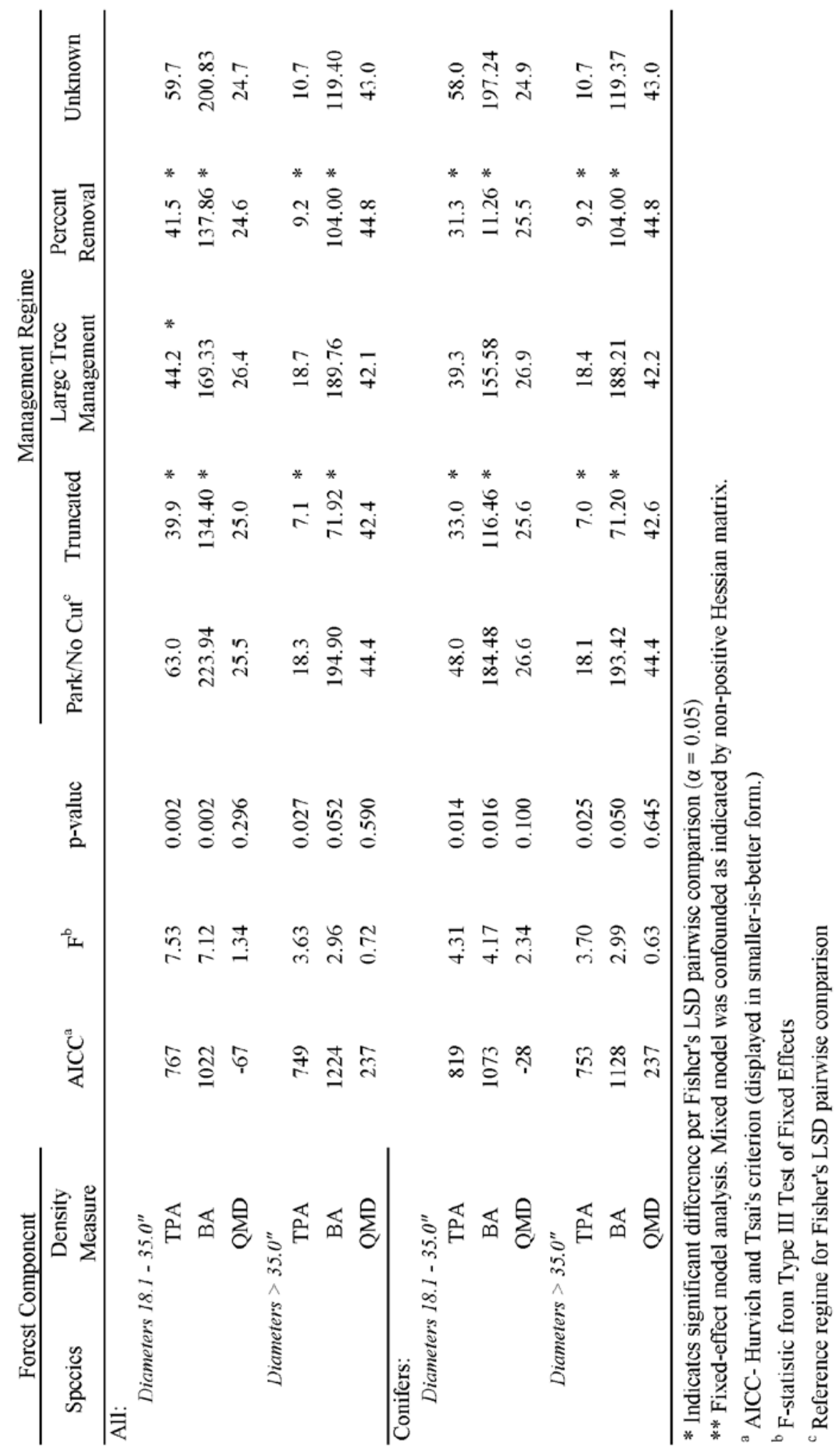


Table 15: Type A Owl Habitat Medium \& Large Stem Density (continued)

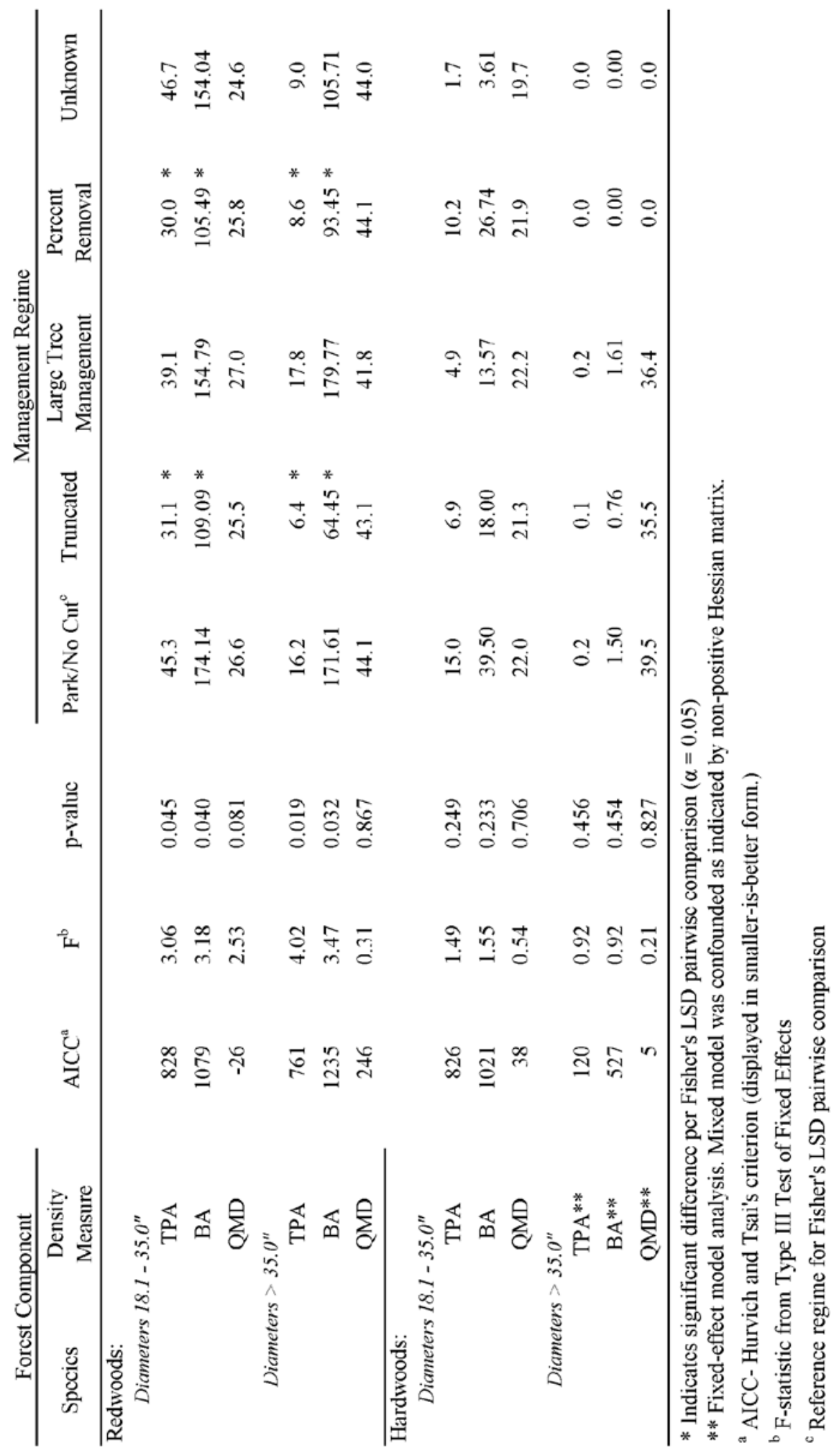




\section{Overstory Canopy Layer (Parisi, Motroni and Robards 2007)}

This classification of vertical structure is a combination of two crown classes and used in the classification of LSF stands. The analysis of overstory density in terms of differences in forest structure and components is presented in this objective. The LSF aspect of the overstory layer continues in Objective 4 and is assessed in the Discussion chapter.

The overstory canopy layer includes stems in the Dominant and Codominant crown classes. Components that failed to reject the null hypothesis were TPA of overstory conifers ( $p$-value $=0.056)$, TPA of overstory redwoods ( $p$-value $=0.118)$, TPA of overstory hardwoods (p-value $=0.271$ ), and BA of overstory hardwoods (p-value $=0.317)$. In addition, all QMD components failed to reject the null hypothesis, which indicated no significant difference beyond management regime. Truncated and Percent Removal regimes were both identified as significantly different per Fisher's LSD for TPA of overstory conifers and overstory redwoods, however, since the F-test failed to reject the null hypothesis these results are inconclusive.

Only two regimes differed significantly from the Park/No Cut regime. The Truncated and Percent Removal regimes were significantly different in terms of TPA of all overstory trees $(\mathrm{p}$-value $=0.019)$. Furthermore, the Truncated and Percent Removal regimes were also significantly different in terms of overstory BA for all overstory trees $(p$-value $=0.010)$, overstory conifers $(p$-value $=0.029)$, and overstory redwoods (p-value $=0.017)$. No other regimes were significantly different according to the LSD pairwise comparison. Refer to Table 16 (page 131) for pertinent statistics regarding the components of this grouping and Table C-11 for all pairwise comparisons in Appendix C. 
Table 16: Overstory Stem Density

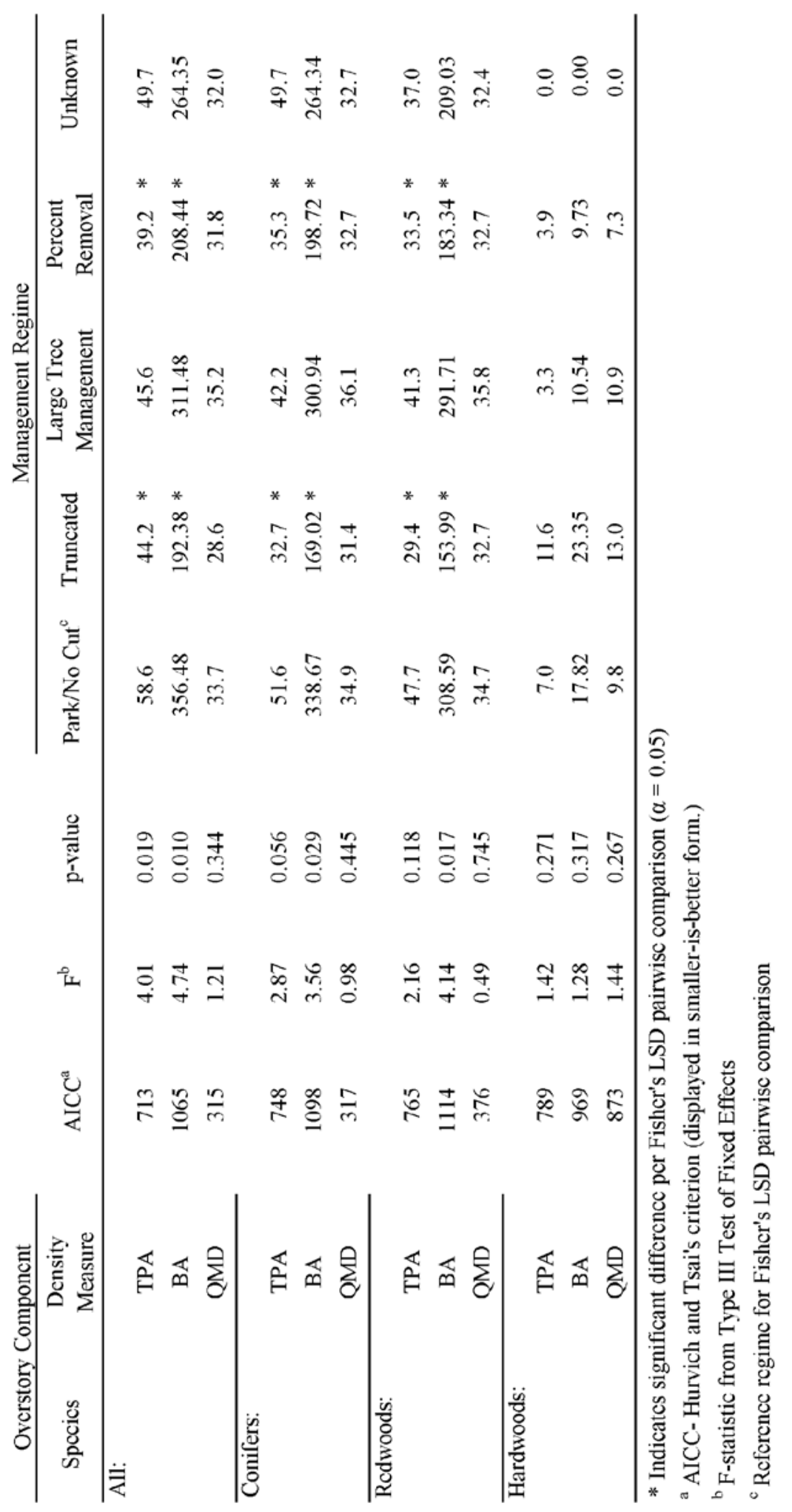


Brief Summary of Results for Objectives One, Two, and Three Significant findings are:

- Finding 1- All Harvest origin stands or regimes, whether managed for timber or unmanaged, are significantly different from Natural origin stands or regime relative to stand-level measures.

- Finding 2- Overstory TPA in timber management regimes (Truncated, Percent Removal, and Large Tree Management) was not significantly different from the Natural regime. The difference between forest origins is in the distribution and size of the overstory trees, not the quantity.

- Finding 3- Large Tree Management may be effectively utilized as an approach to restoration forestry objectives. This silvicultural approach does not significantly alter the TPA and BA from unharvested second growth, but significantly changes the forest canopy and structure.

- Finding 4- Truncated and Percent Removal regimes create significantly different stand structures than unharvested second-growth stands.

- Finding 5- No evidence in this study to support timber management has created or induced a hardwood-dominated understory relative to management regime or forest origin.

- Finding 6- Significant differences in forest composition, density, and structure for timber management regimes coincide with the prescribed silvicultural method and management regime.

- Finding 7- Forest density and structure can be significantly altered with one harvest entry. 
The exploratory nature of this project has led to an enormous number of variables tested and it may be unclear to some readers which results are pertinent. The results from Objective One showed that there are statistical differences between and among forest origins and forest management regimes. This initial analysis was unable to pinpoint in which faction of the forest the differences exist. Objectives Two and Three refined the search for significant differences and divided the forest into two groups, small/understory and large/overstory. With these two groups, the analysis continued to identify where noteworthy differences are in the forest. The analyses of the small stem and understory components showed few patterns or commonalities throughout the results. However, the results can be attributed to the great variability and diversity that exists underneath the redwood forest canopy. Furthermore, the large stem and overstory analyses showed distinct patterns in forest component differences focused on two regimes, Truncated and Percent Removal. These two regimes had the highest proportional representation of the timber management regimes in the dataset, and the significant differences identified by the model existed exactly where the regimes target to manipulate a forest stand. Complete conclusions and evaluations are presented in Chapter 6- Discussion (page 150).

\section{Objective Four- Late Successional Forest Classification Comparison}

Two methods of quadratic mean diameter calculations were compared. These methods have been accepted practices by CAL FIRE, however, the method that uses diameter limits is an in lieu practice permitted by the Forest Practice Rules. Descriptive statistics for the components analyzed are shown in Table 17 (page 134). The comparison consists of two graphical methods and a statistical test, the paired sample 
t-test. A histogram of the difference between the QMD measures would be expected to be centered at zero if the measures are similar. A two-dimensional scatterplot of the measures would be expected to follow a slope of 1:1, or 45 degrees if the measures are alike. The graphical analysis lacks statistical significance. The t-test further analyzes the data and tests whether the average difference between the measurements could be zero.

Table 17: Late Successional Forest Classification Comparison Descriptive Statistics

\begin{tabular}{cccccc}
$\begin{array}{c}\text { Quadratic Mean } \\
\text { Diameter }\end{array}$ & $\begin{array}{c}\text { Number of Plots } \\
\text { (n) }\end{array}$ & $\begin{array}{c}\text { Mean } \\
\text { (in.) }\end{array}$ & Standard Error & Correlation & Significance \\
\hline Overstory & $229 *$ & 36.01 & 0.77 & & \\
Greater than 24.0" & $229 *$ & 37.25 & 0.59 & 0.942 & $<0.001$ \\
Understory & 233 & 11.38 & 0.18 & & \\
Greater than 2.0" & 233 & 18.97 & 0.43 & 0.645 & $<0.001$ \\
\hline
\end{tabular}

*Plots without trees greater than 24" DBH were omitted from analysis.

\section{Large and Overstory QMD}

The quadratic mean diameter of all trees in the overstory was compared to the quadratic mean diameter of all trees greater than 24.0 inches. Refer to Inventory Calculations in Methods and Materials beginning on page 88 for the calculation methods. For the histogram, the difference was calculated by the QMD of overstory trees minus the QMD of all trees greater than 24.0 inches. Trees greater than 24.0 inches were absent on four of the plots, therefore these four observations were removed from the dataset prior to this analysis. 
Figure 13: Histogram of $\mathrm{QMD}_{\text {Overstory }}-\mathrm{QMD}_{>24.0}$ ”

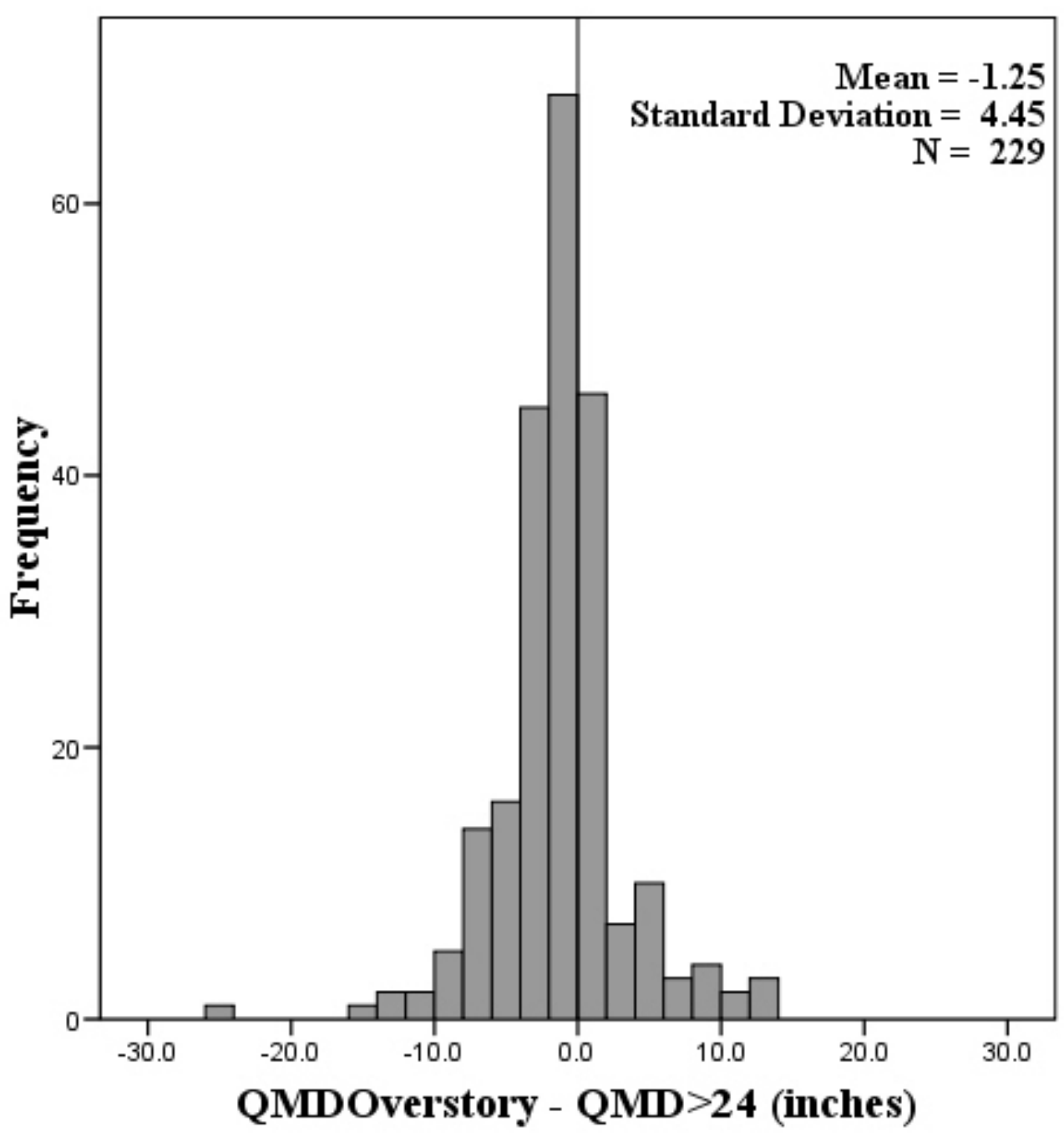

The histogram (Figure 13, above) shows the frequency of the difference between the two measures grouped into 2-inch bins. The highest frequency occurred in the -2.0 through 0.0 class. The histogram presents a fairly normal distribution centered at -1.25 inches. 
Figure 14: Scatterplot of QMD ${ }_{\text {Overstory versus }} \mathrm{QMD}_{>24.0}$

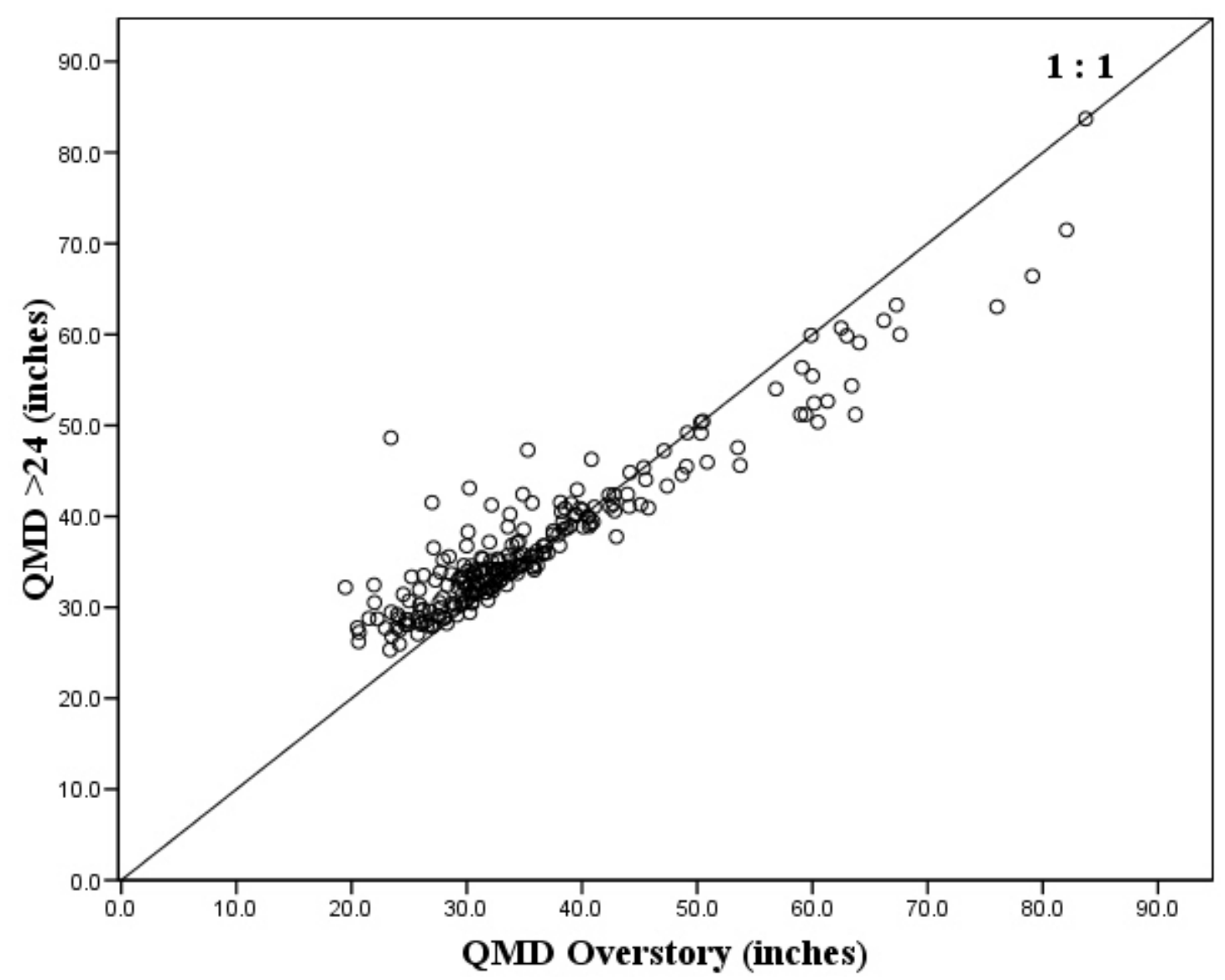

The scatterplot (Figure 14, above) of the data shows a consistent grouping around the 1:1 line, but the trend of observations is slightly different. The majority of observations are clustered between 20.0 and 50.0 inches, which loosely represents the harvest origin plots. The remainder of the observations greater than 50.0 inches generally represents the Natural regime plots. 
Table 18: Paired-sample t-Test of $\mathrm{QMD}_{\text {Overstory }}$ and $\mathrm{QMD}_{>24.0 \text { ” }}$

\begin{tabular}{|c|c|c|c|c|c|c|c|c|}
\hline \multirow[b]{2}{*}{$\begin{array}{l}\text { Quadratic Mean } \\
\text { Diameter Pair }\end{array}$} & \multirow[b]{2}{*}{$\begin{array}{c}\text { Number of } \\
\text { Plots (n) }\end{array}$} & \multirow[b]{2}{*}{$\begin{array}{c}\text { Mean } \\
\text { Difference (in.) }\end{array}$} & \multirow[b]{2}{*}{$\begin{array}{l}\text { Standard } \\
\text { Error }\end{array}$} & \multicolumn{2}{|c|}{$95 \%$ Confidence Interval } & \multirow[b]{2}{*}{$\begin{array}{l}\text { Degrees of } \\
\text { Freedom (dn) }\end{array}$} & \multirow[b]{2}{*}{ t } & \multirow[b]{2}{*}{ p-value* } \\
\hline & & & & Iower & Upper & & & \\
\hline $\begin{array}{l}\text { Overstory } \\
\text { mimus } \\
>24.0^{\prime \prime}\end{array}$ & 229 & -1.24 & 0.294 & -1.82 & -0.67 & 228 & 4.24 & $<0.001$ \\
\hline
\end{tabular}

* 2-tailed significance test $(a=0.05)$

The hypothesis for this test is:

$\mathrm{H}_{\mathrm{O}}$ : Average $\mathrm{QMD}_{\text {Overstory }}=$ Average $\mathrm{QMD}_{>24.0}$ "

$\mathrm{H}_{\mathrm{A}}$ : Average QMD ${ }_{\text {Overstory }} \neq$ Average $\mathrm{QMD}>24.0$ "

The t-test results state the mean difference between the two methods of QMD calculation equals 1.25 inches, with a standard error of the mean equal to 0.294 (refer to Table 18). The t-statistic for this model is 4.236 with an associated two-tailed significance value, or p-value of less than 0.001. Based on 95 percent confidence $(\alpha=0.05)$, the null hypothesis was rejected and the alternative hypothesis, the two methods of calculating QMD are not equal, was concluded.

\section{$\underline{\text { Small and Understory QMD }}$}

The comparison of two different methods of QMD calculation for all understory trees and all trees greater than 2.0 inches is presented in the same manner as the large and overstory trees. All plot observations were included in this analysis. 
Figure 15: Histogram of $\mathrm{QMD}_{\text {Understory }}-\mathrm{QMD}_{>2.0}$ "

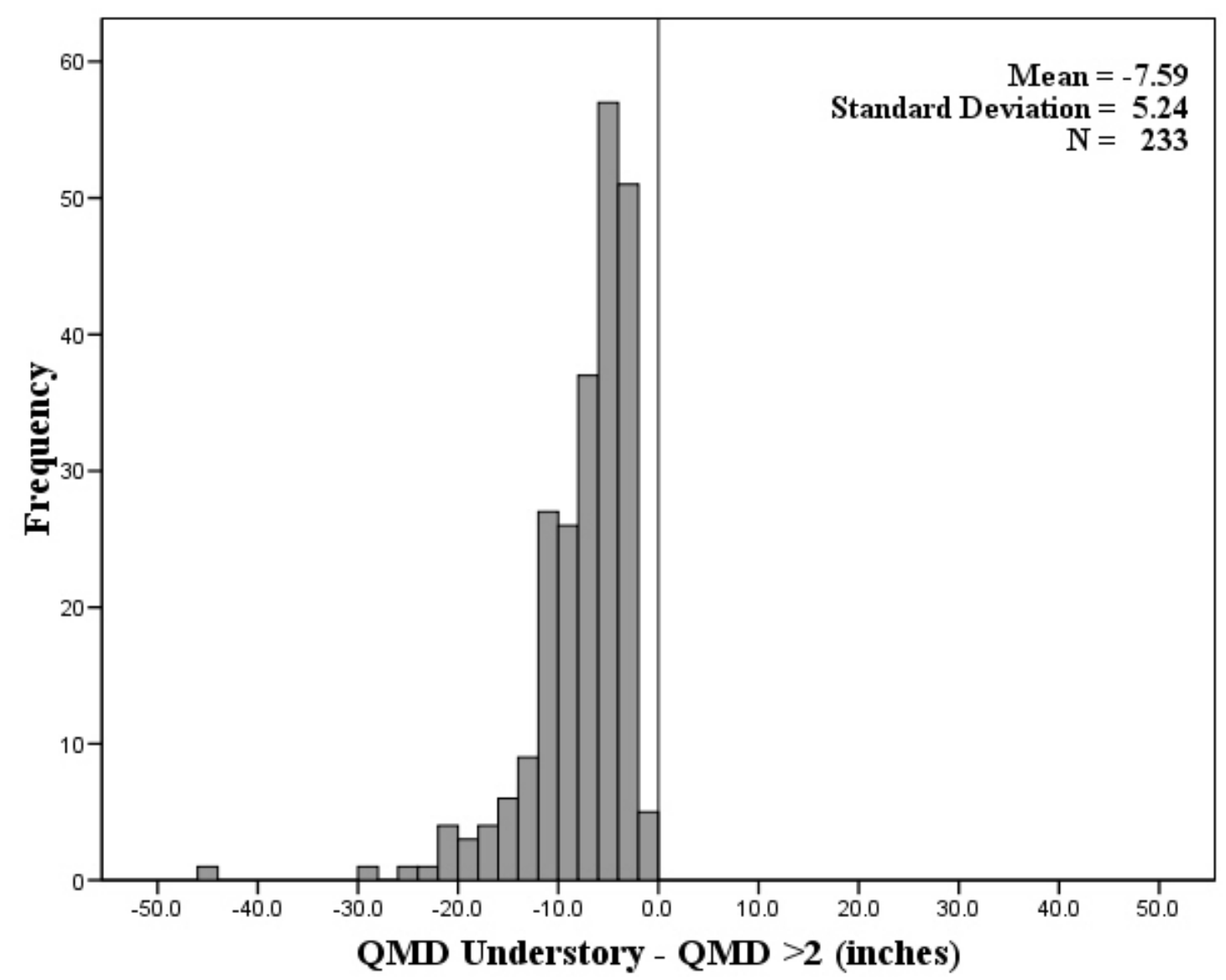

This graphical analysis holds the same expectations as the large/overstory tree comparison. The histogram (Figure 15) shows the frequency of the difference between QMD of understory trees and QMD of all trees greater than 2.0 inches. The differences were grouped into 2-inch bins. The lack of occurrences greater than zero is notable. The distribution is skewed-left and centered at -7.59 inches. 
Figure 16: Scatterplot of $\mathrm{QMD}_{\text {Understory }}$ versus $\mathrm{QMD}>2.0$ ”

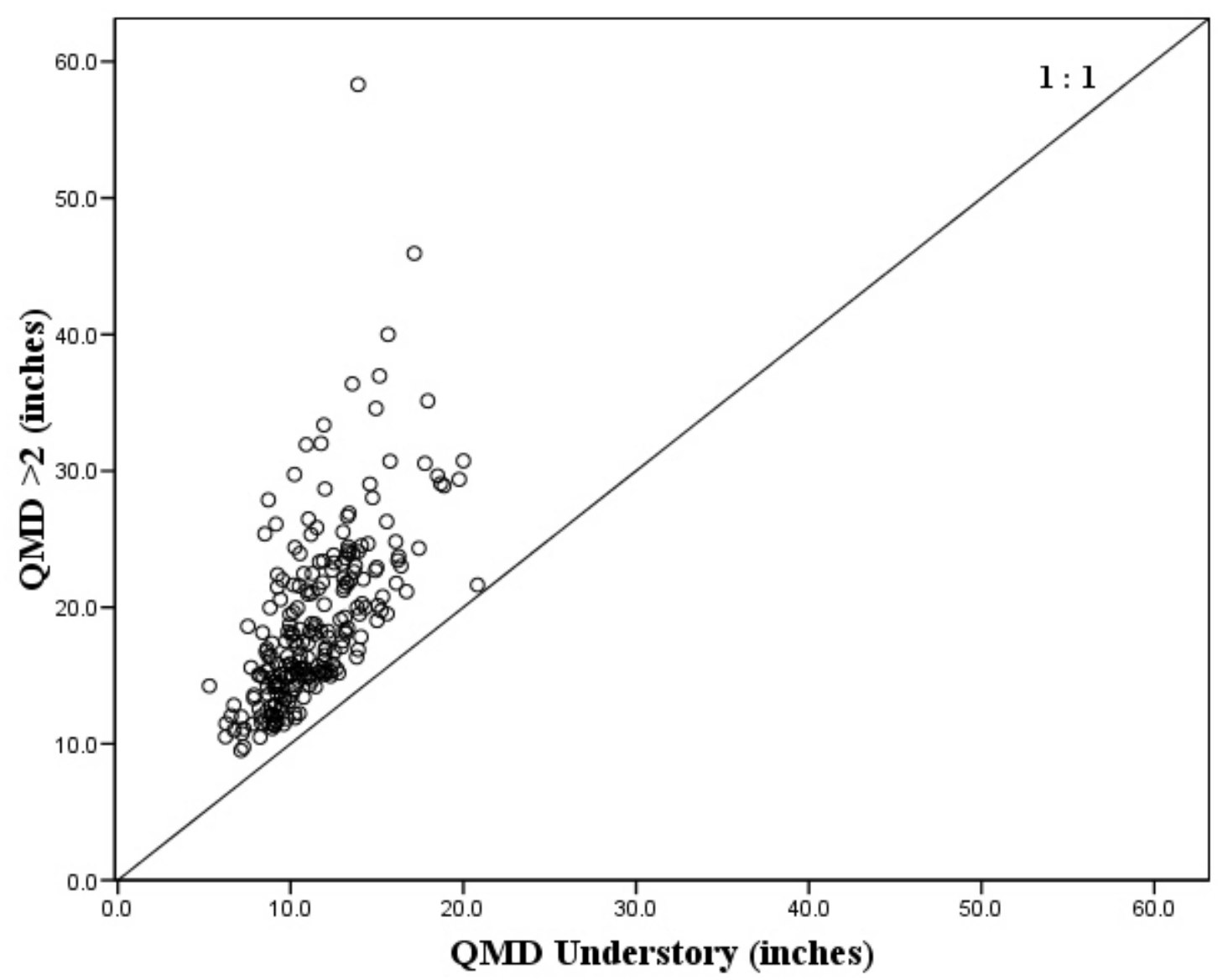

This scatterplot mimics the lack of positive values in the histogram by showing no observations below the 1:1 line (refer to Figure 16). The trend of the observations does not coincide with the slope of the 1:1 line as well. The variability between harvest and natural origin plots was less evident with the small/understory QMD measures.

Table 19: Paired-sample t-Test of $\mathrm{QMD}_{\text {Understory }}$ and $\mathrm{QMD}_{>2.0}$ "

\begin{tabular}{|c|c|c|c|c|c|c|c|c|}
\hline \multirow[b]{2}{*}{$\begin{array}{l}\text { Quadratic Mcan } \\
\text { Diameter Pair }\end{array}$} & \multirow[b]{2}{*}{$\begin{array}{c}\text { Number of } \\
\text { Plots (n) }\end{array}$} & \multirow[b]{2}{*}{$\begin{array}{c}\text { Mcan } \\
\text { Difference (in.) }\end{array}$} & \multirow[b]{2}{*}{$\begin{array}{c}\text { Standard } \\
\text { Error }\end{array}$} & \multicolumn{2}{|c|}{$95 \%$ Conlidence Inlerval } & \multirow[b]{2}{*}{$\begin{array}{l}\text { Degrees of } \\
\text { Freedom }(\mathrm{d})\end{array}$} & \multirow[b]{2}{*}{$t$} & \multirow[b]{2}{*}{$\mathrm{p}$-value } \\
\hline & & & & Lower & Upper & & & \\
\hline \multicolumn{9}{|l|}{ Understory } \\
\hline mimus & 233 & .7 .59 & 0.343 & .8 .27 & -6.91 & 232 & 22.13 & $<0.001$ \\
\hline$>2.0^{\prime \prime}$ & & & & & & & & \\
\hline
\end{tabular}

* 2-tailed significance test $(a=0.05)$ 
The mean difference between QMD of understory trees and QMD of trees greater than 2.0 inches is -7.59 inches, with a standard error of the mean of 0.343 (Table 19, page 139). A negative mean difference demonstrates that on average $\mathrm{QMD}_{>2.0 \text { ” is typically }}$ larger than the average $\mathrm{QMD}$ Understory. The t-statistic from the model equals 22.125 with an associated p-value of less than 0.001 . The null hypothesis was rejected and the

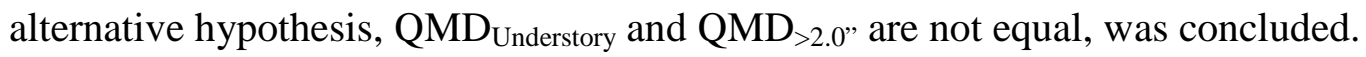
It should be noted that the assumption of normally distributed differences is not satisfied for the Small and Understory QMD analysis. Therefore, the t-test results are treated with caution. However, the data clearly supports that there is a difference between the surrogate measures being analyzed, given the unanimous negative differences. 
Table 20: Descriptive Statistics for General Forest Components

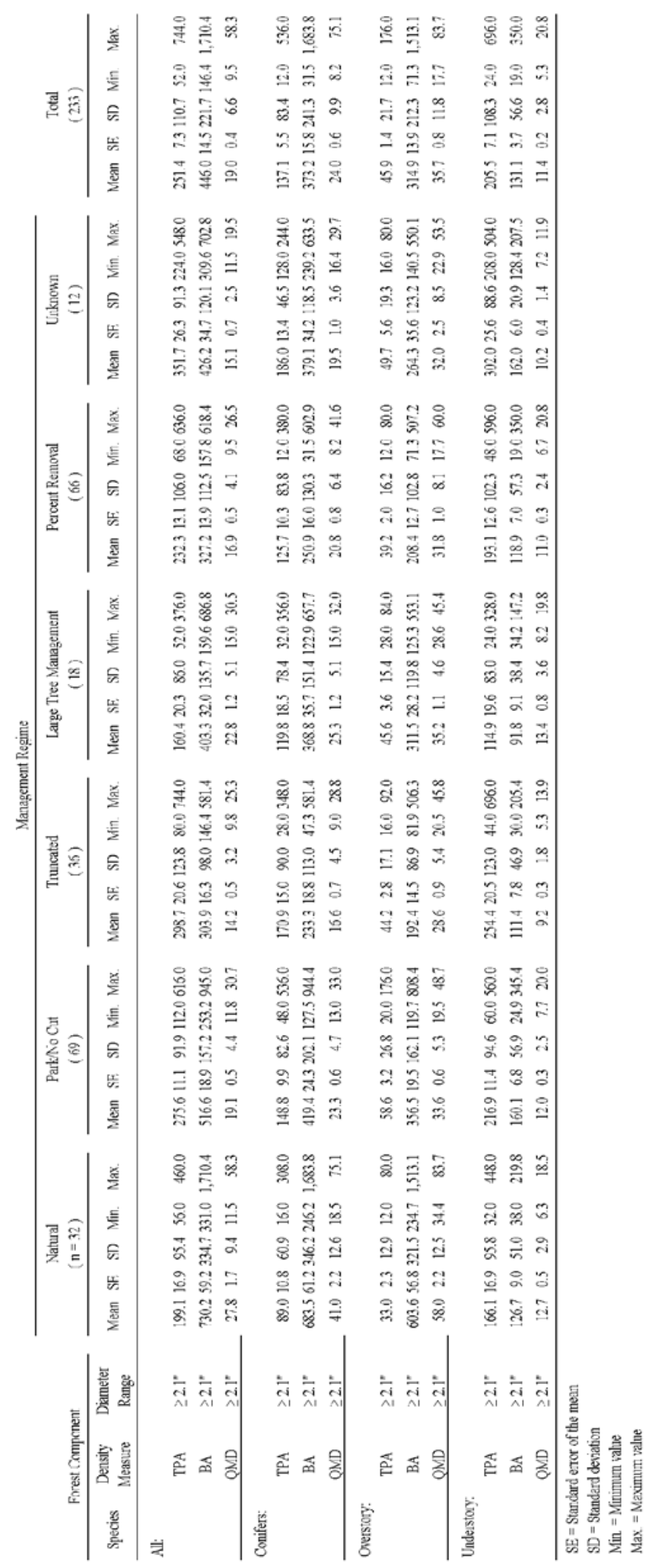


Table 21: Descriptive Statistics for 6-inch Diameter Class Components

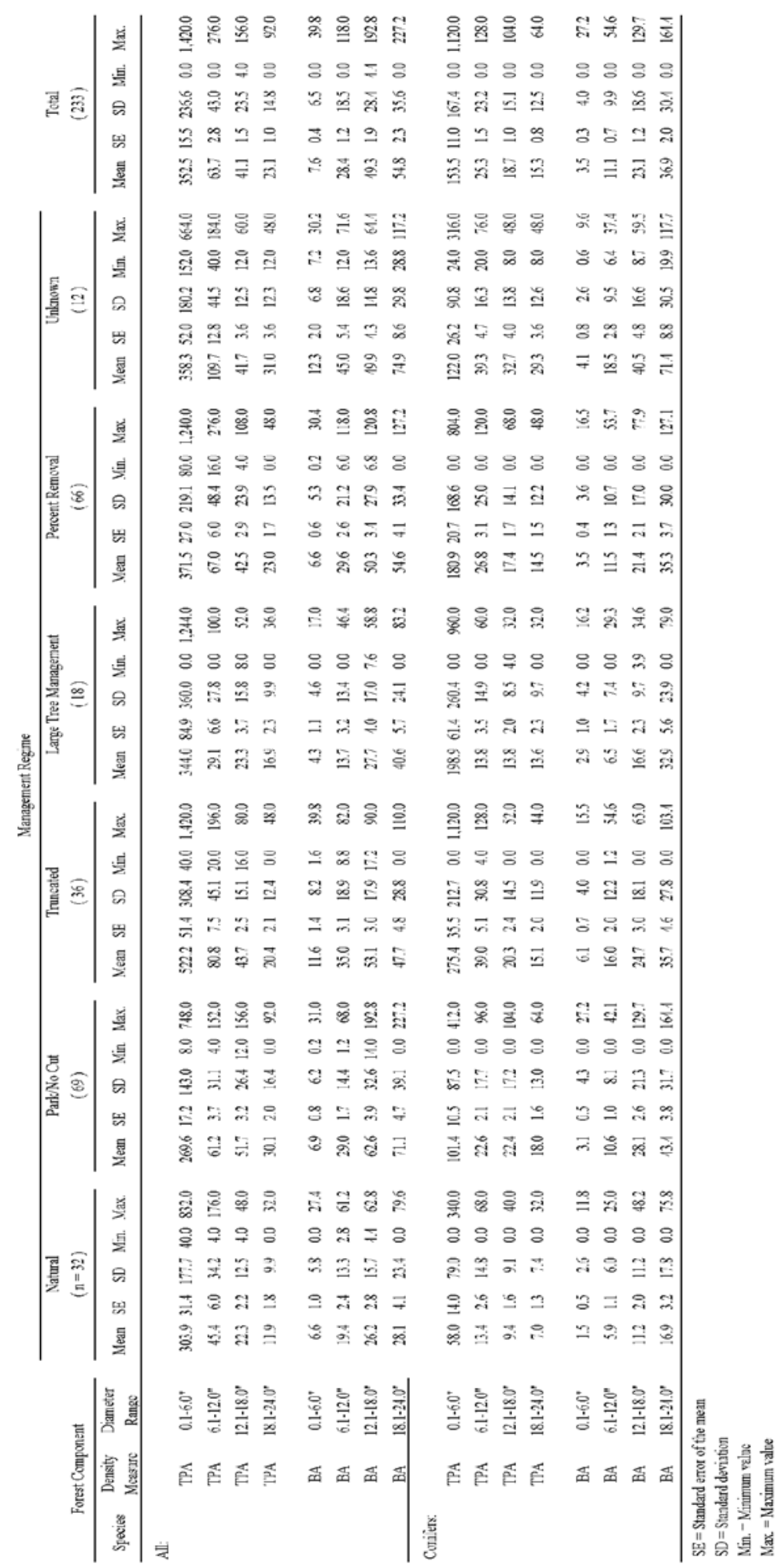


Table 21: Descriptive Statistics for 6-inch Diameter Class Components (continued)

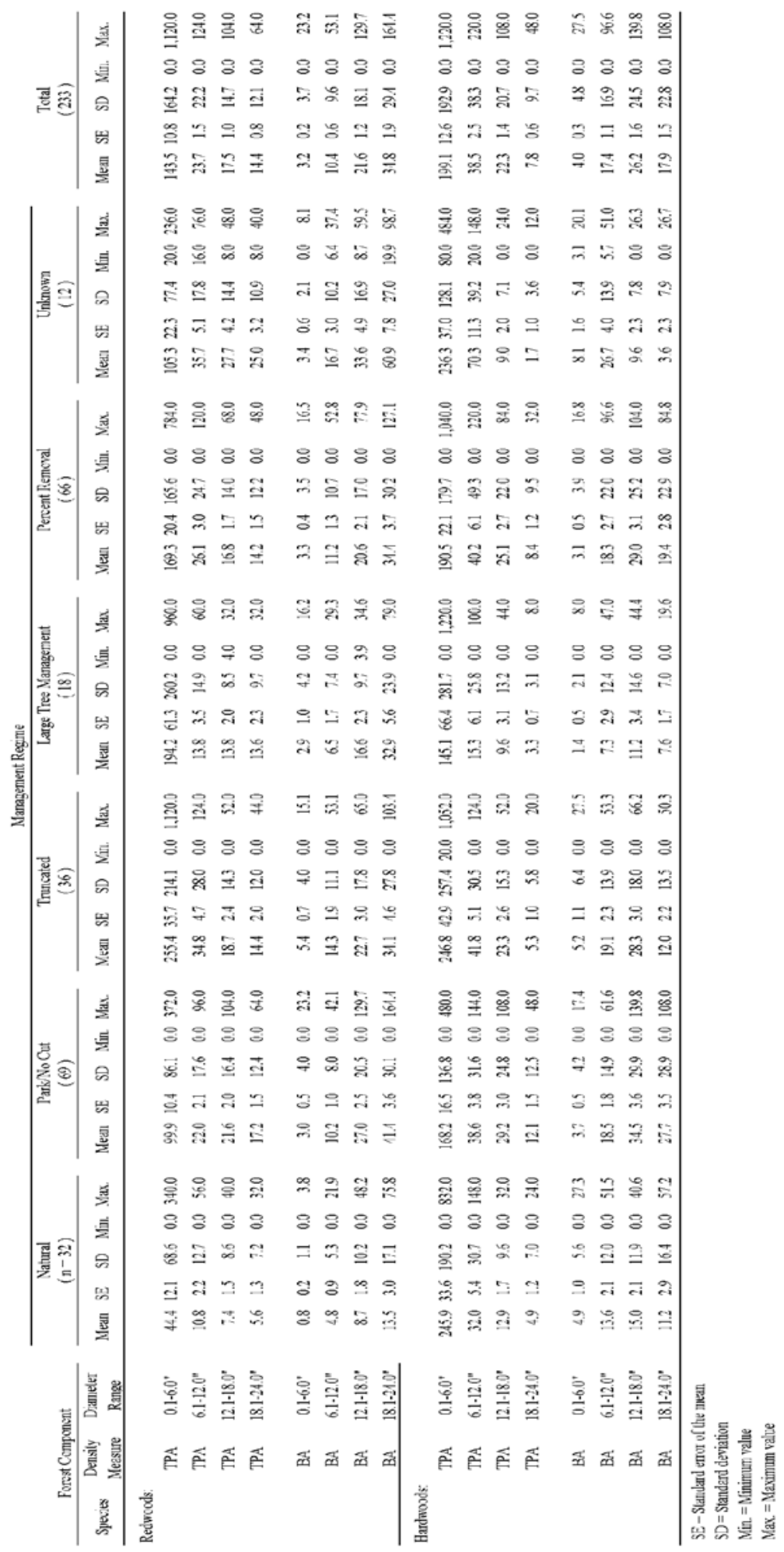


Table 22: Descriptive Statistics for Small Stem “60/50 Rule” (14 CCR § 926.25)

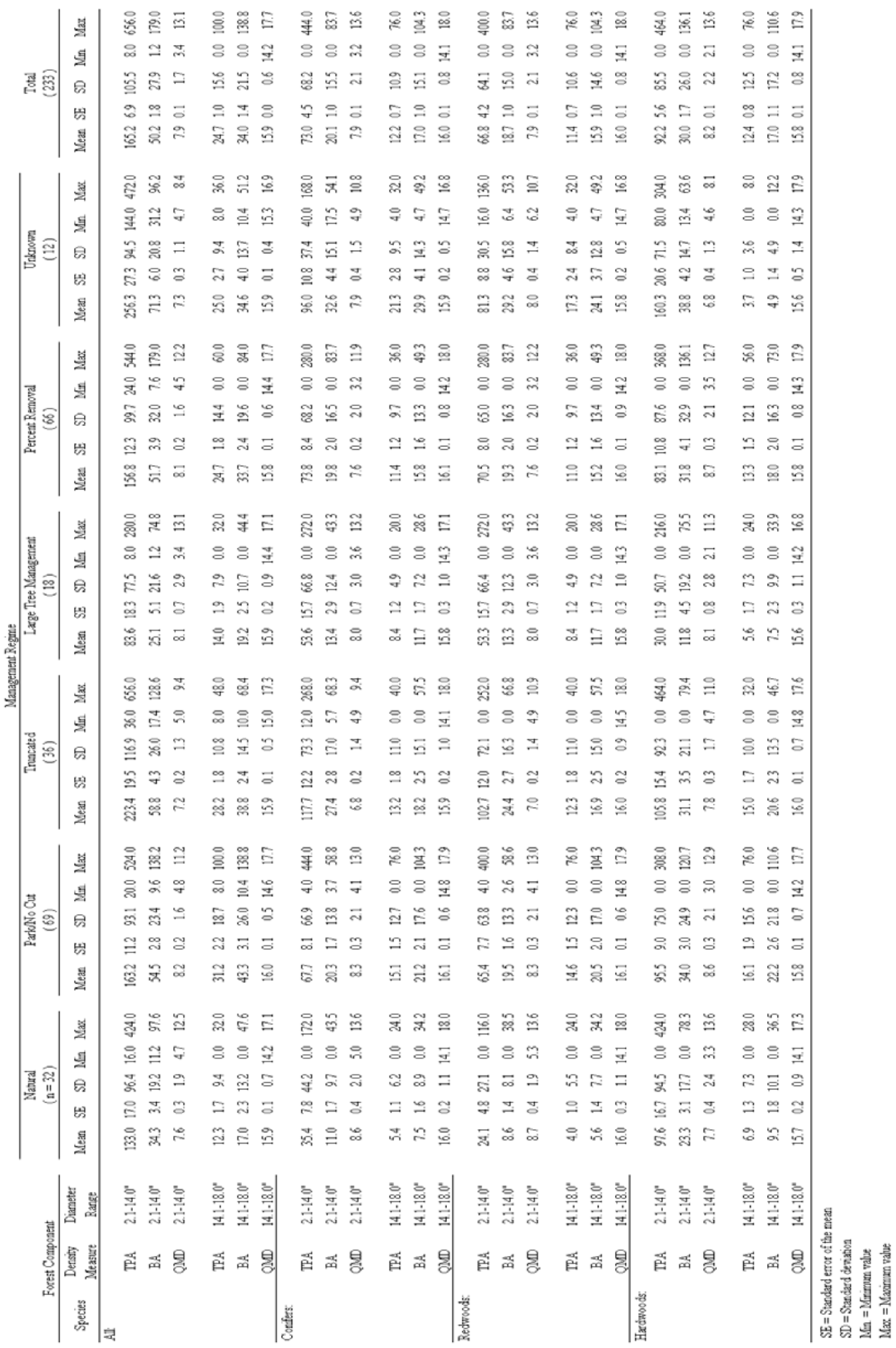


Table 23: Descriptive Statistics for Small Stem Type A Owl Habitat and Understory

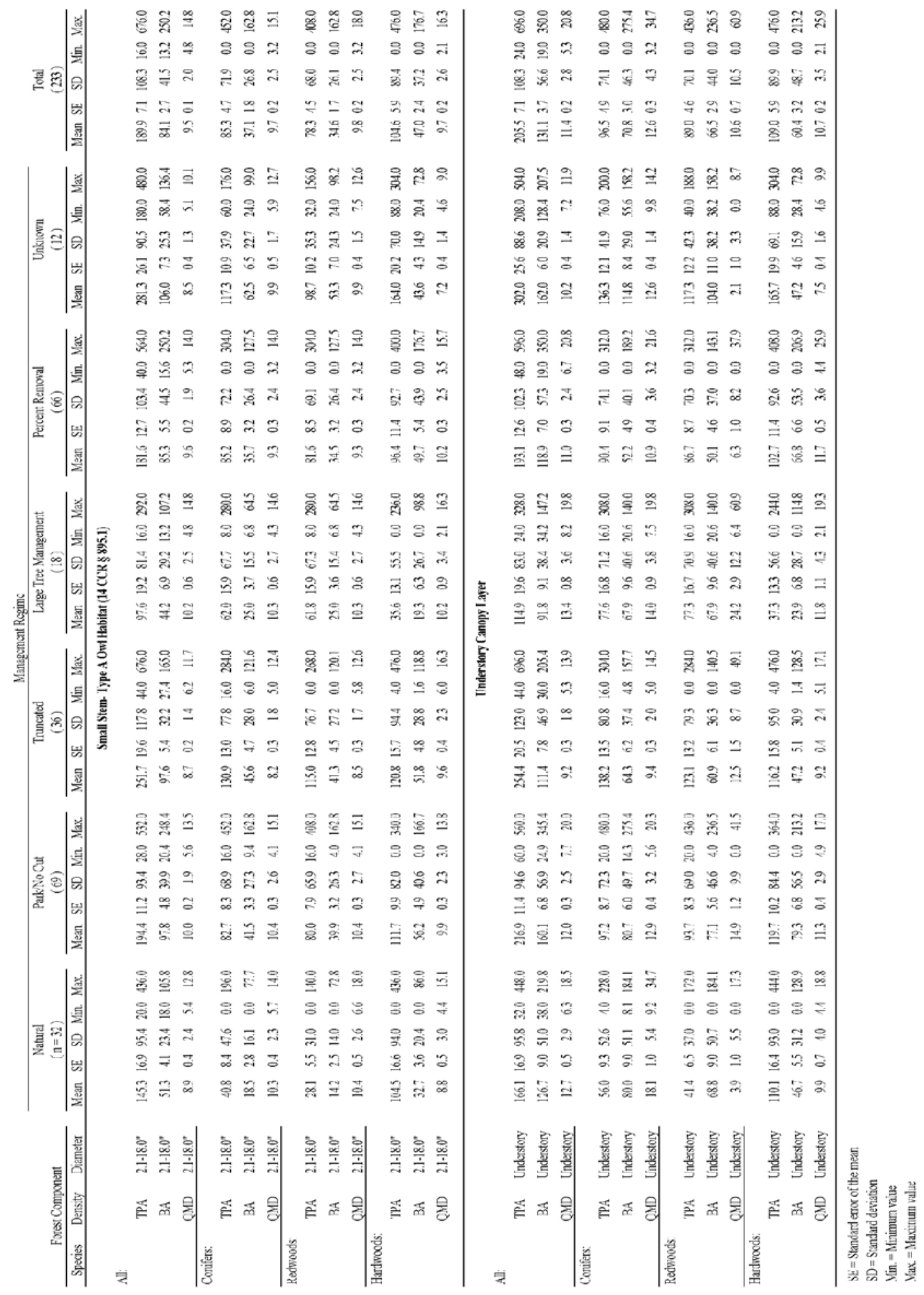


Table 24: Descriptive Statistics for Large Stem Sawtimber and Special Harvesting Methods

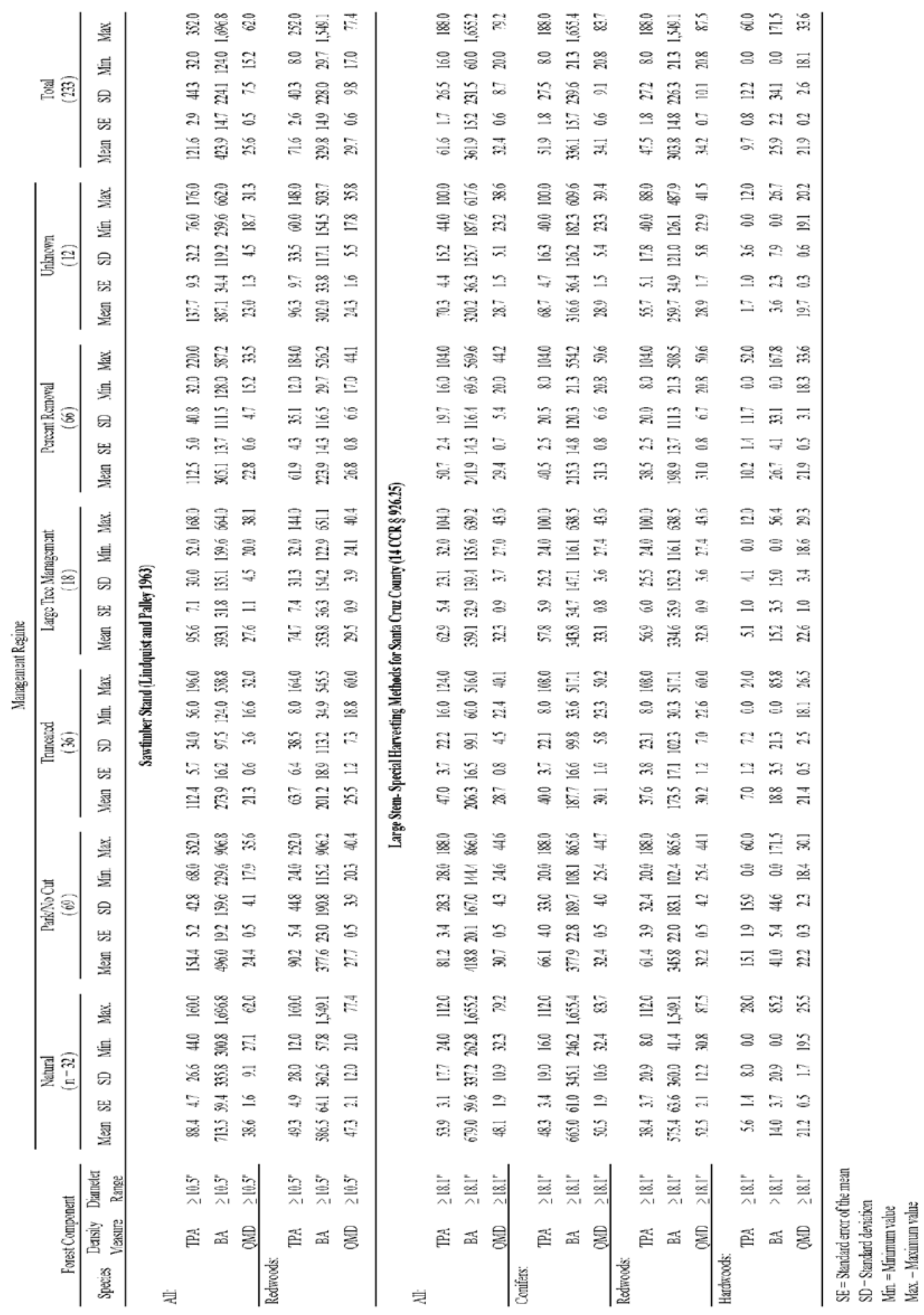


Table 25: Descriptive Statistics for “Mature” Trees (per Fox 1989)

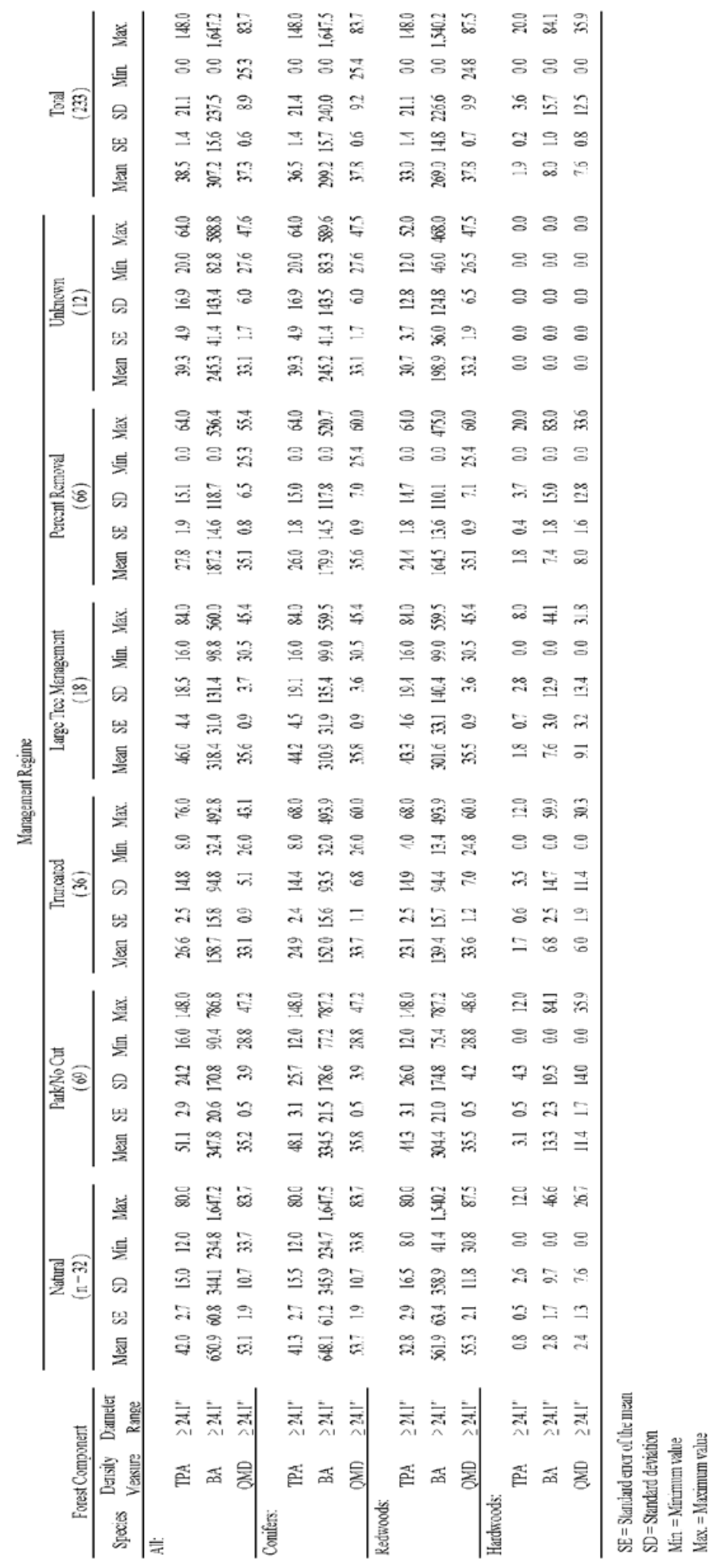


Table 26: Descriptive Statistics for Medium and Large Tree Type A Owl Habitat

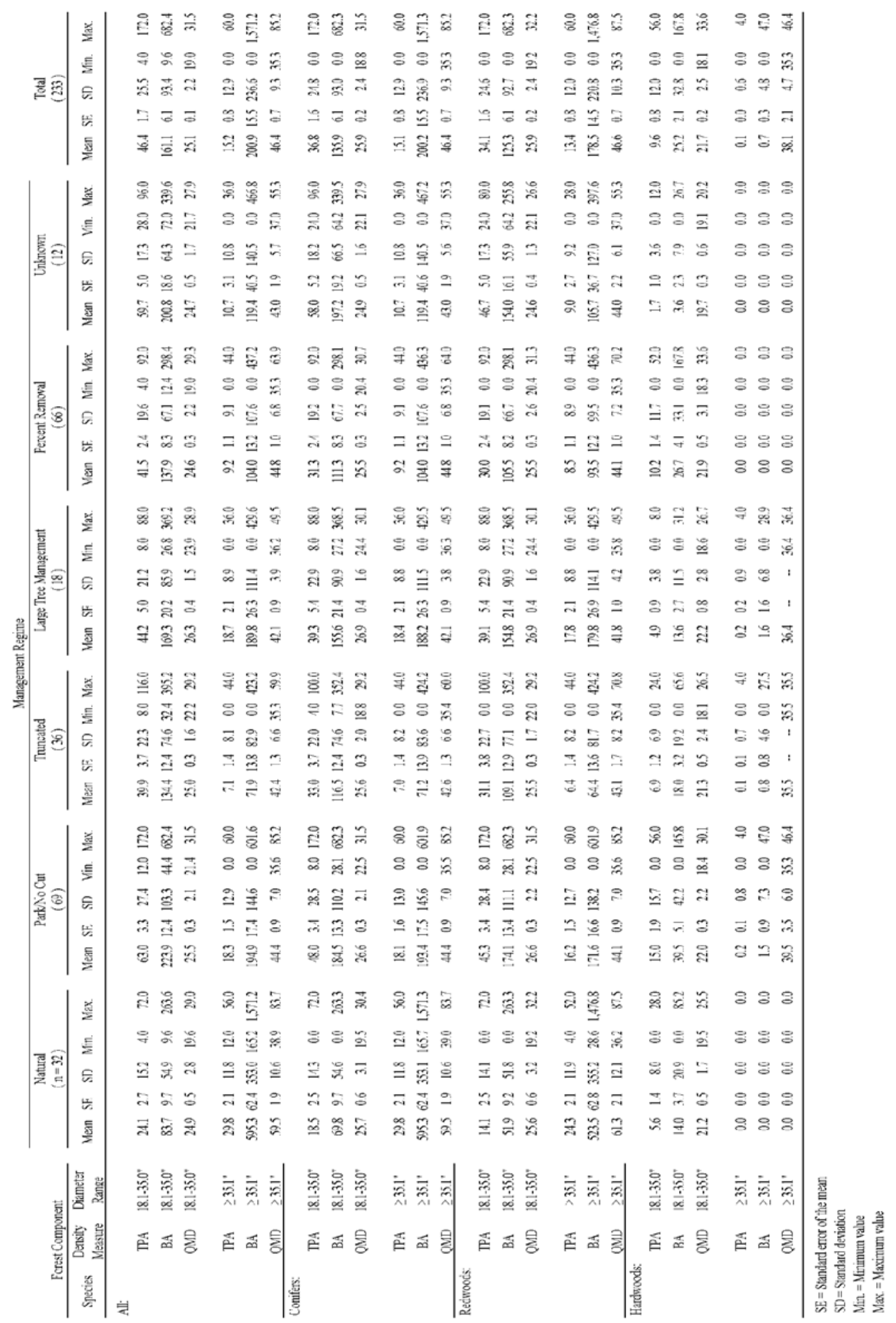


Table 27: Descriptive Statistics for Overstory

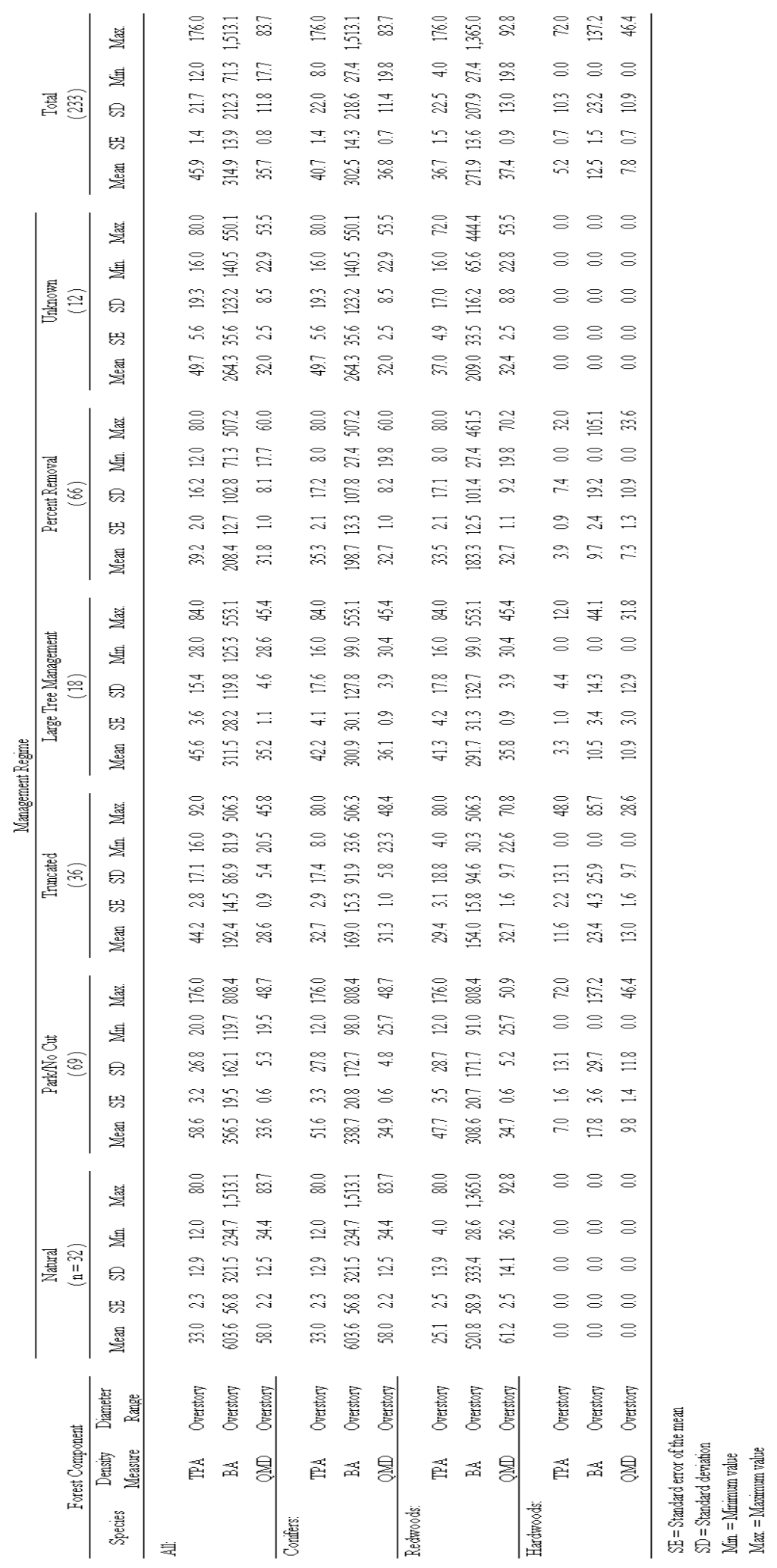




\section{DISCUSSION}

The following chapter discusses this study in terms of the overall purpose and goal. This exploratory study has many facets that may be intertwined in the minds of some readers; however, the discussion will continue to follow the research objectives and forest component groupings. This chapter includes an evaluation of the data and analyses, conclusions drawn from the statistical results, and recommendations concerning LSF policy and classification, as well as applied restoration management.

\section{Evaluation}

A review of all sampling methods, statistical analyses, and interpretations was conducted for evaluative purposes. The discussion includes plausible factors that influenced the data or analyses, which are not represented by the empirical data.

\section{$\underline{\text { Regeneration Sampling }}$}

Inventory and analysis of regeneration is problematic in the redwoods. The clumpy spatial arrangement and abundance of coppice regeneration renders extremely high variability in plot data. Therefore, two random plot samples have a high likelihood of returning drastically different results. A replication of this study could very well identify statistically different results for stems less than 6.0 inches DBH. Interpretations and conclusions based on analyses that included regeneration diameters should account for this variability. For one case in particular, the time between harvest and data collection most likely influenced the data and analyses. One of the Large Tree Management stands, comprising half of the plots for the entire regime, was inventoried approximately three months after harvest. This period is insufficient for coppice sprouts 
to grow to a measurable size. Data collected in this stand proceeded due to time and financial constraints of the project.

It is expected, by design and definition, that harvesting decreases density. However, the unexpected result is that there are statistical differences in overstory density after a minimum of one harvest entry. When planning to convert an even-aged forest to uneven-aged, the desired structure is obtained after two to four harvest entries, approximately 20 to 40 years. Some anticipated results were that very few significant differences would be noted since most inventory stands had only been harvested one to three times. The data and analyses in Objectives 1-3 all show significantly different forest components. This demonstrates that even though uneven-aged structure has not been obtained, applied management has significantly altered the structure of the forest in as few as one entry.

\section{Diameter Ranges and QMD}

The quadratic mean diameter was chosen as a measure since it is a function of both TPA and BA. The measure proved to be a good indicator of structural differences when applied to wide diameter ranges. However, the usefulness of QMD decreased with the width of the diameter or class. Evaluating the analyses based on diameter range leads to the recommendation that QMD is valuable when analyzing or summarizing diameter ranges greater than 15-inches wide. The use of QMD calculations for total stand or canopy layers is also acceptable. Objective One tested four QMD components and the only one that failed to reject the null hypothesis was Overstory QMD excluding the Natural regime. The analysis of understory stems in Objective 2 also had three out of four components reject the null hypothesis (Table 11, page 118). All four overstory 
QMD components tested in Objective 3 failed to reject the null hypothesis (Table 16, page 131). However, all eight QMD components with ranges less than 15-inches failed to reject the null hypothesis of the statistical test. QMD is a suitable stand-level measure, but caution is advised when using it with narrow diameter ranges.

\section{Large Stem Hardwood Density Analysis}

The maximum diameters of commonly associated hardwood species are obviously smaller than redwood and Douglas-fir. Hardwoods within the study rarely exceed 30 inches DBH. However, the densities of hardwoods were still analyzed in the Large Stem Density objective. A few of the groupings, such as Type A Owl Habitat "large" trees, did not have a large enough sample plots with hardwoods that met the criteria to complete the analysis (Table 15, page 128). The analysis results were invalid and conclusions were omitted.

\section{Conclusions}

Statistical analysis has rendered many definitive results. Some were expected and others were not. The conclusions from those results continue to be presented in the same manner, by the associated research objectives. Given 162 forest components were tested, this seems the most logical approach.

\section{Objective One- General Stand Components}

Components of broad-based stand descriptions were analyzed with and without the Natural regime. The first iteration, with Natural management regime included, compared Natural origin to Harvest origin. In general, the analyses identified the majority of harvest origin regimes significantly different from the natural regime in terms 
of BA and QMD. The nearly unanimous differences for BA and QMD components of all species groups, except hardwoods, led to the conclusion that Natural and Harvest origins plots are two separate populations (Table 6, page 102). This analysis confirmed the anticipated result as history, management, literature, and ecology imply. All subsequent analyses filtered the population of Natural regime plots.

Differences in TPA components varied dependent upon the forest component. Overstory TPA in timber management regimes (Truncated, Percent Removal, and Large Tree Management) was not significantly different from the Natural regime. It is incorrect to imply that timber harvesting effectively manages the number of overstory trees to mimic natural origins forests. The definitions and silvicultural prescription support this statement. For example, the Truncated regime manages a stand based on a desired maximum diameter. Even with "heritage" or "legacy" trees retained, the stand structure should never approach LSF thresholds. However, given the desired future condition of the Large Tree Management regime, I believe that this is a valid approach to restoring LSF conditions. Currently the TPA components of the Large Tree Management regime are not significantly different from the Natural regime. In general, overstory TPA does not differ beyond management regime. The visible difference between the origins of the forest is in the distribution and size of the overstory trees, not the quantity.

The second iteration of these analyses filtered the Natural origin plots to compare unharvested second-growth (Park/No Cut regime) to harvested second-growth (all remaining harvest origin regimes). Trends note that BA in Park/No Cut plots were generally greater than all other regimes. Also, the Truncated and Percent Removal regimes are consistently different from Park/No Cut regime in many forest components. 
The greater BA in merchantable timber is explained by lack of harvesting. The greater understory tree BA in Park/No Cut regime may be due to (1) the lack of residual logging damage to understory/small diameter trees and removal for harvest operations (roads, trails, corridors); (2) the lack of herbicide treatments to reduce hardwood competition; or (3) there is a significant height and/or diameter difference in canopy layers, which causes more larger-diameter stems to be relatively classified as understory. A verifiable conclusion is beyond this dataset and analyses.

Overall, few patterns emerged from these analyses when comparing harvested and unharvested second growth, because of the stand-level measures used in this forest-origin based objective. Research objectives two and three focused on small stem density distribution and large stem density to refine these topics. Significant differences of species, structure, TPA, BA, QMD are discussed in the following sections.

\section{Objective Two- Small Stem Density and Distribution}

The analysis of small stem density and density distributions rendered many interesting results. The various groupings have overlapping forest components; however, each grouping is presented individually and is mutually exclusive.

\section{Density distributions by 6-inch diameter classes}

These analyses investigated trees less than 24 inches DBH, stratified into 6-inch diameter classes. These diameter ranges span merchantable and non-merchantable tree diameters. For this region, conifers become merchantable between 14 and 16 inches DBH. 
Spatial variability of coppice regeneration in the clumpy redwood forest influenced the data. Some 0.05 -acre plots had zero or one stem less than 6-inches, while others had more than 70. However, significant differences were identified in the diameter classes greater than 6.0 inches DBH.

Data suggests management has affected trees from 6.0 to 24.0 inches DBH. In most cases, the significant difference identified in merchantable species and diameter classes were associated with the corresponding silvicultural prescriptions and management approaches. The most surprising results were associated with hardwood densities. The data and analysis suggest that management regime has had very little significant effect on the density distribution of hardwood trees less than 24 inches DBH (refer to Table 8, page 108). It appears the notion timber harvesting has created a hardwood understory is not supported. Trends in the data suggest that harvesting of conifers has actually decreased the amount the hardwood trees less than 24 inches, but this decrease is not significantly different. Furthermore, the overall conifer-to-hardwood ratio of regeneration $(<6.0$ ” DBH) is variable across management regimes. No discernable trend is apparent which suggests there is not a dominant species group in the understory. Management activities designed to favor one group already affect, and will continue to affect this observation.

Douglas-fir composition also appears influenced by management regimes. Comparing analyses between all conifers and redwoods highlight this compositional difference. The separating factor between these groups is the composition of Douglas-fir. In general, timber harvesting has reduced the Douglas-fir density in trees less than 24 inches DBH, when compared to unharvested second growth forest structure. 
The two management regimes most often used in this region should be highlighted for this analysis. Truncated and Percent Removal regimes both carry similar density levels for trees 18.1-24.0” DBH, however the density distribution for stems 0.118.0" is different. The Truncated regime carries heavy stocking of stems less than 12.0" DBH, whereas the Percent Removal approach carries less stocking in the same diameter range. Some foresters might consider the Truncated approach to be more conservative, because more small stems are left in the ground as insurance against potential stand-level disturbances like wildfire. However, the drawback to this approach is more intensive or expensive harvesting costs because thinning occurs across all diameter class, instead of only merchantable diameter classes as in Percent Removal. Whether the forester is more or less conservative, each management regime carries adequate small-stem stocking to create a distinct age-class and they both currently have similar stocking in the 18.1-24.0" DBH class. In my opinion, both are viable options for uneven-aged management, the selection of which one will depend on landowner objectives and their level of allowable risk.

\section{Special Harvesting Methods for Santa Cruz County (14 CCR § 926.25)}

The small stem diameter ranges outlined by the “60/50 rule” (14 CCR § 926.25) were analyzed for all species groups and density measures. Significant differences in density for specific management regimes coincide with definitions and silvicultural prescriptions of the associated regime. The Truncated regime has significantly higher TPA conifer density in trees less than 14 inches DBH, as would be expected by the inverse J-shaped stand curve derived from the BDq function. The significantly lower density of all trees and hardwoods less than 14 inches in the Large Tree Management 
regime is still most likely associated with the time since last harvest. The significantly lower density of conifers 14 to 18 inches is attributed to the thin-from-below silviculture.

Percent Removal regime also has significantly decreased the density of conifers 14 to 18 inches (Table 9, page 111). The data suggests that even the "cleansing cut” prescribed for this diameter range has significantly altered the density. Other reductions in BA for this diameter range may be due to residual logging damage. The differences identified in commercial species is notable, given less than three harvest entries have occurred in many of the plots under the various regimes. The significant reductions in BA directly apply to uneven-aged management in general for the region. While it was unexpected to see significantly different results, the effect is creating more growing space in the understory for higher stocking in the regenerating age-class following harvest. This is important since a stand is not considered uneven-aged until there are at least three distinct age-classes.

Hardwood density in small stem diameters per the 60/50 rule guidelines rendered no major differences. This analysis supports the findings of the 6-inch diameter class distribution analysis. Data trends suggest that harvesting of conifer overstory trees tends to increase the density of conifer regeneration, but effects on hardwood regeneration vary. However, these trends are not supported by statistically significant differences. Hardwood densities are also influenced by residual logging activities and herbicide treatments to reduce regeneration competition for conifers.

\section{Type A Owl Habitat- Small Trees}

The "small” diameter trees (2.1-18.0” DBH) associated with owl habitat have been affected by timber harvesting. Overall, the regime with the most evident effect on 
small trees was Large Tree Management, as explained by prescribed silviculture. Hardwood densities of small trees appear rather unaffected by timber harvesting. Data trends show decreased TPA and BA with QMD remaining rather constant. This suggests that fewer hardwood trees are retained post-harvest, but of larger diameters (Table 10 on page 115). Ecologically, this trend may improve wildlife habitat since small diameter hardwoods produce less mast and offer less nest- and roost- habitat for many bird species.

\section{Understory Canopy Layer (Parisi, Motroni, and Robards 2007)}

The understory canopy layer density has been significantly affected by timber harvesting. In general, the understory BA is greater in the Park/No Cut regime than in all other management regimes, but TPA is significantly decreased in the Large Tree Management regime. This suggests that the understory trees in the Park/No Cut plots are generally larger in diameter than in timber management plots. Other possible explanations for this difference are related to canopy closure and silvicultural treatments, however the implications of this finding are directly linked to fuel loading and fire behavior.

The author recorded descriptions of the canopy in the field notes during data collection (Field Notes, page 87). These descriptions are anecdotal and comparative between regimes because of a lack of cohesion in the scientific community concerning canopy measures, methods, instruments, and interpretation.

The canopy in Park/No Cut plots were typically contiguous compared to timber management plots that had gaps from overstory tree harvesting. This characteristic could lead one to believe that understory densities under a closed canopy (>90\%) would be significantly lower do to shading out of understory trees, especially for shade-intolerant 
species. However, the higher density may be attributed to the closed canopy causing larger diameter trees to be relatively classified as understory. Conversely, the decreased density in timber management regimes may be attributed to tanoak-targeted herbicide treatments to reduce regeneration competition for conifers, or residual damage to understory trees during felling and yarding operations.

Due to the silvics and shade-tolerance of the species analyzed, it is beyond the data to state that Park/No Cut forest structure has reached the stage of shade-induced mortality. Further research is needed to determine which of these possibilities is affecting this forest component.

The current state of the Park/No Cut stands is critical in terms of fuel loading and potential fire behavior, both of which are greater in comparison to all other timber management regimes. The Park/No Cut stands typically have vertical continuity between surface, ladder, and aerial fuels, as well as moderate horizontal continuity of fuels. The timber management regime stands have both light-to-moderate horizontal and vertical continuity of fuels. The only exceptions would be a complete lack of vertical continuity for the Large Tree Management and Natural regimes. Although this is not a fire behavior study, a forester can interpret the potential fire behavior of a stand based on many of the forest components presented in this analysis. In my opinion, the Park/No Cut regime has a far greater risk of catastrophic crown fire than any other regime in this study.

Recent history has shown that fire still plays an active role in the redwood forests of Santa Cruz and San Mateo Counties. The Summit Fire in 2008 and Lockheed Fire in 2009 are evidence of this. Combined, the two fires burned 12,087 acres of mixed-forest and brush cover types (CALFIRE 2008, 2009). A few of the timber management stands 
from this project were burned in one of these fires, with light-to-moderate post-fire mortality. None of the Park/No Cut stands were burned; however when (not if) a fire enters one of the state parks, there is a high likelihood a catastrophic crown fire will ensue due to the heavy surface fuel accumulations and fuel continuity. As these stands grow into the future, the ladder fuels will decrease or remain constant because of continued shade-induced mortality, but the surface fuel loading will continually increase as those ladder and aerial fuels fall to the ground. The potential for catastrophic crown fire remains constant, or increasing with time. Hazardous fuel reduction projects in these areas is something California State Parks managers will need to take a close look at in the near future, if they have not started already.

\section{Objective Three- Large Stem Density}

The analyses of large stem densities rendered consistent results. The upper canopy layer and large diameter trees are the most valuable and often managed for timber production. The management regimes focus harvest on the stems in these forest component groupings. The groupings are summarized individually since they are independent.

\section{$\underline{\text { Sawtimber Stand (Lindquist and Palley 1963) }}$}

The sawtimber stand described and defined by the redwood species empirical yield tables gave a surprising result considering the broad diameter range. As expected, the timber management regimes have decreased the TPA and BA density in comparison to the uncut second growth forest structure. The effects on forest structure coincide with the management regime definitions and silvicultural practices. For instance, Large Tree 
Management has significantly decreased the TPA, but the BA is not significantly different since the regime model carries a high density of large trees (Table 12, page 121). This supports the use of LTM as a viable approach to restoration forestry.

The Truncated and Percent Removal regimes also affect the sawtimber stand with a significant decrease in TPA and BA. Overall, there were no significant differences in terms of QMD. The decrease in TPA and BA density has most likely been a beneficial alteration on forest vigor since harvesting larger trees increases the amount of available growing space, water, nutrients, and light. In essence, the forest structure characterized by the Park/No cut regime is over-crowded and harvesting timber reduces the competition between trees resulting in faster growth rates and more vigorous trees.

\section{Special Harvesting Methods for Santa Cruz County (14 CCR § 926.25)}

Management has significantly affected the trees greater than 18.0 inches DBH. Percent Removal and Truncated regimes are consistently different from the Park/No Cut regime in terms of TPA and BA. In order of decreasing TPA density, the regimes rank as Park/No Cut, Unknown, LTM, Percent Removal, and Truncated, respectively. In order of decreasing BA density, the regimes rank as Park/No Cut, LTM, Unknown, Percent Removal, Truncated, respectively (Table 13, page 123). These results and trends coincide with the applied silviculture, since a greater proportion of large diameter trees are removed in the Percent Removal regime than in the Truncated regime. The Large Tree Management should have higher densities in this diameter range by regime definition, especially note this regime’s ranking for TPA versus BA. This difference highlights the concept of fewer stems but of larger diameter. Park/No Cut and Unknown regimes are unharvested and therefore very dense. 
The conifer densities between Large Tree Management and Park/No cut are not significantly different; however, the forest looks completely different. Few large trees widely spaced in the overstory with canopy closures approximately 50-60 percent characterize the Large Tree Management structure; whereas a relatively unbroken upper canopy with very little light extending to the forest floor is characteristic of Park/No Cut structure. This is only one instance where a forester must not rely on data alone to describe the forest. As previously stated, canopy closure estimates are anecdotal and comparative.

Hardwood density of trees greater than 18.0 inches DBH has had little influence from commercial timber management. The data suggests that timber harvesting has decreased the amount of hardwood density, however not at a statistically significant level. The decreased hardwood density may be attributed to silvicultural herbicide treatments or to the general favoring of conifer regeneration following harvest. Throughout the research area, modified silvicultural practices retain large diameter hardwoods, especially mast producing species. The most significant manner of retention is directional felling of conifers away from large diameter hardwoods whenever possible.

\section{Mature or Old Growth Trees (per Fox 1989)}

Management, as it pertains to forest structure, has affected the density of "mature" or "old growth" trees. The Truncated and Percent Removal regimes consistently affect the forest structure and density with significantly decreased TPA and BA. The other two management regimes, Large Tree Management and Unknown, also decreased the TPA and BA densities, however not to a significant level (Table 14, page 125). All significant differences coincide with definitions and prescriptions of the associated regimes. 
This is a major finding for this study. These results show that Large Tree Management is not significantly different than Park/No Cut in terms of the quantity and the size of the stems present. This means that this restoration forestry approach can be applied on the ground without quantitatively changing the density of a stand. However, in terms of structure and potential habitat the stand is drastically different. This could have meaningful effects on the development and review of THP's in the region for restoration.

To illustrate the difference described, I will use a metaphor. Imagine each stand is a large glass jar. The jar representing the Park/No Cut stand is filled with five-pounds of grapes. The jar representing the Large Tree Management stand is filled with fivepounds of apples. Once filled, the jars are equal in weight, but different in quantity and arrangement. At the jar-level of this example, the difference is the Large Tree Management jar contains fewer, yet larger objects than the Park/No Cut jar.

\section{Type A Owl Habitat "Medium” and "Large” Trees (14 CCR § 895.1)}

Medium (18.1-35.0” DBH) and large diameter trees (>35.0” DBH), according to the Forest Practice Rules owl habitat definition, are significantly different in terms of TPA and BA, but QMD was a poor indicator. The results trend continues with these analyses regarding similarities of the Truncated and Percent Removal regimes (Table 15, page 128). Large Tree Management and Unknown regimes were generally not significantly different from Park/No Cut. The differences noted in trees greater than 35.0 inches DBH were observed only in groups containing conifers. The density of hardwood trees of this size is minimal on the landscape, mainly due to species silvics. For hardwoods, only a handful of plots had stems that fit this diameter classification, and two 
of the five management regimes had zero occurrences of large diameter hardwoods on all plots.

Overall, the harvesting of timber has significantly decreased forest density. However, Large Tree Management data observations show more TPA (>35” DBH) than Park/No Cut. This is unique among the large diameter and overstory groupings. In most other cases, the timber management regimes have consistently fewer TPA (>35” DBH) than Park/No Cut. The timber management regimes, especially LTM due to thinning from below, have ample growing space and few restraints on growth allowing stems to grow to their full potential. Conversely, the Park/No Cut are over-crowded and competing for all available resources, which tend to limit diameter growth between 24 to 36 inches DBH.

This seemingly trivial fact of more growing space for large diameter stems has far-reaching ecological implications. Stems that are free to grow, such as those in the LTM regime, will produce wider crowns and larger branch diameters. The crowns are able to increase in complexity and structure, which in turn increases habitat. All of these outcomes are late successional characteristics, which are spawned by management practices such as LTM.

Overstory Canopy Layer (per Parisi, Motroni and Robards 2007)

The overstory canopy layer shows consistent differences with management regimes and other large tree density objectives analyzed. The Truncated and Percent Removal regimes have changed forest density and structure in terms of TPA and BA. Nevertheless, the BA densities are significantly different from the uncut second growth 
regime. The forest structure affects from timber management regimes have significantly decreased the density through harvesting.

The overstory hardwood components show little affect by management. The hardwood component in the upper canopy layer is minor, ranging from zero to approximately 12 TPA for all regimes. The overall effect of management on this scattered component is minimal.

\section{Forest Structure Analysis Summary}

This study has presented a vast number of conclusions. In summary, I would like to point out the most significant trends and conclusions. When this study began, the driving question was “Is forest management making a difference?” The results have shown that, yes, management is creating different forest structure. The surprising result is that significant changes can be seen after the first harvest. Furthermore, the results associated with the hardwood understory layer were unexpected. Whether you are cruising timber, or just hiking for pleasure, one thing is ever-present in the redwood understory...tanoak. However, the data suggests the understory composition of harvested and unharvested stands is not different. Once again, this is another reason to rely on data rather intuition.

The overstory results confirmed that many of the management regime objectives are being met. The regimes are significantly changing the overstory forest structure in the manner designed. However, the overstory TPA densities of all timber management regimes are closer to Natural origin TPA than expected. Only one regime in the study is deemed restoration management, but the trend of timber management is on par with the target stand of the restoration regime (Table 29 on page 181). In some cases, the regime 
methods directly contradict restoration objectives, which is understandable. However, the point is the majority of second growth forests are closer to the target restoration stand than originally thought. Instead of four or five restoration harvests, only two or three may be needed to achieve the restoration desired future condition. Refer to a "Brief Summary of Results for Objectives One, Two, and Three” on page 132 for all major findings.

\section{Objective Four-Late Successional Forest Classification Comparison}

There are few subjects in forestry that are debated less often and more heated than late successional or old growth forest classifications. The definitions are rarely agreed upon, structures difficult to define, and measurement protocols often render drastically varying results. In all California forest types, the Quadratic Mean Diameter is utilized for classification. The use of QMD is beneficial because it is a quantitative measure, however many of the other factors that collectively define late successional forests (LSF) are only qualitatively defined. These other factors are referred to as functional characteristics or late successional elements (LSE). The LSE are characteristics and structures such as large woody debris, snags, large diameter limbs, broken or forked tops, and basal hollows. Refer to Table 1 in the Redwood Ecology section of the Literature Review chapter for LSE and synonyms on page 34.

The comparison of QMD calculation methods resulted in definite conclusions, but the implications and interpretations may influence forest management decisions unassociated with late successional forests. The surrogate measures developed by the authors of the Swanton Pacific Ranch NTMP are acceptable in lieu practices and the analysis supports CAL FIRE's decision in finding the LSF classifications in conformance 
with the Rules. Even though the calculation methods are significantly different, the surrogate measures tend to overestimate QMD for each canopy layer. Overestimation of the QMD would lead to classifying stands as LSF more often, but due to the qualitative nature of LSE, misclassification is rare.

The combination of quantitative and qualitative measures used in the classification of LSF renders the process highly discretionary between researchers, foresters, and THP review teams. Arguments could be made for or against LSF classification even when the minimum QMD criteria are satisfied. The lack of quantitative densities for characteristics such as large woody debris and snags leaves classification dependent upon persons present, rather than current forest structure. What may seem like an overabundance of snags to one reviewer could be very few to another. This type of discretion and interpretation is common in the field of forestry, however the case of LSF is highlighted by a number of disconnects involving the quantitative measures and the policy as a whole.

The first disconnect is a minor inconsistency with the functional size of the habitat unit or stand. The methods outlined by agencies identify the habitat unit inventoried for classification should be a minimum of 40 acres (Parisi et al. 2007). The definition of LSF in the Forest Practice Rules identifies the minimum functional area as 20 acres (14 CCR § 895.1). This disconnect calls into question many practical matters of data collection, analysis, and interpretation. The agencies recommend stratification of habitats within the assessment stand; however, this may lead to a common problem in the redwoods of the Santa Cruz Mountains, and possibly throughout the redwood range. 


\section{Hypothetical LSF Classification Scenario}

A forester inventories a 40 -acre stand to determine the successional stage. The inventory states that for the entire multi-storied (CWHR size class 6) stand, the overstory QMD equals 26.7 inches and the understory QMD equals 9.4 inches. The stratified data also shows 22 acres of the stand meet the structural criteria for LSF; however, the 22 acres are dispersed throughout the stand in 10 discontinuous clumps. Most clumps are centered on residual old growth trees left during clearcutting approximately 100 years ago. Half of the clumps have additional late successional elements (snags or large woody debris) present.

A few of the issues associated with this example are: (1) should the entire 40-acre stand be classified as LSF given the QMD threshold? (2) Does the late successional element density meet the standards for LSF classification of the stand? (3) Is the spatial arrangement of the ten clumps truly discontinuous or are there species present that may view the entire 40 acres as suitable habitat? (4) What is the ultimate purpose behind LSF classification? (5) Will LSF policy ultimately change the management of second-growth forests?

In my opinion, this example would likely unfold in this manner. Although the entire 40-acre stand satisfied the QMD criteria for LSF, the entire stand would not be classified as late successional. The dispersed late successional element density in ten clumps averaging 2.2 acres in size would aid in this argument, since these clumps are far less than the 20-acre minimum size stated in the Rules. However, without quantitative thresholds for the LSE densities, a lengthy debate could ensue dependent upon the review team, the forest manager, and the species of concern present in the THP area. For this 
example, my opinion is that less than 0.5 snags per acre are not dense enough to support LSF classification (active nesting status of TES species would change this opinion). The same is true for the spatial arrangement of the clumps. The review team would refer the RPF to the agency memorandum "Disclosure, evaluation, and protection of large old trees” (Shintaku 2005). This memorandum outlines sufficient protection measures in the Rules to minimize significant on-site and cumulative adverse impacts to the LSE within the plan area. The RPF would agree to the review team recommendation since the remainder of the stand can be harvested. Special treatment zones would be designated around the ten LSE subunits and the RPF would instruct the timber operator to exclude equipment use and directionally fell away from these zones.

Finally, this mitigation is preserving the individual LSE structures, but since the remainder of the stand will be harvested, it is unlikely the stand will ever reach LSF classification, if continually managed. With this example commonly occurring in the study area, albeit exceptional from the low LSE densities, it seems the policy and regulations focus on preserving rather than promoting the late successional forest characteristics. The current LSF policy fulfills the protection and preservation of structures currently in place. By definition, these structures are decadent and decaying. The policy lacks in the area of promoting the creation or accretion of future late successional elements and habitat.

\section{LSF Policy: Protect or Promote?}

The common impression by foresters in the area is LSF classification will lead to loss of management rights to some or all timber within that stand. Uncertainty with LSF policy and agency/review team discretion can make this impression a reality. In short, 
the current "reward" for promoting late successional forest structure is the loss of timber harvesting rights. There are no incentives for forestland owners to promote late successional habitat. There are no "safe harbor” agreements in place for forestland owners seeking to create late successional habitat through applied forest management.

The lack of landowner incentives is evident with one of the stands represented in this study. After completion of data collection, one of the two Large Tree Management stands inventoried was harvested under a Truncated management regime harvest. This stand will continue to be managed under the new regime in perpetuity. Moreover, the current LSF policy has unduly influenced the managers of this stand to change management regimes in order to preserve future timber harvest rights and avoid LSF classification. I would not be surprised if forest management objectives develop in the near future that focus on maintaining an overstory QMD less than 24.0 inches DBH and actively manage to avoid LSF classification. These reasons and examples call into question the practicality of restoration management in general under the current policy.

Knowledge regarding forest restoration is minimal, yet researchers and practitioners tend to agree upon current approaches (Poage and Tappeiner 2002). Applied management through thin-from-below harvesting is the best way to increase stand diameters and mimic late successional, park-like structure (Giusti 2004). However, it is possible that current regulations could not allow thinning-from-below for restoration purposes once a stand has reached a certain successional stage, which may or may not be the desired future condition. This quandary highlights the ambiguous purpose of LSF policy in California. If the purpose is to protect, then the policy is adequate but the future distribution and densities of late successional habitats and structures are questionable. If 
the purpose is to promote, then the policy obviously falls short of the intended spirit and is counteractive to the accretion of LSF forest characteristics.

Table 28: Overstory and Understory QMD by Harvest Origin Inventory Stand

\begin{tabular}{|c|c|c|c|c|}
\hline \multirow[b]{2}{*}{$\begin{array}{c}\text { Management } \\
\text { Reginuc }\end{array}$} & \multirow[b]{2}{*}{ Stand Nane } & \multirow[b]{2}{*}{$\begin{array}{l}\text { Number of Plots } \\
\text { (II) }\end{array}$} & \multicolumn{2}{|c|}{ Quadratic Mean Diameter } \\
\hline & & & Overstory & Linderstor: \\
\hline \multicolumn{5}{|l|}{ Park/No Cut } \\
\hline & 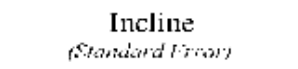 & 12 & $\begin{array}{l}32.6 \\
\text { rig; }\end{array}$ & $\begin{array}{l}10.5 \\
(1)+1\end{array}$ \\
\hline & $\begin{array}{c}\text { Lower Bridge } \\
\text { (N); }\end{array}$ & 12 & $\begin{array}{l}35.3 \\
111\end{array}$ & $\begin{array}{l}1.3 .3 \\
1101\end{array}$ \\
\hline & $\begin{array}{c}\text { Upper Bridge } \\
\text { SE; }\end{array}$ & y & $\begin{array}{l}32 . \mathrm{s} \\
11,9 j\end{array}$ & $\begin{array}{l}12.3 \\
w^{-}\end{array}$ \\
\hline & Lower Split Stuff & 9 & $\begin{array}{l}3: 2 \% \\
1 \ldots i j\end{array}$ & $\begin{array}{l}1,3.4 \\
a(t)\end{array}$ \\
\hline & Lpper Split Stuff & 12 & $\begin{array}{l}32.6 \\
1 i .3 j\end{array}$ & $\begin{array}{l}11.3 \\
\text { ari }\end{array}$ \\
\hline & $\begin{array}{l}\text { Lagoon } \\
\text { s:s }\end{array}$ & 6 & $\begin{array}{l}27.2 \\
2.2 \%\end{array}$ & $\begin{array}{l}10.5 \\
(1 / 6)\end{array}$ \\
\hline & $\underset{N \infty:)}{O}$ & y & $\begin{array}{l}+\ldots 1 \\
2.23 j\end{array}$ & $\begin{array}{l}12.8 \\
11 \%\end{array}$ \\
\hline \multicolumn{5}{|l|}{ Truncilcd } \\
\hline & $\underset{\text { Stand E }}{\text { St: }}$ & 6 & $\begin{array}{l}309 \\
2-9\end{array}$ & $\begin{array}{l}10,0 \\
113\end{array}$ \\
\hline & 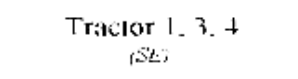 & 6 & $\begin{array}{l}28 \% \\
1+\ldots ;\end{array}$ & $\begin{array}{l}9 y \\
0: 1\end{array}$ \\
\hline & $\underset{\substack{\text { Triclor } \\
\text { NES }}}{\text {. } 6}$ & 9 & 29.7 & $\begin{array}{r}8.6 \\
(a+1)\end{array}$ \\
\hline & $\begin{array}{c}\text { Tractor } 8.9 .10 \\
\text { ( }\end{array}$ & 9 & $\begin{array}{l}25.7 \\
11 .+i\end{array}$ & $\begin{array}{c}8.3 \\
(1)+1\end{array}$ \\
\hline & $\begin{array}{c}\text { Cable } 3 \\
\text { int }\end{array}$ & 6 & $\begin{array}{l}28.9 \\
r i e\end{array}$ & $\begin{array}{r}9.8 \\
m b i\end{array}$ \\
\hline \multicolumn{5}{|c|}{ Large Trec Management } \\
\hline & $\begin{array}{l}\text { Lale Successional Unil } \\
\qquad\end{array}$ & ) & $\begin{array}{l}34.5 \\
11.15\end{array}$ & $\begin{array}{l}15.3 \\
1 \% ? 3\end{array}$ \\
\hline & $\begin{array}{c}\text { Tranquility Flats } \\
\text { (St; }\end{array}$ & 9 & $\begin{array}{l}360 \\
17\end{array}$ & 11.4 \\
\hline \multicolumn{5}{|l|}{ Percent Removal } \\
\hline & 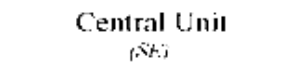 & 9 & $\begin{array}{l}360 \\
11.95\end{array}$ & $\begin{array}{l}10.6 \\
10-5\end{array}$ \\
\hline & $\begin{array}{c}\text { Amaya Wost } \\
\text { AE; }\end{array}$ & 12 & $\begin{array}{l}30.9 \\
2 \therefore .7\end{array}$ & $\begin{array}{l}10.6 \\
6.9\end{array}$ \\
\hline & Amayn East & 12 & $\begin{array}{l}28.8 \\
1 ! 1 !\end{array}$ & $\begin{array}{l}10.9 \\
10.5\end{array}$ \\
\hline & Long Ridge & ) & $\begin{array}{l}30.7 \\
11 . x\end{array}$ & $\begin{array}{l}11.8 \\
(1) \times 2\end{array}$ \\
\hline & 2001 Northeast & 6 & $\begin{array}{l}322 \\
1235\end{array}$ & $\begin{array}{l}11.4 \\
1201\end{array}$ \\
\hline & Upper McCormick & 9 & $\begin{array}{l}+2.1 \\
+3.2 ;\end{array}$ & $\begin{array}{l}104 \\
10 \%\end{array}$ \\
\hline & $\underset{\mathrm{N}}{\text { Raunscy }}$ & 9 & $\begin{array}{l}23.3 \\
11.23\end{array}$ & $\begin{array}{l}10.9 \\
6 ?\end{array}$ \\
\hline \multicolumn{5}{|l|}{ Lnknonn } \\
\hline & $\underset{+\infty}{\text { Gazos Falls }}$ & 12 & $\begin{array}{l}320 \\
205 \\
2-5\end{array}$ & $\begin{array}{l}10.2 \\
61+1\end{array}$ \\
\hline
\end{tabular}


Another disconnect of the classification method is the QMD threshold. Twentytwo harvest origin stands were inventoried for this study, of which only one did not meet the QMD criteria for LSF. It should be noted that the one stand failing to meet the quantitative LSF criteria fell short of the overstory minimum QMD of 24.0-inch DBH by a mere 0.7 inches. The largest overstory QMD for a harvest origin stand was 42.1 inches DBH (Table 28, previous page). All other stands satisfied the overstory, understory, structure, and canopy closure criteria. Figure 17 (next page) depicts the overstory and understory QMD relationship by management regime. However, a few stands failed to meet the Rules 20-acre minimum standard. Based on field observations and stand structure notes, I believe that none of these stands would classify as LSF based on insufficient LSE occurrence stand-wide. With this many iterations across various stand structures of second growth redwood, the use of the 24.0-inch minimum QMD threshold is questionable. The data suggests that when a harvest origin stand reaches a 24.0 inch QMD, the stand is still young and vigorous with very few, if any, signs of decadence. While a QMD of 24.0 inches may be a feasible threshold for other forest types in California, the number does not aid identification of LSF redwoods of the Santa Cruz Mountains. 
Figure 17: Overstory and Understory QMD by Management Regime

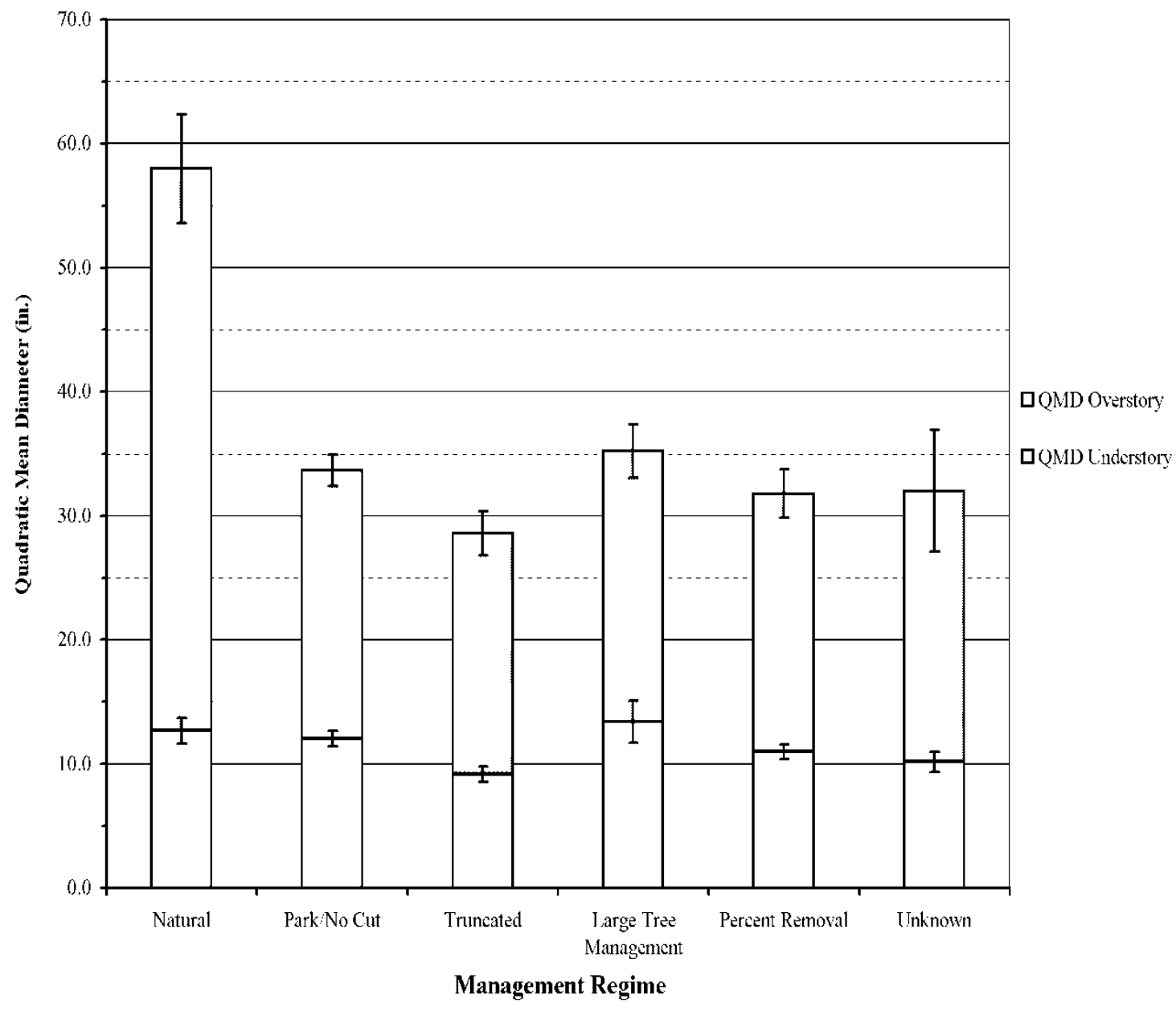

Figure 17: Error bars represent 2*Standard Error 


\section{Recommendations}

Most of the management regimes assessed in this study have been tried and tested over long periods. They have continually achieved the goals and objectives of the landowners, and conform to the regulations and policies of the counties and California. However, the Large Tree Management regime is a relatively new approach to restoration forestry, especially in the redwoods. Specific prescriptions and target densities are generalized in the fledgling science of restoration. Therefore, the recommendations from this study are focused on late successional forest classification and policy, and applied restoration management of redwoods in the Santa Cruz Mountains. It should also be noted that this is only one of many approaches to restoration forestry.

\section{Late Successional Forest Policy and Classification}

A lot of weight is placed on QMD in the classification of late successional forests in California. The measure is best suited for describing stand structure, especially when divided into canopy layer components. However, the application and minimum thresholds of this measure for classifying LSF are in need of review.

The first modification I recommend is to increase the LSF minimum QMD criteria. Regulation of the California’s forests has been divided into districts broadly based on forest type. These districts should be utilized with respect to the LSF minimum overstory QMD. For the Coast district, largely comprised of coast redwood and Douglasfir forests, I recommend the LSF minimum overstory QMD be increased to between 30.0 and 36.0 inches DBH. Further research is needed to determine the precise diameter for this and the other two districts. However, the threshold of 24.0 inches seems arbitrarily 
chosen given 21 of 22 harvest-origin inventory stands met the minimum QMD criteria, yet al.l 22 stands lacked sufficient LSE densities to be classified LSF.

Policy makers and researchers should strive to find quantitative thresholds for late successional elements, which are currently qualitatively described. The most biologically significant LSE is most likely snags. The efforts should begin with attempting to quantify a minimum threshold for snag density related to LSF structure.

Since the forests are widely variable, I also recommend that instead of a finite number, such as 2.0 snags per acre, the policy framers should consider a relative proportion based on a stand density measure, such as a snag percent per TPA greater than 14.0 inches DBH. This percentage of snags per merchantable tree density would thereby adjust dependent upon the density of the stand. Further research is needed to determine actual proportional snag density, but I estimated a range of $1.5-3.0 \%$ of snags per merchantable TPA as a minimum threshold for LSF classification. Subsequent methods, measures, and thresholds for downed woody debris and large branch diameters should follow. The addition of quantifiable measures for LSE would aid in minimizing the amount of widely varying discretion seen in plan review.

The purpose and spirit of late successional forest policy should also be examined. It is my contention current LSF policy is counteractive to the promotion and accretion of LSF structure. Incentives should be in place for landowners actively managing forests for restoration purposes. Many of these of lands are held by non-profit organization and conservation easements. The restoration harvests are not driven by profit, but need to be economically feasible for the owners to move forward with the plans. Under current policy, restoration projects may be halted prior to the desired future condition being 
reached. Success of restoration could be measured by site occupation of an endangered species (e.g. Marbled Murrelet ). Nevertheless, when and if this occurs, future thin-frombelow harvests may not be allowed. This is just one example of situations that could restrict restoration harvests.

\section{Landowner Incentives}

I propose two options to increase landowner incentives in restoration management. The first is the development of a "safe harbor" agreement focused on late successional forest creation or rehabilitation. This agreement could allow the landowner to retain some property and timber rights in the instance a non-LSF stand is accelerated into a classified LSF state through applied management. Similar agreements are in place regarding landowners creating or restoring wetland habitat for amphibians and birds. The retained property rights may not allow the landowner to remove the created or restored LSF habitat, but it should allow for continuing restoration activities.

The second option is to amend a new form of uneven-aged silviculture to the Forest Practice Rules (14 CCR § 913.2). Alternative to the safe harbor agreement, the proposed form of silviculture, entitled “restoration,” could outline the methods used in the Large Tree Management regime and commercial thin-from-below harvesting. Certain stipulations could be codified to allow commercial harvesting after the stand has been classified as LSF, since the purpose of the silviculture is to promote threatened or endangered habitat. Special protection measures regarding take and jeopardy of threatened or endangered species could also be developed if one of the listed species occupies the site. Furthermore, if codified into the Rules, "restoration" silviculture could be easily adapted for different forest types according to the three forest districts, based on 
the format of the Rules. It is understandable that amending a new form of silviculture would take much time and effort. However, the process of amending the Rules undertaken by the California Board of Forestry and Fire Protection is the greatest benefit. The process would mobilize resource agencies, researchers, forest industry, non-profit organizations and the public to disclose and discuss the issues surrounding LSF policy and forest restoration.

Either of these recommendations would provide sufficient incentive to promote the creation of late successional forests or to continue applied restoration management in California. Late successional forest policy, as with most aspects concerning late successional forests, is still in its infancy. Quantifiable measures of LSF and LSE are not a panacea for the policy. Additional and alternate methods need to be sought that are mutually agreeable by agencies and landowners, and are beneficial to the forest ecosystem.

\section{Applied Restoration Management}

Having collected data and assessed harvest and natural origin stands, the recommendations for applied restoration management rely on these data and are specific to the minimum stand criteria established for this study. Natural origin stand data from Big Basin Redwoods State Park and Soquel Demonstration State Forest define the target stand.

Changing a forest's structure through management cannot be completed overnight, nor can it be accomplished with one harvest. Although this study has shown that one harvest entry can significantly alter forest components, the desired future condition of the stand may not be attained for at least three entries. Similar to most other 
forest management, restoration silviculture should be applied in an adaptive manner. This implies that even the best-developed management plan may be tossed into the recycling bin after the first cutting cycle and re-written.

Silvicultural prescriptions for restoration should focus on TPA density and overstory spacing. First, the Special Harvesting Methods for Santa Cruz County (14 CCR § 926.25) outlines allowable harvest volume based on TPA density. Prescriptions compliant with this rule are adaptable to suit restoration silviculture at this time. Second, regulating basal area appears to be an insurmountable task considering that the desired future condition requires the accumulation of an additional 200-450 square feet per acre, nearly double the present BA density. Converse to most timber management regimes, this accumulated basal area should be concentrated on a few select stems, rather than distributed throughout the stand. Therefore, density control by TPA and spacing is recommended.

There are other reasons that density should be controlled by TPA and spacing. By spacing out the overstory stems in the stand and thinning to a target TPA, the distance between crowns is increased. With more growing space, the stems will be able to increase primary and secondary growth, by which crown width and branch diameters will be increased. Increased distance between crowns will also allow for more wind passage through the canopy, and higher likelihood of wind damage to the crowns. This silvicultural treatment will ultimately lead to large crown widths, large diameter branches, and crowns with complex/reiterated structure, which are all desirable latesuccessional forest characteristics. 
This study has also noted low occurrences of LSE. Restoration managers should consider a proactive approach to LSE accretion. Logs or whole trees could be left on the forest floor, rather than hauled to the mill. The "donation" to the forest of logs less than 36 inches in diameter would be most beneficial in debris piles. Logs larger than 36 inches could be left solitary to develop into nurse-logs. Snag creation by intentionally girdling and/or topping below the live crown is plausible. Topping below the live crowns reduces the hazard of falling debris from recently girdled stems. Topping of trees to induce reiteration or to create platforms could also be done. Many of these activities could be completed with minimal time and money if planned prior to harvesting. The main drawbacks to these activities are safety and liability. 
Figure 18: Typical Natural Regime Plot Photograph

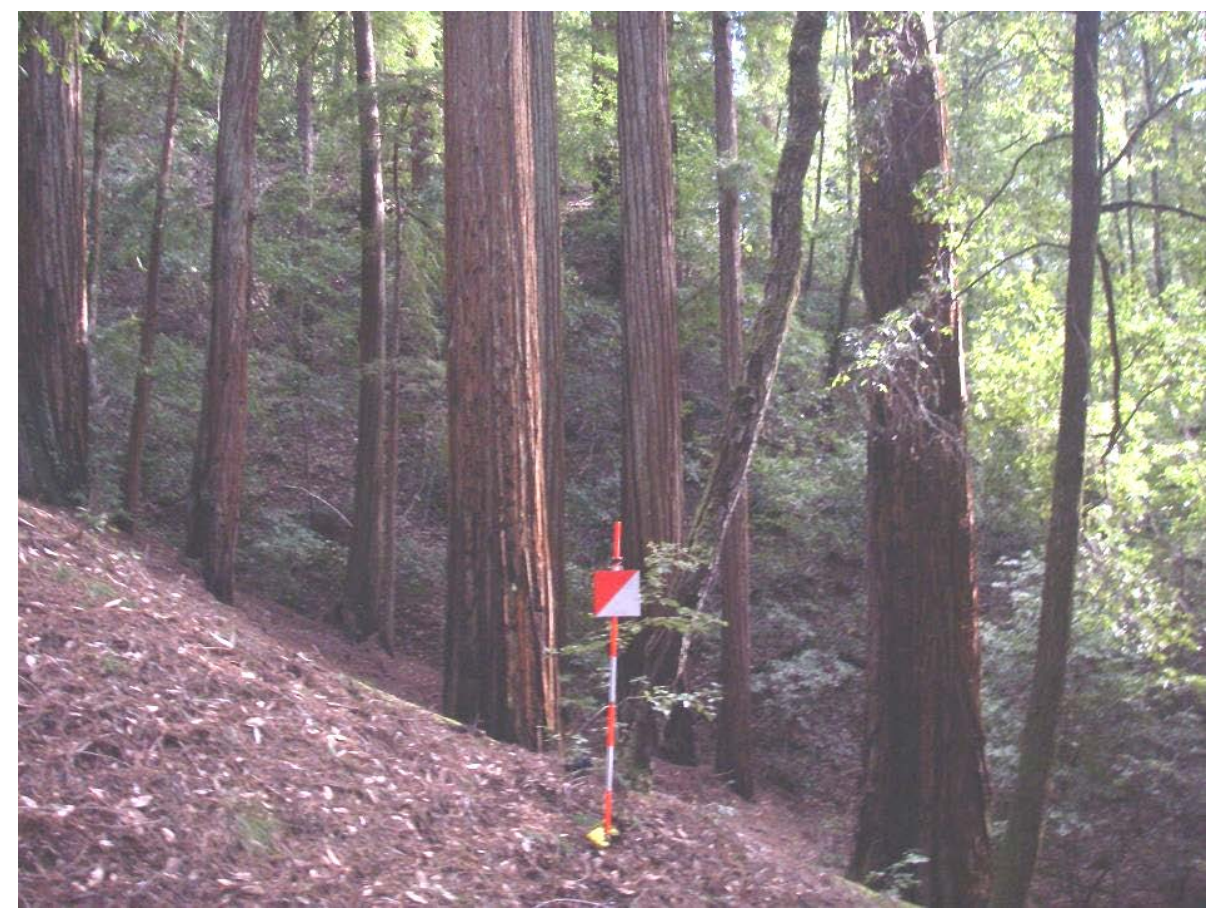

Figure 18: Big Basin Redwoods SP, North Escape stand; plot 2B; photo direction South.

\section{LSF Target Sand (Desired Future Condition)}

The typical TPA density of the target stand is approximately 200, with 10-20 percent of these trees in the overstory. The remaining stems occur in the understory with very little regeneration. Basal area density of the target stand is greater than 700 square feet per acre and overstory QMD is greater than 50 inches DBH (Figure 18). The composition of the target stand should balance evenly between conifer and hardwood, plus or minus 10 percent. However, the overstory composition is commonly 95-99 percent conifer. The spacing of the overstory trees in this target stand is between 30 and 45 feet. The spatial arrangement of trees varies from uniformly or randomly distributed to no greater than nine clumps per acre. Spatially clumped redwood stands have 1-3 overstory trees and 4-8 understory trees per clump. With this clumped arrangement, the 
spacing between clumps is approximately 70 feet; otherwise, the spacing between randomly arranged overstory redwoods is approximately 35 feet. Hardwood trees are usually arranged randomly in the areas between the redwood clumps. Specific density measures and data of natural origin stands are presented in Tables 4, 5, and 6 on pages 98,100 , and 102, respectively.

Table 29: Summary of Target Stand and Potential Restoration Stand Descriptions

\begin{tabular}{|c|c|c|c|c|}
\hline \multirow{2}{*}{$\begin{array}{l}\text { Forest Component or } \\
\text { Descriptive Attribute }\end{array}$} & \multicolumn{2}{|c|}{ Target Stand } & \multicolumn{2}{|c|}{ Potential Restoration Stand } \\
\hline & Nominal Range & Percent Range & Nominal Range & Percent Range \\
\hline \multicolumn{5}{|l|}{ Density Measures: } \\
\hline \multicolumn{5}{|l|}{ Trees per acre: } \\
\hline$>2.0^{\prime \prime}$ & $185-215$ & 100 & $230-290$ & 100 \\
\hline Overstory & $20-40$ & $10-20$ & $40-60$ & $15-30$ \\
\hline Conifer & $80-100$ & $40-60$ & $135-165$ & $50-65$ \\
\hline \multicolumn{5}{|l|}{ Basal area $\left(\mathrm{ft}^{2} /\right.$ acre $)$ : } \\
\hline$>2.0^{\prime \prime}$ & $>700$ & 100 & $350-430$ & 100 \\
\hline Overstory & $550-650$ & $80-95$ & $220-305$ & $55-75$ \\
\hline Conifer & $620-740$ & $80-95$ & $290-370$ & $70-90$ \\
\hline \multicolumn{5}{|l|}{$\begin{array}{l}\text { Quadratic mean } \\
\text { diameter (in.): }\end{array}$} \\
\hline$>2.0^{\prime \prime}$ & $26-30$ & -- & $15-19$ & -- \\
\hline Overstory & $>50$ & -- & $28-36$ & -- \\
\hline Conifer & $39-43$ & -- & $20-23$ & -- \\
\hline Snags per acre ${ }^{a}$ : & $3-6$ & $1.5-3.0$ & $\mathrm{~N} / \mathrm{A}$ & $\mathrm{N} / \mathrm{A}$ \\
\hline \multicolumn{5}{|l|}{ Spatial arrangement: } \\
\hline Clumps per acre & $<9$ & -- & $18-24$ & -- \\
\hline Overstory trees per clump & $1-3$ & -- & $1-2$ & -- \\
\hline Understory trees per clump & $4-8$ & -- & $5-9$ & -- \\
\hline Clump spacing (ft.) & $65-75$ & -- & $40-50$ & -- \\
\hline Random spacing (ft.) & $30-40$ & -- & $\mathrm{N} / \mathrm{A}$ & -- \\
\hline Overstory tree spacing (ft.) & $30-45$ & -- & $25-35$ & -- \\
\hline
\end{tabular}

a Recommended LSF minimum snag density threshold (this volume) 
Within the study area of harvest origin stands, the percent of overstory trees ranges between 15-30 percent, or 40-60 TPA (Figure 19, page 183). The target stand of the desired future condition has approximately 20-40 overstory TPA. A general guideline for the overstory TPA range of the target stand is TPA decreases as slope increases. Therefore, the majority of harvest activities will focus on the spacing of the understory around the selected overstory trees. Given the overstory density, only 1-4 overstory TPA will be harvested per entry. Economic feasibility is a major hurdle to overcome with the bulk of the harvest volume comprised of small diameter logs. The art of forestry will be a factor in determining the harvest volume from the overstory and understory to cover harvest operation costs while not cutting below the target densities.

“Opening up” a stand has many pros and cons that will influence the desired future condition. Equilibrium must be attained between spacing too wide and too close. For restoration purposes, a wide overstory tree spacing ( $>45 \mathrm{ft}$.) can accomplish many beneficial tree and forest characteristics. The wide spacing induces canopy diameter increase and promotes the development of large diameter branches. Wide spacing also increases the likelihood of upper canopy wind damage, such as broken tops that may reiterate, creating complex structure. Conversely, a spacing that is too wide can allow for catastrophic wind damage to a stand, where the majority of trees are windthrown or broken at the base of the live crown. Wide spacing also increases light availability to the forest floor, which will increase growth of understory trees and plants. Tight spacing of overstory trees will shade out understory growth, but this approach does not significantly reduce competition for overstory trees. Growth rates of the selected trees may not 
improve. The restoration management of redwoods will ultimately come down to clumpby-clump assessment when marking harvest trees.

Figure 19: Typical Large Tree Management Regime Plot Photograph

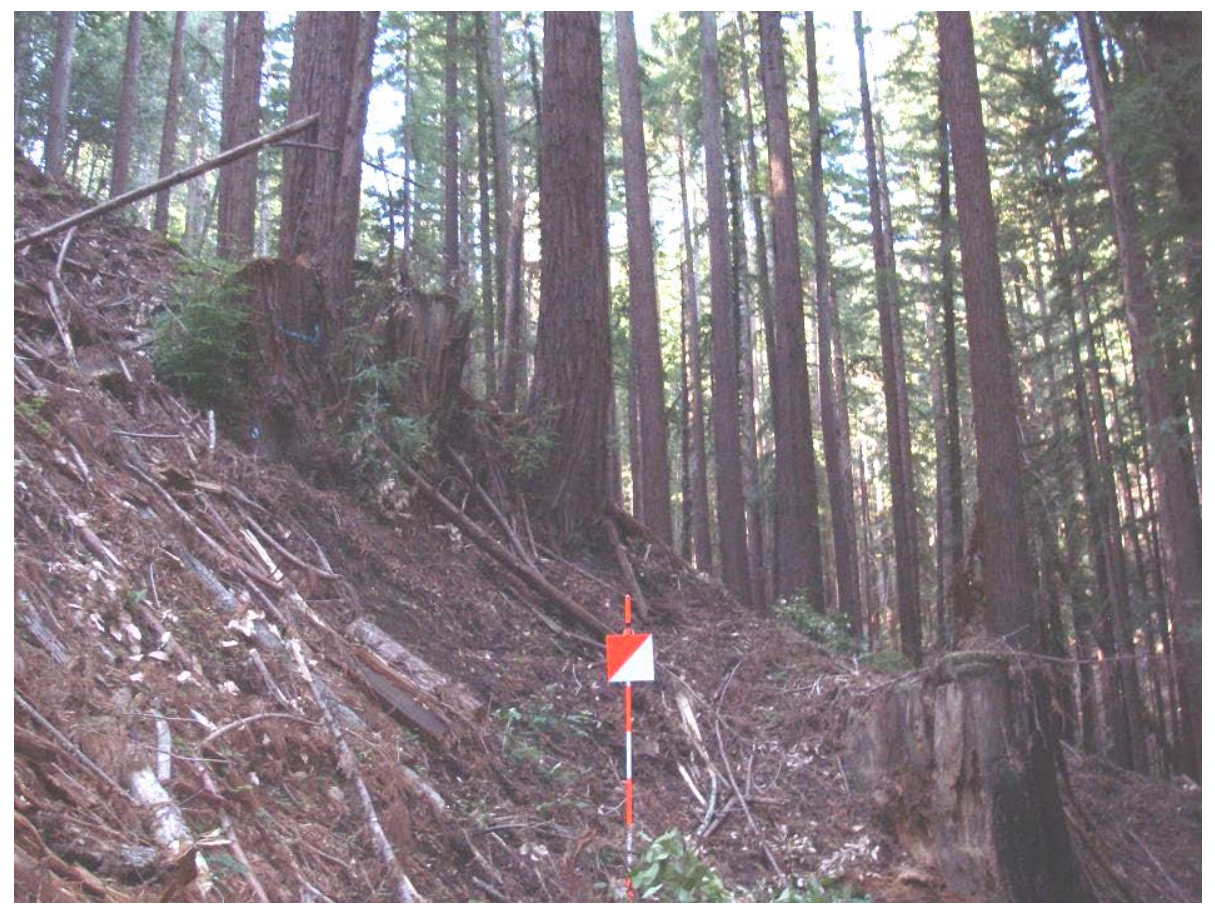

Figure 19: The Byrne Forest, Late Successional Unit stand; plot 3B; photo direction West.

The common approach for spacing and harvest tree marking is thin-from-below.

Ideally, all stems under the dripline of the selected overstory trees shall be harvested.

The area between the overstory trees should be thinned, but an intermediate canopy of conifers and hardwoods should be retained to reduce light to the understory and wind passage through the stand.

TPA density must be regulated through the harvest cycles. The density should not be reduced to the target stand levels after one entry, and in some cases cannot be, pursuant the Forest Practice Rules. The TPA density should be regulated throughout the 
harvest rotation of two to four entries. This approach will also reduce the likelihood of “opening up” the stand to potential adverse impacts.

Controlling the amount of ingrowth is also a major management concern. Prolific coppice regeneration of redwood and tanoak will need to be controlled. The most effective control is by chemical or mechanical means, but many restoration stands may be candidates for third-party sustainable certifications, which may prohibit some treatments. However, it is unknown how post-harvest stocking reports will be viewed by the agencies during the second or third harvest cycle. Currently, the stands are considered "obviously stocked upon completion,” but with the continual decrease of understory tree density and fewer, but larger overstory trees, the stocking levels may be called into question. This is another valid argument for the creation of a "restoration" silviculture in the Rules.

\section{Project Summary}

This project has explored a vast array of questions, forest components, conclusions, and a few sweeping recommendations. This section will summarize the central findings of the project as a whole and present them in a non-scientific manner.

The findings from the General Stand Components objective confirmed that natural origin and harvest origin stands are different. This is obvious to the hiker and the forester alike. There seems to be a stage in forest succession missing between the origin types, and this missing stage is not represented in the dataset. However, the Large Tree Management regime may be bridging that gap, as it is a valid approach to restoration forestry in the redwoods in my opinion.

The analysis of Small Stem Density and Distributions provided the most compelling results. For years, foresters have been battling tanoak in the understory. It 
was perceived that harvesting timber was causing tanoak to thrive and was creating a hardwood-dominated understory. The data and analysis do not support this perception. Harvested or unharvested forests, tanoak is constant. It is a competitive, shade-tolerant hardwood species that thrives under the redwood canopy because that is the tanoak's ideal niche. Furthermore, this objective showed that even miniscule prescriptions, such as a cleansing cut for malformed trees 14-18 inch DBH could significantly alter forest structure and density. The data also suggested that harvesting of conifers increases the amount of conifer regeneration, as would be expected due to redwood's stump sprouting ability. The remaining differences noted by the analysis conformed to definitions and prescriptions of the respective management regime.

The Large Stem Density objective continued the trend from previous objectives. The majority of significant differences were either anticipated or conformed to the treatments of the regime. This objective also warned not to rely solely on data, because there is no substitute for a keen pair of eyes and good pair of boots (refer to Conclusions for Large Stem Density- Special harvesting methods of Santa Cruz County on page 161). In my opinion, the Park/No Cut stands are drastically overcrowded. This is a warning light flashing bright, because as the forest begins to thin naturally, the volume of standing and downed fuels will increase dramatically concurrent with the threat of catastrophic wildfire.

Even though the two methods of LSF classification were found to be significantly different, in my opinion, it does not matter. The classification process relies on weak, descriptive criteria and discretion by whomever is assigned to the CAL FIRE review team. The mathematical calculation of QMD by canopy layer is needed; however, it does 
not strengthen the process if 95 percent of stands meet the quantitative measure only to have zero stands meet the descriptive criteria, rendering zero LSF stands. In order to find consistency, we must strive to find a working classification method that is adaptable to various forest types, given the diversity of California's forestlands. Furthermore, the LSF policy is in need of revision. Currently, the LSE in the forest are being protected, but we need to measure how much of each type exists at various stages of forest growth.

As a forester, I am obligated to manage all values of the forest for our children, our grandchildren, and our great-grandchildren. Incentives for landowners to not only protect, but promote late successional forest characteristics need to be developed so that future generations can enjoy magnificent, mature redwood forests in perpetuity. 


\section{REFERENCES}

Ahuja, M. Raj and D. B. Neale. 2002. Origins of polyploidy in coast redwood (Sequoia sempervirens (D. Don.) Endl.) and relationship of coast redwood to other genera of Taxodiaceae. Silvae Genetica, Vol. 51: 2-3 Pp. 93-100.

Arvola, T.F. 1962. Forest practice regulation in California. Journal of Forestry, Vol. 60: 8. Pp. 872-6.

1970. State versus local forest practice regulation in California. Journal of Forestry, Vol. 68: 7. Pp. 688-91.

--------. 1976. Regulation of logging in California: 1945-1975. Division of Forestry, Department of Conservation, Sacramento, CA.

-. 1985. The maturing of California state forestry, 1943-47. Journal of Forest History, Vol. 29: 1. Pp.22-29, 31.

Avery, Thomas E. and Harold E. Burkhart. 2002. Forest measurements. Fifth ed. McGraw-Hill, Inc. New York. Pp. 11-70, 144-167, 196-229.

Becking, Rudolf W. 1967. The ecology of the coastal redwood forests of Northern California and the impact of the 1964 flood upon redwood vegetation. Final Report, National Science Foundation Grant GB \#3468.

---------. 1996. Seed germination capacity and seedling survival of the coast redwood (Sequoia sempervirens). In: Proceedings of the conference on coast redwood forest ecology and management. June 18-20, 1996. Arcata, CA: Humboldt State University.

Bega, Robert V., tech. coord., 1978. Diseases of Pacific Coast conifers. U. S. Department of Agriculture, Agriculture Handbook 521. Washington, DC. Pp. 206.

Biswell, H. H., H. Buchanan and R. P. Gibbens. 1966. Ecology of the vegetation of a second-growth Sequoia forest. Ecology, Vol. 47: 4. Pp. 630-34.

Bolsinger, Charles L. and Karen L. Waddell. 1993. Area of old-growth forests in California, Oregon, and Washington. Resource. Bulletin. PNW-RB-197. Portland, OR: USDA, Forest Service, Pacific Northwest Research Station. 
Bonnicksen, Thomas M. 2000. America's ancient forests: from the ice age to the age of discovery. John Wiley and Sons, Inc. New York. Pp. 594.

Brean, R. and L. Svensgaard-Brean. 1998. Prescribed burning in state parks: a perspective. California Parklands (Spring). In: Reed F. Noss, ed. The redwood forest, history, ecology, and conservation of the coast redwoods. Island Press, Washington, DC.

Brooks, Kenneth N., Peter F. Ffolliott, Hans M. Gregersen and Leonard F. DeBano. 2003. Hydrology and the management of watersheds. Iowa State Univ. Press. Ames, IA.

Brown, P. M. and T. W. Sweetnam. 1994. A cross-dated fire history from coast redwood near Redwood National Park, California. Canadian Journal of Forest Research, Vol. 24: 2131.

Burns, Russell M., and Barbara H. Honkala, tech. coords. 1990. Silvics of North America: 1. Conifers; 2. Hardwoods. Agriculture Handbook 654. U.S. Department of Agriculture, Forest Service, Washington, DC. Vol. 2. Pp. 877. California Department of Forestry and Fire Protection (CAL FIRE). 2008. CAL FIRE Incident Report- "Summit Fire” (Final: 30 May 2008, accessed Oct. 2010); available from: $\underline{\text { http://bof.ca.gov/incidents/incidents_details_info?incident_id=263 }}$ --. 2009. CAL FIRE Incident Report- "Lockheed Fire” (Final: 23 Aug. 2009, accessed Oct. 2010); available from: http://bof.ca.gov/incidents/incidents_details_info?incident_id=361 - 2010. California Forest Practice Rules 2010. Title 14, California Code of Regulations (CCR), Chapters 4, 4.5, and 10. Sacramento, CA.

California Oak Mortality Task Force. 2002. UC researchers confirm coast redwood and Douglas-fir as hosts for Sudden Oak Death pathogen. News Release Sept. 4, 2002.

Camann, Michael A., Karen L. Lamoncha and Laura E. Hagenhauer. 2004. Legacy trees maintain soil and litter microarthropod abundance and assemblage organization in managed secondary redwood forests. Project final report for Save the Redwoods League. San Francisco, CA. 
Carranco, Lynwood and John T. Labbe. 1975. Logging the redwoods. Caxton Printers. Caldwell, ID.

Clar, C. Raymond. 1959. California government and forestry: from Spanish days until the creation of the Department of Natural Resources in 1927. Division of Forestry, Department of Natural Resources. Sacramento, CA.

1969. California government and forestry- II: during the Young and Rolph administrations. Division of Forestry, Department of Natural Resources, Sacramento, CA.

Clements, Frederic E. 1936. Nature and structure of the climax. The Journal of Ecology, Vol. 24: 1 Pp. 252-84.

Cole, Dana W. 1983. Redwood sprout growth three decades after thinning. Journal of Forestry, Vol. 81: 2. Pp. 148-50.

Cubbage, Frederick W. 1995. Regulation of private forest practices: what rights, which policies? Journal of Forestry, Vol. 93: 1. Pp. 14-20.

Davis, Lawrence S., Lawrence W. Ruth, Dennis E. Teeguarden, and Russell K. Henly. 1991. Ballot box forestry: tremors from the California epicenter. Journal of Forestry, Vol. 89: 8. Pp 10-18.

Davis, Lawrence S., K. Norman Johnson, Peter S. Bettinger and Theodore E. Howard. 2001. Forest management: to sustain ecological, economic, and social values. Fourth ed. McGraw-Hill, Inc. New York. Pp. 26-180.

Dicus, Christopher A. and Kenneth Delfino. 2003. A comparison of California forest practice rules and two forest certification systems. Urban Forest Ecosystem Institute, California Polytechnic State Univ., San Luis Obispo, CA.

Douhovnikoff, Vladimir, Adelaide M. Cheng and Richard S. Dodd. 2004. Incidence, size and spatial structure of clones in second-growth coast redwood, Sequoia sempervirens (Cupressaceae). Journal of American Botany, Vol. 91: 7 Pp. 1140-6.

ESRI, Inc. 2006. ArcGIS release 9.2 software. 380 New York St., Redlands, CA 92373.

Finney, Mark A. 1996. Development of fire scar cavities on old-growth coast redwood. Pp. 86-89. In: Proceedings of the conference on coast redwood forest ecology and management. June 18-20, 1996. Arcata, CA: Humboldt State University. 
Florence, R. G. 1965. Decline of old-growth redwood forests in relation to some soil microbiological processes. Ecology, Vol. 46: 1\&2. Pp. 52-64.

Fox, L. 1989. A classification, map, and volume estimate for the coast redwood forest in California. Final Report. Interagency agreement \# 8CA52849. The Forest and Rangeland Resources Assessment Program. CDF. Sacramento, California. Pp. 37. 1996. Current status and distribution of coast redwood. In: Proceedings of the conference on coast redwood forest ecology and management. June 18-20, 1996. Humboldt State University, Arcata, CA.

Franklin, Jerry F. and Thomas A. Spies. 1991a. Ecological definitions of old-growth Douglas-fir forests. Pacific Northwest Research Station, USDA Forest Service. Portland, OR. General Technical Report PNW-GTR-285 Pp. 61-69.

1991b. Composition, function, and structure of old-growth Douglas-fir forests. Pacific Northwest Research Station, USDA Forest Service. Portland, OR. General Technical Report PNW-GTR-285 Pp. 71-90.

FRAP, 2003. The Changing California: Forest and Range 2003 Assessment Summary. Fire and Resource Assessment Program (FRAP), California Department of Forestry and Fire Protection. State of California. Pp.197.

Fritz, Emmanuel. 1931. The role of fire in the redwood region. Journal of Forestry, Vol. 29: 939-950.

----------. 1938. Growth of redwood trees left after selective logging. Timberman, Vol. 39: 14-16, 53-56.

1945. Twenty years' growth on a redwood sample plot. Journal of Forestry, Vol. 43: 30-36.

Furniss, R. L., and V. M. Carolin. 1977. Western forest insects. U.S. Department of Agriculture, Miscellaneous Publication 1339. Washington, DC. 654 p.

Gasser, Donald P. 1996. Forest codes of practice: contributing to environmentally sound forest operations. FAO Forestry Paper No. 133.

Giusti, Gregory A. 2004. Management practices related to the restoration of old forest characteristics in coast redwood forests. Final Report. Save the Redwoods League. San Francisco, CA. 
Guldin, J.M. 1991. Uneven-aged BDq Regulation of Sierra Nevada Conifers. Western Journal of Applied Forestry, Vol. 6: 2. Pp. 27-32.

Halbert, Portia. 2007. Personal communication with author. California State Parks Ecologist, Santa Cruz District. August 10, 2007.

Helms, John A., ed. 1998. The Dictionary of Forestry. Society of American Foresters. Bethesda, MD.

Helms, J.A. and C. Hipkin. 1996. Growth of coast redwood under alternative silvicultural systems. Pp. 65-68. In: Proceedings of the conference on coast redwood forest ecology and management. June 18-20, 1996. Humboldt State University, Arcata, CA.

Hepting, George H. 1971. Diseases of forest and shade trees of the United States. U.S. Department of Agriculture, Agriculture Handbook 386. Washington, DC. Pp. 658.

Hickman, James, ed. 1993. The Jepson manual: higher plants of California. University of California Press. Los Angeles, CA.

Hobbs, R. J. 2004. Forum: Restoration ecology: the challenge of social values and expectations. Frontiers in Ecology and the Environment, Vol. 2: 43.

Hobbs, R. J. and D. A. Norton. 1996. Towards a conceptual framework for restoration ecology. Restoration Ecology, Vol. 4: 93.

Holland, V. L. and David J. Keil. 1995. California vegetation. Kendall/Hunt Publishing Co. Dubuque, IA.

Ice, George, Liz Dent, Josh Robben, Pete Cafferata, Jeff Light, Brian Sugden and Terry Cundy. 2004. Programs assessing implementation and effectiveness of state forest practice rules and best management practices in the West. Water, Air, and Soil Pollution: Focus, Vol. 4. Pp. 143-69.

Keddy, P. A. and C. G. Drummond. 1996. Ecological properties for the evaluation, management, and restoration of temperate deciduous forest ecosystems. Ecological Applications, Vol. 6: 748.

Keeley, Jon E. 2002. Native American impacts on fire regimes of the California coastal ranges. Journal of Biogeography, Vol. 29: 303-20.

Krumland, Bruce. 2007. E-mail correspondence with author. July 13, 2007. 
Laaksonen-Craig, Susanna, George E. Goldman and William McKillop. 2003. Forestry, forest industry, and forest products consumption in California. Publication 8070, Division of Agriculture and Natural Resources, Univ. of California.

Leak, W.B. 1964. An Expression of diameter distribution of unbalanced, uneven-aged stands and forest. Forest Science, Vol. 10: 39-50. -. 1965. The J-shaped probability distribution. Forest Science, Vol. 11: 405-9.

Lindquist, J. L. 2004. Growth and yield report for the Whiskey Springs redwood commercial thinning study: a twenty-nine year status report (1970-1999). California Forestry Report No. 3. California Department of Forestry and Fire and Protection. Sacramento, CA. Pp. 25.

Lindquist, J.L. and M.N. Palley. 1963. Empirical yield tables for young-growth redwood. University of California, Agricultural Experiment Station Bulletin 796. Pp. 47. Maclean, Norman. 1992. Young men and fire. Univ. of Chicago Press. Chicago, IL. Maloney, P. E., D. M. Rizzo, T. Y. Harnik and M. Garbelotto. 2002. First report of Phytophthora ramorum on coast redwood in California. Plant Disease, Vol. 86: 11. Pp. 1274.

Martin, Edward F. 1989. A tale of two certificates: the California forest practice program, 1976 through 1988. Department of Forestry and Fire Protection, Sacramento, CA.

Mason, David T. 1922. California redwood. General report. Division of Forestry, Department of Conservation. Sacramento, CA.

Mazurek, M. J. and William J. Zielinski. 2004. Individual legacy trees influence vertebrate wildlife diversity in commercial forests. Forest Ecology and Management, Vol. 193: 321-34.

Morrison, P. H. 1988. Old growth in the Pacific Northwest: a status report. The Wilderness Society. Seattle, WA.

Muir, John. 1997. God's first temples: how shall we preserve our forests? In: William Cronon, ed. Nature writings. (Selections). Penguin Putnam Inc., New York. First published in Sacramento Daily Union, February 5, 1876.

Nautiyal, J. C. 1983. Towards a method of uneven-aged forest management based on the theory of financial maturity. Forest Science, Vol. 29: 1. Pp. 47-58. 
Norse, Elliott A. 1990. Ancient forests of the Pacific Northwest. Island Press, Washington, DC.

Noss, Reed F., ed. 2000. The redwood forest, history, ecology, and conservation of the coast redwoods. Island Press, Washington, DC.

Noss, Reed F. and A. Cooperrider. 1994. Saving nature’s legacy: protecting and restoring biodiversity. Island Press. Washington, DC.

Nyland, Ralph D. 2002. Silviculture concepts and applications. McGraw-Hill Inc., New York.

O’Hara, Kevin L., Penelope A. Latham, Paul Hessburg and Bradley G. Smith. 1996. A structural classification for inland Northwest forest vegetation. Western Journal of Applied Forestry, Vol. 11: 3 Pp. 97-102.

O’Hara, Kevin L. 2002. The historical development of uneven-aged silviculture in North America. Forestry, Vol. 75: 4. Pp. 339-46

Old-Growth Definition Task Group. 1986. Interim definitions for old-growth Douglas-fir and mixed conifer forests in the Pacific Northwest and California. PNW-447. Portland, OR: USDA Forest Service.

Oliver, W.W., J.L. Lindquist, and R.O. Strothmann. 1994. Young-growth redwood stands respond well to various thinning intensities. Western Journal of Applied Forestry, Vol. 9: 4. Pp. 106-112.

Olson, David. F., Douglass. F. Roy, and Gerald. A. Walters. 1990. Sequoia sempervirens (D. Don) Endl. Pp. 541-51. In: R. M. Burns and B. H. Honkala, eds., Silvics of North America. Vol. 1, Conifers. Agriculture Handbook 654. Washington D.C.: USDA Forest Service.

Parisi, Monica D., Robert S. Motroni and Timothy A. Robards. 2007. Clarification of the measurement of California Wildlife Habitat Relationships (CWHR) system size classes 5 and 6 for tree habitats. CWHR Technical Report No. 32. California Department of Fish and Game. Sacramento, CA. Pp. 11.

Peattie, Donald C. 1953. A natural history of western trees. Riverside Press. Cambridge, MA.

Person, Hubert L. 1942. Increment of residual redwoods. Journal of Forestry, Vol. 40: 926-9. 
Piirto, Douglas D., Richard P. Thompson and Kevin L. Piper. 1996. Implementing uneven-aged redwood management at Cal Poly’s school forest. Pp. 69-73 in Proceedings of the conference on coast redwood forest ecology and management. June 18-20, 1996. Arcata, CA: Humboldt State University.

Poage, N.J. and J.C. Tappeiner. 2002. Long-term patterns of diameter and basal area growth of old-growth Douglas-fir trees in western Oregon. Canadian Journal of Forest Research, Vol. 32: 1232-43.

Rogers, D.L. 2000. Genotypic diversity and clone size in old-growth populations of coast redwood (Sequoia sempervirens). Canadian Journal of Botany, Vol. 78: 1408-19.

Roy, Douglass F. 1980. Redwood, forest cover type number 232. Pp 109-10 in F. H. Eyre, eds. Forest cover types of the United States and Canada. Society of American Foresters. Washington, DC.

Russell, W. H., Joe R. McBride and Ky Carnell. 2000. Edge effects and the effective size of old-growth coast redwood preserves. USDA Forest Service, Rocky Mountain Research Station. RMRS-P-15-VOL-3. Pp. 128-36.

Russell, W. H. and C. Jones. 2001. The effects of timber harvesting on the structure and composition of adjacent old-growth coast redwood forest, California, USA. Landscape Ecology, Vol. 16: 731-41.

Sawyer, John O., Stephen C. Sillett, James H. Popenoe, Anthony LaBanca, Teresa Sholars, David L. Largent, Fred Euphrat, Reed F. Noss and Robert Van Pelt. 2000a. Characteristics of redwood forests. Pp. 39-79. In: Reed F. Noss, ed. The redwood forest, history, ecology, and conservation of the coast redwoods. Island Press, Washington, DC.

Sawyer, J.O., S.C. Sillett, W.J. Libby, T.E. Dawson, J.H. Popenoe, D.L. Largent, R.Van Pelt, S.D. Veirs, Jr., R.F. Noss, D.A. Thornburgh, and P.D. Tredeci. 2000b. Redwood trees, communities, and ecosystems: a closer look. Pp. 81-118. In: R.F. Noss, ed. The redwood forest, history, ecology, and conservation of the coast redwoods. Island Press, Washington, DC.

Sawyer, J.O., Jane Gray, G. James West, Dale A. Thornburgh, Reed F. Noss, Joseph H. Engbeck Jr., Bruce Marcot and Roland Raymond. 2000c. History of redwood and 
redwood forests. Pp. 7-38. In: Reed F. Noss, ed. The redwood forest, history, ecology, and conservation of the coast redwoods. Island Press, Washington, DC.

Sclarbaum, S. E., and T. Tsuchiya. 1984. A chromosome study of coast redwood, Sequoia sempervirens (D. Don) Endl. Silvae Genetica Vol. 3: 2/3. Pp.56-62.

Shih, Tian-Ting. 2002. Timberland conversion in California from 1969 to 1998.

Technical Working Paper 1-01-02. Fire and Resource Assessment Program. California Department of Forestry and Fire Protection. Sacramento, CA. Pp. 13.

Shintaku, Duane. 2005. Disclosure, evaluation and protection of large old trees. Memorandum March 2, 2005. California Department of Forestry and Fire Protection. Sacramento, CA.

Sholars, Teresa and Clare Golec. 2007. Rare plants of the redwood forest and forest management effects. USDA Forest Service, Pacific Southwest Research Station, General Technical Report PSW-GTR-194.

Siegel, William C. 1974. State forest practice laws today. Journal of Forestry, Vol. 72: 4. Pp. 208-11.

Sillett, Stephen C. 1999. Tree crown structure and epiphyte distribution in Sequoia sempervirens rain forest canopies. Selbyana, Vol. 20: Pp. 76-97.

---------. 2009. Thoughts on redwood ecology today. Speech at HSU Redwood Summit. Humboldt State University, Arcata, CA. October 3, 2009.

Society for Ecological Restoration. 2004. The SER International Primer on Ecological Restoration. Society for Ecological Restoration International Science and Policy Working Group. Viewed at: www.ser.org.

Spies, Thomas A. and Jerry F. Franklin. 1991. The structure of natural young, mature, and old-growth Douglas-fir forests in Oregon and Washington. Pacific Northwest Research Station, USDA Forest Service. Portland, OR. General Technical Report PNW-GTR-285 Pp. 91-111.

Spies, Thomas A., John Cissel, Jerry F. Franklin, Frederick Swanson, Nathan Poage, Robert Pabst, John Tappeiner and Linda Winter. 2002. Summary of workshop on development of old-growth Douglas-fir forests along the Pacific Coast of North America: a regional perspective. Nov. 7-9, 2001, H.J. Andrews Experimental Forest, Blue River, OR. 
SPSS, Inc. 2007. SPSS Base release 15.0. SPSS, Inc. 223 S. Wacker Dr. $11^{\text {th }}$ Floor, Chicago, IL 60606.

Stanford Environmental Law Society. 1973. California's private timberlands: regulation, taxation, preservation. Stanford Univcersity, Palo Alto, CA.

Stanger, Frank M. 1967. Sawmills in the redwoods: logging on the San Francisco peninsula, 1849-1967. San Mateo County Historical Association, CA.

Stanturf, John A. 2005. What is forest restoration? Restoration of boreal and temperate forests, CRC Press, Boca Raton, FL. Pp. 3-11.

Stephens, Scott L. and Danny L. Fry. 2005. Fire history in coast redwood stands in the Northeastern Santa Cruz Mountains, California. Fire Ecology, Vol. 1: 1. Pp. 2-19.

Stone, E.C. and R.B. Vasey. 1968. Preservation of coast redwood on alluvial flats. Science, Vol. 159(3811). Pp. 157-61.

Stuart, John D. and John O. Sawyer. 2001. Trees and shrubs of California. University of California Press. Los Angeles, CA.

Sugihara, Neil G. 1996. The dynamics of treefall gaps in alluvial flat coast redwood (Sequoia sempervirens (D. Don) Endl.) forests. Pp.84-5. In: Proceedings of the conference on coast redwood forest ecology and management. June 18-20, 1996. Humboldt State University, Arcata, CA.

Swanton Pacific Ranch. 2007. Swanton Pacific Ranch Non-industrial timber management plan (1-07NTMP-020 SCR). Received by Coast District of CAL FIRE Nov. 6, 2007. Submitted by Cal Poly Corporation (landowner).

Thompson, L. 1916. To the American Indian. Cummins Print Shop, Eureka, CA. Pp. 21. Thompson, Richard P. and Christopher A. Dicus. 2005. The impact of California's changing environmental regulations on timber harvest planning costs. Sponsored by California Institute for the Study of Specialty Crops and The Forest Foundation. California Polytechnic State Univ., San Luis Obispo, CA. Thornburgh, D.A., R.F. Noss, D.P. Angelides, C.M. Olson, F. Euphrat, and H.H. Welsh, Jr. 2000. Managing redwoods. Pp. 229-63. In: R.F. Noss, ed. The redwood forest, history, ecology, and conservation of the coast redwoods. Island Press, Washington, DC. 
Van Pelt, R. and J.F. Franklin. 2000. Influence of canopy structure on the understory environment in tall, old-growth, conifer forests. Canadian Journal of Forest Research, Vol. 30: 1231-45.

Vaux, Henry J. 1986. The regulation of private forest practices in California: a case in policy evolution. Journal of Forest History, Vol. 30:3. Pp. 128-34.

Veirs, S. D. 1980. The role of fire in northern coast redwood forest dynamics. Pp. 190209. In: Proceedings of conference on scientific research in the national parks. Vol. 10, Fire Ecology. San Francisco, CA. Washington DC: National Park Service. - 1982. Coast redwood forest: Stand dynamics, successional status and the role of fire. In: J. E. Means (ed.). Forest succession and stand development in the Northwest. Forest Research Laboratory, Oregon State University. Corvallis, OR. Pp. 119-41.

--------. 1996. Ecology of the coast redwood. In: Proceedings of the conference on coast redwood forest ecology and management. June 18-20, 1996. Humboldt State University, Arcata, CA.

Wagner, M. R., W. M. Block, B. W. Geils, and K. F. Wegner. 2000. Restoration ecology: A new forest management paradigm, or another merit badge for foresters? Journal of Forestry, Vol.98: 23.

Welsh, Hartwell H., Terry D. Roelofs and Christopher A. Frissell. 2000. Aquatic ecosystems of the redwood region, Pp. 165-99. In: R.F. Noss, ed. The redwood forest, history, ecology, and conservation of the coast redwoods. Island Press, Washington, DC.

West, James A. 2009. "Traversing Swanton Road.” [manuscript online] (University of California- Santa Cruz, accessed Jan. 2011); available from http://arboretum.ucsc.edu/pdfs/TraversingSwantonRoad1.pdf.

Willett, T.R. 2001. Spiders and other arthropods as indicators in old-growth versus logged redwood stands. Restoration Ecology, Vol. 9: 4. Pp.410-20.

Wilson, Matt. 2007. Discovery: the tallest living beings on Earth. Spring Bulletin, 2007. Save-the-Redwoods League. San Francisco, CA. 
Yee, Carlton S. 2003. California's forest practices and environmental quality: response to California state senate natural resources committee report on forest policy alternatives; and the California state senate office of research report on timber harvesting and water quality. Commissioned by the Forest Products Industry National Labor Management Committee, California Chapter. Pp. 39.

Youngblood, Andrew. 2001. Old growth forest structure in eastern Oregon and Washington. Northwest Science, Vol. 75: special issue. Pp. 110-18. 


\section{APPENDICES}

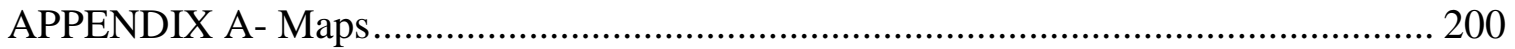

APPENDIX B- Sampling and Frequency Tables .................................................... 213

APPENDIX C- Pairwise Comparisons (Fisher’s LSD)............................................. 216

APPENDIX D- Inventory Stand Tables and Summaries ............................................ 231

APPENDIX E- Agreements and Permits.............................................................. 259 


\section{APPENDIX A- Maps}

Figure A-1: Forest Boundaries Map, Southern San Mateo and Northern Santa Cruz

Counties, California (Northern Portion of Study Area)................................... 201

Figure A-2: Forest Boundaries Map, Southern San Mateo and Northern Santa Cruz

Counties, California (Central Portion of Study Area) ..................................... 202

Figure A-3: Map of Forest Boundaries Map, Southern Santa Cruz County, California

(Southern Portion of Study Area) …................................................................ 203

Figure A-4: Map of YMCA Camp Jones Gulch and Inventory Stand ........................ 204

Figure A-5: Map of Butano State Park and Inventory Stands .................................... 205

Figure A-6: Map of Big Basin Redwoods State Park and Inventory Stands ................ 206

Figure A-7: Map of CEMEX- Davenport and Inventory Stand ................................. 207

Figure A-8: Map of Swanton Pacific Ranch (Little Creek) and Inventory Stands ........ 208

Figure A-9: Map of Soquel Demonstration State Forest and Inventory Stands ........... 209

Figure A-10: Map of Forest of Nisene Marks State Park and Inventory Stands ........... 210

Figure A-11: Map of Swanton Pacific Ranch (Valencia Creek) and Inventory Stands 211

Figure A-12: Map of Land Trust of Santa Cruz County (Byrne Forest) and Redwood

Empire Inventory Stands.................................................................... 212 
Figure A-1: Forest Boundaries Map, Southern San Mateo and Northern Santa Cruz Counties, California (Northern Portion of Study Area).
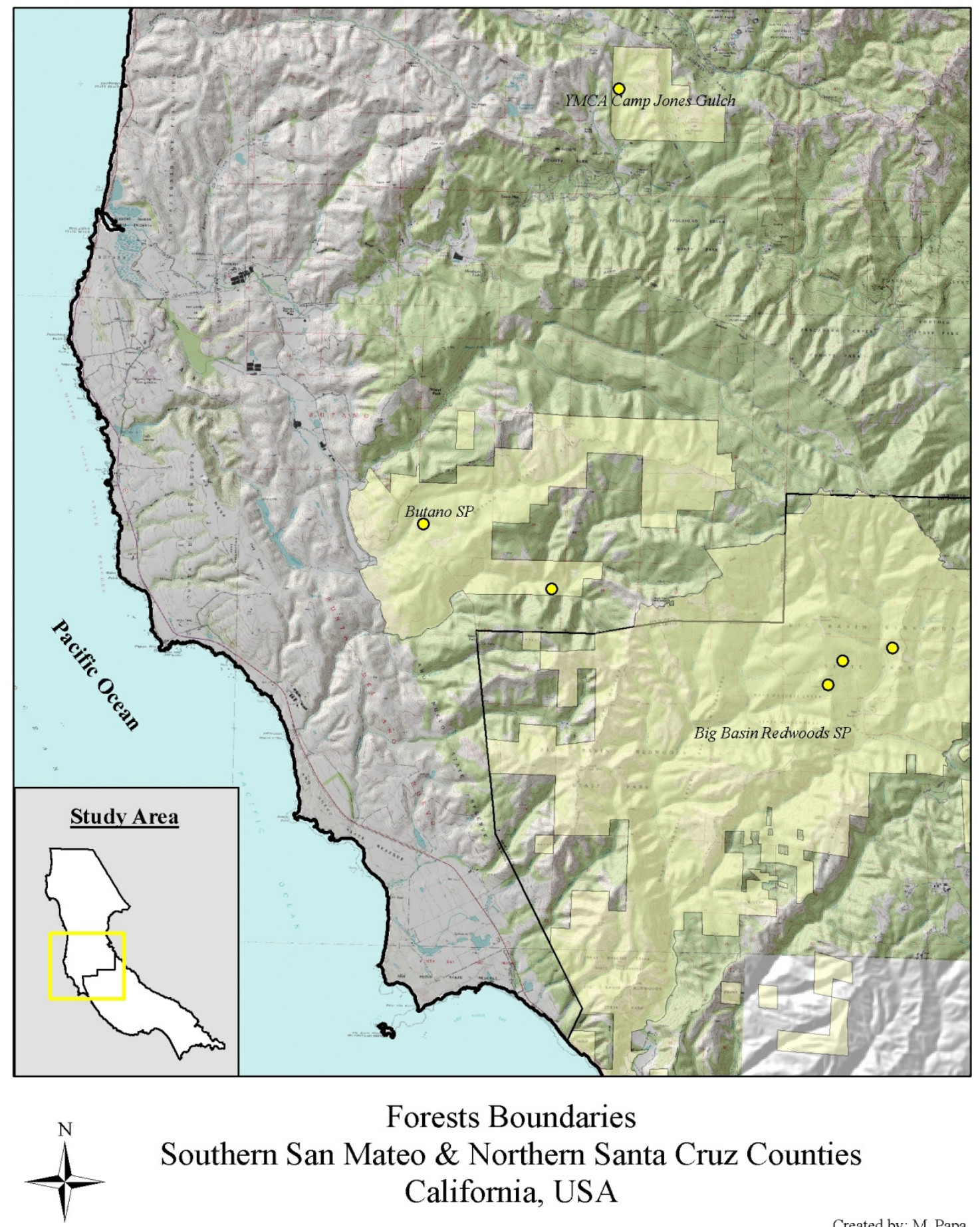

Forests Boundaries Southern San Mateo \& Northern Santa Cruz Counties California, USA 
Figure A-2: Forest Boundaries Map, Southern San Mateo and Northern Santa Cruz Counties, California (Central Portion of Study Area)
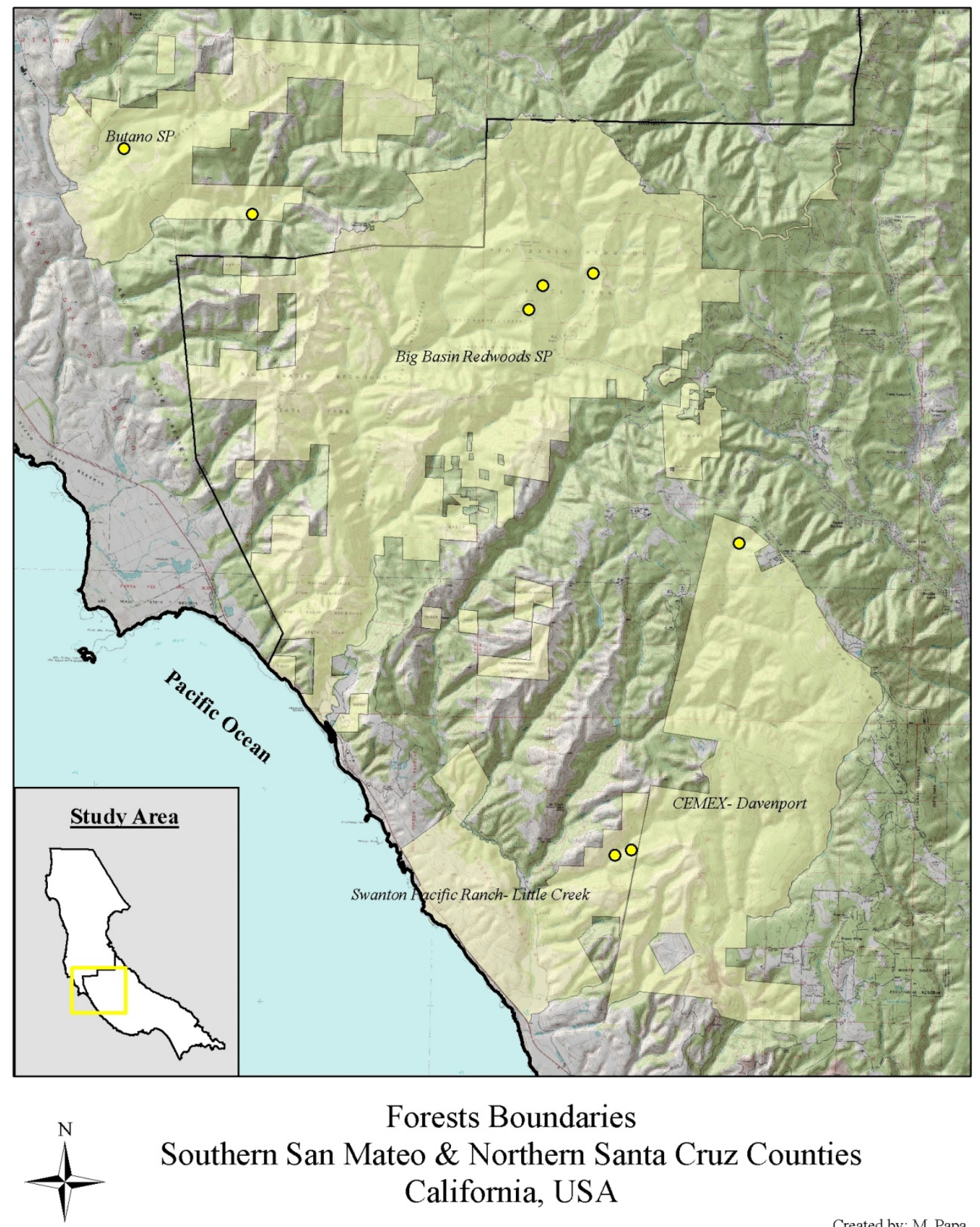

Forests Boundaries Southern San Mateo \& Northern Santa Cruz Counties California, USA 
Figure A-3: Map of Forest Boundaries Map, Southern Santa Cruz County, California (Southern Portion of Study Area)
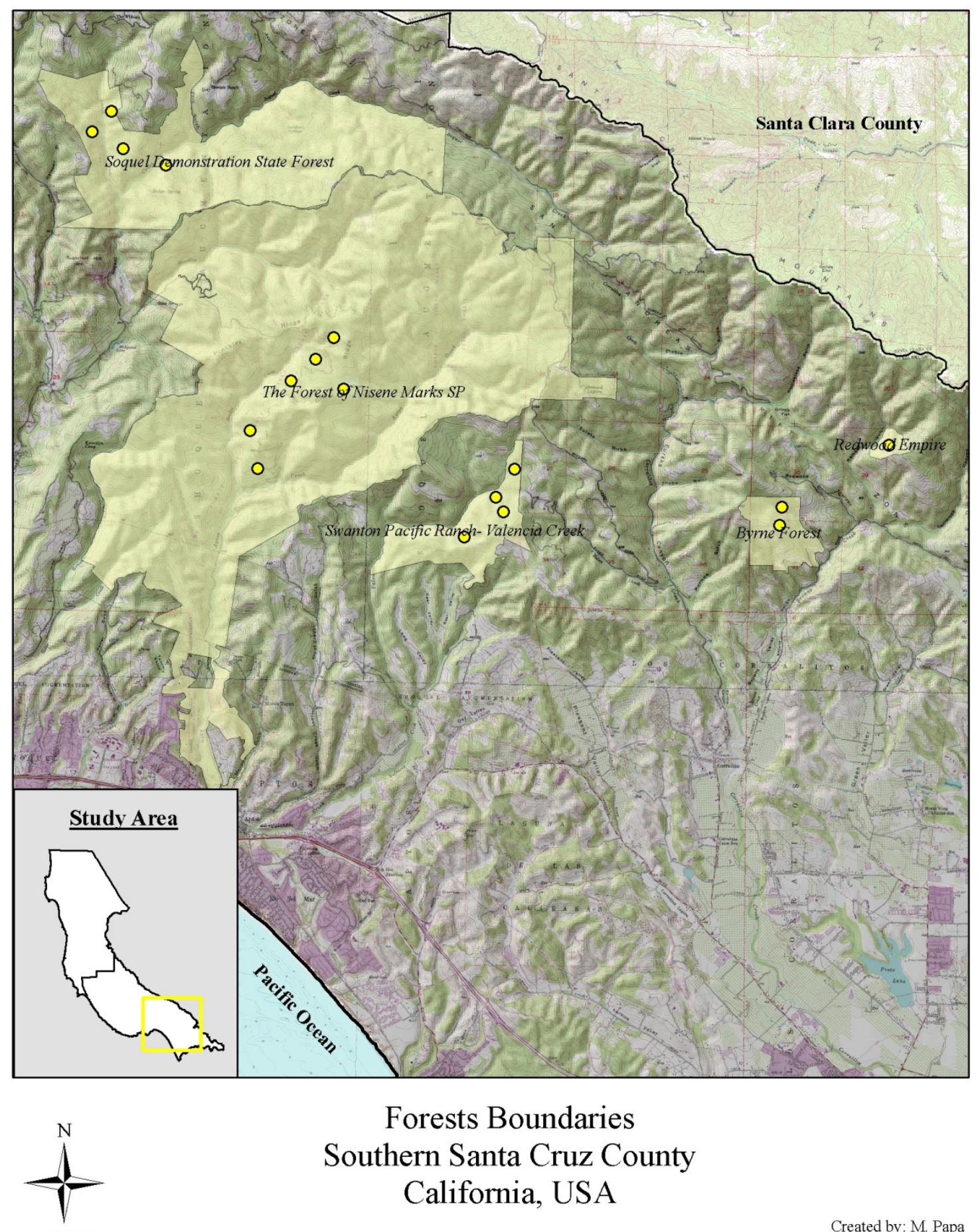

Forests Boundaries Southern Santa Cruz County California, USA 
Figure A-4: Map of YMCA Camp Jones Gulch and Inventory Stand

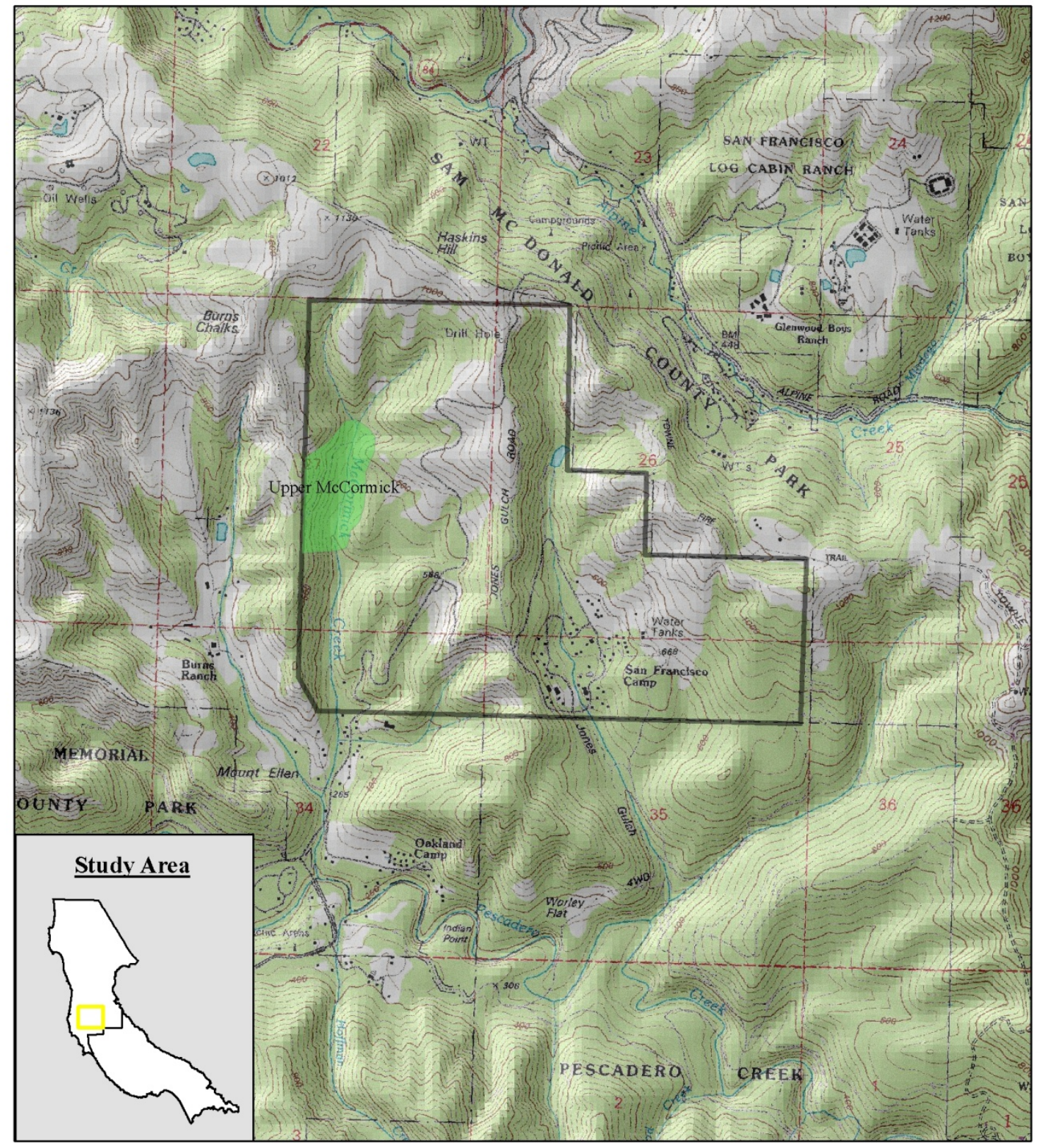

\section{N Upper McCormick Creek Stand- YMCA Camp Jones Gulch San Mateo County, California}


Figure A-5: Map of Butano State Park and Inventory Stands
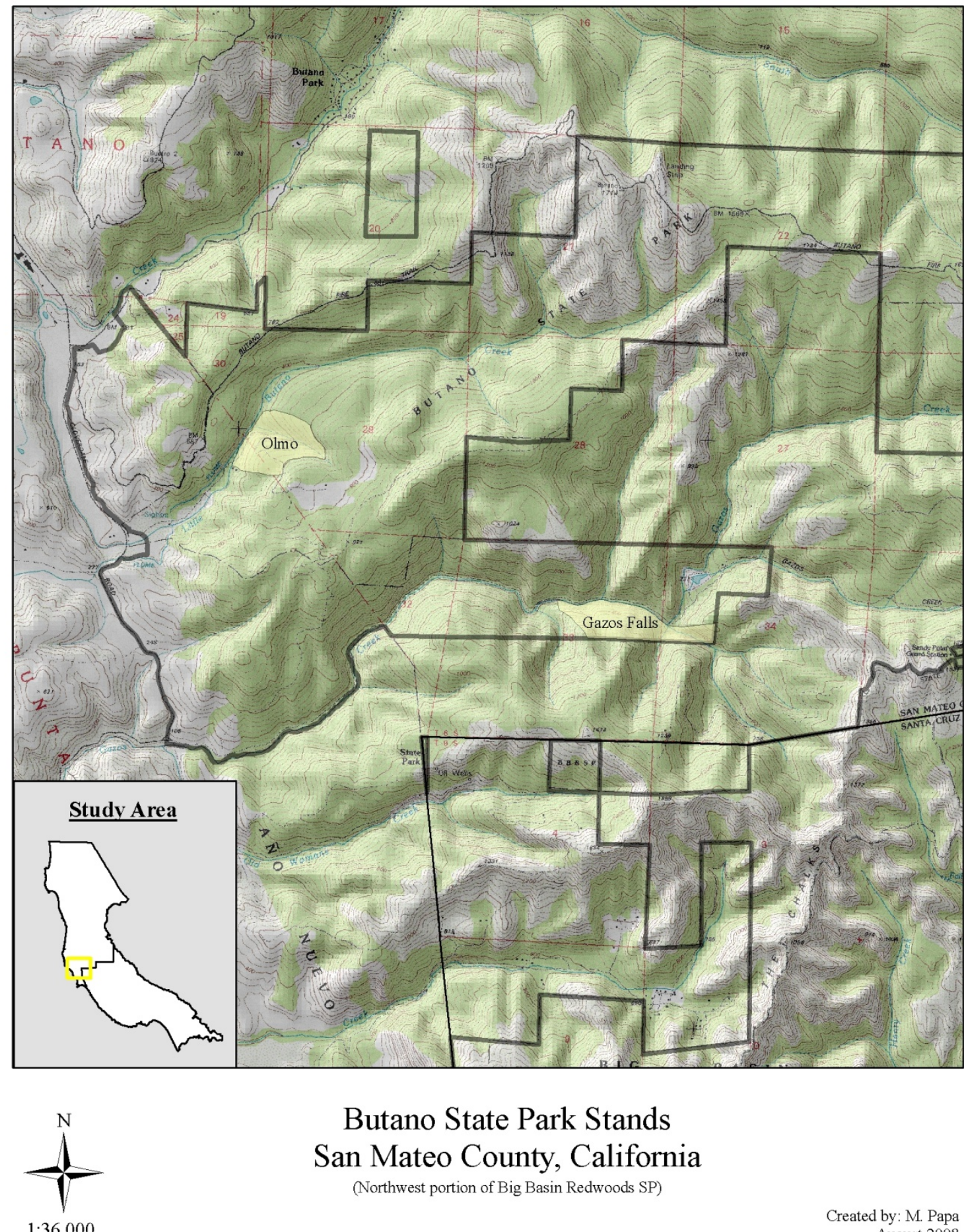

\section{Butano State Park Stands San Mateo County, California}

(Northwest portion of Big Basin Redwoods SP) 
Figure A-6: Map of Big Basin Redwoods State Park and Inventory Stands
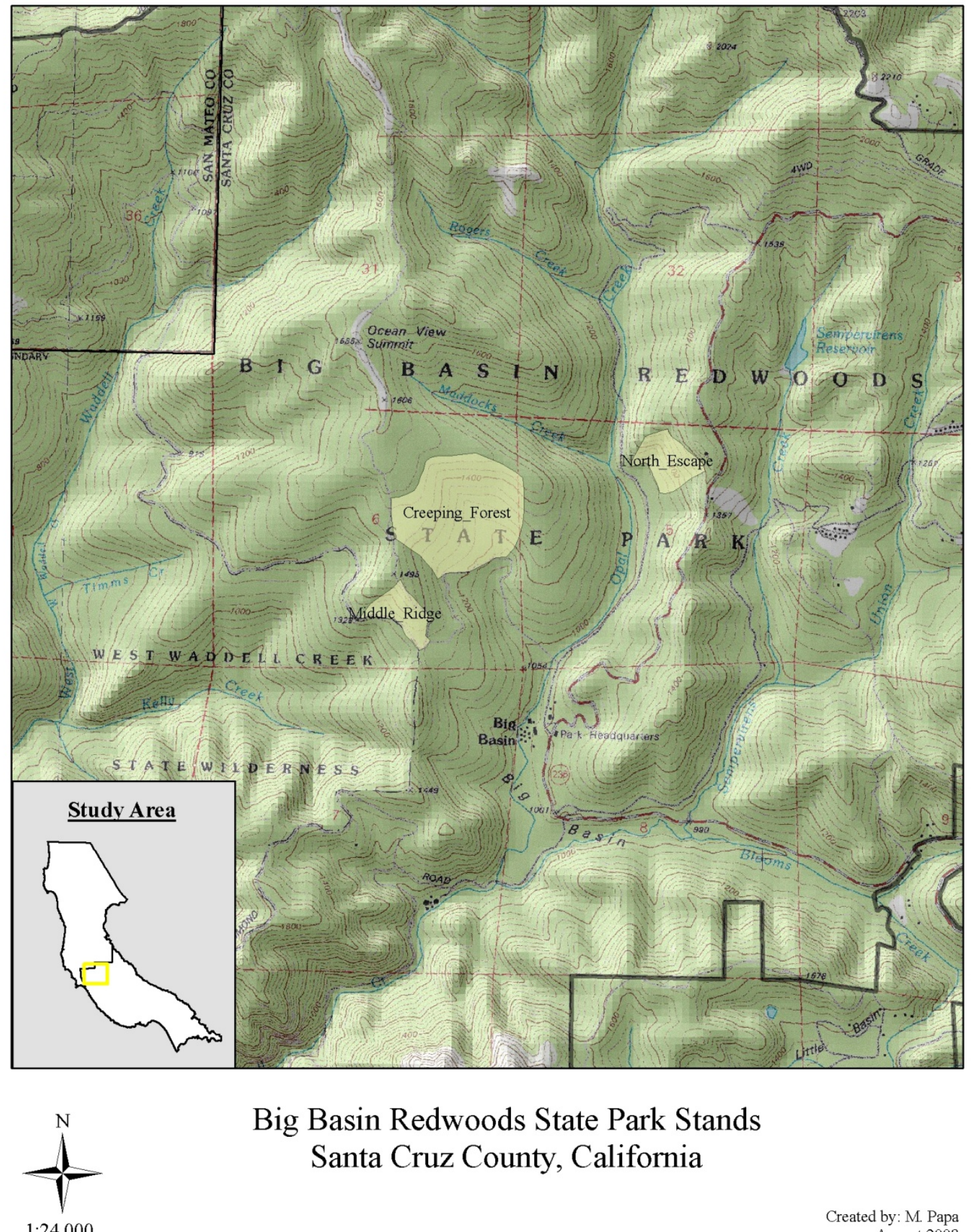

Big Basin Redwoods State Park Stands Santa Cruz County, California 
Figure A-7: Map of CEMEX- Davenport and Inventory Stand
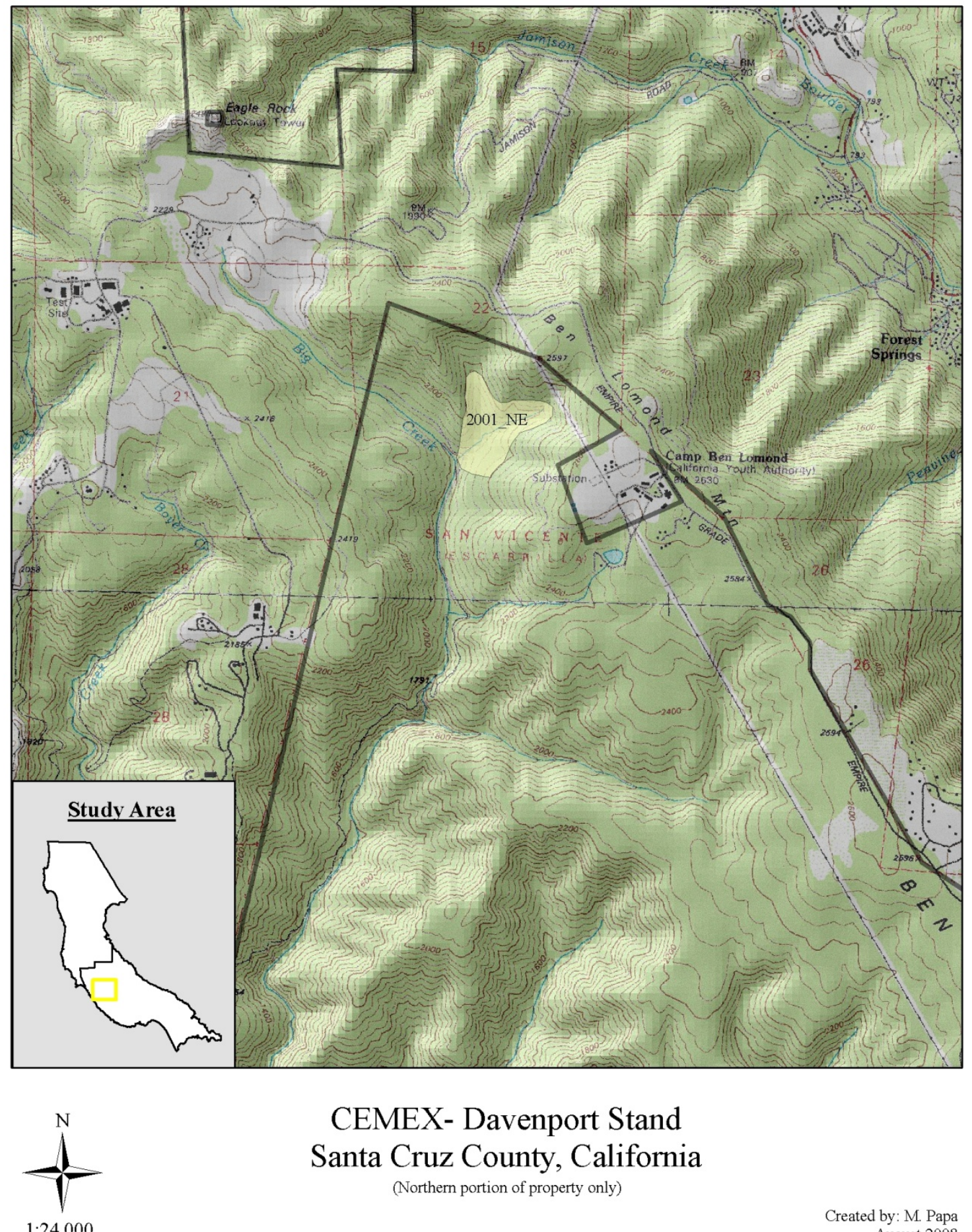

\section{CEMEX- Davenport Stand Santa Cruz County, California (Northern portion of property only)}


Figure A-8: Map of Swanton Pacific Ranch (Little Creek) and Inventory Stands
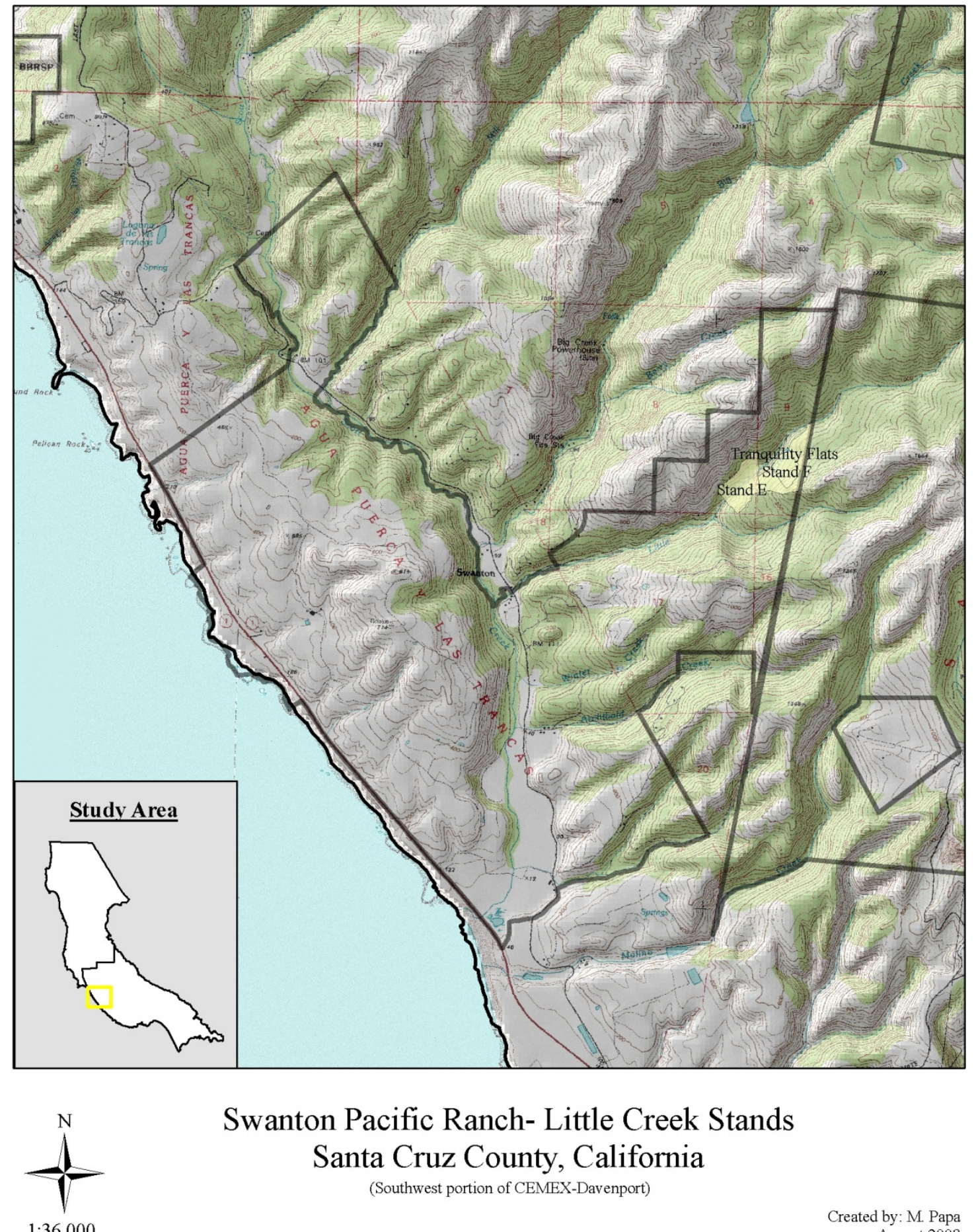

Swanton Pacific Ranch- Little Creek Stands Santa Cruz County, California

(Southwest portion of CEMEX-Davenport) 
Figure A-9: Map of Soquel Demonstration State Forest and Inventory Stands
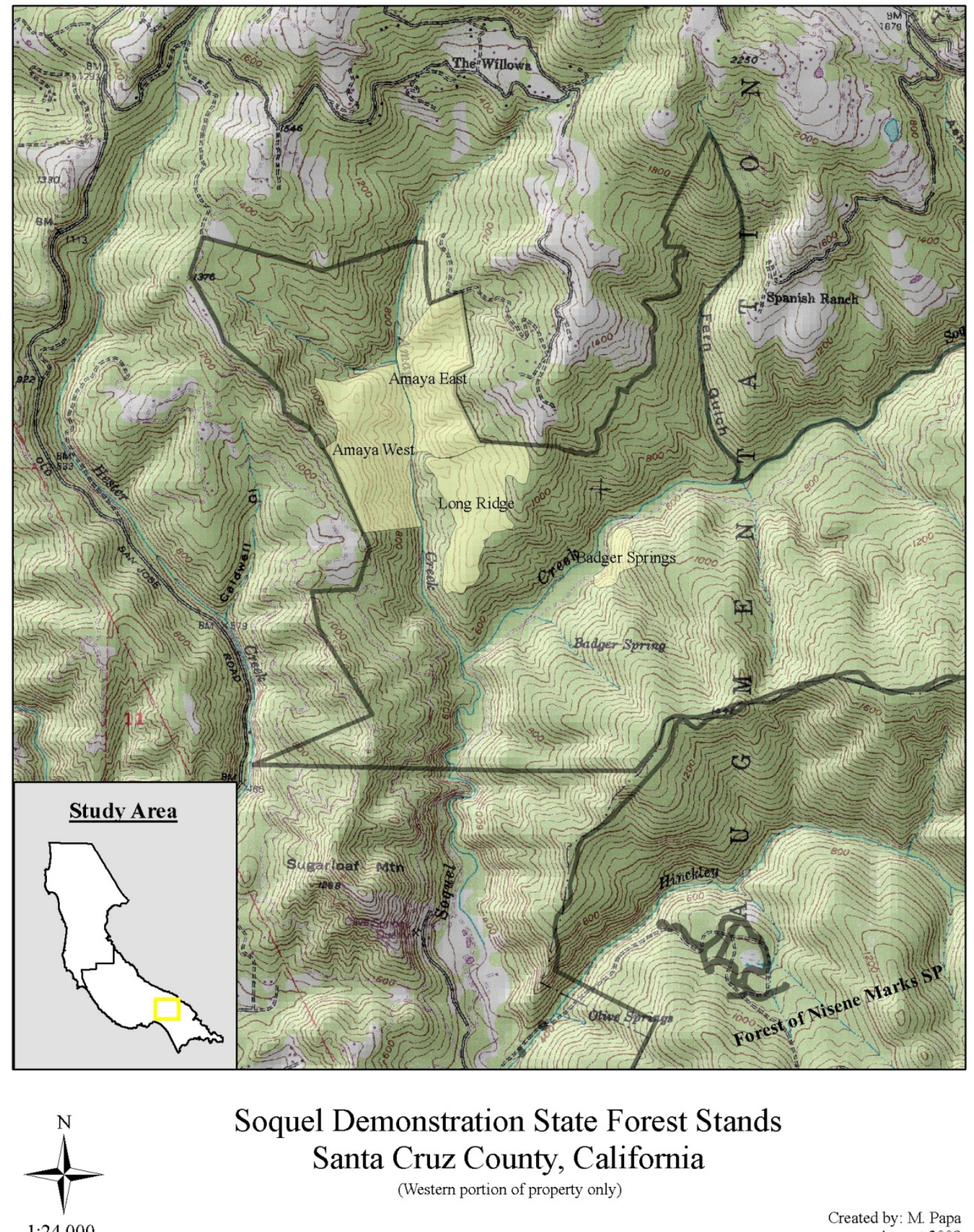

\section{Soquel Demonstration State Forest Stands Santa Cruz County, California \\ (Western portion of property only)}


Figure A-10: Map of Forest of Nisene Marks State Park and Inventory Stands
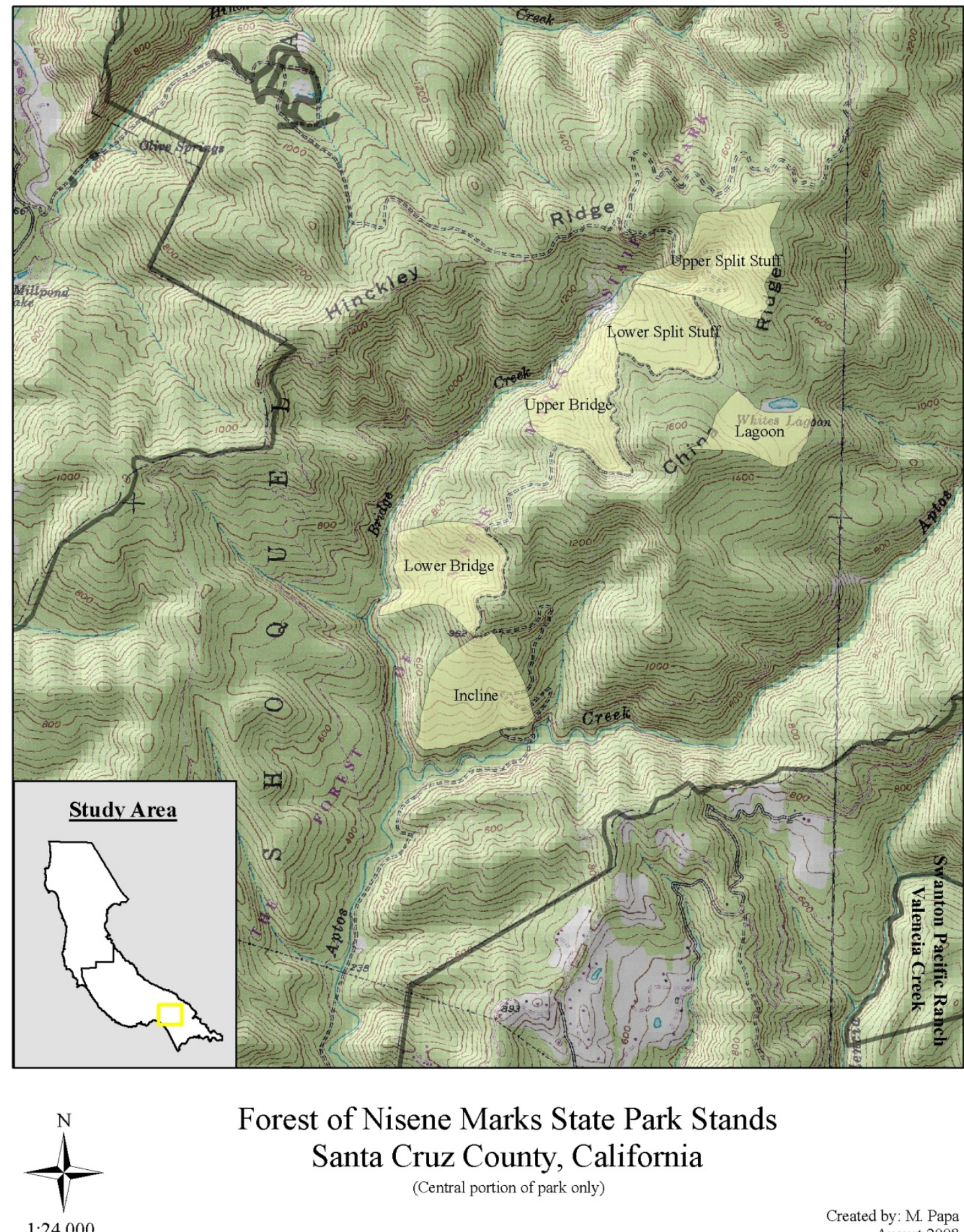

Forest of Nisene Marks State Park Stands Santa Cruz County, California

$$
\text { (Central portion of park only) }
$$


Figure A-11: Map of Swanton Pacific Ranch (Valencia Creek) and Inventory Stands
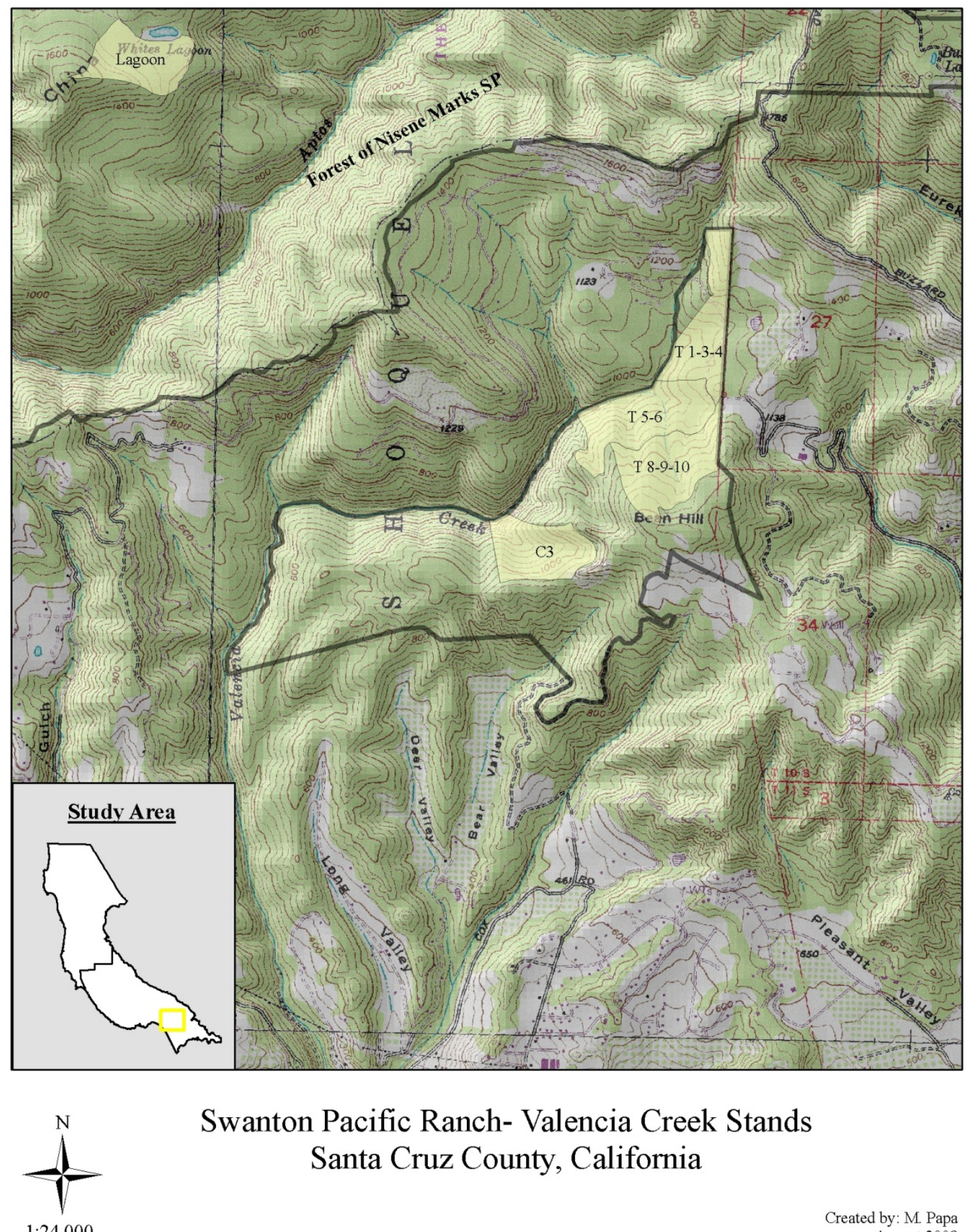

\section{Swanton Pacific Ranch- Valencia Creek Stands Santa Cruz County, California}


Figure A-12: Map of Land Trust of Santa Cruz County (Byrne Forest) and Redwood Empire Inventory Stands
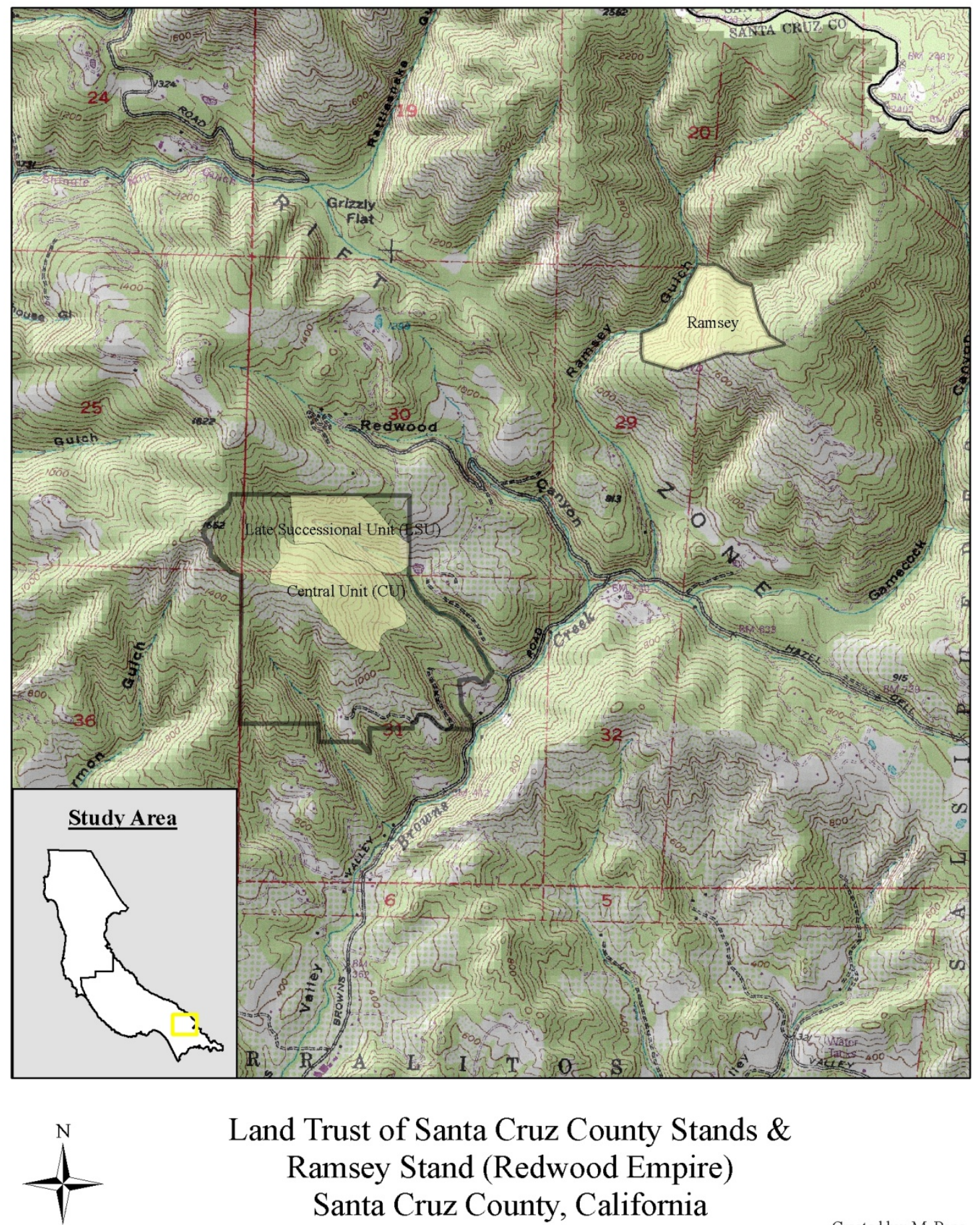

\section{Land Trust of Santa Cruz County Stands \& Ramsey Stand (Redwood Empire) Santa Cruz County, California}




\section{APPENDIX B- Sampling and Frequency Tables}

Table B-1: Plot Frequency and Allocation ............................................................ 214

Table B-2: Plot Frequency by 10-year Age Class ......................................................... 214

Table B-3: Plot Frequency by Aspect............................................................................ 215

Table B-4: Plot Frequency by Slope (percent) …………………………………….... 215 
Table B-1: Plot Frequency and Allocation

\begin{tabular}{|c|c|c|c|c|c|}
\hline \multirow[b]{2}{*}{$\begin{array}{l}\text { Forest } \\
\text { Origin }\end{array}$} & \multirow[b]{2}{*}{ Management Regime } & \multirow[b]{2}{*}{$\begin{array}{l}\text { Number of Plots* } \\
\text { (n) }\end{array}$} & \multicolumn{3}{|c|}{ Inventory Sample } \\
\hline & & & $\begin{array}{c}\text { Plot Area } \\
\text { (ac) }\end{array}$ & $\begin{array}{c}\text { Stand Area } \\
\text { (ac) }\end{array}$ & $\begin{array}{c}\text { Sample Intensity } \\
(\%)\end{array}$ \\
\hline \multicolumn{6}{|c|}{$\begin{array}{l}\text { Pre-Liuropean/ } \\
\text { Natural: }\end{array}$} \\
\hline & Natural & 32 & 8.00 & 124.40 & 6.4 \\
\hline \multicolumn{6}{|l|}{ I Iarvest: } \\
\hline & Park/No Cut & 69 & 17.25 & 379.10 & 4.6 \\
\hline & Truncated & 36 & 9.00 & 186.30 & 4.8 \\
\hline & Large lree Management & 18 & 4.50 & 67.70 & 6.6 \\
\hline & Percent Removal & 66 & 16.50 & 371.40 & 4.4 \\
\hline & Unknown & 12 & 3.00 & 60.20 & 5.0 \\
\hline & Total & 233 & 58.25 & 1189.10 & 4.9 \\
\hline
\end{tabular}

* Number of 0.25 -acre fixed radius inventory plots.

Table B-2: Plot Frequency by 10-year Age Class

\begin{tabular}{|c|c|c|c|c|c|c|c|c|}
\hline \multirow{2}{*}{$\begin{array}{l}\text { Forest } \\
\text { Origin }\end{array}$} & \multirow[b]{2}{*}{ Management Regime } & \multicolumn{5}{|c|}{ Age Class (ycars) } & \multirow[b]{2}{*}{ Total } & \multirow[b]{2}{*}{$(\%)$} \\
\hline & & $80-89$ & $90-99$ & $100-109$ & $110-119$ & Natural & & \\
\hline \multicolumn{9}{|c|}{$\begin{array}{l}\text { Pre-Furopean/ } \\
\text { Natural: }\end{array}$} \\
\hline & Natural & 0 & 0 & 0 & 0 & 32 & 32 & $(13.7)$ \\
\hline \multicolumn{9}{|l|}{ Harvest: } \\
\hline & Park/No Cul & 9 & 0 & 60) & 0 & 0 & 69 & $(29.6)$ \\
\hline & Truncated & 0 & 6 & 30 & 0 & 0 & 36 & (15.5) \\
\hline & Large Tree Management & 0 & 9 & 0 & 9 & 0 & 18 & $(7,7)$ \\
\hline & Percent Removal & 33 & 9 & 6 & 18 & 0 & 66 & $(28,3)$ \\
\hline & Unknown & 0 & 0 & 0 & 12 & 0 & 12 & (5.2) \\
\hline & $\begin{array}{c}\text { Total } \\
(\%)\end{array}$ & $\begin{array}{r}42 \\
(18.0)\end{array}$ & $\begin{array}{r}24 \\
(10.3)\end{array}$ & $\begin{array}{r}96 \\
(41.2)\end{array}$ & $\begin{array}{r}39 \\
(16.7)\end{array}$ & $\begin{array}{r}32 \\
(13.7)\end{array}$ & $\begin{array}{r}233 \\
(100.0)\end{array}$ & $(100.0)$ \\
\hline
\end{tabular}


Table B-3: Plot Frequency by Aspect

\begin{tabular}{|c|c|c|c|c|c|c|c|c|c|c|c|}
\hline \multirow[b]{2}{*}{$\begin{array}{l}\text { Forest } \\
\text { Origin }\end{array}$} & \multirow[b]{2}{*}{ Management Regime } & \multicolumn{8}{|c|}{ Aspect } & \multirow[b]{2}{*}{ Total } & \multirow[b]{2}{*}{$(\%)$} \\
\hline & & North & $\begin{array}{c}\text { North- } \\
\text { west }\end{array}$ & West & $\begin{array}{c}\text { South- } \\
\text { west }\end{array}$ & South & $\begin{array}{c}\text { South- } \\
\text { east }\end{array}$ & East & $\begin{array}{c}\text { North- } \\
\text { east }\end{array}$ & & \\
\hline \multicolumn{12}{|c|}{$\begin{array}{l}\text { Pre-European/ } \\
\text { Natural: }\end{array}$} \\
\hline Natural: & Natural & 0 & 1 & 9 & 6 & 7 & 5 & 4 & 0 & 32 & (13.7) \\
\hline \multicolumn{12}{|l|}{ Harvest: } \\
\hline & Park/No Cut & 9 & 6 & 19 & 9 & 16 & 1 & 8 & 1 & 69 & (29.6) \\
\hline & Truncated & 8 & 8 & 8 & 3 & 2 & 3 & 0 & 4 & 36 & (15.5) \\
\hline & Large Tree Management & 2 & 4 & 5 & 1 & 4 & 1 & 0 & 1 & 18 & $(7.7)$ \\
\hline & Percent Removal & 12 & 10 & 19 & 5 & 0 & 4 & 10 & 6 & 66 & (28.3) \\
\hline & Unknown & 9 & 0 & 0 & 0 & 0 & 0 & 2 & 1 & 12 & $(5.2)$ \\
\hline & $\begin{array}{c}\text { Total } \\
(\%)\end{array}$ & $\begin{array}{r}40 \\
(17.2)\end{array}$ & $\begin{array}{r}29 \\
(12.4)\end{array}$ & $\begin{array}{r}60 \\
(25.8)\end{array}$ & $\begin{array}{r}24 \\
(10.3)\end{array}$ & $\begin{array}{r}29 \\
(12.4)\end{array}$ & $\begin{array}{r}14 \\
(6.0)\end{array}$ & $\begin{array}{r}24 \\
(10.3)\end{array}$ & $\begin{array}{r}13 \\
(5.6)\end{array}$ & $\begin{array}{r}233 \\
(100.0)\end{array}$ & $(100.0)$ \\
\hline
\end{tabular}

\section{Table B-4: Plot Frequency by Slope (percent)}

\begin{tabular}{|c|c|c|c|c|c|c|c|c|}
\hline \multirow{2}{*}{$\begin{array}{l}\text { Forest } \\
\text { Origin }\end{array}$} & \multirow{2}{*}{ Management Regime } & \multicolumn{5}{|c|}{ Slope Range } & \multirow[b]{2}{*}{ Total } & \multirow[b]{2}{*}{$(\%)$} \\
\hline & & $0-25 \%$ & $26-50 \%$ & $51-75 \%$ & $76-100 \%$ & $>100 \%$ & & \\
\hline \multicolumn{9}{|c|}{$\begin{array}{l}\text { Pre-European/ } \\
\text { Natural: }\end{array}$} \\
\hline & Natural & 11 & 11 & 7 & 3 & 0 & 32 & $(13.7)$ \\
\hline \multicolumn{9}{|l|}{ Harvest: } \\
\hline & Park/No Cut & 20 & 28 & 14 & 7 & 0 & 69 & $(29.6)$ \\
\hline & Truncated & 12 & 15 & 9 & 0 & 0 & 36 & (15.5) \\
\hline & Large Tree Management & 1 & 6 & 9 & 1 & 1 & 18 & $(7.7)$ \\
\hline & Percent Removal & 11 & 29 & 22 & 4 & 0 & 66 & $(28,3)$ \\
\hline & Unknown & 1 & 0 & 3 & 8 & 0 & 12 & (5.2) \\
\hline & $\begin{array}{c}\text { Total } \\
(\%)\end{array}$ & $\begin{array}{r}56 \\
(24.0)\end{array}$ & $\begin{array}{r}89 \\
(38.2)\end{array}$ & $\begin{array}{r}\mathbf{6 4} \\
(27.5)\end{array}$ & $\begin{array}{r}23 \\
(9.9)\end{array}$ & $\begin{array}{r}1 \\
(0.4)\end{array}$ & $\begin{array}{r}233 \\
(100.0)\end{array}$ & $(I f(f),())$ \\
\hline
\end{tabular}




\section{APPENDIX C- Pairwise Comparisons (Fisher’s LSD)}

Table C-1: All Pairwise Comparisons of General Forest Components Between

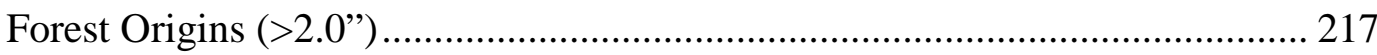

Table C-2: All Pairwise Comparisons of General Forest Components Between Harvest Origin Regimes (>2.0") .................................................................. 218

Table C-3: All Pairwise Comparisons of Small Stem Density Distribution by

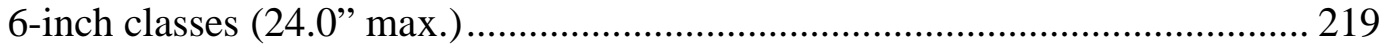

Table C-4: All Pairwise Comparisons of “60/50 Rule” Small Stem Density Distribution (18.0" max.) 221

Table C-5: All Pairwise Comparisons of Type A Owl Habitat Small Stem Density (18.0” max.) 223

Table C-6: All Pairwise Comparisons of Understory Stem Density 224

Table C-7: All Pairwise Comparisons of Large Stem Sawtimber Density (10.5” min.)225

Table C-8: All Pairwise Comparisons of “60/50 Rule” Large Stem Density (18.1” min.) 226

Table C-9: All Pairwise Comparisons of Mature Large Stem Density (24.1” min.)..... 227 Table C-10: All Pairwise Comparisons of Type A Owl Habitat, Medium and Large Stem Density (18.1” min.) 228

Table C-11: All Pairwise Comparisons of Overstory Stem Density 230 
Table C-1: All Pairwise Comparisons of General Forest Components Between Forest Origins (>2.0”)

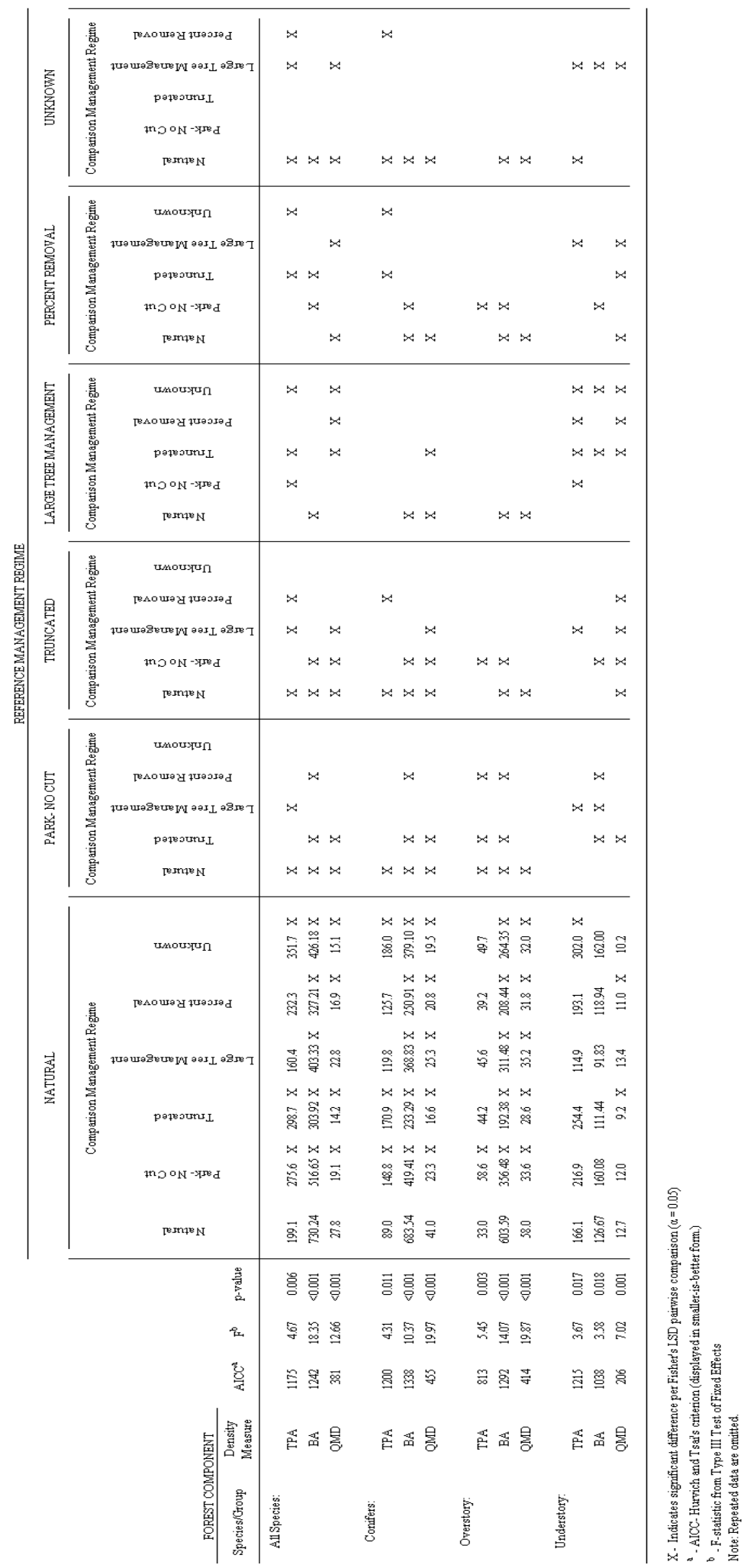


Table C-2: All Pairwise Comparisons of General Forest Components Between Harvest Origin Regimes (>2.0”)

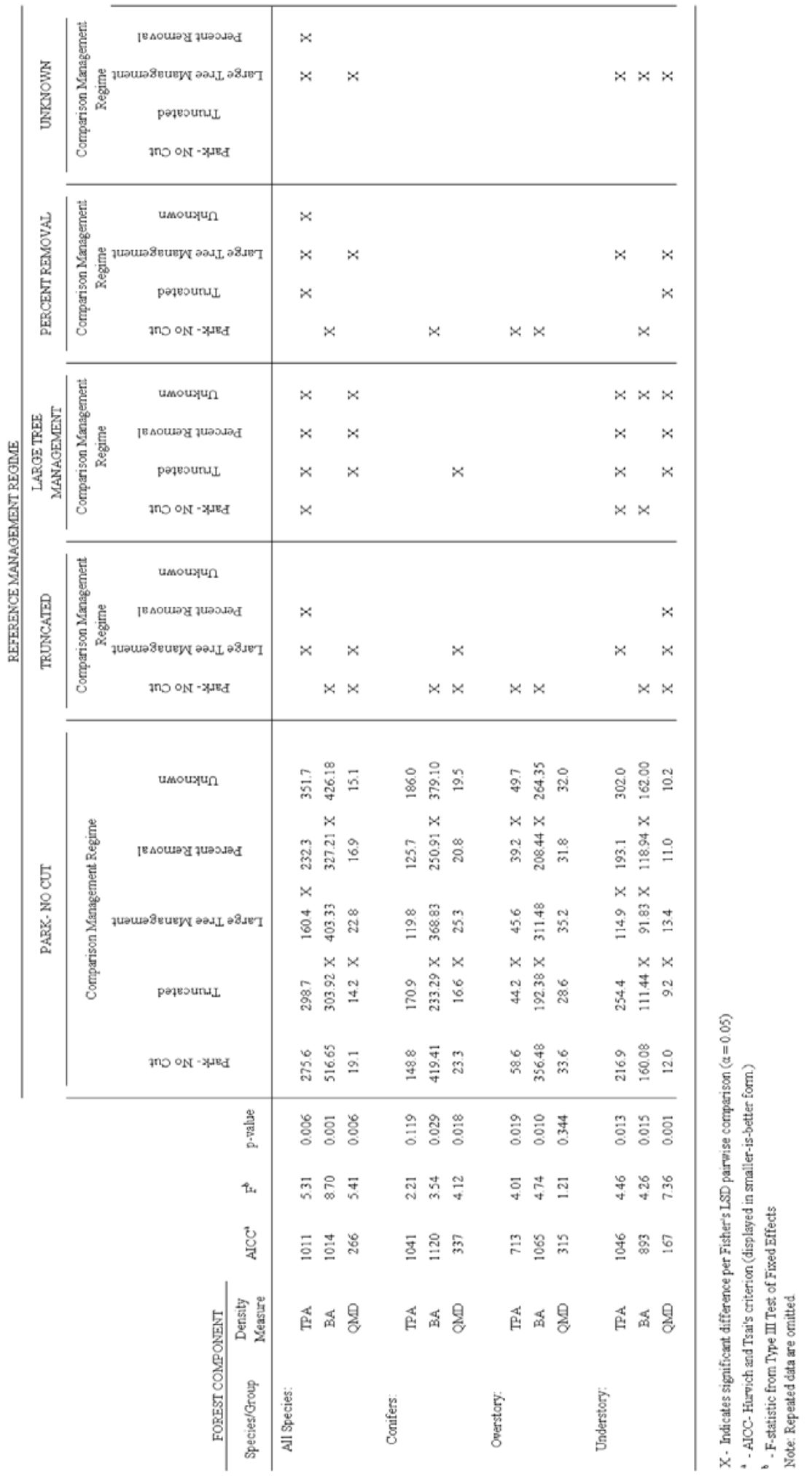


Table C-3: All Pairwise Comparisons of Small Stem Density Distribution by 6-inch classes (24.0” max.)

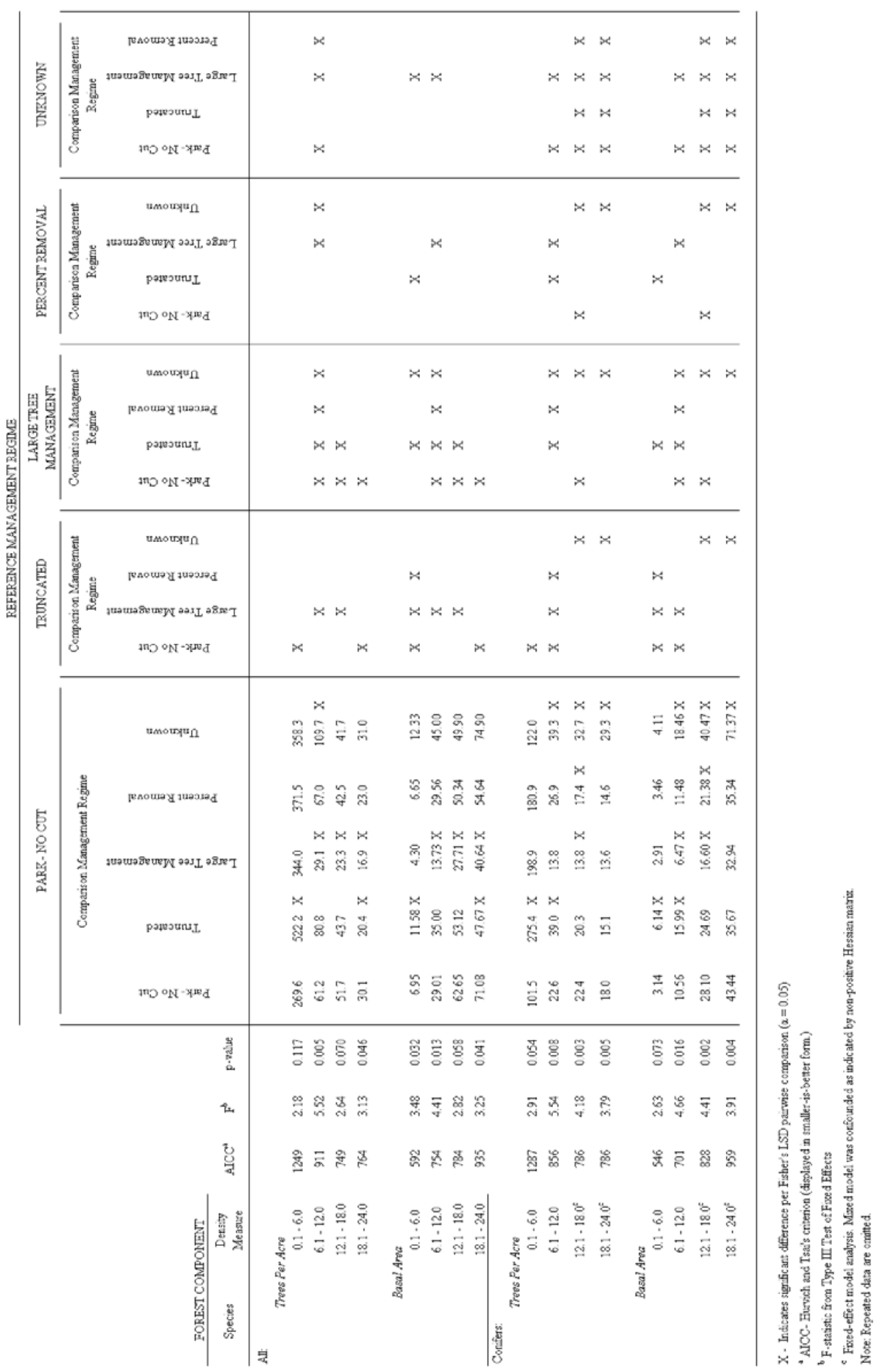


Table C-3: All Pairwise Comparisons of Small Stem Density Distribution by 6-inch classes (24.0” max.), Continued.

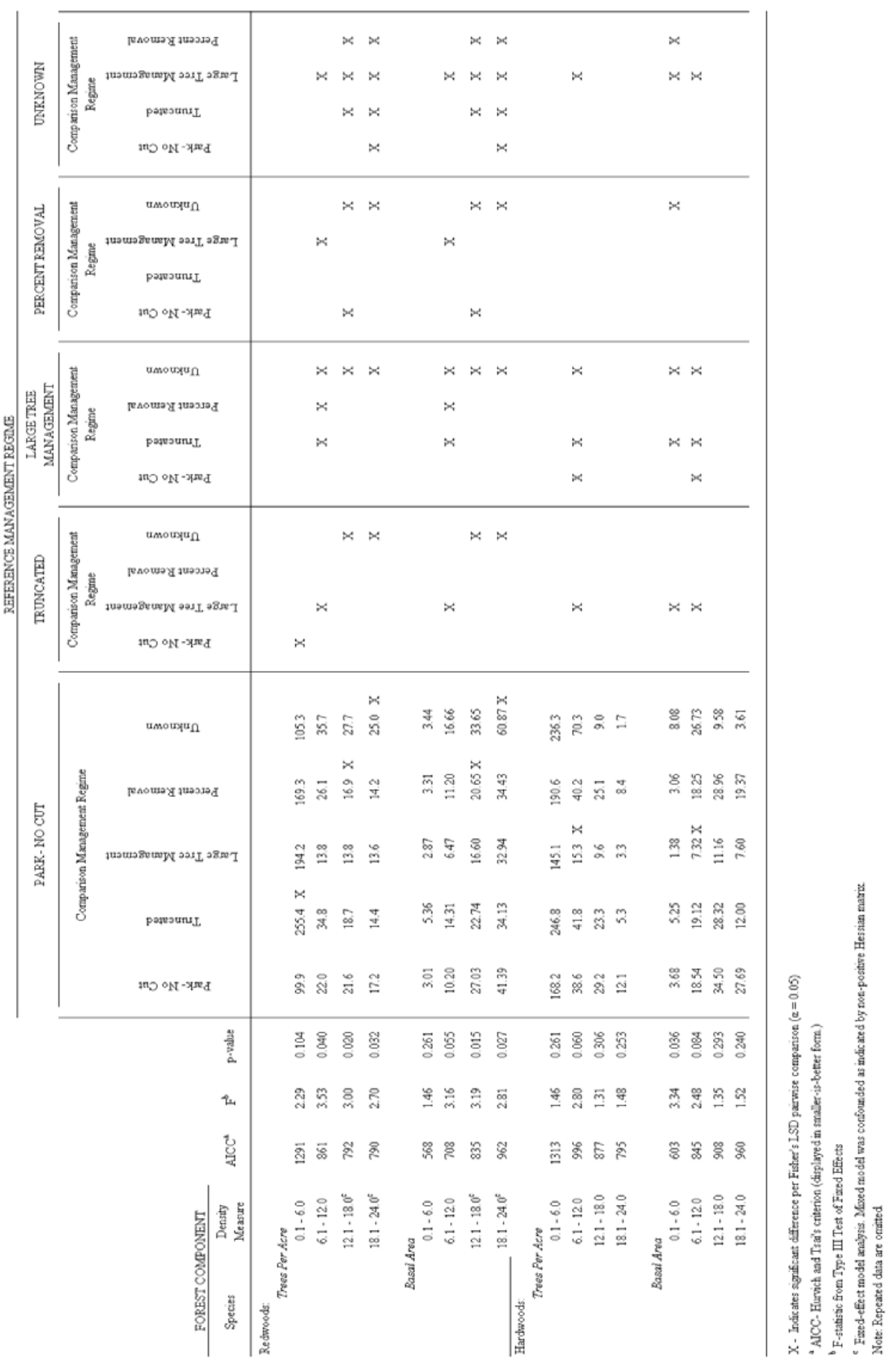


Table C-4: All Pairwise Comparisons of “60/50 Rule” Small Stem Density Distribution (18.0” max.)

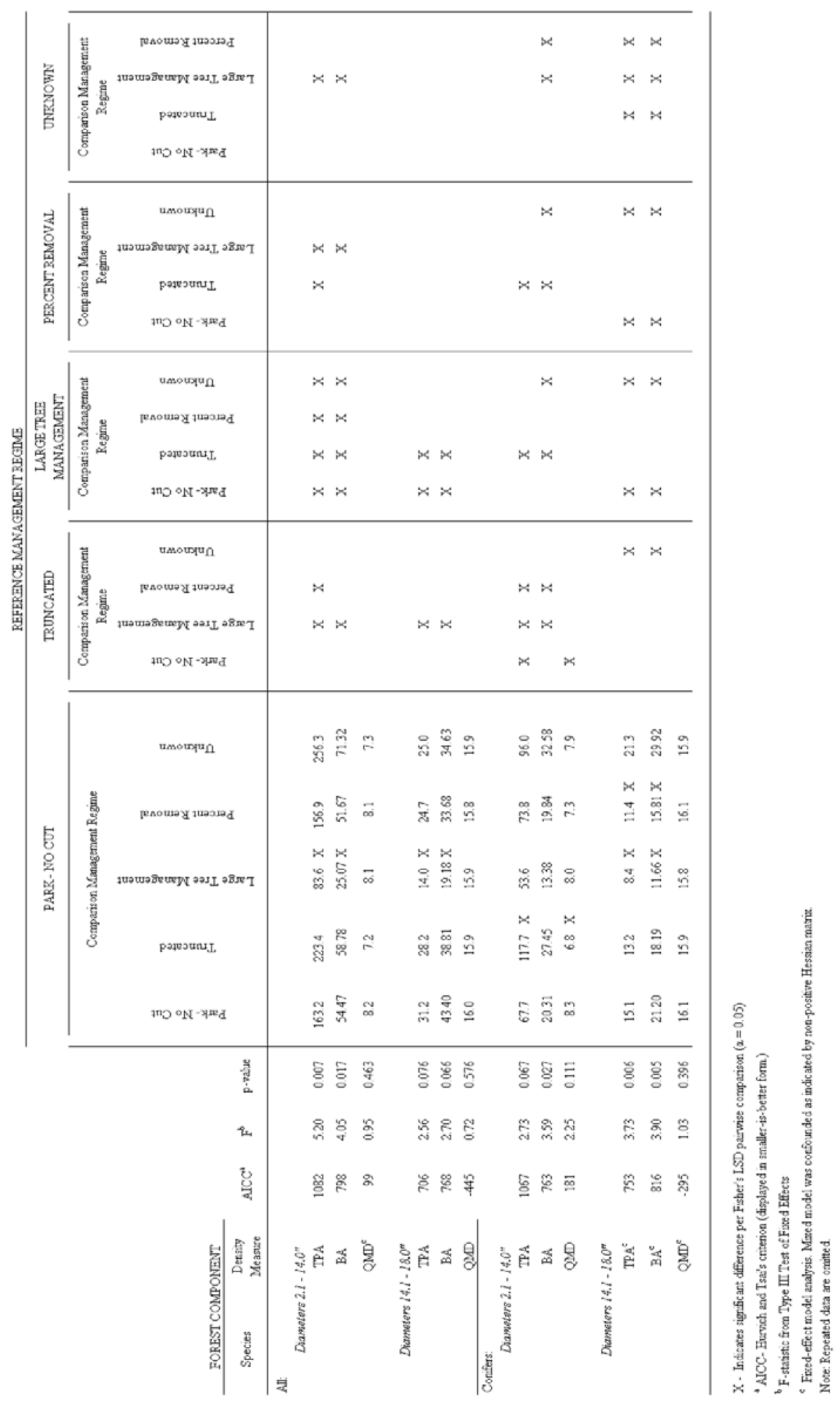


Table C-4: All Pairwise Comparisons of “60/50 Rule” Small Stem Density Distribution (18.0” max.), Continued.

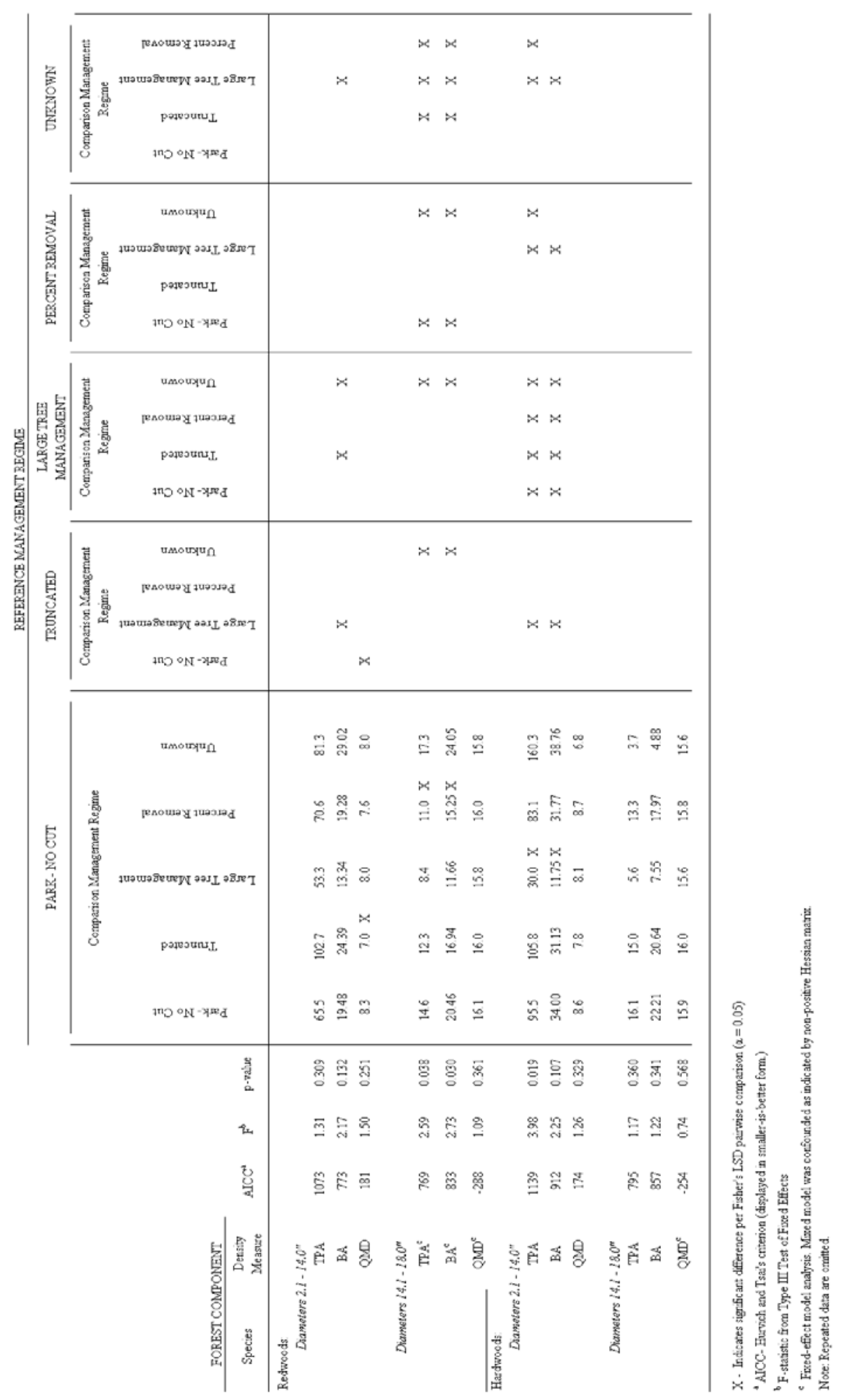


Table C-5: All Pairwise Comparisons of Type A Owl Habitat Small Stem Density (18.0” max.)

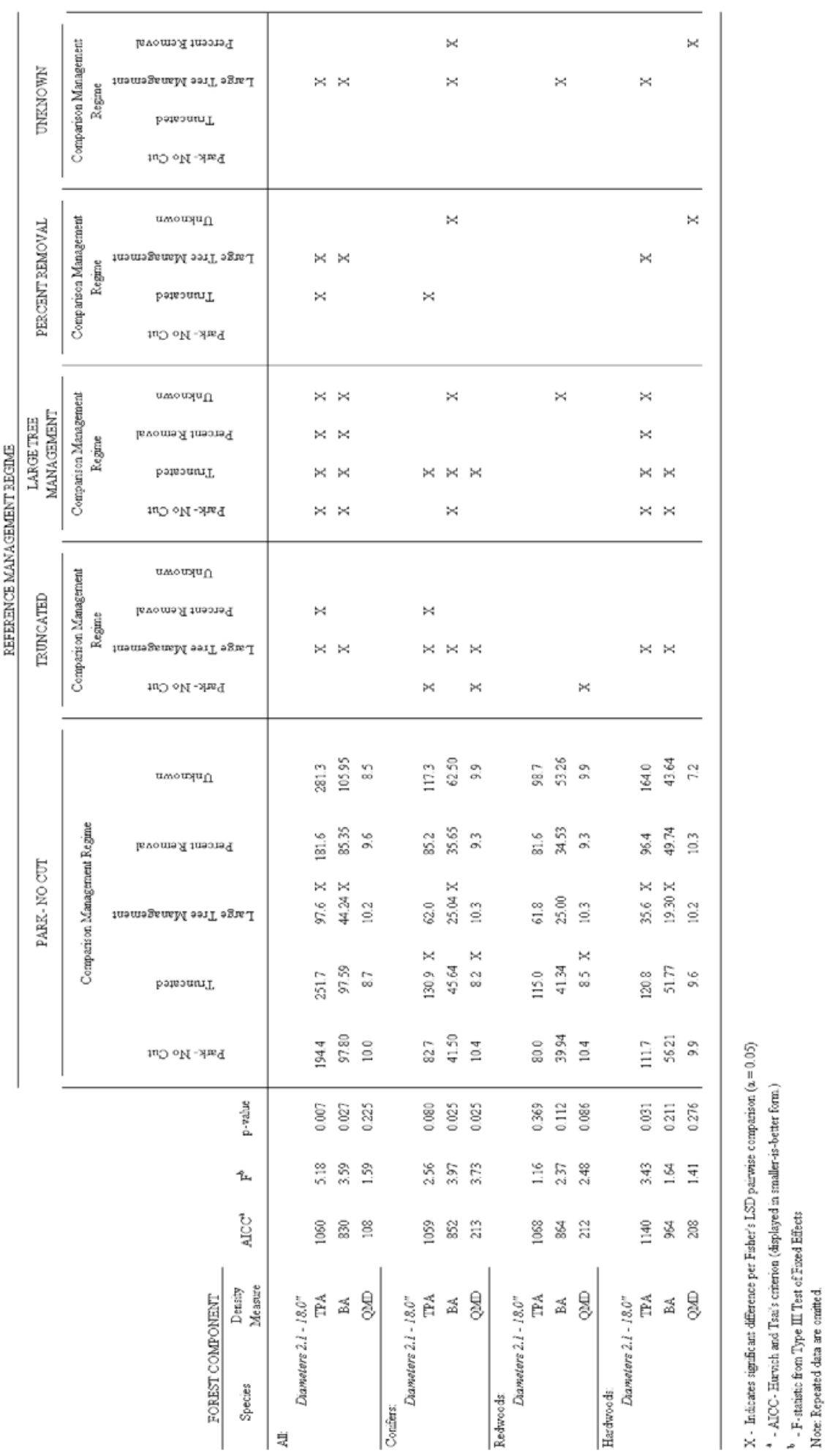


Table C-6: All Pairwise Comparisons of Understory Stem Density

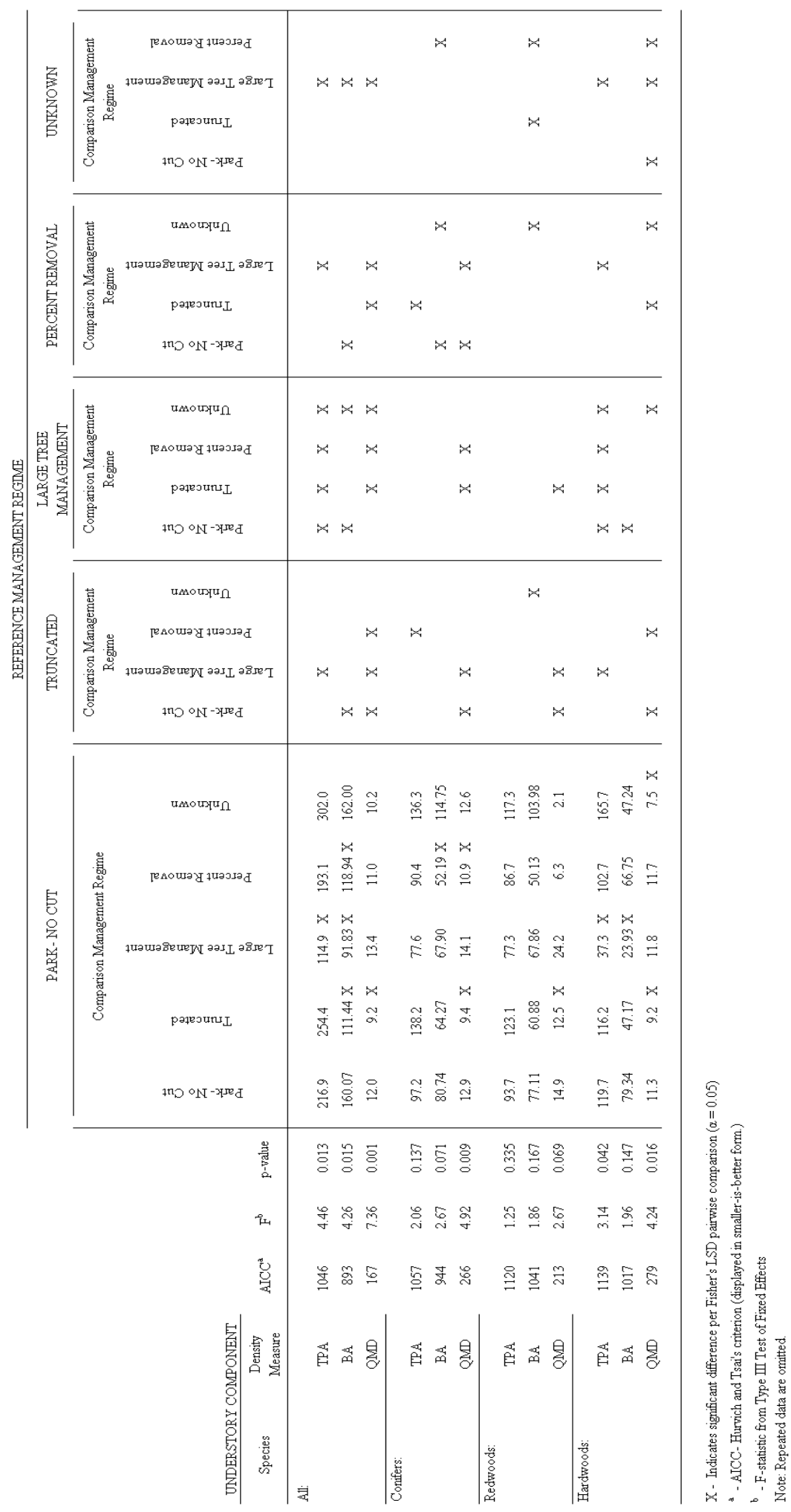


Table C-7: All Pairwise Comparisons of Large Stem Sawtimber Density (10.5” min.)

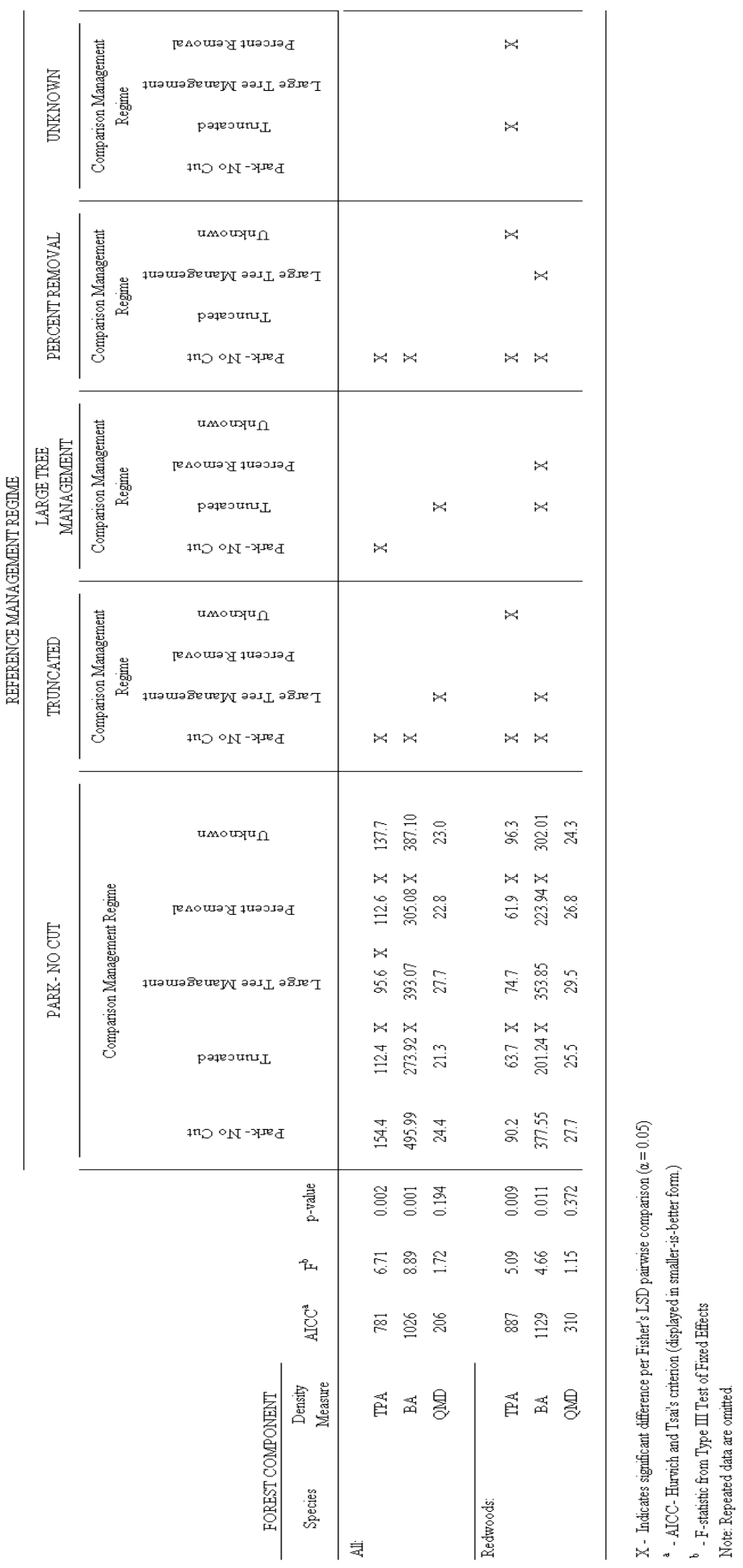


Table C-8: All Pairwise Comparisons of “60/50 Rule” Large Stem Density (18.1” min.)

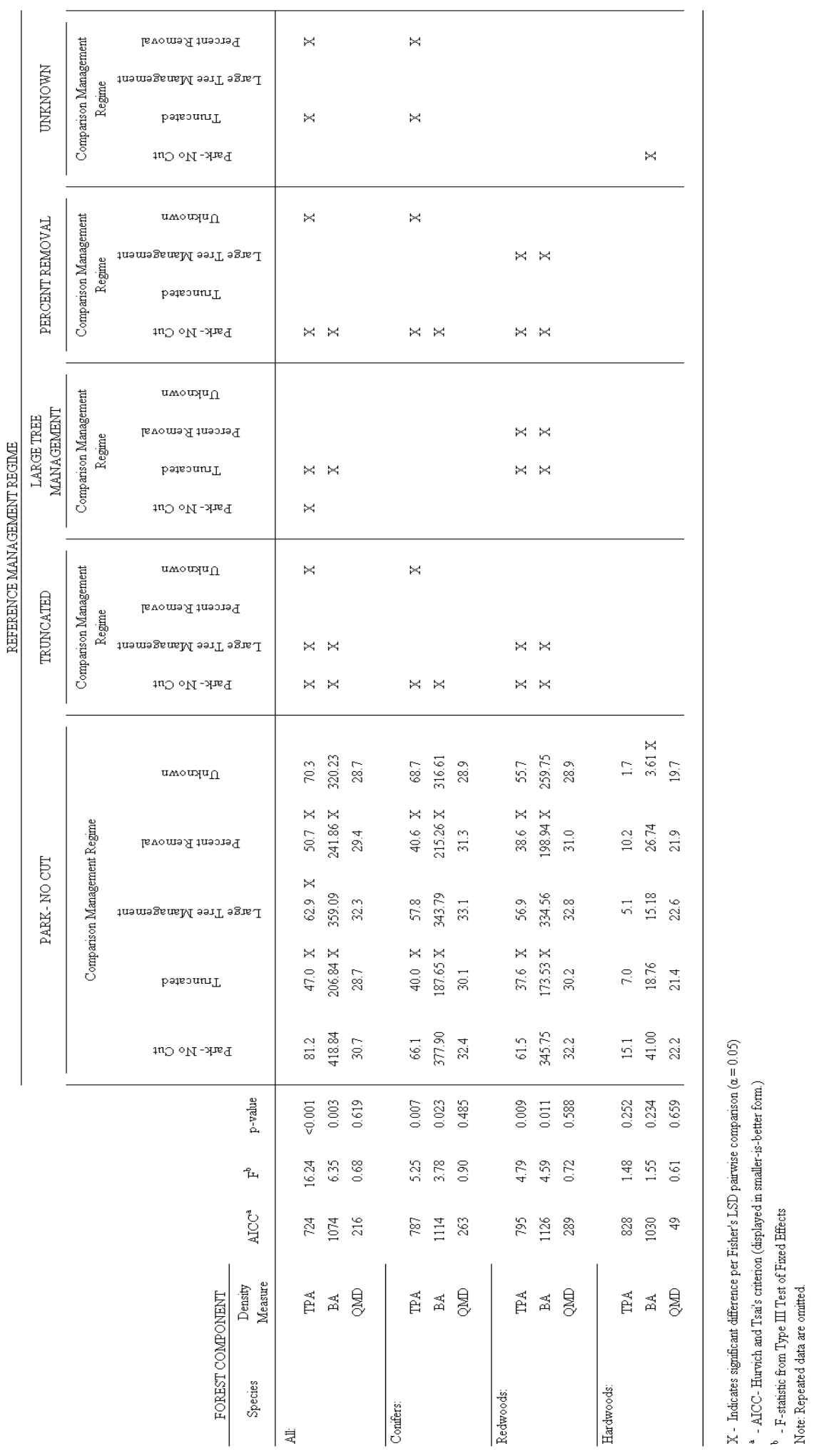


Table C-9: All Pairwise Comparisons of Mature Large Stem Density (24.1” min.)

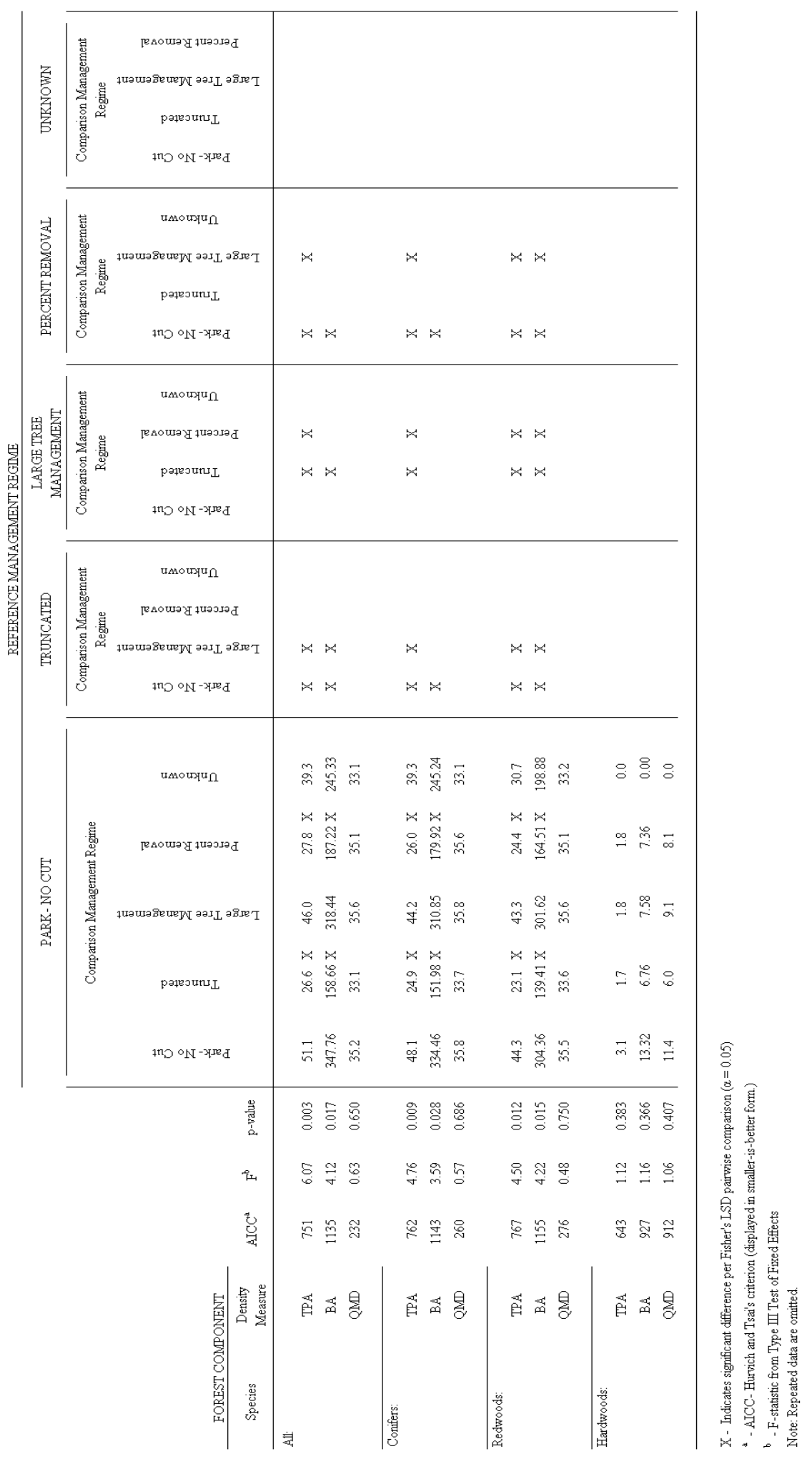


Table C-10: All Pairwise Comparisons of Type A Owl Habitat, Medium and Large Stem Density (18.1” min.)

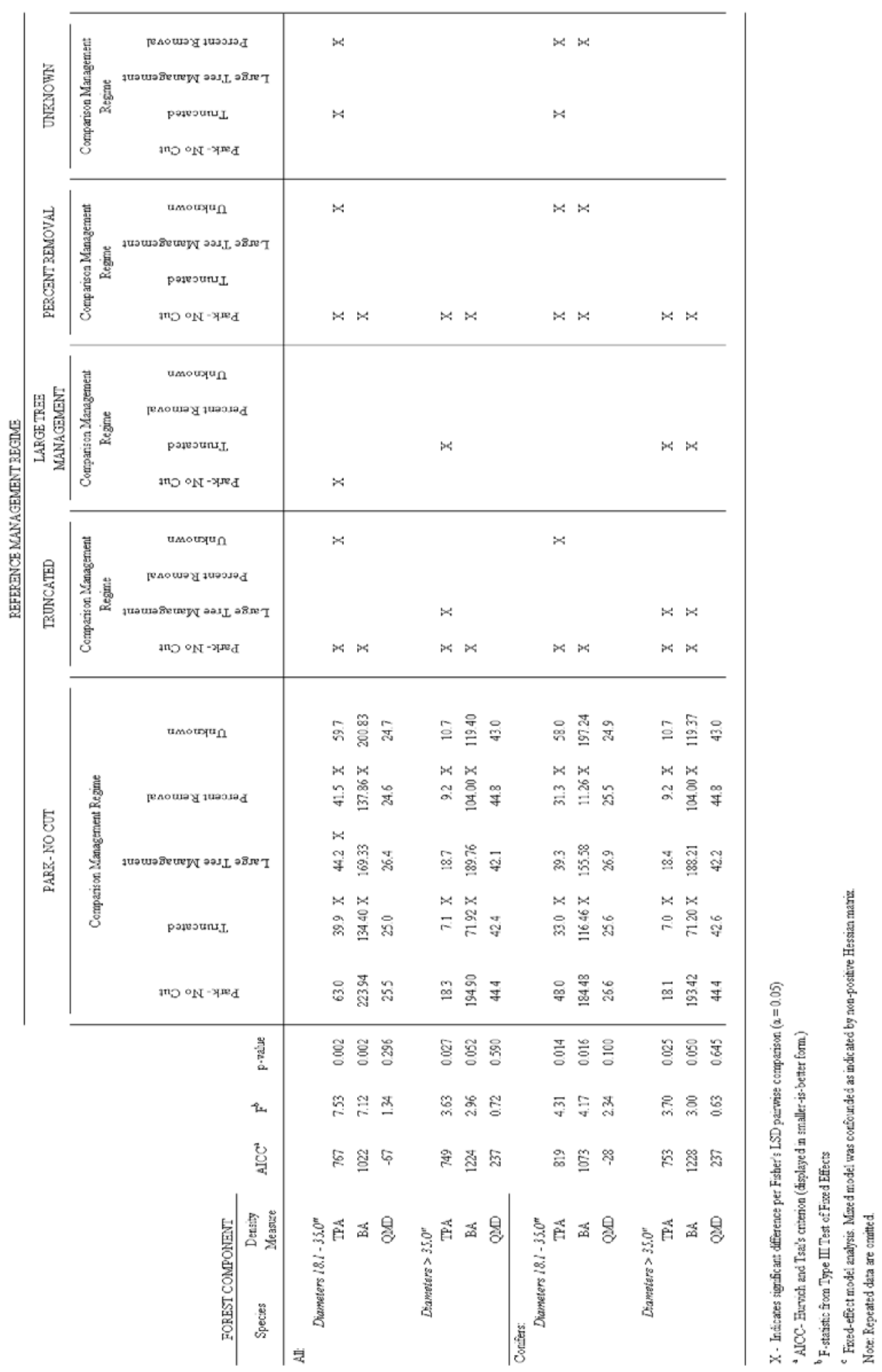


Table C-10: All Pairwise Comparisons of Type A Owl Habitat, Medium and Large Stem Density (18.1” min.), Continued.

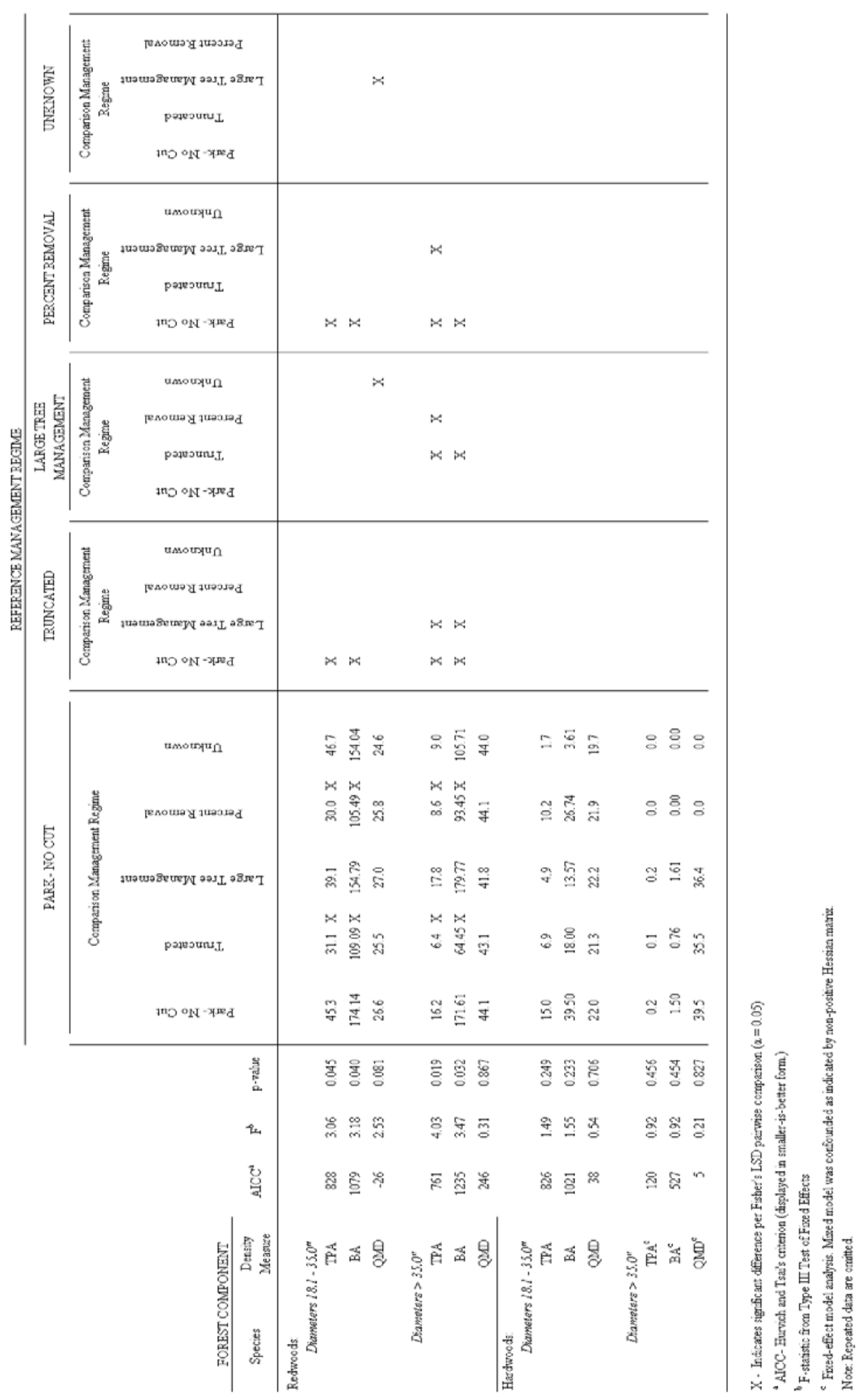


Table C-11: All Pairwise Comparisons of Overstory Stem Density

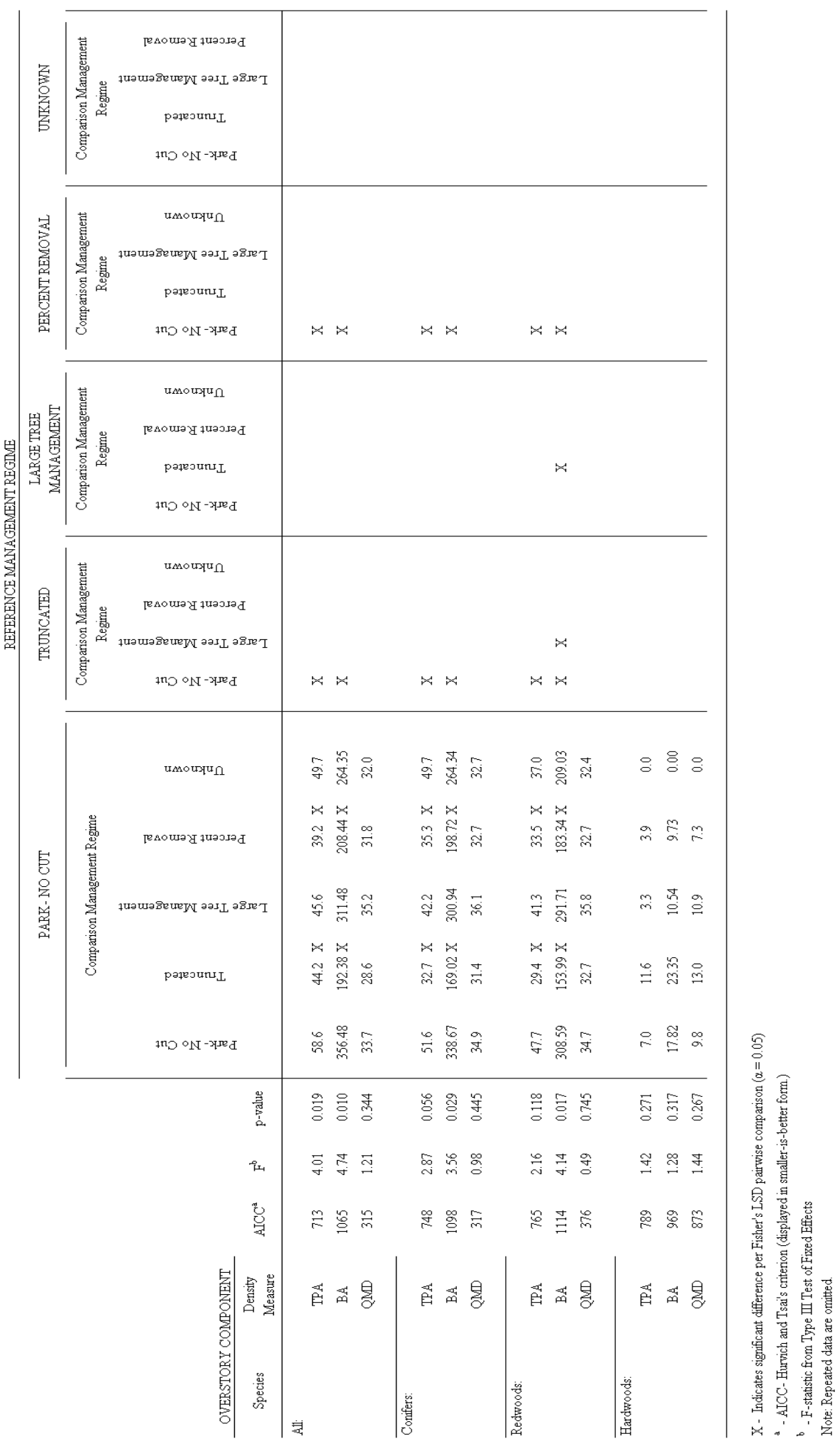


APPENDIX D- Inventory Stand Tables and Summaries

Table D-2: Stand Summary, Middle Ridge, Big Basin Redwoods State Park 234

Table D-3: Stand Summary, North Escape, Big Basin Redwoods State Park................ 235

Table D-4: Stand Summary, Gazos Falls, Butano State Park......................................... 236

Table D-5: Stand Summary, Olmo, Butano State Park .................................................. 237

Table D-6: Stand Summary, 2001 Northeast, CEMEX- Davenport................................ 238

Table D-7: Stand Summary, Incline, Forest of Nisene Marks State Park ...................... 239

Table D-8: Stand Summary, Lagoon, Forest of Nisene Marks State Park ...................... 240

Table D-9: Stand Summary, Lower Bridge, Forest of Nisene Marks State Park .......... 241

Table D-10: Stand Summary, Lower Split Stuff, Forest of Nisene Marks State Park .. 242

Table D-11: Stand Summary, Upper Bridge, Forest of Nisene Marks State Park......... 243

Table D-12: Stand Summary, Upper Split Stuff, Forest of Nisene Marks State Park... 244

Table D-13: Stand Summary, Central Unit, Land Trust of Santa Cruz County ............ 245

Table D-14: Stand Summary, Late Successional Unit, Land Trust of Santa Cruz

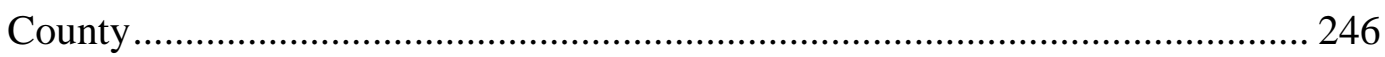

Table D-15: Stand Summary, Ramsey Gulch, Redwood Empire.................................... 247

Table D-16: Stand Summary, Amaya East, Soquel Demonstration State Forest ........... 248

Table D-17: Stand Summary, Amaya West, Soquel Demonstration State Forest......... 249

Table D-18: Stand Summary, Badger Spring, Soquel Demonstration State Forest ...... 250

Table D-19: Stand Summary, Long Ridge, Soquel Demonstration State Forest............ 251

Table D-20: Stand Summary, Stand E, Swanton Pacific Ranch (Little Creek)............. 252 
Table D-21: Stand Summary, Tranquility Flats, Swanton Pacific Ranch

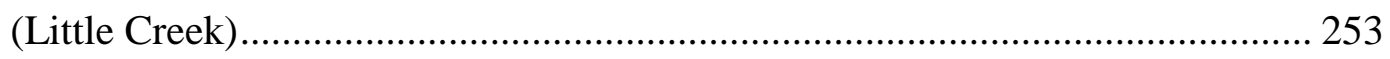

Table D-22: Stand Summary, Cable-3, Swanton Pacific Ranch (Valencia Creek)....... 254

Table D-23: Stand Summary, Tractor-1,3,4 , Swanton Pacific Ranch

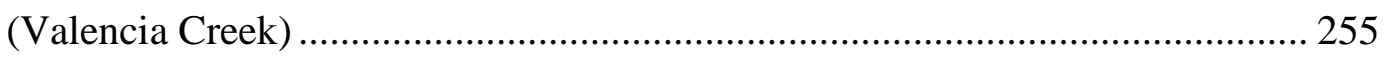

Table D-24: Stand Summary, Tractor-5,6 , Swanton Pacific Ranch (Valencia Creek). 256

Table D-25: Stand Summary, Tractor-8,9,10, Swanton Pacific Ranch

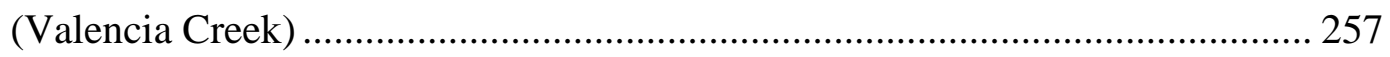

Table D-26: Stand Summary, Upper McCormick, YMCA Camp Jones Gulch............. 258 
Table D-1: Stand Summary, Creeping Forest, Big Basin Redwoods State Park

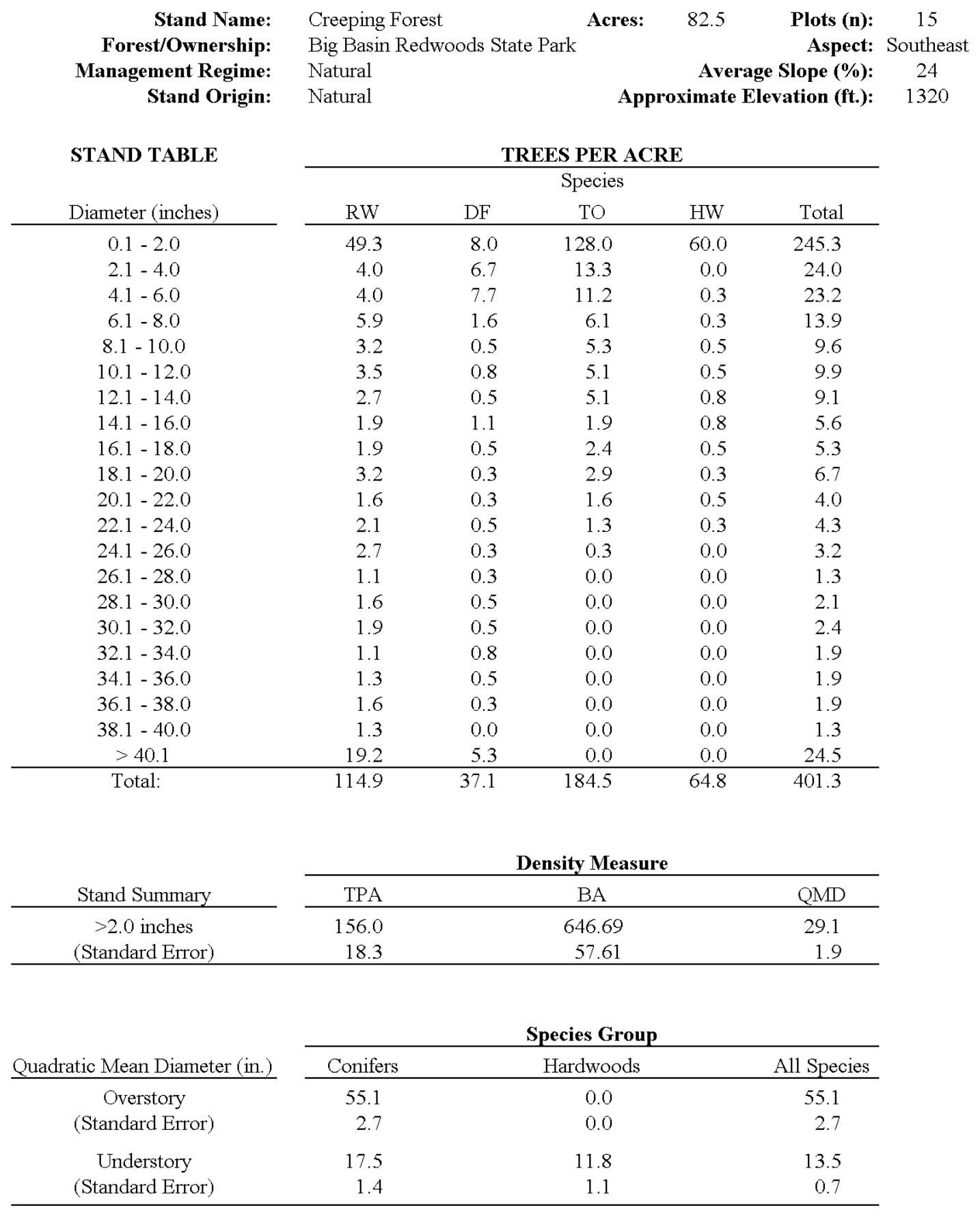


Table D-2: Stand Summary, Middle Ridge, Big Basin Redwoods State Park

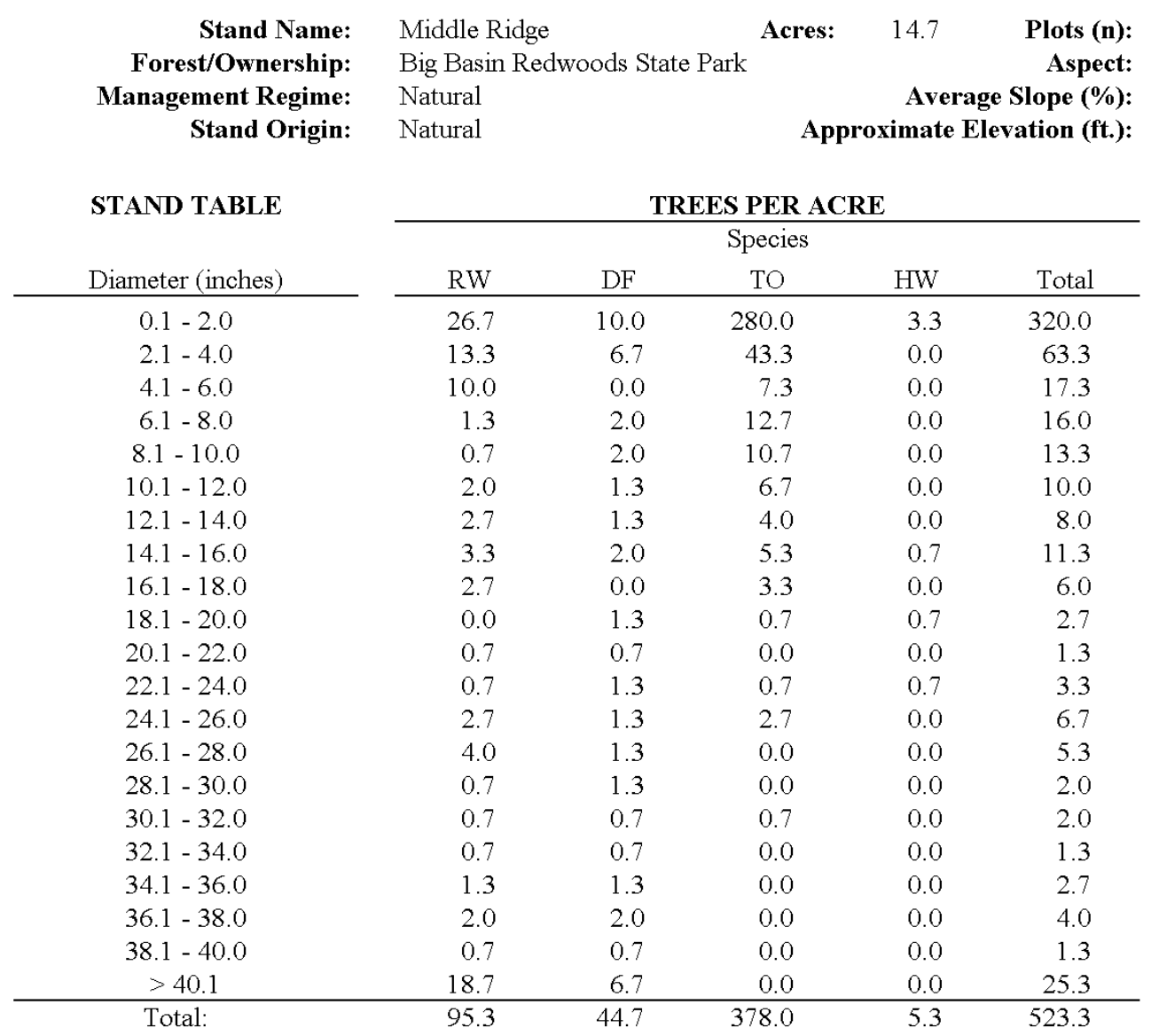

\begin{tabular}{crrrr} 
& & \multicolumn{3}{c}{ Density Measure } \\
\cline { 3 - 5 } \cline { 3 - 5 } \cline { 3 - 5 } Stand Summary & TPA & BA & QMD \\
\cline { 1 - 3 }$>2.0$ inches & & 203.3 & 791.00 & 27.0 \\
(Standard Error) & & 29.6 & 193.36 & 3.6 \\
\hline
\end{tabular}

\begin{tabular}{ccccc} 
& \multicolumn{3}{c}{ Species Group } \\
\cline { 3 - 5 } \cline { 3 - 5 } Quadratic Mean Diameter (in.) & Conifers & Hardwoods & All Species \\
\cline { 1 - 4 } \cline { 3 - 5 } Overstory & 55.7 & 0.0 & 55.7 \\
(Standard Error) & 5.8 & 0.0 & 5.8 \\
Understory & 15.3 & 9.1 & 12.3 \\
(Standard Error) & 1.8 & 1.7 & 1.3 \\
\hline
\end{tabular}


Table D-3: Stand Summary, North Escape, Big Basin Redwoods State Park

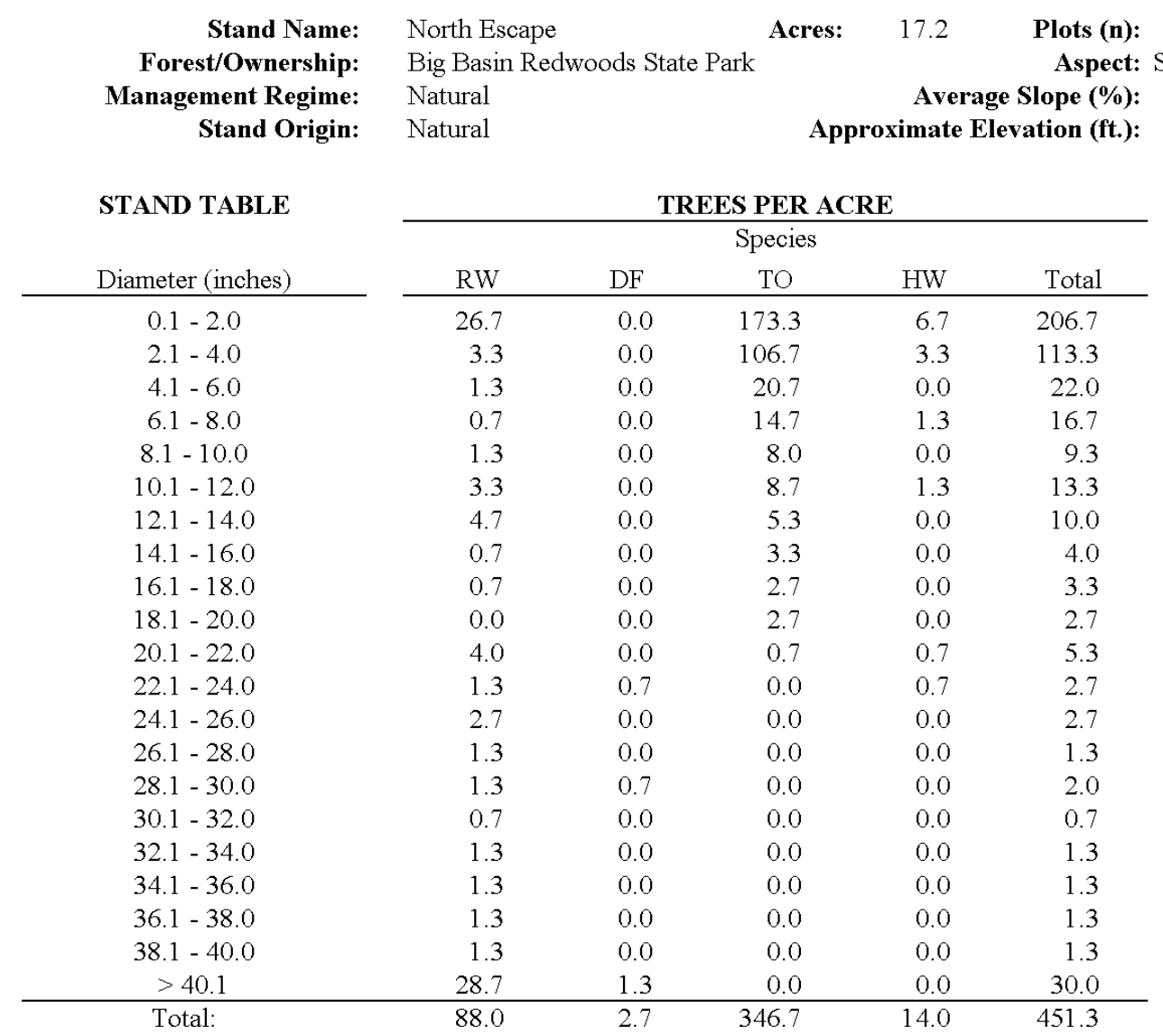

\begin{tabular}{|c|c|c|c|}
\hline \multirow[b]{2}{*}{ Stand Summary } & \multicolumn{3}{|c|}{ Density Measure } \\
\hline & TPA & $\mathrm{BA}$ & $\mathrm{QMD}$ \\
\hline$>2.0$ inches & 244.7 & 884.43 & 29.4 \\
\hline (Standard Error) & 52.3 & 186.67 & 6.7 \\
\hline
\end{tabular}

\begin{tabular}{ccccc} 
& \multicolumn{3}{c}{ Species Group } \\
\cline { 3 - 5 } \cline { 3 - 5 } Quadratic Mean Diameter (in.) & Conifers & Hardwoods & All Species \\
\cline { 1 - 5 } \cline { 3 - 5 } Overstory & 64.4 & 0.0 & 64.4 \\
(Standard Error) & 6.1 & 0.0 & 6.1 \\
Understory & 22.0 & 7.9 & 11.8 \\
(Standard Error) & 2.9 & 1.3 & 1.3 \\
\hline
\end{tabular}


Table D-4: Stand Summary, Gazos Falls, Butano State Park

\begin{tabular}{|c|c|c|c|c|c|}
\hline \multirow{4}{*}{$\begin{array}{r}\text { Stand Name: } \\
\text { Forest/Ownership: } \\
\text { Management Regime: } \\
\text { Stand Origin: } \\
\text { STAND TABLE } \\
\text { Diameter (inches) }\end{array}$} & \multicolumn{2}{|c|}{$\begin{array}{l}\text { Gazos Falls } \\
\text { Butano State Park } \\
\text { Unknown } \\
\text { Harvest }\end{array}$} & \multirow{2}{*}{$\begin{array}{r}\text { Acres: } \\
\text { Appr } \\
\text { S PER ACF }\end{array}$} & \multirow{2}{*}{$\begin{array}{r}60.2 \\
\text { Aves } \\
\text { ximate }\end{array}$} & \multirow{2}{*}{$\begin{array}{r}\text { Plots (n): } \\
\text { Aspect: } \\
\text { Slope (\%): } \\
\text { ation (ft.): }\end{array}$} \\
\hline & \multicolumn{2}{|c|}{ TREES PER ACRE } & & & \\
\hline & \multicolumn{5}{|c|}{ Species } \\
\hline & RW & $\mathrm{DF}$ & $\mathrm{TO}$ & $\mathrm{HW}$ & Total \\
\hline $0.1-2.0$ & 70.0 & 6.7 & 143.3 & 8.3 & 228.3 \\
\hline $2.1-4.0$ & 21.7 & 8.3 & 46.7 & 0.0 & 76.7 \\
\hline $4.1-6.0$ & 13.7 & 1.7 & 37.7 & 0.3 & 53.3 \\
\hline $6.1-8.0$ & 11.3 & 1.0 & 34.0 & 1.7 & 48.0 \\
\hline $8.1-10.0$ & 11.3 & 1.0 & 23.0 & 0.7 & 36.0 \\
\hline $10.1-12.0$ & 13.0 & 1.7 & 10.3 & 0.7 & 25.7 \\
\hline $12.1-14.0$ & 10.3 & 1.0 & 5.3 & 0.0 & 16.7 \\
\hline $14.1-16.0$ & 9.7 & 1.7 & 2.3 & 0.0 & 13.7 \\
\hline $16.1-18.0$ & 7.7 & 2.3 & 1.0 & 0.3 & 11.3 \\
\hline $18.1-20.0$ & 8.0 & 1.3 & 1.3 & 0.0 & 10.7 \\
\hline $20.1-22.0$ & 8.0 & 1.7 & 0.3 & 0.0 & 10.0 \\
\hline $22.1-24.0$ & 9.0 & 1.3 & 0.0 & 0.0 & 10.3 \\
\hline $24.1-26.0$ & 7.0 & 1.7 & 0.0 & 0.0 & 8.7 \\
\hline $26.1-28.0$ & 7.0 & 1.3 & 0.0 & 0.0 & 8.3 \\
\hline $28.1-30.0$ & 3.0 & 1.3 & 0.0 & 0.0 & 4.3 \\
\hline $30.1-32.0$ & 2.0 & 1.0 & 0.0 & 0.0 & 3.0 \\
\hline $32.1-34.0$ & 2.0 & 1.3 & 0.0 & 0.0 & 3.3 \\
\hline $34.1-36.0$ & 1.0 & 0.7 & 0.0 & 0.0 & 1.7 \\
\hline $36.1-38.0$ & 1.0 & 0.7 & 0.0 & 0.0 & 1.7 \\
\hline $38.1-40.0$ & 1.7 & 0.0 & 0.0 & 0.0 & 1.7 \\
\hline$>40.1$ & 6.0 & 0.7 & 0.0 & 0.0 & 6.7 \\
\hline Total: & 224.3 & 38.3 & 305.3 & 12.0 & 580.0 \\
\hline
\end{tabular}

\begin{tabular}{crrrr} 
& & \multicolumn{3}{c}{ Density Measure } \\
\cline { 4 - 5 } \cline { 3 - 5 } \cline { 3 - 5 } Stand Summary & TPA & BA & QMD \\
\hline$>2.0$ inches & & 351.7 & 426.18 & 15.1 \\
(Standard Error) & & 26.3 & 34.66 & 0.7 \\
\hline
\end{tabular}

\begin{tabular}{ccccc} 
& \multicolumn{3}{c}{ Species Group } \\
\cline { 3 - 5 } Quadratic Mean Diameter (in.) & Conifers & Hardwoods & All Species \\
\cline { 1 - 4 } \cline { 3 - 5 } Overstory & 32.0 & 0.0 & 32.0 \\
(Standard Error) & 2.5 & 0.0 & 2.5 \\
Understory & 12.6 & 7.5 & 10.2 \\
(Standard Error) & 0.4 & 0.5 & 0.4 \\
\hline
\end{tabular}


Table D-5: Stand Summary, Olmo, Butano State Park

\begin{tabular}{|c|c|c|c|c|c|}
\hline \multirow{3}{*}{$\begin{array}{r}\text { Stand Name: } \\
\text { Forest/Ownership: } \\
\text { Management Regime: } \\
\text { Stand Origin: } \\
\text { STAND TABLE }\end{array}$} & \multicolumn{2}{|c|}{$\begin{array}{l}\text { Olmo } \\
\text { Butano State Park } \\
\text { Park/No Cut } \\
\text { Harvest }\end{array}$} & Acres: & Ave & $\begin{array}{r}\text { Plots (n): } \\
\text { Aspect: } \\
\text { Slope (\%): } \\
\text { ation (ft.): }\end{array}$ \\
\hline & \multicolumn{5}{|c|}{ TREES PER ACRE } \\
\hline & \multicolumn{5}{|c|}{ Species } \\
\hline Diameter (inches) & RW & $\mathrm{DF}$ & $\mathrm{TO}$ & HW & Total \\
\hline $0.1-2.0$ & 51.1 & 0.0 & 133.3 & 57.8 & 242.2 \\
\hline $2.1-4.0$ & 40.0 & 2.2 & 26.7 & 6.7 & 75.6 \\
\hline $4.1-6.0$ & 15.6 & 5.3 & 3.6 & 0.0 & 24.4 \\
\hline $6.1-8.0$ & 7.6 & 0.0 & 9.8 & 0.0 & 17.3 \\
\hline $8.1-10.0$ & 11.1 & 0.4 & 5.3 & 0.0 & 16.9 \\
\hline $10.1-12.0$ & 8.9 & 2.2 & 8.9 & 0.0 & 20.0 \\
\hline $12.1-14.0$ & 12.9 & 1.3 & 2.7 & 0.0 & 16.9 \\
\hline $14.1-16.0$ & 10.2 & 1.3 & 0.4 & 0.0 & 12.0 \\
\hline $16.1-18.0$ & 9.8 & 1.3 & 0.0 & 0.0 & 11.1 \\
\hline $18.1-20.0$ & 7.1 & 0.9 & 0.0 & 0.0 & 8.0 \\
\hline $20.1-22.0$ & 6.7 & 4.0 & 0.4 & 0.0 & 11.1 \\
\hline $22.1-24.0$ & 6.7 & 0.4 & 0.4 & 0.0 & 7.6 \\
\hline $24.1-26.0$ & 3.6 & 2.2 & 0.0 & 0.0 & 5.8 \\
\hline $26.1-28.0$ & 1.8 & 3.1 & 0.0 & 0.0 & 4.9 \\
\hline $28.1-30.0$ & 3.6 & 2.2 & 0.0 & 0.0 & 5.8 \\
\hline $30.1-32.0$ & 2.7 & 1.3 & 0.0 & 0.0 & 4.0 \\
\hline $32.1-34.0$ & 3.1 & 1.3 & 0.0 & 0.0 & 4.4 \\
\hline $34.1-36.0$ & 1.3 & 1.8 & 0.0 & 0.0 & 3.1 \\
\hline $36.1-38.0$ & 2.2 & 1.3 & 0.0 & 0.0 & 3.6 \\
\hline $38.1-40.0$ & 1.8 & 1.3 & 0.0 & 0.0 & 3.1 \\
\hline$>40.1$ & 16.0 & 5.8 & 0.0 & 0.0 & 21.8 \\
\hline Total: & 223.6 & 40.0 & 191.6 & 64.4 & 519.6 \\
\hline
\end{tabular}

\begin{tabular}{|c|c|c|c|}
\hline \multirow[b]{2}{*}{ Stand Summary } & \multicolumn{3}{|c|}{ Density Measure } \\
\hline & TPA & $\mathrm{BA}$ & $\mathrm{QMD}$ \\
\hline$>2.0$ inches & 277.3 & 652.22 & 22.0 \\
\hline (Standard Error) & 47.8 & 40.83 & 1.5 \\
\hline
\end{tabular}

\begin{tabular}{cccc} 
& \multicolumn{3}{c}{ Species Group } \\
\cline { 3 - 5 } Quadratic Mean Diameter (in.) & Conifers & Hardwoods & All Species \\
\cline { 3 - 5 } \cline { 3 - 4 } Overstory & 41.1 & 0.0 & 41.1 \\
(Standard Error) & 2.0 & 0.0 & 2.0 \\
Understory & 14.4 & 8.5 & 12.8 \\
(Standard Error) & 1.1 & 1.2 & 1.1 \\
\hline
\end{tabular}


Table D-6: Stand Summary, 2001 Northeast, CEMEX- Davenport

\begin{tabular}{|c|c|c|c|c|c|}
\hline \multirow{4}{*}{$\begin{array}{r}\text { Stand Name: } \\
\text { Forest/Ownership: } \\
\text { Management Regime: } \\
\text { Stand Origin: } \\
\text { STAND TABLE } \\
\text { Diameter (inches) }\end{array}$} & \multicolumn{2}{|c|}{$\begin{array}{l}2001 \text { Northeast } \\
\text { CEMEX- Davenport } \\
\text { Percent Removal } \\
\text { Harvest }\end{array}$} & \multirow{2}{*}{$\begin{array}{c}\text { Acres: } \\
\text { APp } \\
\text { ES PER ACF }\end{array}$} & \multirow{2}{*}{$\begin{array}{r}34.9 \\
\text { Ave } \\
\text { ximate } \\
\end{array}$} & \multirow{2}{*}{$\begin{array}{r}\text { Plots (n): } \\
\text { Aspect: } \\
\text { Slope (\%): } \\
\text { ation (ft.): }\end{array}$} \\
\hline & \multicolumn{2}{|c|}{ TREES PER ACRE } & & & \\
\hline & \multicolumn{5}{|c|}{ Species } \\
\hline & RW & $\mathrm{DF}$ & $\mathrm{TO}$ & $\mathrm{HW}$ & Total \\
\hline $0.1-2.0$ & 150.0 & 6.7 & 103.3 & 40.0 & 300.0 \\
\hline $2.1-4.0$ & 36.7 & 3.3 & 20.0 & 10.0 & 70.0 \\
\hline $4.1-6.0$ & 10.0 & 0.0 & 16.0 & 7.3 & 33.3 \\
\hline $6.1-8.0$ & 16.7 & 0.7 & 6.7 & 2.0 & 26.0 \\
\hline $8.1-10.0$ & 20.0 & 0.0 & 1.3 & 1.3 & 22.7 \\
\hline $10.1-12.0$ & 12.0 & 0.0 & 3.3 & 0.7 & 16.0 \\
\hline $12.1-14.0$ & 4.0 & 0.0 & 4.0 & 2.0 & 10.0 \\
\hline $14.1-16.0$ & 8.0 & 0.0 & 2.7 & 2.0 & 12.7 \\
\hline $16.1-18.0$ & 6.7 & 0.0 & 3.3 & 0.7 & 10.7 \\
\hline $18.1-20.0$ & 6.0 & 0.0 & 3.3 & 1.3 & 10.7 \\
\hline $20.1-22.0$ & 4.7 & 0.0 & 3.3 & 0.0 & 8.0 \\
\hline $22.1-24.0$ & 5.3 & 0.0 & 3.3 & 0.0 & 8.7 \\
\hline $24.1-26.0$ & 3.3 & 0.0 & 0.7 & 0.0 & 4.0 \\
\hline $26.1-28.0$ & 4.7 & 0.0 & 1.3 & 0.7 & 6.7 \\
\hline $28.1-30.0$ & 2.7 & 0.0 & 2.0 & 0.0 & 4.7 \\
\hline $30.1-32.0$ & 2.7 & 0.0 & 0.7 & 0.0 & 3.3 \\
\hline $32.1-34.0$ & 2.0 & 0.0 & 0.0 & 0.0 & 2.0 \\
\hline $34.1-36.0$ & 4.0 & 0.0 & 0.0 & 0.0 & 4.0 \\
\hline $36.1-38.0$ & 0.7 & 0.0 & 0.0 & 0.0 & 0.7 \\
\hline $38.1-40.0$ & 1.3 & 0.0 & 0.0 & 0.0 & 1.3 \\
\hline$>40.1$ & 2.7 & 0.7 & 0.0 & 0.0 & 3.3 \\
\hline Total: & 304.0 & 11.3 & 175.3 & 68.0 & 558.7 \\
\hline
\end{tabular}

\begin{tabular}{|c|c|c|c|}
\hline \multirow[b]{2}{*}{ Stand Summary } & \multicolumn{3}{|c|}{ Density Measure } \\
\hline & TPA & $\mathrm{BA}$ & $\mathrm{QMD}$ \\
\hline$>2.0$ inches & 258.7 & 332.93 & 15.5 \\
\hline (Standard Error) & 32.0 & 44.42 & 1.4 \\
\hline
\end{tabular}

\begin{tabular}{ccccc} 
& \multicolumn{3}{c}{ Species Group } \\
\cline { 4 - 5 } \cline { 3 - 5 } Quadratic Mean Diameter (in.) & Conifers & Hardwoods & All Species \\
\cline { 1 - 4 } \cline { 3 - 5 } Overstory & 32.3 & 5.3 & 32.2 \\
(Standard Error) & & 2.6 & 5.3 & 2.6 \\
Understory & 12.3 & 10.4 & 11.4 \\
(Standard Error) & 2.0 & 2.3 & 2.0 \\
\hline
\end{tabular}


Table D-7: Stand Summary, Incline, Forest of Nisene Marks State Park

\begin{tabular}{|c|c|c|c|c|c|}
\hline \multirow{3}{*}{$\begin{array}{r}\text { Stand Name: } \\
\text { Forest/Ownership: } \\
\text { Management Regime: } \\
\text { Stand Origin: } \\
\text { STAND TABLE }\end{array}$} & \multicolumn{4}{|c|}{$\begin{array}{lr}\text { Forest of Nisene Marks State Park } & \text { Aspect: } \\
\text { Park/No Cut } & \text { Average Slope (\%): } \\
\text { Harvest } & \text { Approximate Elevation (ft.): }\end{array}$} & $\begin{array}{l}\text { Plots (n): } \\
\text { Aspect: } \\
\text { llope (\%): } \\
\text { ation (ft.): }\end{array}$ \\
\hline & \multicolumn{5}{|c|}{ TREES PER ACRE } \\
\hline & \multicolumn{5}{|c|}{ Species } \\
\hline Diameter (inches) & RW & DF & $\mathrm{TO}$ & $\mathrm{HW}$ & Total \\
\hline $0.1-2.0$ & 71.7 & 1.7 & 113.3 & 8.3 & 195.0 \\
\hline $2.1-4.0$ & 26.7 & 0.0 & 35.0 & 6.7 & 68.3 \\
\hline $4.1-6.0$ & 14.3 & 0.0 & 21.0 & 3.0 & 38.3 \\
\hline $6.1-8.0$ & 9.7 & 0.0 & 10.0 & 1.7 & 21.3 \\
\hline $8.1-10.0$ & 9.3 & 0.0 & 9.3 & 2.3 & 21.0 \\
\hline $10.1-12.0$ & 5.3 & 0.0 & 7.7 & 2.0 & 15.0 \\
\hline $12.1-14.0$ & 6.3 & 0.0 & 4.7 & 3.0 & 14.0 \\
\hline $14.1-16.0$ & 6.7 & 0.0 & 3.0 & 3.7 & 13.3 \\
\hline $16.1-18.0$ & 7.3 & 0.0 & 2.0 & 2.0 & 11.3 \\
\hline $18.1-20.0$ & 7.0 & 0.0 & 2.7 & 2.0 & 11.7 \\
\hline $20.1-22.0$ & 4.3 & 0.3 & 2.3 & 1.0 & 8.0 \\
\hline $22.1-24.0$ & 5.7 & 0.0 & 0.3 & 2.0 & 8.0 \\
\hline $24.1-26.0$ & 5.7 & 0.0 & 0.7 & 0.3 & 6.7 \\
\hline $26.1-28.0$ & 10.3 & 0.0 & 0.0 & 0.3 & 10.7 \\
\hline $28.1-30.0$ & 10.7 & 0.0 & 0.0 & 0.0 & 10.7 \\
\hline $30.1-32.0$ & 10.7 & 0.0 & 0.0 & 0.3 & 11.0 \\
\hline $32.1-34.0$ & 6.0 & 0.0 & 0.0 & 0.3 & 6.3 \\
\hline $34.1-36.0$ & 5.7 & 0.0 & 0.0 & 0.0 & 5.7 \\
\hline $36.1-38.0$ & 4.0 & 0.0 & 0.0 & 0.0 & 4.0 \\
\hline $38.1-40.0$ & 4.7 & 0.0 & 0.0 & 0.0 & 4.7 \\
\hline$>40.1$ & 7.3 & 0.3 & 0.0 & 0.0 & 7.7 \\
\hline Total: & 239.3 & 2.3 & 212.0 & 39.0 & 492.7 \\
\hline
\end{tabular}

\begin{tabular}{crrrr} 
& & \multicolumn{3}{c}{ Density Measure } \\
\cline { 4 - 5 } \cline { 3 - 5 } Stand Summary & & TPA & BA & QMD \\
\cline { 1 - 3 } \cline { 4 - 6 } (Standard Error) & & 297.7 & 558.40 & 18.7 \\
& & 23.3 & 59.26 & 1.2 \\
\hline
\end{tabular}

\begin{tabular}{ccccc} 
& \multicolumn{3}{c}{ Species Group } \\
\cline { 3 - 5 } Quadratic Mean Diameter (in.) & Conifers & Hardwoods & All Species \\
\cline { 3 - 5 } \cline { 3 - 4 } Overstory & 33.4 & 9.0 & 32.6 \\
(Standard Error) & 1.0 & 3.2 & 1.0 \\
Understory & 11.9 & 10.4 & 10.5 \\
(Standard Error) & 0.8 & 0.7 & 0.4 \\
\hline
\end{tabular}


Table D-8: Stand Summary, Lagoon, Forest of Nisene Marks State Park

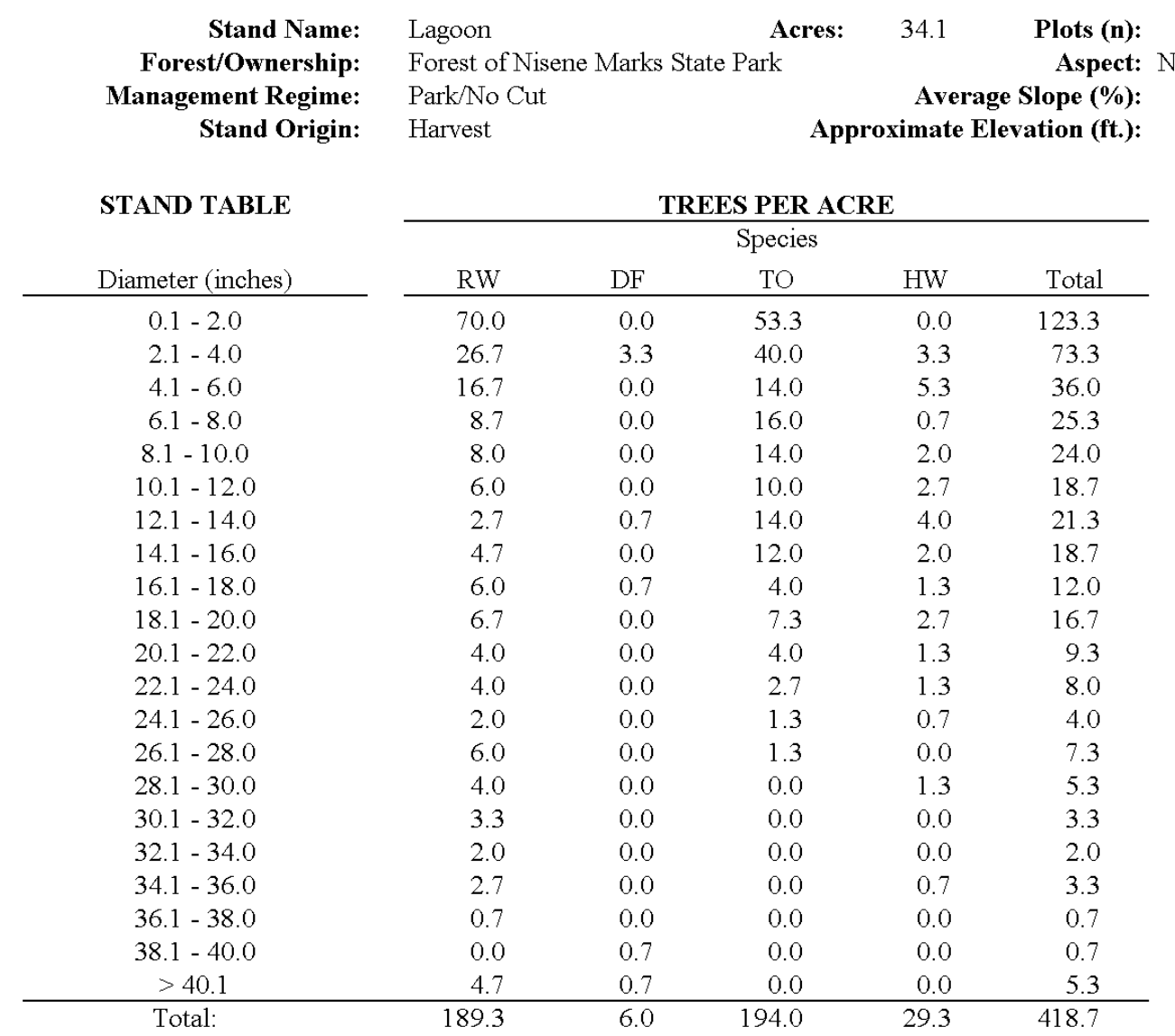

\begin{tabular}{crrrr} 
& & \multicolumn{3}{c}{ Density Measure } \\
\cline { 3 - 5 } \cline { 3 - 5 } Stand Summary & TPA & BA & QMD \\
\cline { 1 - 3 } \cline { 4 - 6 } (Standard Error) & & 295.3 & 367.99 & 0.7 \\
\hline
\end{tabular}

\begin{tabular}{ccccc} 
& \multicolumn{3}{c}{ Species Group } \\
\cline { 3 - 5 } \cline { 3 - 5 } Quadratic Mean Diameter (in.) & Conifers & Hardwoods & All Species \\
\cline { 3 - 5 } \cline { 3 - 5 } Overstory & 30.8 & 20.3 & 27.2 \\
(Standard Error) & & 1.2 & 1.4 & 2.0 \\
Understory & 11.3 & 10.5 & 10.5 \\
(Standard Error) & 1.2 & 0.4 & 0.6 \\
\hline
\end{tabular}


Table D-9: Stand Summary, Lower Bridge, Forest of Nisene Marks State Park

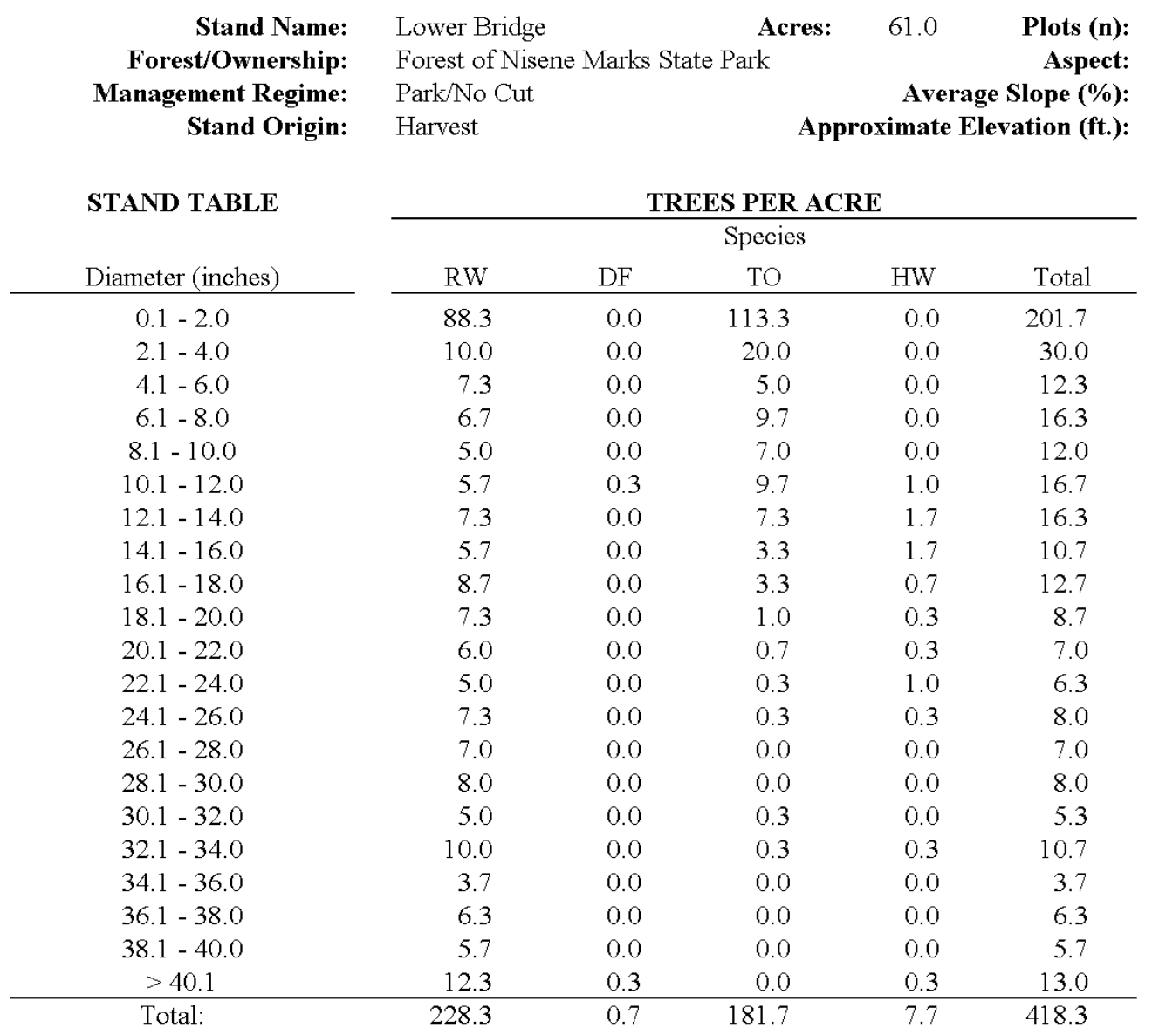

\begin{tabular}{|c|c|c|c|}
\hline \multirow[b]{2}{*}{ Stand Summary } & \multicolumn{3}{|c|}{ Density Measure } \\
\hline & TPA & $\mathrm{BA}$ & QMD \\
\hline$>2.0$ inches & 216.7 & 591.37 & 23.1 \\
\hline (Standard Error) & 20.0 & 40.67 & 1.4 \\
\hline
\end{tabular}

\begin{tabular}{ccccc} 
& \multicolumn{3}{c}{ Species Group } \\
\cline { 3 - 5 } Quadratic Mean Diameter (in.) & Conifers & Hardwoods & All Species \\
\cline { 3 - 5 } \cline { 3 - 5 } Overstory & 35.2 & 3.9 & 35.3 \\
(Standard Error) & 1.1 & 3.9 & 1.1 \\
Understory & 14.4 & 11.7 & 13.3 \\
(Standard Error) & 0.9 & 1.1 & 1.0 \\
\hline
\end{tabular}


Table D-10: Stand Summary, Lower Split Stuff, Forest of Nisene Marks State Park

\begin{tabular}{|c|c|c|c|c|c|}
\hline \multirow{4}{*}{$\begin{array}{r}\text { Stand Name: } \\
\text { Forest/Ownership: } \\
\text { Management Regime: } \\
\text { Stand Origin: } \\
\text { STAND TABLE } \\
\text { Diameter (inches) } \\
\end{array}$} & \multicolumn{3}{|c|}{$\begin{array}{l}\text { Lower Split Stuff Acres } \\
\text { Forest of Nisene Marks State Park } \\
\text { Park/No Cut } \\
\text { Harvest }\end{array}$} & \multirow{2}{*}{$\begin{array}{r}48.3 \\
\text { Aver } \\
\text { imate } \\
\\
\end{array}$} & \multirow{2}{*}{$\begin{array}{r}\text { Plots (n): } \\
\text { Aspect: } \\
\text { Slope (\%): } \\
\text { ation (ft.): }\end{array}$} \\
\hline & \multicolumn{3}{|c|}{ TREES PER ACRE } & & \\
\hline & \multicolumn{5}{|c|}{ Species } \\
\hline & RW & DF & TO & $\mathrm{HW}$ & Total \\
\hline $0.1-2.0$ & 62.2 & 0.0 & 117.8 & 0.0 & 180.0 \\
\hline $2.1-4.0$ & 8.9 & 0.0 & 24.4 & 0.0 & 33.3 \\
\hline $4.1-6.0$ & 3.6 & 0.0 & 8.4 & 0.0 & 12.0 \\
\hline $6.1-8.0$ & 5.3 & 0.0 & 8.9 & 0.0 & 14.2 \\
\hline $8.1-10.0$ & 8.0 & 0.0 & 15.1 & 0.0 & 23.1 \\
\hline $10.1-12.0$ & 4.9 & 0.0 & 18.7 & 0.0 & 23.6 \\
\hline $12.1-14.0$ & 5.8 & 0.0 & 20.4 & 0.0 & 26.2 \\
\hline $14.1-16.0$ & 6.7 & 0.0 & 20.0 & 0.0 & 26.7 \\
\hline $16.1-18.0$ & 6.7 & 0.4 & 13.3 & 1.3 & 21.8 \\
\hline $18.1-20.0$ & 5.3 & 0.0 & 8.9 & 1.3 & 15.6 \\
\hline $20.1-22.0$ & 7.6 & 0.0 & 4.0 & 0.9 & 12.4 \\
\hline $22.1-24.0$ & 5.3 & 0.4 & 5.3 & 0.4 & 11.6 \\
\hline $24.1-26.0$ & 3.1 & 0.0 & 1.3 & 0.0 & 4.4 \\
\hline $26.1-28.0$ & 5.3 & 0.0 & 1.8 & 0.0 & 7.1 \\
\hline $28.1-30.0$ & 4.4 & 0.0 & 0.4 & 0.4 & 5.3 \\
\hline $30.1-32.0$ & 4.0 & 0.4 & 0.0 & 0.4 & 4.9 \\
\hline $32.1-34.0$ & 3.1 & 0.0 & 0.0 & 0.0 & 3.1 \\
\hline $34.1-36.0$ & 4.4 & 0.4 & 0.0 & 0.0 & 4.9 \\
\hline $36.1-38.0$ & 4.4 & 0.9 & 0.0 & 0.4 & 5.8 \\
\hline $38.1-40.0$ & 2.7 & 0.0 & 0.0 & 0.0 & 2.7 \\
\hline$>40.1$ & 5.3 & 0.9 & 0.0 & 0.0 & 6.2 \\
\hline Total: & 167.1 & 3.6 & 268.9 & 5.3 & 444.9 \\
\hline
\end{tabular}

\begin{tabular}{crrrr} 
& & \multicolumn{3}{c}{ Density Measure } \\
\cline { 3 - 5 } \cline { 3 - 5 } Stand Summary & TPA & BA & QMD \\
\cline { 1 - 3 } \cline { 5 - 6 } (Standard Error) & & 264.9 & 519.44 & 1.0 \\
\hline
\end{tabular}

\begin{tabular}{ccccc} 
& \multicolumn{3}{c}{ Species Group } \\
\cline { 3 - 5 } \cline { 3 - 5 } Quadratic Mean Diameter (in.) & Conifers & Hardwoods & All Species \\
\cline { 3 - 5 } \cline { 3 - 5 } Overstory & 34.9 & 16.7 & 32.0 \\
(Standard Error) & & 1.4 & 3.2 & 1.3 \\
Understory & 14.4 & 13.0 & 13.4 \\
(Standard Error) & 1.2 & 0.6 & 0.6 \\
\hline
\end{tabular}


Table D-11: Stand Summary, Upper Bridge, Forest of Nisene Marks State Park

\begin{tabular}{|c|c|c|c|c|c|c|}
\hline Stand Name: & Upper Bridge & & Acres: & 53.6 & Plots (n): & 9 \\
\hline Forest/Ownership: & Forest of Nise & Marks & te Park & & Aspect: & Northwest \\
\hline Management Regime: & Park/No Cut & & & Aver & e Slope (\%): & 45 \\
\hline Stand Origin: & Harvest & & Ap & imate & evation (ft.): & 1200 \\
\hline \multirow[t]{2}{*}{ STAND TABLE } & \multicolumn{5}{|c|}{ TREES PER ACRE } & \\
\hline & \multicolumn{5}{|c|}{ Species } & \\
\hline Diameter (inches) & RW & DF & TO & HW & Total & \\
\hline $0.1-2.0$ & 35.6 & 0.0 & 57.8 & 0.0 & 93.3 & \\
\hline $2.1-4.0$ & 26.7 & 0.0 & 17.8 & 0.0 & 44.4 & \\
\hline $4.1-6.0$ & 12.9 & 0.0 & 8.9 & 0.4 & 22.2 & \\
\hline $6.1-8.0$ & 5.8 & 0.0 & 12.4 & 0.4 & 18.7 & \\
\hline $8.1-10.0$ & 5.8 & 0.4 & 24.0 & 0.4 & 30.7 & \\
\hline $10.1-12.0$ & 8.9 & 0.4 & 19.6 & 2.7 & 31.6 & \\
\hline $12.1-14.0$ & 3.6 & 0.9 & 17.3 & 3.1 & 24.9 & \\
\hline $14.1-16.0$ & 4.9 & 0.4 & 8.4 & 1.8 & 15.6 & \\
\hline $16.1-18.0$ & 4.4 & 0.0 & 10.2 & 0.9 & 15.6 & \\
\hline $18.1-20.0$ & 4.0 & 0.4 & 6.7 & 0.9 & 12.0 & \\
\hline $20.1-22.0$ & 4.9 & 0.0 & 6.7 & 0.4 & 12.0 & \\
\hline $22.1-24.0$ & 2.7 & 0.0 & 2.2 & 0.9 & 5.8 & \\
\hline $24.1-26.0$ & 5.8 & 0.9 & 1.8 & 0.4 & 8.9 & \\
\hline $26.1-28.0$ & 6.2 & 0.9 & 1.3 & 0.0 & 8.4 & \\
\hline $28.1-30.0$ & 2.7 & 0.4 & 0.9 & 0.9 & 4.9 & \\
\hline $30.1-32.0$ & 3.1 & 0.4 & 0.4 & 0.0 & 4.0 & \\
\hline $32.1-34.0$ & 2.7 & 0.4 & 0.0 & 0.0 & 3.1 & \\
\hline $34.1-36.0$ & 1.8 & 0.4 & 0.0 & 0.0 & 2.2 & \\
\hline $36.1-38.0$ & 1.8 & 0.0 & 0.0 & 0.0 & 1.8 & \\
\hline $38.1-40.0$ & 1.8 & 0.0 & 0.0 & 0.0 & 1.8 & \\
\hline$>40.1$ & 4.9 & 0.4 & 0.0 & 0.0 & 5.3 & \\
\hline \multirow[t]{2}{*}{ Total: } & 150.7 & 6.7 & 196.4 & 13.3 & 367.1 & \\
\hline & \multicolumn{5}{|c|}{ Density Measure } & \\
\hline Stand Summary & TPA & & $\mathrm{BA}$ & & QMD & \\
\hline \multirow{3}{*}{$\begin{array}{c}>2.0 \text { inches } \\
\text { (Standard Error) }\end{array}$} & 273.8 & & 427.89 & & 17.2 & \\
\hline & 20.9 & & 23.84 & & 0.9 & \\
\hline & \multicolumn{5}{|c|}{ Species Group } & \\
\hline Quadratic Mean Diameter (in.) & Conifers & & Hardwoods & & All Species & \\
\hline Overstory & 33.6 & & 8.4 & & 32.8 & \\
\hline (Standard Error) & 1.1 & & 4.2 & & 1.0 & \\
\hline Understory & 11.8 & & 13.1 & & 12.3 & \\
\hline (Standard Error) & 1.1 & & 0.9 & & 0.7 & \\
\hline
\end{tabular}


Table D-12: Stand Summary, Upper Split Stuff, Forest of Nisene Marks State Park

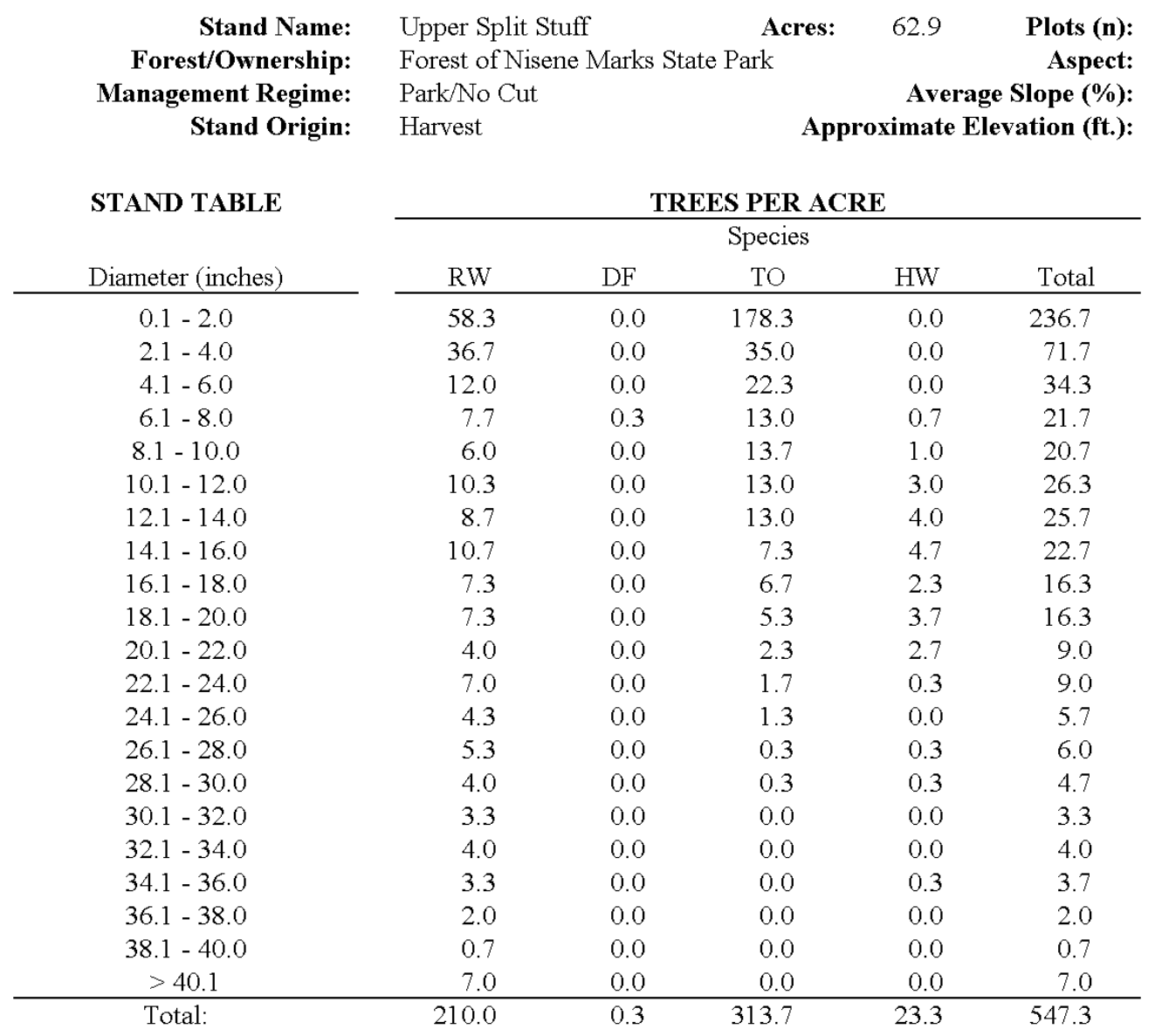

\begin{tabular}{|c|c|c|c|}
\hline \multirow[b]{2}{*}{ Stand Summary } & \multicolumn{3}{|c|}{ Density Measure } \\
\hline & TPA & $\mathrm{BA}$ & $\mathrm{QMD}$ \\
\hline$>2.0$ inches & 310.7 & 437.28 & 16.5 \\
\hline (Standard Error) & 31.7 & 34.07 & 0.8 \\
\hline
\end{tabular}

\begin{tabular}{ccccc} 
& \multicolumn{3}{c}{ Species Group } \\
\cline { 3 - 5 } Quadratic Mean Diameter (in.) & Conifers & Hardwoods & All Species \\
\cline { 3 - 5 } \cline { 3 - 5 } Overstory & 34.2 & 14.6 & 32.6 \\
(Standard Error) & 1.4 & 3.2 & 1.3 \\
Understory & 12.1 & 11.5 & 11.3 \\
(Standard Error) & 0.7 & 0.7 & 0.6 \\
\hline
\end{tabular}


Table D-13: Stand Summary, Central Unit, Land Trust of Santa Cruz County

\begin{tabular}{|c|c|c|c|c|c|}
\hline \multirow{2}{*}{$\begin{array}{r}\text { Stand Name: } \\
\text { Forest/Ownership: } \\
\text { Management Regime: } \\
\text { Stand Origin: }\end{array}$} & \multicolumn{4}{|c|}{$\begin{array}{lr}\text { Central Unit } & \text { Acres: } \\
\text { Land Trust of Santa Cruz County (Byrne Forest) }\end{array}$} & $\begin{array}{r}\text { Plots (n): } \\
\text { Aspect: }\end{array}$ \\
\hline & \multicolumn{4}{|c|}{ Percent Removal Ave } & Approximate Elevation (ft.): \\
\hline \multirow[t]{2}{*}{ STAND TABLE } & \multicolumn{5}{|c|}{ TREES PER ACRE } \\
\hline & \multicolumn{5}{|c|}{ Species } \\
\hline Diameter (inches) & RW & DF & TO & $\mathrm{HW}$ & Total \\
\hline $0.1-2.0$ & 160.0 & 0.0 & 104.4 & 22.2 & 286.7 \\
\hline $2.1-4.0$ & 24.4 & 0.0 & 4.4 & 2.2 & 31.1 \\
\hline $4.1-6.0$ & 7.6 & 0.0 & 1.3 & 0.9 & 9.8 \\
\hline $6.1-8.0$ & 10.7 & 0.0 & 2.2 & 0.4 & 13.3 \\
\hline $8.1-10.0$ & 7.1 & 0.0 & 2.7 & 0.4 & 10.2 \\
\hline $10.1-12.0$ & 2.2 & 0.0 & 4.0 & 0.0 & 6.2 \\
\hline $12.1-14.0$ & 4.0 & 0.0 & 3.6 & 0.0 & 7.6 \\
\hline $14.1-16.0$ & 3.6 & 0.0 & 2.2 & 0.0 & 5.8 \\
\hline $16.1-18.0$ & 2.7 & 0.0 & 1.3 & 0.0 & 4.0 \\
\hline $18.1-20.0$ & 1.3 & 0.0 & 3.6 & 0.0 & 4.9 \\
\hline $20.1-22.0$ & 2.7 & 0.0 & 1.8 & 0.0 & 4.4 \\
\hline $22.1-24.0$ & 1.3 & 0.4 & 0.9 & 0.0 & 2.7 \\
\hline $24.1-26.0$ & 0.9 & 0.0 & 0.9 & 0.0 & 1.8 \\
\hline $26.1-28.0$ & 1.3 & 0.0 & 0.4 & 0.0 & 1.8 \\
\hline $28.1-30.0$ & 1.3 & 0.0 & 0.9 & 0.0 & 2.2 \\
\hline $30.1-32.0$ & 2.2 & 0.0 & 0.4 & 0.0 & 2.7 \\
\hline $32.1-34.0$ & 1.3 & 0.0 & 0.4 & 0.0 & 1.8 \\
\hline $34.1-36.0$ & 3.1 & 0.0 & 0.0 & 0.0 & 3.1 \\
\hline $36.1-38.0$ & 5.3 & 0.0 & 0.0 & 0.0 & 5.3 \\
\hline $38.1-40.0$ & 1.3 & 0.0 & 0.0 & 0.0 & 1.3 \\
\hline$>40.1$ & 6.7 & 0.4 & 0.0 & 0.0 & 7.1 \\
\hline Total: & 251.1 & 0.9 & 135.6 & 26.2 & 413.8 \\
\hline
\end{tabular}

\begin{tabular}{|c|c|c|c|}
\hline \multirow[b]{2}{*}{ Stand Summary } & \multicolumn{3}{|c|}{ Density Measure } \\
\hline & TPA & BA & $\mathrm{QMD}$ \\
\hline$>2.0$ inches & 127.1 & 271.24 & 20.4 \\
\hline (Standard Error) & 18.7 & 31.47 & 1.3 \\
\hline
\end{tabular}

\begin{tabular}{ccccc} 
& \multicolumn{3}{c}{ Species Group } \\
\cline { 3 - 5 } \cline { 3 - 5 } Quadratic Mean Diameter (in.) & Conifers & Hardwoods & All Species \\
\cline { 3 - 5 } \cline { 3 - 5 } Overstory & 37.9 & 16.8 & 36.0 \\
(Standard Error) & & 1.5 & 4.5 & 1.5 \\
Understory & 11.1 & 12.3 & 10.6 \\
(Standard Error) & 1.2 & 1.5 & 0.7 \\
\hline
\end{tabular}


Table D-14: Stand Summary, Late Successional Unit, Land Trust of Santa Cruz County

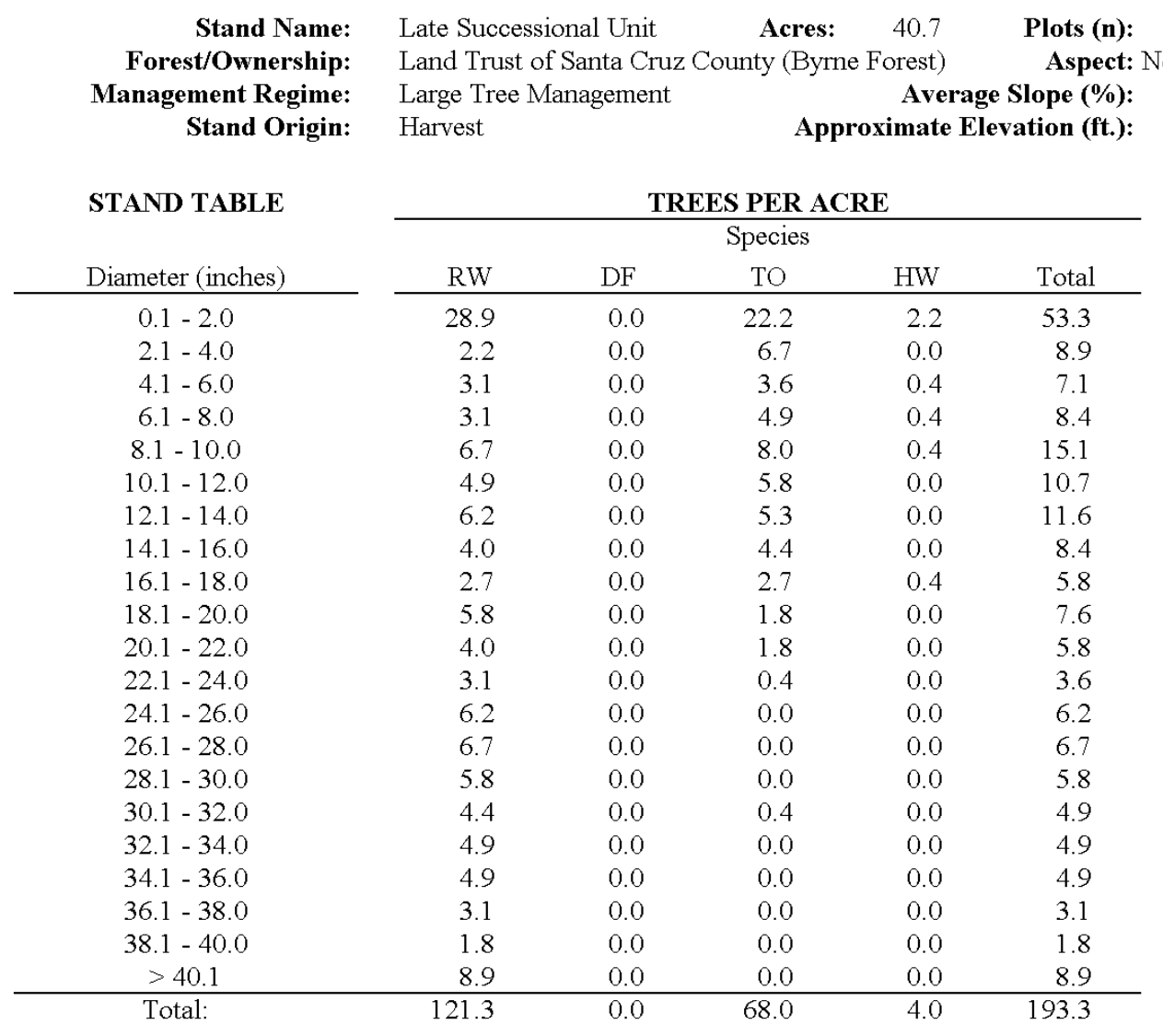

\begin{tabular}{|c|c|c|c|}
\hline \multirow[b]{2}{*}{ Stand Summary } & \multicolumn{3}{|c|}{ Density Measure } \\
\hline & TPA & $\mathrm{BA}$ & $\mathrm{QMD}$ \\
\hline$>2.0$ inches & 140.0 & 398.42 & 24.2 \\
\hline (Standard Error) & 27.2 & 53.78 & 1.8 \\
\hline
\end{tabular}

\begin{tabular}{ccccc} 
& \multicolumn{3}{c}{ Species Group } \\
\cline { 3 - 5 } Quadratic Mean Diameter (in.) & Conifers & Hardwoods & All Species \\
\cline { 3 - 5 } \cline { 3 - 5 } Overstory & 35.5 & 7.4 & 34.5 \\
(Standard Error) & 1.0 & 3.9 & 1.4 \\
Understory & 16.2 & 13.0 & 15.3 \\
(Standard Error) & 1.0 & 1.5 & 1.2 \\
\hline
\end{tabular}


Table D-15: Stand Summary, Ramsey Gulch, Redwood Empire

\begin{tabular}{|c|c|c|c|c|c|}
\hline \multirow{4}{*}{$\begin{array}{r}\text { Stand Name: } \\
\text { Forest/Ownership: } \\
\text { Management Regime: } \\
\text { Stand Origin: } \\
\text { STAND TABLE } \\
\text { Diameter (inches) }\end{array}$} & \multicolumn{2}{|c|}{$\begin{array}{l}\text { Ramsey Gulch } \\
\text { Redwood Empire } \\
\text { Percent Removal } \\
\text { Harvest }\end{array}$} & Acres: & 55.2 & $\begin{array}{r}\text { Plots (n) } \\
\text { Aspec } \\
\text { Slope (\%) } \\
\text { ation (ft.) }\end{array}$ \\
\hline & \multicolumn{5}{|c|}{ TREES PER ACRE } \\
\hline & \multicolumn{5}{|c|}{ Species } \\
\hline & RW & $\mathrm{DF}$ & TO & HW & Total \\
\hline $0.1-2.0$ & 126.7 & 0.0 & 120.0 & 20.0 & 266.7 \\
\hline $2.1-4.0$ & 37.8 & 0.0 & 6.7 & 8.9 & 53.3 \\
\hline $4.1-6.0$ & 12.0 & 0.0 & 2.7 & 0.0 & 14.7 \\
\hline $6.1-8.0$ & 7.6 & 0.0 & 8.9 & 1.8 & 18.2 \\
\hline $8.1-10.0$ & 5.8 & 0.0 & 13.3 & 1.3 & 20.4 \\
\hline $10.1-12.0$ & 8.0 & 0.0 & 12.9 & 2.7 & 23.6 \\
\hline $12.1-14.0$ & 5.3 & 0.0 & 11.6 & 3.6 & 20.4 \\
\hline $14.1-16.0$ & 5.3 & 0.0 & 11.1 & 1.8 & 18.2 \\
\hline $16.1-18.0$ & 7.1 & 0.0 & 8.4 & 0.4 & 16.0 \\
\hline $18.1-20.0$ & 4.4 & 0.0 & 5.3 & 0.4 & 10.2 \\
\hline $20.1-22.0$ & 3.6 & 0.0 & 5.3 & 1.3 & 10.2 \\
\hline $22.1-24.0$ & 7.6 & 0.0 & 3.6 & 0.0 & 11.1 \\
\hline $24.1-26.0$ & 3.6 & 0.0 & 0.9 & 0.0 & 4.4 \\
\hline $26.1-28.0$ & 4.0 & 0.0 & 0.4 & 0.0 & 4.4 \\
\hline $28.1-30.0$ & 1.3 & 0.0 & 0.9 & 0.0 & 2.2 \\
\hline $30.1-32.0$ & 0.0 & 0.0 & 0.0 & 0.0 & 0.0 \\
\hline $32.1-34.0$ & 0.4 & 0.0 & 0.0 & 0.0 & 0.4 \\
\hline $34.1-36.0$ & 0.4 & 0.0 & 0.0 & 0.0 & 0.4 \\
\hline $36.1-38.0$ & 0.9 & 0.0 & 0.0 & 0.0 & 0.9 \\
\hline $38.1-40.0$ & 0.0 & 0.0 & 0.0 & 0.0 & 0.0 \\
\hline$>40.1$ & 0.0 & 0.4 & 0.0 & 0.0 & 0.4 \\
\hline Total: & 241.8 & 0.4 & 212.0 & 42.2 & 496.4 \\
\hline
\end{tabular}

\begin{tabular}{|c|c|c|c|}
\hline \multirow[b]{2}{*}{ Stand Summary } & \multicolumn{3}{|c|}{ Density Measure } \\
\hline & TPA & $\mathrm{BA}$ & $\mathrm{QMD}$ \\
\hline$>2.0$ inches & 229.8 & 240.04 & 14.2 \\
\hline (Standard Error) & 23.9 & 26.78 & 1.0 \\
\hline
\end{tabular}

\begin{tabular}{ccccc} 
& \multicolumn{3}{c}{ Species Group } \\
\cline { 3 - 5 } \cline { 3 - 5 } Quadratic Mean Diameter (in.) & Conifers & Hardwoods & All Species \\
\cline { 1 - 4 } \cline { 3 - 5 } Overstory & 24.6 & 13.5 & 23.3 \\
(Standard Error) & & 3.5 & 1.5 & 1.2 \\
Understory & & 8.8 & 0.7 & 10.9 \\
(Standard Error) & 1.0 & & 0.7 \\
\hline
\end{tabular}


Table D-16: Stand Summary, Amaya East, Soquel Demonstration State Forest

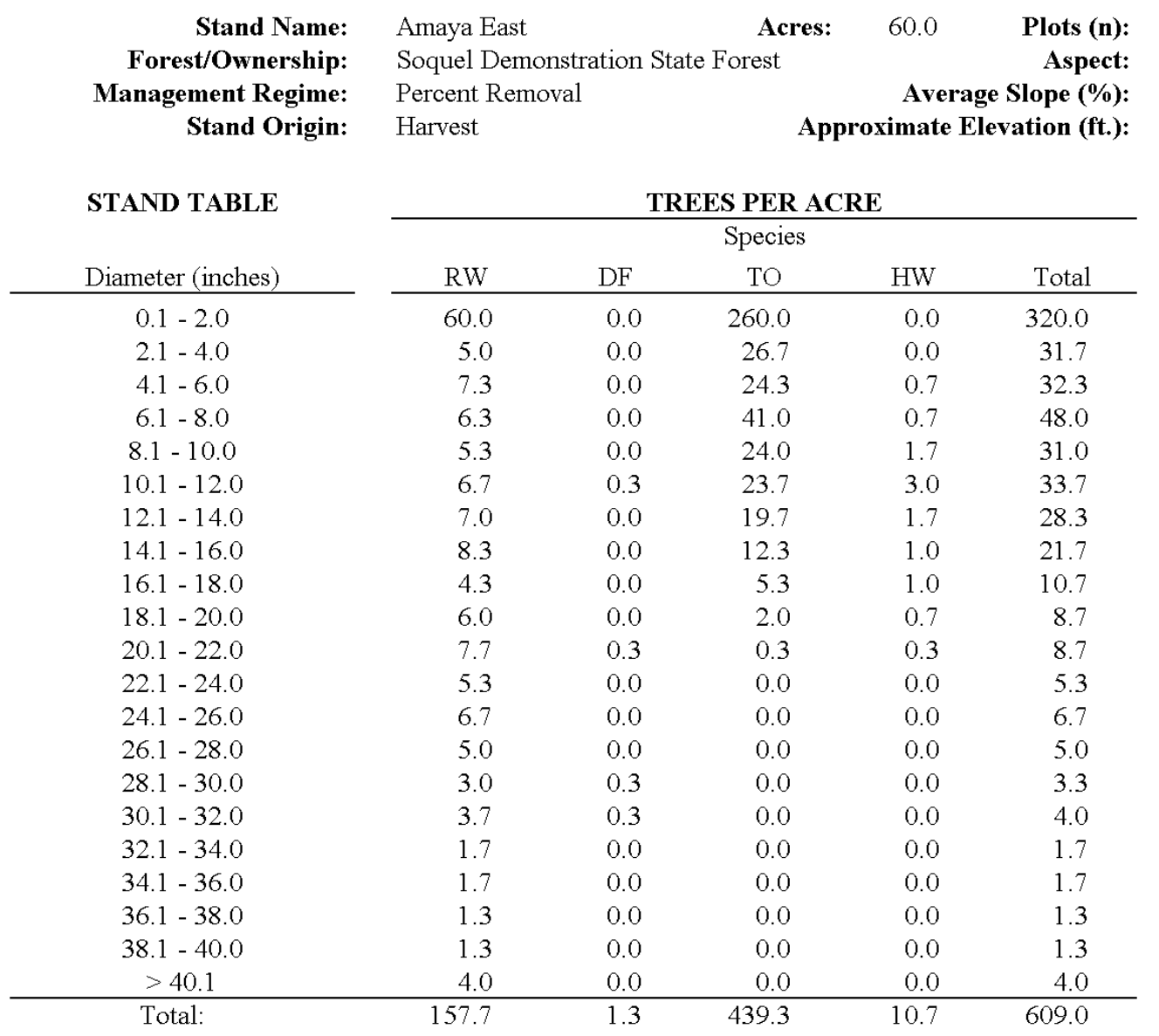

\begin{tabular}{|c|c|c|c|}
\hline \multirow[b]{2}{*}{ Stand Summary } & \multicolumn{3}{|c|}{ Density Measure } \\
\hline & TPA & $\mathrm{BA}$ & $\mathrm{QMD}$ \\
\hline$>2.0$ inches & 289.0 & 345.02 & 15.7 \\
\hline (Standard Error) & 37.5 & 26.81 & 1.3 \\
\hline
\end{tabular}

\begin{tabular}{ccccc} 
& \multicolumn{3}{c}{ Species Group } \\
\cline { 3 - 5 } \cline { 3 - 5 } Quadratic Mean Diameter (in.) & Conifers & Hardwoods & All Species \\
\cline { 1 - 4 } \cline { 3 - 5 } Overstory & 29.9 & 2.8 & 28.8 \\
(Standard Error) & & 2.0 & 1.9 & 1.4 \\
Understory & 12.6 & 10.1 & 10.9 \\
(Standard Error) & 0.9 & 0.5 & 0.5 \\
\hline
\end{tabular}


Table D-17: Stand Summary, Amaya West, Soquel Demonstration State Forest

\begin{tabular}{|c|c|c|c|c|c|}
\hline $\begin{array}{r}\text { Stand Name: } \\
\text { Forest/Ownership: } \\
\text { Management Regime: } \\
\text { Stand Origin: }\end{array}$ & $\begin{array}{l}\text { Amaya West } \\
\text { Soquel Demo } \\
\text { Percent Remc } \\
\text { Harvest }\end{array}$ & ation & $\begin{array}{l}\text { Acres: } \\
\text { Forest }\end{array}$ & $\begin{array}{r}\text { Ave } \\
\text { ximate }\end{array}$ & $\begin{array}{r}\text { Plots (n): } \\
\text { Aspect: } \\
\text { Slope (\%): } \\
\text { ation (ft.): }\end{array}$ \\
\hline \multirow[t]{2}{*}{ STAND TABLE } & \multicolumn{5}{|c|}{ TREES PER ACRE } \\
\hline & \multicolumn{5}{|c|}{ Species } \\
\hline Diameter (inches) & RW & $\mathrm{DF}$ & $\mathrm{TO}$ & HW & Total \\
\hline $0.1-2.0$ & 195.0 & 1.7 & 148.3 & 6.7 & 351.7 \\
\hline $2.1-4.0$ & 38.3 & 0.0 & 13.3 & 0.0 & 51.7 \\
\hline $4.1-6.0$ & 7.7 & 0.0 & 8.7 & 0.3 & 16.7 \\
\hline $6.1-8.0$ & 8.7 & 0.0 & 16.0 & 1.7 & 26.3 \\
\hline $8.1-10.0$ & 8.3 & 0.0 & 8.3 & 2.3 & 19.0 \\
\hline $10.1-12.0$ & 6.0 & 0.0 & 12.3 & 1.0 & 19.3 \\
\hline $12.1-14.0$ & 6.0 & 0.3 & 13.7 & 1.7 & 21.7 \\
\hline $14.1-16.0$ & 5.7 & 0.0 & 9.0 & 1.7 & 16.3 \\
\hline $16.1-18.0$ & 4.0 & 0.0 & 3.7 & 0.3 & 8.0 \\
\hline $18.1-20.0$ & 4.7 & 0.0 & 2.0 & 1.7 & 8.3 \\
\hline $20.1-22.0$ & 5.0 & 0.0 & 1.7 & 0.0 & 6.7 \\
\hline $22.1-24.0$ & 3.7 & 0.0 & 2.3 & 0.0 & 6.0 \\
\hline $24.1-26.0$ & 3.7 & 0.0 & 0.0 & 0.3 & 4.0 \\
\hline $26.1-28.0$ & 4.0 & 0.3 & 0.3 & 0.3 & 5.0 \\
\hline $28.1-30.0$ & 3.3 & 0.0 & 0.0 & 0.0 & 3.3 \\
\hline $30.1-32.0$ & 4.0 & 0.0 & 0.0 & 0.0 & 4.0 \\
\hline $32.1-34.0$ & 1.7 & 0.0 & 0.0 & 0.0 & 1.7 \\
\hline $34.1-36.0$ & 1.3 & 0.3 & 0.0 & 0.0 & 1.7 \\
\hline $36.1-38.0$ & 2.0 & 0.0 & 0.0 & 0.0 & 2.0 \\
\hline $38.1-40.0$ & 2.0 & 0.0 & 0.0 & 0.0 & 2.0 \\
\hline$>40.1$ & 5.3 & 0.0 & 0.0 & 0.0 & 5.3 \\
\hline Total: & 320.3 & 2.7 & 239.7 & 18.0 & 580.7 \\
\hline
\end{tabular}

\begin{tabular}{|c|c|c|c|}
\hline \multirow[b]{2}{*}{ Stand Summary } & \multicolumn{3}{|c|}{ Density Measure } \\
\hline & TPA & $\mathrm{BA}$ & QMD \\
\hline$>2.0$ inches & 229.0 & 320.00 & 16.3 \\
\hline (Standard Error) & 19.8 & 30.43 & 0.9 \\
\hline
\end{tabular}

\begin{tabular}{ccccc} 
& \multicolumn{3}{c}{ Species Group } \\
\cline { 3 - 5 } \cline { 3 - 5 } Quadratic Mean Diameter (in.) & Conifers & Hardwoods & All Species \\
\cline { 1 - 4 } Overstory & 32.0 & 6.3 & 30.9 \\
(Standard Error) & & 2.1 & 2.8 & 2.3 \\
Understory & 10.3 & 11.7 & 10.6 \\
(Standard Error) & 0.9 & 0.7 & 0.5 \\
\hline
\end{tabular}


Table D-18: Stand Summary, Badger Spring, Soquel Demonstration State Forest

\begin{tabular}{|c|c|c|c|c|c|}
\hline \multirow{4}{*}{$\begin{array}{r}\text { Stand Name: } \\
\text { Forest/Ownership: } \\
\text { Management Regime: } \\
\text { Stand Origin: } \\
\text { STAND TABLE } \\
\text { Diameter (inches) }\end{array}$} & $\begin{array}{l}\text { Badger Spring } \\
\text { Soquel Demo } \\
\text { Natural } \\
\text { Natural }\end{array}$ & ratio & $\begin{array}{l}\text { Acres: } \\
\text { orest }\end{array}$ & $\begin{array}{r}10.0 \\
\text { Ave } \\
\text { imate }\end{array}$ & $\begin{array}{r}\text { Plots (n): } \\
\text { Aspect: } \\
\text { lope (\%): } \\
\text { ation (ft.): }\end{array}$ \\
\hline & \multicolumn{5}{|c|}{ TREES PER ACRE } \\
\hline & \multicolumn{5}{|c|}{ Species } \\
\hline & RW & $\mathrm{DF}$ & $\mathrm{TO}$ & $\mathrm{HW}$ & Total \\
\hline $0.1-2.0$ & 8.0 & 0 . & 72.0 & 0.0 & 80.0 \\
\hline $2.1-4.0$ & 4.0 & 0 . & 60.0 & 0.0 & 64.0 \\
\hline $4.1-6.0$ & 2.4 & 0 . & 28.8 & 0.8 & 32.0 \\
\hline $6.1-8.0$ & 9.6 & 0 . & 36.0 & 2.4 & 48.0 \\
\hline $8.1-10.0$ & 4.8 & 1. & 20.0 & 0.8 & 27.2 \\
\hline $10.1-12.0$ & 5.6 & 0 . & 13.6 & 1.6 & 20.8 \\
\hline $12.1-14.0$ & 4.8 & 0. & 8.8 & 0.8 & 15.2 \\
\hline $14.1-16.0$ & 2.4 & 0 . & 5.6 & 0.0 & 8.0 \\
\hline $16.1-18.0$ & 3.2 & 1. & 3.2 & 0.0 & 8.0 \\
\hline $18.1-20.0$ & 1.6 & 0. & 0.8 & 0.0 & 3.2 \\
\hline $20.1-22.0$ & 2.4 & 0. & 0.8 & 0.0 & 3.2 \\
\hline $22.1-24.0$ & 3.2 & 0 . & 0.0 & 0.0 & 3.2 \\
\hline $24.1-26.0$ & 3.2 & 0. & 0.0 & 0.0 & 4.0 \\
\hline $26.1-28.0$ & 0.8 & 0 . & 0.0 & 0.0 & 0.8 \\
\hline $28.1-30.0$ & 0.8 & 0. & 0.0 & 0.0 & 1.6 \\
\hline $30.1-32.0$ & 0.0 & 0. & 0.0 & 0.0 & 0.8 \\
\hline $32.1-34.0$ & 2.4 & 0. & 0.0 & 0.0 & 3.2 \\
\hline $34.1-36.0$ & 1.6 & 0 . & 0.0 & 0.0 & 1.6 \\
\hline $36.1-38.0$ & 3.2 & 0. & 0.0 & 0.0 & 4.0 \\
\hline $38.1-40.0$ & 0.8 & 0. & 0.0 & 0.0 & 1.6 \\
\hline$>40.1$ & 16.0 & 2. & 0.0 & 0.0 & 18.4 \\
\hline Total: & 80.8 & 12 . & 249.6 & 6.4 & 348.8 \\
\hline
\end{tabular}

\begin{tabular}{|c|c|c|c|}
\hline \multirow[b]{2}{*}{ Stand Summary } & \multicolumn{3}{|c|}{ Density Measure } \\
\hline & TPA & $\mathrm{BA}$ & $\mathrm{QMD}$ \\
\hline$>2.0$ inches & 268.8 & 722.92 & 22.5 \\
\hline (Standard Error) & 44.3 & 130.11 & 1.9 \\
\hline
\end{tabular}

\begin{tabular}{ccccc} 
& \multicolumn{3}{c}{ Species Group } \\
\cline { 3 - 5 } \cline { 3 - 5 } Quadratic Mean Diameter (in.) & Conifers & Hardwoods & All Species \\
\cline { 1 - 4 } \cline { 3 - 5 } Overstory & 61.7 & 0.0 & 61.7 \\
(Standard Error) & 6.1 & 0.0 & 6.1 \\
Understory & 18.3 & 8.0 & 11.6 \\
(Standard Error) & 0.9 & 1.0 & 1.2 \\
\hline
\end{tabular}


Table D-19: Stand Summary, Long Ridge, Soquel Demonstration State Forest

\begin{tabular}{|c|c|c|c|c|c|}
\hline \multirow{4}{*}{$\begin{array}{r}\text { Stand Name: } \\
\text { Forest/Ownership: } \\
\text { Management Regime: } \\
\text { Stand Origin: } \\
\text { STAND TABLE } \\
\text { Diameter (inches) } \\
\end{array}$} & \multicolumn{2}{|c|}{$\begin{array}{l}\text { Long Ridge } \\
\text { Soquel Demons } \\
\text { Percent Remova } \\
\text { Harvest }\end{array}$} & $\begin{array}{l}\text { Acres: } \\
\text { rest } \\
\end{array}$ & 56.0 & $\begin{array}{r}\text { Plots (n): } \\
\text { Aspect: } \\
\text { Slope (\%): } \\
\text { ation (ft.): }\end{array}$ \\
\hline & \multicolumn{5}{|c|}{ TREES PER ACRE } \\
\hline & \multicolumn{5}{|c|}{ Species } \\
\hline & RW & DF & TO & $\mathrm{HW}$ & Total \\
\hline $0.1-2.0$ & 146.7 & 17.8 & 57.8 & 11.1 & 233.3 \\
\hline $2.1-4.0$ & 31.1 & 0.0 & 0.0 & 0.0 & 31.1 \\
\hline $4.1-6.0$ & 11.6 & 0.0 & 4.0 & 0.9 & 16.4 \\
\hline $6.1-8.0$ & 16.4 & 0.0 & 2.7 & 2.2 & 21.3 \\
\hline $8.1-10.0$ & 14.2 & 0.4 & 2.7 & 8.9 & 26.2 \\
\hline $10.1-12.0$ & 7.6 & 0.0 & 1.8 & 4.9 & 14.2 \\
\hline $12.1-14.0$ & 7.6 & 0.0 & 2.7 & 4.9 & 15.1 \\
\hline $14.1-16.0$ & 7.6 & 0.0 & 4.0 & 3.1 & 14.7 \\
\hline $16.1-18.0$ & 4.9 & 0.4 & 1.8 & 2.2 & 9.3 \\
\hline $18.1-20.0$ & 4.4 & 0.0 & 4.0 & 0.9 & 9.3 \\
\hline $20.1-22.0$ & 5.8 & 0.0 & 1.8 & 3.6 & 11.1 \\
\hline $22.1-24.0$ & 5.8 & 0.0 & 2.2 & 0.0 & 8.0 \\
\hline $24.1-26.0$ & 4.9 & 0.0 & 0.4 & 0.0 & 5.3 \\
\hline $26.1-28.0$ & 6.7 & 0.4 & 0.9 & 0.0 & 8.0 \\
\hline $28.1-30.0$ & 6.2 & 1.3 & 0.0 & 0.0 & 7.6 \\
\hline $30.1-32.0$ & 4.0 & 0.0 & 0.0 & 0.0 & 4.0 \\
\hline $32.1-34.0$ & 0.9 & 0.0 & 0.0 & 0.0 & 0.9 \\
\hline $34.1-36.0$ & 0.0 & 0.4 & 0.0 & 0.0 & 0.4 \\
\hline $36.1-38.0$ & 0.4 & 0.0 & 0.0 & 0.0 & 0.4 \\
\hline $38.1-40.0$ & 0.9 & 0.0 & 0.0 & 0.0 & 0.9 \\
\hline$>40.1$ & 4.4 & 0.9 & 0.0 & 0.0 & 5.3 \\
\hline Total: & 292.0 & 21.8 & 86.7 & 42.7 & 443.1 \\
\hline
\end{tabular}

\begin{tabular}{|c|c|c|c|}
\hline \multirow[b]{2}{*}{ Stand Summary } & \multicolumn{3}{|c|}{ Density Measure } \\
\hline & TPA & $\mathrm{BA}$ & QMD \\
\hline$>2.0$ inches & 209.8 & 343.38 & 18.1 \\
\hline (Standard Error) & 25.5 & 22.34 & 1.3 \\
\hline
\end{tabular}

\begin{tabular}{ccccc} 
& \multicolumn{3}{c}{ Species Group } \\
\cline { 3 - 5 } Quadratic Mean Diameter (in.) & Conifers & Hardwoods & All Species \\
\cline { 1 - 4 } \cline { 3 - 5 } Overstory & 30.9 & 4.8 & 30.7 \\
(Standard Error) & 1.8 & 3.2 & 1.8 \\
Understory & 8.8 & 14.2 & 11.9 \\
(Standard Error) & 1.1 & 0.9 & 0.8 \\
\hline
\end{tabular}


Table D-20: Stand Summary, Stand E, Swanton Pacific Ranch (Little Creek)

\begin{tabular}{|c|c|c|c|c|c|}
\hline \multirow{4}{*}{$\begin{array}{r}\text { Stand Name: } \\
\text { Forest/Ownership: } \\
\text { Management Regime: } \\
\text { Stand Origin: } \\
\text { STAND TABLE } \\
\text { Diameter (inches) }\end{array}$} & \multicolumn{3}{|c|}{$\begin{array}{l}\text { Stand E Acres: } \\
\text { Swanton Pacific Ranch (Little Creek) }\end{array}$} & $\begin{array}{r}21.2 \\
\text { Ave } \\
\text { ximate }\end{array}$ & $\begin{array}{r}\text { Plots (n): } \\
\text { Aspect: } \\
\text { lope (\%): } \\
\text { tion (ft.): }\end{array}$ \\
\hline & \multicolumn{5}{|c|}{ TREES PER ACRE } \\
\hline & \multicolumn{5}{|c|}{ Species } \\
\hline & RW & DF & TO & $\mathrm{HW}$ & Total \\
\hline $0.1-2.0$ & 273.3 & 0.0 & 43.3 & 36.7 & 353.3 \\
\hline $2.1-4.0$ & 23.3 & 6.7 & 6.7 & 20.0 & 56.7 \\
\hline $4.1-6.0$ & 9.3 & 0.7 & 0.7 & 7.3 & 18.0 \\
\hline $6.1-8.0$ & 5.3 & 3.3 & 4.7 & 1.3 & 14.7 \\
\hline $8.1-10.0$ & 4.0 & 2.0 & 8.0 & 1.3 & 15.3 \\
\hline $10.1-12.0$ & 3.3 & 0.7 & 4.7 & 2.7 & 11.3 \\
\hline $12.1-14.0$ & 3.3 & 1.3 & 7.3 & 1.3 & 13.3 \\
\hline $14.1-16.0$ & 4.7 & 2.0 & 6.7 & 0.0 & 13.3 \\
\hline $16.1-18.0$ & 5.3 & 0.7 & 5.3 & 2.0 & 13.3 \\
\hline $18.1-20.0$ & 4.7 & 1.3 & 2.0 & 0.0 & 8.0 \\
\hline $20.1-22.0$ & 2.7 & 0.0 & 0.7 & 0.0 & 3.3 \\
\hline $22.1-24.0$ & 6.7 & 0.7 & 0.0 & 0.0 & 7.3 \\
\hline $24.1-26.0$ & 3.3 & 0.0 & 2.0 & 0.0 & 5.3 \\
\hline $26.1-28.0$ & 4.0 & 0.7 & 0.0 & 1.3 & 6.0 \\
\hline $28.1-30.0$ & 1.3 & 0.7 & 0.0 & 0.0 & 2.0 \\
\hline $30.1-32.0$ & 3.3 & 0.0 & 0.0 & 0.0 & 3.3 \\
\hline $32.1-34.0$ & 2.7 & 0.0 & 0.0 & 0.0 & 2.7 \\
\hline $34.1-36.0$ & 2.0 & 0.0 & 0.0 & 0.0 & 2.0 \\
\hline $36.1-38.0$ & 2.7 & 0.0 & 0.0 & 0.0 & 2.7 \\
\hline $38.1-40.0$ & 0.7 & 0.0 & 0.0 & 0.0 & 0.7 \\
\hline$>40.1$ & 7.3 & 1.3 & 0.0 & 0.0 & 8.7 \\
\hline Total: & 373.3 & 22.0 & 92.0 & 74.0 & 561.3 \\
\hline
\end{tabular}

\begin{tabular}{|c|c|c|c|}
\hline \multirow[b]{2}{*}{ Stand Summary } & \multicolumn{3}{|c|}{ Density Measure } \\
\hline & TPA & $\mathrm{BA}$ & $\mathrm{QMD}$ \\
\hline$>2.0$ inches & 208.0 & 360.93 & 18.3 \\
\hline (Standard Error) & 33.2 & 66.95 & 1.8 \\
\hline
\end{tabular}

\begin{tabular}{ccccc} 
& \multicolumn{3}{c}{ Species Group } \\
\cline { 3 - 5 } Quadratic Mean Diameter (in.) & Conifers & Hardwoods & All Species \\
\cline { 3 - 5 } \cline { 3 - 5 } Overstory & 33.3 & 12.3 & 31.0 \\
(Standard Error) & 2.5 & 4.1 & 2.7 \\
Understory & 9.6 & 9.8 & 10.0 \\
(Standard Error) & 1.2 & 1.2 & 1.3 \\
\hline
\end{tabular}


Table D-21: Stand Summary, Tranquility Flats, Swanton Pacific Ranch (Little Creek)

\begin{tabular}{|c|c|c|c|c|c|}
\hline $\begin{array}{r}\text { Stand Name: } \\
\text { Forest/Ownership: } \\
\text { Management Regime: } \\
\text { Stand Origin: }\end{array}$ & \multicolumn{3}{|c|}{$\begin{array}{l}\text { Tranquility Flats Acres: } \\
\text { Swanton Pacific Ranch (Little Creek) }\end{array}$} & Ave & $\begin{array}{r}\text { Plots (n): } \\
\text { Aspect: } \\
\text { Slope (\%): } \\
\text { ation (ft.): }\end{array}$ \\
\hline \multirow[t]{2}{*}{ STAND TABLE } & \multicolumn{5}{|c|}{ TREES PER ACRE } \\
\hline & \multicolumn{5}{|c|}{ Species } \\
\hline Diameter (inches) & RW & $\mathrm{DF}$ & $\mathrm{TO}$ & $\mathrm{HW}$ & Total \\
\hline $0.1-2.0$ & 291.1 & 8.9 & 235.6 & 8.9 & 544.4 \\
\hline $2.1-4.0$ & 57.8 & 0.0 & 8.9 & 0.0 & 66.7 \\
\hline $4.1-6.0$ & 5.3 & 0.4 & 1.8 & 0.0 & 7.6 \\
\hline $6.1-8.0$ & 4.0 & 0.0 & 4.0 & 0.0 & 8.0 \\
\hline $8.1-10.0$ & 5.8 & 0.0 & 2.2 & 0.0 & 8.0 \\
\hline $10.1-12.0$ & 3.1 & 0.0 & 4.9 & 0.0 & 8.0 \\
\hline $12.1-14.0$ & 4.4 & 0.0 & 2.7 & 0.0 & 7.1 \\
\hline $14.1-16.0$ & 4.4 & 0.0 & 0.9 & 0.0 & 5.3 \\
\hline $16.1-18.0$ & 5.8 & 0.0 & 2.7 & 0.0 & 8.4 \\
\hline $18.1-20.0$ & 4.0 & 0.0 & 0.9 & 0.0 & 4.9 \\
\hline $20.1-22.0$ & 4.9 & 0.0 & 1.3 & 0.0 & 6.2 \\
\hline $22.1-24.0$ & 5.3 & 0.0 & 0.4 & 0.0 & 5.8 \\
\hline $24.1-26.0$ & 4.9 & 0.4 & 1.3 & 0.0 & 6.7 \\
\hline $26.1-28.0$ & 2.7 & 0.0 & 1.3 & 0.0 & 4.0 \\
\hline $28.1-30.0$ & 4.9 & 0.0 & 0.0 & 0.0 & 4.9 \\
\hline $30.1-32.0$ & 0.9 & 0.0 & 0.0 & 0.0 & 0.9 \\
\hline $32.1-34.0$ & 4.4 & 0.0 & 0.0 & 0.0 & 4.4 \\
\hline $34.1-36.0$ & 4.9 & 0.0 & 0.0 & 0.0 & 4.9 \\
\hline $36.1-38.0$ & 4.9 & 0.0 & 0.4 & 0.0 & 5.3 \\
\hline $38.1-40.0$ & 1.8 & 0.0 & 0.0 & 0.0 & 1.8 \\
\hline$>40.1$ & 10.7 & 1.3 & 0.0 & 0.0 & 12.0 \\
\hline Total: & 436.0 & 11.1 & 269.3 & 8.9 & 725.3 \\
\hline
\end{tabular}

\begin{tabular}{|c|c|c|c|}
\hline \multirow[b]{2}{*}{ Stand Summary } & \multicolumn{3}{|c|}{ Density Measure } \\
\hline & TPA & $\mathrm{BA}$ & QMD \\
\hline$>2.0$ inches & 180.9 & 408.24 & 21.5 \\
\hline (Standard Error) & 30.1 & 38.11 & 1.6 \\
\hline
\end{tabular}

\begin{tabular}{ccccc} 
& \multicolumn{3}{c}{ Species Group } \\
\cline { 3 - 5 } Quadratic Mean Diameter (in.) & Conifers & Hardwoods & All Species \\
\cline { 3 - 5 } \cline { 3 - 5 } Overstory & 36.7 & 14.3 & 36.0 \\
(Standard Error) & 1.6 & 4.6 & 1.7 \\
Understory & 11.9 & 10.7 & 11.4 \\
(Standard Error) & 1.1 & 1.6 & 0.9 \\
\hline
\end{tabular}


Table D-22: Stand Summary, Cable-3, Swanton Pacific Ranch (Valencia Creek)

\begin{tabular}{|c|c|c|c|c|c|}
\hline \multirow{4}{*}{$\begin{array}{r}\text { Stand Name: } \\
\text { Forest/Ownership: } \\
\text { Management Regime: } \\
\text { Stand Origin: } \\
\text { STAND TABLE } \\
\text { Diameter (inches) }\end{array}$} & \multicolumn{3}{|c|}{ Cable- $3 \quad$ Acres: } & $\begin{array}{r}35.3 \\
\text { Ave } \\
\text { ximate }\end{array}$ & $\begin{array}{r}\text { Plots (n): } \\
\text { Aspect: } \\
\text { Slope (\%): } \\
\text { ation (ft.): }\end{array}$ \\
\hline & \multicolumn{5}{|c|}{ TREES PER ACRE } \\
\hline & \multicolumn{5}{|c|}{ Species } \\
\hline & RW & DF & $\mathrm{TO}$ & $\mathrm{HW}$ & Total \\
\hline $0.1-2.0$ & 123.3 & 43.3 & 213.3 & 10.0 & 390.0 \\
\hline $2.1-4.0$ & 26.7 & 13.3 & 20.0 & 3.3 & 63.3 \\
\hline $4.1-6.0$ & 12.0 & 0.7 & 29.3 & 0.0 & 42.0 \\
\hline $6.1-8.0$ & 11.3 & 0.7 & 18.7 & 3.3 & 34.0 \\
\hline $8.1-10.0$ & 8.0 & 0.7 & 24.0 & 4.7 & 37.3 \\
\hline $10.1-12.0$ & 6.7 & 0.7 & 15.3 & 4.7 & 27.3 \\
\hline $12.1-14.0$ & 4.0 & 1.3 & 14.0 & 1.3 & 20.7 \\
\hline $14.1-16.0$ & 5.3 & 0.0 & 13.3 & 3.3 & 22.0 \\
\hline $16.1-18.0$ & 3.3 & 0.0 & 3.3 & 2.7 & 9.3 \\
\hline $18.1-20.0$ & 2.7 & 0.7 & 1.3 & 0.7 & 5.3 \\
\hline $20.1-22.0$ & 5.3 & 0.0 & 0.7 & 1.3 & 7.3 \\
\hline $22.1-24.0$ & 2.7 & 0.0 & 0.0 & 0.0 & 2.7 \\
\hline $24.1-26.0$ & 4.0 & 0.0 & 0.7 & 0.7 & 5.3 \\
\hline $26.1-28.0$ & 6.0 & 1.3 & 0.0 & 0.0 & 7.3 \\
\hline $28.1-30.0$ & 0.7 & 0.0 & 0.0 & 0.0 & 0.7 \\
\hline $30.1-32.0$ & 2.0 & 0.7 & 0.0 & 0.0 & 2.7 \\
\hline $32.1-34.0$ & 0.7 & 0.0 & 0.0 & 0.0 & 0.7 \\
\hline $34.1-36.0$ & 0.7 & 0.7 & 0.0 & 0.0 & 1.3 \\
\hline $36.1-38.0$ & 0.7 & 0.7 & 0.0 & 0.0 & 1.3 \\
\hline $38.1-40.0$ & 0.0 & 0.0 & 0.0 & 0.0 & 0.0 \\
\hline$>40.1$ & 1.3 & 0.0 & 0.0 & 0.0 & 1.3 \\
\hline Total: & 227.3 & 64.7 & 354.0 & 36.0 & 682.0 \\
\hline
\end{tabular}

\begin{tabular}{|c|c|c|c|}
\hline \multirow[b]{2}{*}{ Stand Summary } & \multicolumn{3}{|c|}{ Density Measure } \\
\hline & TPA & $\mathrm{BA}$ & $\mathrm{QMD}$ \\
\hline$>2.0$ inches & 292.0 & 261.40 & 13.0 \\
\hline (Standard Error) & 36.1 & 26.06 & 0.8 \\
\hline
\end{tabular}

\begin{tabular}{ccccc} 
& \multicolumn{3}{c}{ Species Group } \\
\cline { 3 - 5 } Quadratic Mean Diameter (in.) & Conifers & Hardwoods & All Species \\
\cline { 1 - 4 } \cline { 3 - 5 } Overstory & 31.1 & 9.4 & 28.9 \\
(Standard Error) & 3.5 & 4.3 & 3.6 \\
Understory & 10.2 & 9.8 & 9.8 \\
(Standard Error) & 0.8 & 0.5 & 0.6 \\
\hline
\end{tabular}


Table D-23: Stand Summary, Tractor-1,3,4 , Swanton Pacific Ranch (Valencia Creek)

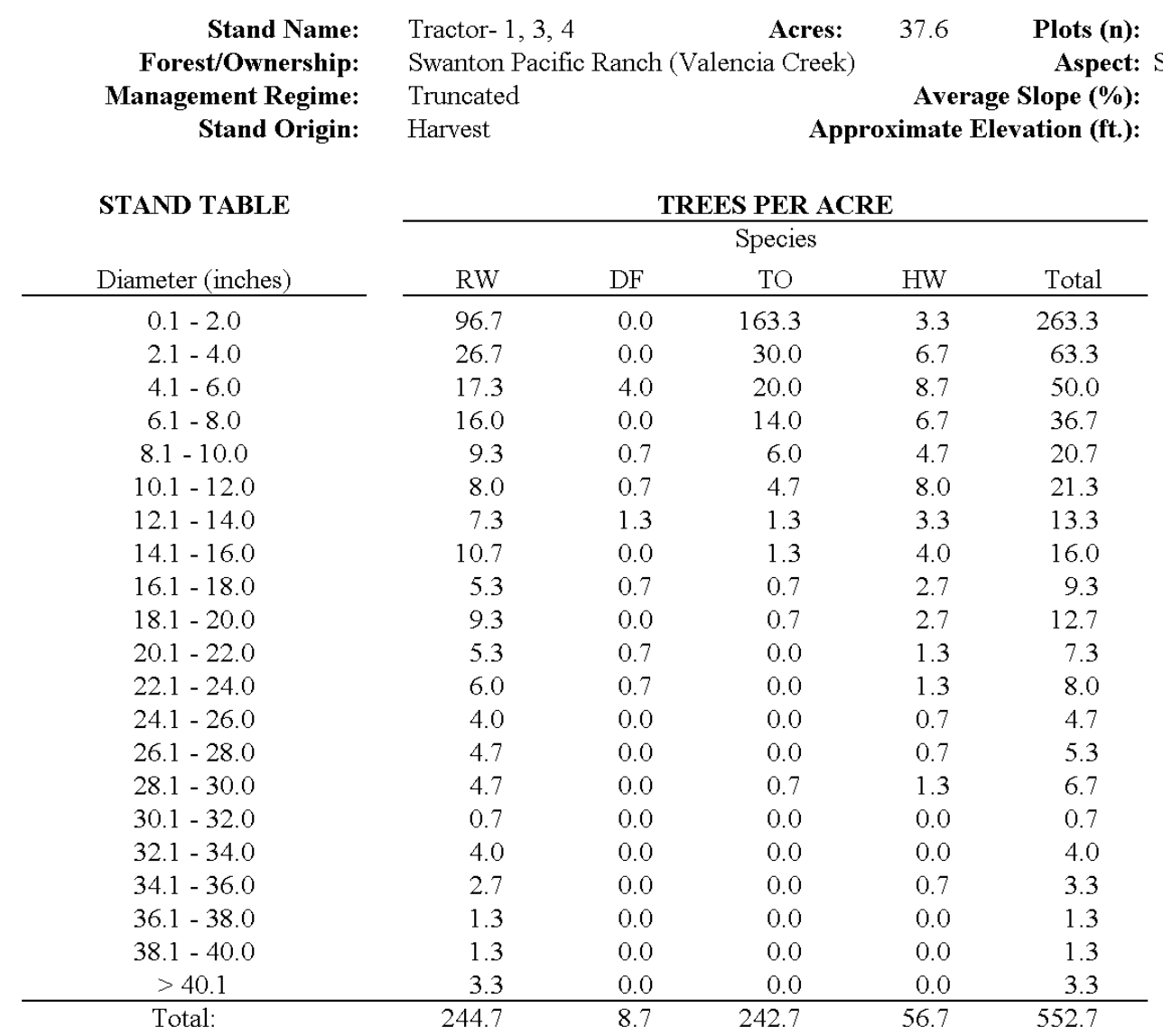

\begin{tabular}{|c|c|c|c|}
\hline \multirow[b]{2}{*}{ Stand Summary } & \multicolumn{3}{|c|}{ Density Measure } \\
\hline & TPA & $\mathrm{BA}$ & $\mathrm{QMD}$ \\
\hline$>2.0$ inches & 289.3 & 331.13 & 15.1 \\
\hline (Standard Error) & 49.3 & 26.42 & 1.1 \\
\hline
\end{tabular}

\begin{tabular}{ccccc} 
& \multicolumn{3}{c}{ Species Group } \\
\cline { 3 - 5 } \cline { 3 - 5 } Quadratic Mean Diameter (in.) & Conifers & Hardwoods & All Species \\
\cline { 1 - 4 } \cline { 3 - 5 } Overstory & 29.8 & 19.2 & 28.7 \\
(Standard Error) & & 1.6 & 4.1 & 1.2 \\
Understory & 10.8 & 9.0 & 9.9 \\
(Standard Error) & 0.6 & 0.7 & 0.5 \\
\hline
\end{tabular}


Table D-24: Stand Summary, Tractor-5,6 , Swanton Pacific Ranch (Valencia Creek)

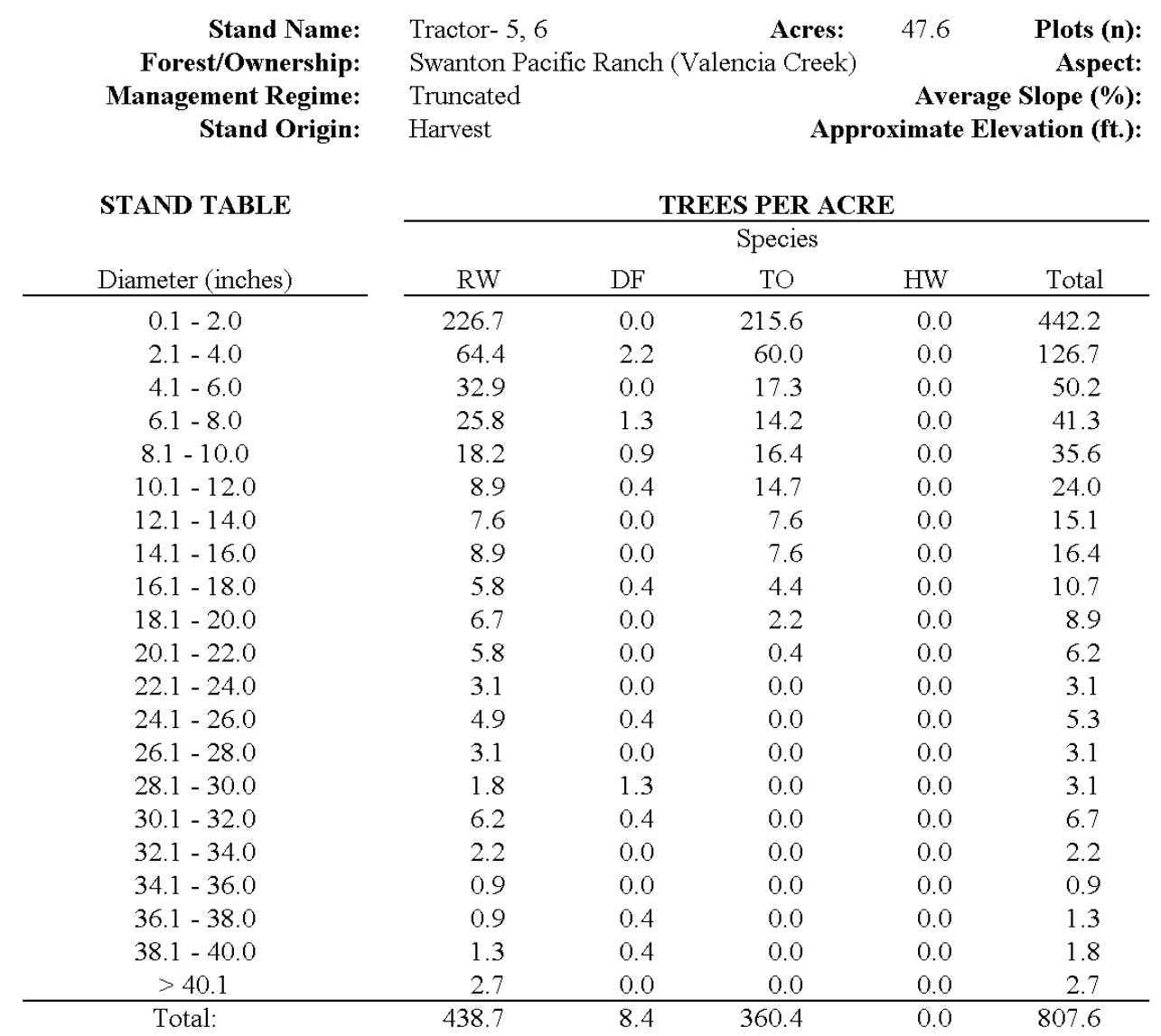

\begin{tabular}{|c|c|c|c|}
\hline \multirow[b]{2}{*}{ Stand Summary } & \multicolumn{3}{|c|}{ Density Measure } \\
\hline & TPA & $\mathrm{BA}$ & QMD \\
\hline$>2.0$ inches & 365.3 & 299.96 & 12.8 \\
\hline (Standard Error) & 60.2 & 27.92 & 0.8 \\
\hline
\end{tabular}

\begin{tabular}{ccccc} 
& \multicolumn{3}{c}{ Species Group } \\
\cline { 3 - 5 } Quadratic Mean Diameter (in.) & Conifers & Hardwoods & All Species \\
\cline { 3 - 5 } \cline { 3 - 5 } Overstory & 30.8 & 6.3 & 29.7 \\
(Standard Error) & 1.5 & 3.2 & 1.2 \\
Understory & 8.7 & 9.1 & 8.6 \\
(Standard Error) & 0.4 & 1.2 & 0.4 \\
\hline
\end{tabular}


Table D-25: Stand Summary, Tractor-8,9,10 , Swanton Pacific Ranch (Valencia Creek)

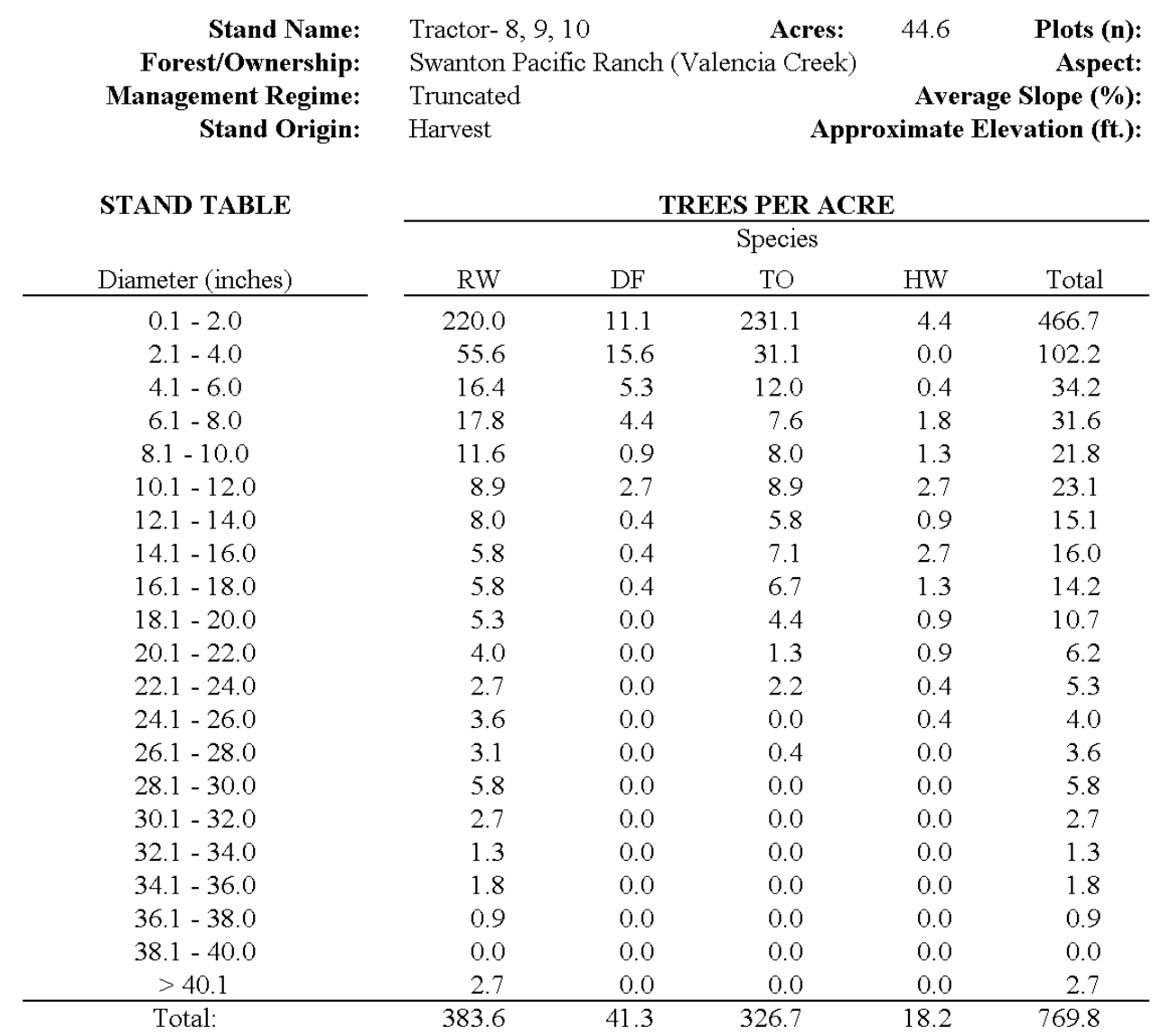

\begin{tabular}{|c|c|c|c|}
\hline \multirow[b]{2}{*}{ Stand Summary } & \multicolumn{3}{|c|}{ Density Measure } \\
\hline & TPA & BA & $\mathrm{QMD}$ \\
\hline$>2.0$ inches & 303.1 & 280.07 & 13.0 \\
\hline (Standard Error) & 23.4 & 29.78 & 0.5 \\
\hline
\end{tabular}

\begin{tabular}{ccccc} 
& \multicolumn{3}{c}{ Species Group } \\
\cline { 3 - 5 } \cline { 3 - 5 } Quadratic Mean Diameter (in.) & Conifers & Hardwoods & All Species \\
\cline { 1 - 4 } Overstory & 31.8 & 18.6 & 25.7 \\
(Standard Error) & 2.3 & 0.7 & 1.4 \\
Understory & 8.5 & 8.5 & 8.3 \\
(Standard Error) & 0.6 & 0.7 & 0.4 \\
\hline
\end{tabular}


Table D-26: Stand Summary, Upper McCormick, YMCA Camp Jones Gulch

\begin{tabular}{|c|c|c|c|c|c|}
\hline \multirow{3}{*}{$\begin{array}{r}\text { Stand Name: } \\
\text { Forest/Ownership: } \\
\text { Management Regime: } \\
\text { Stand Origin: } \\
\text { STAND TABLE }\end{array}$} & \multicolumn{2}{|c|}{$\begin{array}{l}\text { Upper McCormick } \\
\text { YMCA } \\
\text { Percent Removal } \\
\text { Harvest }\end{array}$} & Acres: & 41.0 & $\begin{array}{r}\text { Plots (n): } \\
\text { Aspect: } \\
\text { Slope (\%): } \\
\text { ation (ft.): }\end{array}$ \\
\hline & \multicolumn{5}{|c|}{ TREES PER ACRE } \\
\hline & \multicolumn{5}{|c|}{ Species } \\
\hline Diameter (inches) & RW & DF & TO & HW & Total \\
\hline $0.1-2.0$ & 84.4 & 44.4 & 124.4 & 60.0 & 313.3 \\
\hline $2.1-4.0$ & 26.7 & 13.3 & 24.4 & 26.7 & 91.1 \\
\hline $4.1-6.0$ & 23.6 & 0.9 & 6.2 & 4.9 & 35.6 \\
\hline $6.1-8.0$ & 13.3 & 2.7 & 8.0 & 0.0 & 24.0 \\
\hline $8.1-10.0$ & 5.3 & 1.8 & 10.2 & 0.4 & 17.8 \\
\hline $10.1-12.0$ & 5.3 & 0.0 & 10.7 & 0.4 & 16.4 \\
\hline $12.1-14.0$ & 5.8 & 0.9 & 6.2 & 0.9 & 13.8 \\
\hline $14.1-16.0$ & 6.2 & 0.4 & 4.4 & 0.4 & 11.6 \\
\hline $16.1-18.0$ & 4.0 & 1.8 & 3.6 & 1.3 & 10.7 \\
\hline $18.1-20.0$ & 4.9 & 0.4 & 2.7 & 0.0 & 8.0 \\
\hline $20.1-22.0$ & 4.0 & 0.4 & 1.8 & 0.0 & 6.2 \\
\hline $22.1-24.0$ & 4.4 & 0.9 & 0.4 & 0.0 & 5.8 \\
\hline $24.1-26.0$ & 4.4 & 0.4 & 0.0 & 0.4 & 5.3 \\
\hline $26.1-28.0$ & 2.2 & 0.4 & 0.4 & 0.0 & 3.1 \\
\hline $28.1-30.0$ & 0.9 & 0.4 & 0.0 & 0.0 & 1.3 \\
\hline $30.1-32.0$ & 0.9 & 0.4 & 0.4 & 0.0 & 1.8 \\
\hline $32.1-34.0$ & 1.8 & 0.9 & 0.0 & 0.0 & 2.7 \\
\hline $34.1-36.0$ & 1.3 & 0.4 & 0.0 & 0.0 & 1.8 \\
\hline $36.1-38.0$ & 0.9 & 0.0 & 0.0 & 0.0 & 0.9 \\
\hline $38.1-40.0$ & 1.3 & 0.4 & 0.0 & 0.0 & 1.8 \\
\hline$>40.1$ & 12.0 & 2.2 & 0.0 & 0.0 & 14.2 \\
\hline Total: & 213.8 & 73.8 & 204.0 & 95.6 & 587.1 \\
\hline
\end{tabular}

\begin{tabular}{|c|c|c|c|}
\hline \multirow[b]{2}{*}{ Stand Summary } & \multicolumn{3}{|c|}{ Density Measure } \\
\hline & TPA & BA & $\mathrm{QMD}$ \\
\hline$>2.0$ inches & 273.8 & 436.22 & 18.1 \\
\hline (Standard Error) & 51.0 & 49.63 & 1.6 \\
\hline
\end{tabular}

\begin{tabular}{ccccc} 
& \multicolumn{3}{c}{ Species Group } \\
\cline { 3 - 5 } Quadratic Mean Diameter (in.) & Conifers & Hardwoods & All Species \\
\cline { 3 - 5 } \cline { 3 - 5 } Overstory & 42.2 & 3.0 & 42.1 \\
(Standard Error) & 3.2 & 3.0 & 3.2 \\
Understory & 12.5 & 11.3 & 10.9 \\
(Standard Error) & 1.2 & 2.0 & 0.9 \\
\hline
\end{tabular}




\section{APPENDIX E- Agreements and Permits}

Figure E-1: Access Request Sample Letter ……………...................................... 260

Figure E-2: Scientific Investigation Permit, California State Parks (Front) .................... 261

Figure E-2: Scientific Investigation Permit, California State Parks (Back) ................... 262

Figure E-3: Hold Harmless Agreement (Example) ………………................................ 263 
Figure E-1: Access Request Sample Letter

April 4, 2008
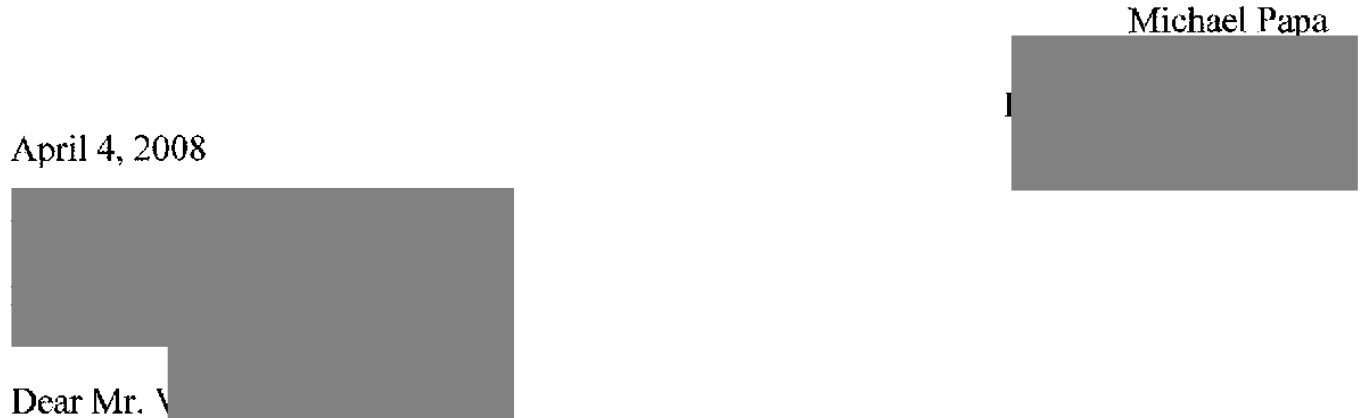

I am a graduate student in Forestry Science at Cal Poly State University, San Luis Obispo. I would like to discuss the possibility of collaboration for my thesis research.

My research is an exploratory study of various types of forest management focused in the redwood forests of Santa Cruz and San Mateo counties. Forest inventory data and site descriptions will be collected from public and private lands. The goal of this study is to show that the various management regimes used in second growth redwood forests are creating significantly different forest stands based on commonly used measures of species composition, stand densily, and stand structure. Stands will be compared within and between the management regimes. A secondary objective is to analyze how management is influencing the development of the largest diameter stems in the stand and compare their structure to stands of natural origin (ie, old growth).

The forest criteria for this study are common in Santa Cruz and San Mateo counties because of the history of the region. The forest stands must have been (1) clearcut between 80 and 120 ycars ago and not clearcut since, (2) on site class II or III ground, and (3) have a minimum redwood basal area of 50 percent. To aid the search, I am looking for stands or harvest units between 20 and 50 acres with a uniform silvicultural prescription applied during the last harvest. Tractor or cable units are both acceptable. Only measurements and photographs will be taken from the sites.

If you are aware of any properties that meet the criteria for my study, and would be interested in collaborating with this project, please let me know. Or, if you manage property for another landowner that fits the study, your assistance in setting up an agreement with the landowner would be greatly appreciated. Thank you very much.

Sincerely,

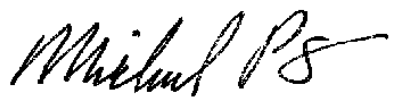

Michael Papa

Graduate Researcher- Forestry Science

Cal Polv State Univeristv- SLO 
Figure E-2: Scientific Investigation Permit, California State Parks (Front)

State of California - The Resources Agency

DEPARTMENT OF PARKS AND RECREATION

\section{APPLICATION AND PERMIT TO CONDUCT BIOLOGICAL, GEOLOGICAL, OR SOIL INVESTIGATIONS/COLLECTIONS $\square$ NEW \\ D RENEWAL}

\begin{tabular}{|l|l|}
\hline \multicolumn{1}{|c|}{ FOR DEPARTMENT USEONL } \\
\hline APPLICATION NO & DATE RECEIVED \\
\hline DISTRICT & CEQA \\
\hline $\begin{array}{l}\text { PERMIT TYPE } \\
\text { Biological } \\
\text { Soil }\end{array}$ & $\square$ Geological \\
\hline
\end{tabular}

\section{APPLICATION}

tistructions A pplications must be T YPEWRITTEN with origlnal signatures. Frecise location of proposed work must be shown on DiachedUSGS topographic map and ather maps Apollcation should be sent to the ois trict office that administers the park thit Where the toffectonjh vestigation wil take place, or to the Resource Management Division for muit oistrict requests AFPLIOANT ORGANIZATION

Cal Poly State University-San Luis Obispo

STREET ALURESSIOTYISTATEZZIF CODE

280 Swanton Rd. Davenport, CA 95017

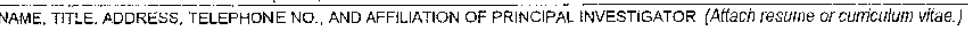

Michael J. Papa- Graduate Researcher

280 Swanton Rd.

Davenport, CA 95017

NAME, ADDRESS, TELEPHONE NO, AND AFFILIATION OF PËRSON IN ACTUAL OIRECT CHARGE OF FIELD WORK (Atlach resume and curTiculum vifee if different from inve stigator.)

Michael J. Papa

COLLECTING ASSISTANT NAME(S) N/A

STREET ADDRESS/CITY/STATEIZIP CODE TELEPHONE NO.

The above applicant hereby applies to the Department of Parks and Recreation for a permit under Title XIV Califomia Code of Regulations, Section 4309, and Public Resources Code Section 5097.5, to conduct investigations on lands of the State of California as follows: STATE PARK UNIT(S) COUNTY(IES)

Big Basin RSP. Forest of Nisene Marks SP, Henry Cowell RSP, Butano SP and Portola R Santa Cruz, San Mateo TYPE OF HAETTAT, GELLOGICAL FORMATION NAME, OR SOIL TYPEE

Coast redwood (Sequoia sempervirens) forest; second-growth and late-successional groves USGS QUADRANGLE(S)

Davenport, Big Basin, Franklin Point, Mindego Hill, Laurel and Loma Prieta

LEGAL DESCRIPTION (Tawnship, Range, and Section of each distinct Jocation

Still to be determined with assistance from State Parks staff

1. AIM AND PURPOSE OF COLIECTION ACTIITY. AND METHOOS OF THIS INVESTIGATION (For Excavations, provide a research design and an outtine of the report. Attach continuation sheets as necessary.

See attached document.

2. METHOD OF COLLECTION

Common forest inventory data collection. Plots include stem count diameter (by D-tape), and tree characteristics 3. TYPES UF SPECIMENS (Species, quantify, size, confifion.)

Specimens will not be collected or removed from the parks, only measurements and photographs.

4 EXPECTEO DURATION OF THE PROJECT (Specify dates of fieiti investigations, laboratory study, and report completion.

Field investigations: August 2007 through December 2007

Laboratory study/data analysis: August 2007 through December 2007

Report completion: December 2007

5. GENERAL SCOPE AND NATURE OF APPLLICANT ORGANIZATION'S ACTIVITIES AND GOALS

See attached document. 


\section{Figure E-2: Scientific Investigation Permit, California State Parks (Back)}

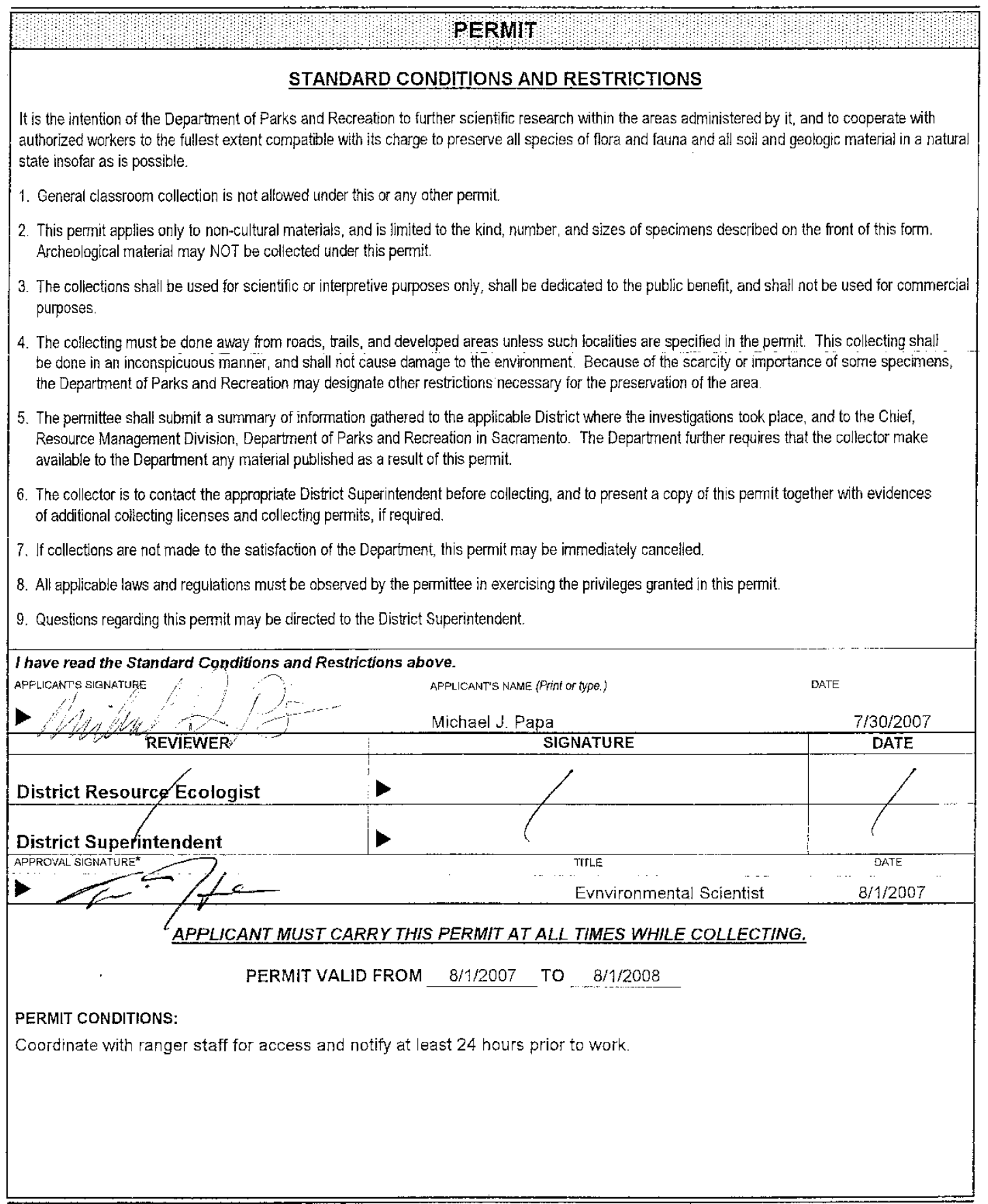

*NOTE: The District Superintendent has the permit authority if one District is involved; the Supervisor, Natural Heritage Section, if more than one District is involved. 


\section{Figure E-3: Hold Harmless Agreement (Example)}

\section{HOLD HARMLESS AGREEMENT}

In consideration for permission for Michael Papa to have access on CEMEX, Inc.'s property on described on attached "Exhibit A", Michael Papa hereby agrees to indemnify, defend, hold harmless and be responsible to CEMEX, Inc. and its directors, officers, agents and employees from and against any or all claims, causes of action, suits, losses, costs, damages, expenses (including, but not limited to, reasonable attorneys' fees) and liabilities on account of injury to, or death of any person, or damage to or loss of any property resulting from or related to the above-stated activity; and Michael Papa hereby specifically agrees to waive all such claims.

Signed:

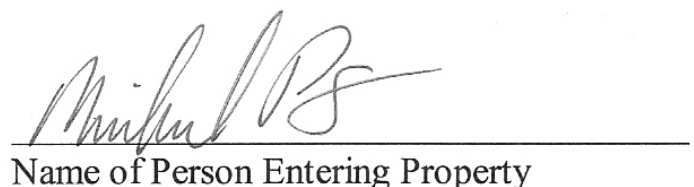

Date: $11 / 2 / 2007$ Name of Person Entering Property

Attested to:

By: Name of Person Giving Permission

Date: of CEMEX. Inc. 